VIVIANE KOTANI SHIMIZU

CLASSIFICAÇÃO E CARACTERIZAÇÃO DE TIPOS DE MINÉRIOS DE COBRE DA MINA DO SOSSEGO - REGIÃO DE CARAJÁS

São Paulo 


\title{
CLASSIFICAÇÃO E CARACTERIZAÇÃO DE TIPOS DE MINÉRIOS DE COBRE DA MINA DO SOSSEGO - REGIÃO DE CARAJÁS
}

\author{
Dissertação apresentada à Escola \\ Politécnica da Universidade de São \\ Paulo para obtenção de título de \\ Mestre em Ciências
}




\title{
CLASSIFICAÇÃO E CARACTERIZAÇÃO DE TIPOS DE MINÉRIOS DE COBRE DA MINA DO SOSSEGO - REGIÃO DE CARAJÁS
}

\author{
Dissertação apresentada à Escola \\ Politécnica da Universidade de São \\ Paulo para obtenção de título de \\ Mestre em Ciências
}

Área de Concentração:

Engenharia Mineral.

Orientador:

Prof. Dr. Henrique Kahn 
Este exemplar foi revisado e alterado em relação à versão original, sob responsabilidade única do autor e com a anuência de seu orientador.

São Paulo, 22 de agosto de 2012.

Assinatura do autor

Assinatura do orientador

FICHA CATALOGRÁFICA

Shimizu,Viviane Kotani

Classificação e caracterização de tipos de minério de cobre da Mina do Sossego - Região de Carajás.

$121 \mathrm{p}$.

Dissertação (Mestrado) - Escola Politécnica da Universidade de São Paulo. Departamento de Engenharia de Minas e de Petróleo.

1. Análise por agrupamento 2. Caracterização tecnológica-3. Mina do Sossego I. Universidade de São Paulo. Escola Politécnica. Departamento de Engenharia de Minas e de Petróleo II. t. 


\section{AGRADECIMENTOS}

Em primeiro lugar, gostaria de agradecer a todas as pessoas que trabalharam no LCT - Laboratório de Caracterização da EPUSP na época em que desenvolvi este trabalho.

Em especial agradeço a Juliana, quem mais me ajudou neste projeto na parte de difração de raios $X$ e análise por agrupamento, e ao Daniel por seus ensinamentos na parte de caracterização tecnológica automatizada. Aos pesquisadores: Manuela, Carina, Mariane, Liz, André, Giuliana e Freud por tantas outras contribuições e ensinamentos.

Agradeço àqueles que me ajudaram na preparação das amostras, um trabalho extenso que demandou muitas mãos: Erílio e Carlos na britagem, moagem e quarteamento, Rafão na moagem de bolas e peneiramento, Vavá na preparação de seções polidas, Rose na montagem para difração de raios $X$, e em especial ao meu querido amigo Rafael Franca, que participou de quase todas estas etapas e foi sempre uma ótima companhia.

Aos amigos, na época também estagiários do LCT, Lucas e Renata, por todos os momentos agradáveis que passamos juntos.

À VALE, por possibilitar a realização deste estudo.

À EPE - Empresa de Pesquisa Energética, por permitir a continuidade deste trabalho, mais especificamente ao Diretor Elson Ronaldo Nunes e Reneu Rodrigues Silva.

Ao Paulo, por seu companheirismo, amor e paciência.

Aos meus pais, Sérgio e Terezinha e às minhas irmãs, Elaine e Carina, por todo apoio, carinho e confiança.

Em especial agradeço ao meu orientador Prof. Dr. Henrique Kahn por seus ensinamentos e incentivos.

Muito obrigada a todos! 


\section{SUMÁRIO}

LISTA DE ILUSTRAÇÕES .................................................................................

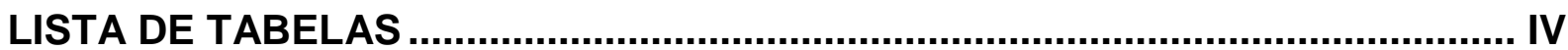

LISTA DE FOTOMICROGRAFIAS .................................................................. VI

LISTA DE ABREVIATURAS E SIGLAS ....................................................... VII

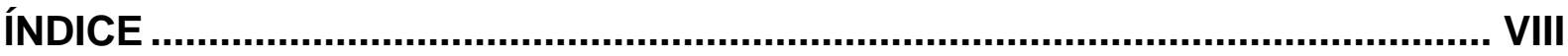

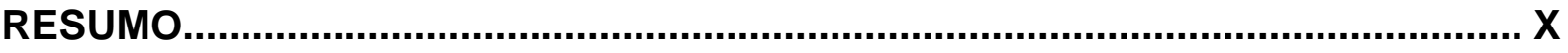

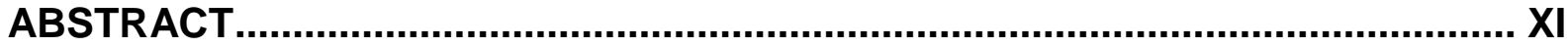

\section{ANEXOS}

Anexo 1 - Relação das amostras estudadas

Anexo 2 - Difratogramas das amostras mais representativas de cada grupo

Anexo 3 - Composição química das fases minerais - banco de dados MLA

Anexo 4 - Composições químicas dosadas (FRX) e calculadas (MLA) 


\section{LISTA DE ILUSTRAÇÕES}

pag.

Figura 1 - Localização da Província Mineral de Carajás no Cráton Amazônico (modificado de GRAINGER et al., 2008).

Figura 2 - Mapa geológico da Província Mineral de Carajás (obtido de MONTEIRO et al., 2008a) 10

Figura 3 - (a) Mapa geológico simplificado com a localização dos corpos Pista, Sequeirinho, Baiano, Curral e Sossego e (b) distribuição esquemática das zonas de alteração hidrotermal (modificado da Vale, obtido de MONTEIRO et al., 2008b)

Figura 4 - Perfil esquemático mostrando a distribuição das zonas de alteração hidrotermal nos corpos Sequeirinho e Sossego (MONTEIRO et al., 2008, obtido em AUGUSTO et al., 2008)

Figura 5 - Etapas do beneficiamento do minério (fluxograma cedido pela Vale) ......16

Figura 6 - Geometria que descreve o fenômeno de difração (Lei de Bragg) 18

Figura 7 - Definições gráficas de proximidade de métodos aglomerativos (TAN;

STEINBACH; KUMAR, 2006). 22

Figura 8 - Dendograma - representação gráfica de um agrupamento. 22

Figura 9 - Processamento para análise mineralógica quantitativa automatizada (obtida de FANDRICH et al., 2007)

Figura 10 - Médodo B utilizado para composição das amostras (BERGERMAN, 2009)

Figura 11 - Contraparte de testemunhos de sondagens, amostras tais quais. 29

Figura 12 - Fluxograma das atividades realizadas 30

Figura 13 - Equipamentos utilizados para cominuição inicial da amostra 31

Figura 14 - Amostra antes e depois da primeira etapa de cominuição e homogeneização 32

Figura 15 - Equipamentos utilizados na coleta por difração de raios $X$. 33 
Figura 16 - Equipamentos utilizados na etapa de caracterização tecnológica 36

Figura 17 - Procedimentos da análise mineralógica quantitativa automatizada 38

Figura 18 - Foto panorâmica da cava de Sequeirinho (foto maio 2010). 40

Figura 19 - Foto panorâmica da cava de Sossego (foto maio 2010) 40

Figura 20 - Dendograma indicando o agrupamento das amostras. 42

Figura 21 - Distribuição espacial dos agrupamentos de amostras segundo análise de componente principal (PCA), sob diferentes pontos de visada - 7 e 4 grupos.

Figura 22 - Comparativo entre os difratogramas 45

Figura 23 - Comparação entre difratogramas mais representativos de cada grupo 46

Figura 24 - Teores de Cu nos grupos definidos (\% massa) 47

Figura 25 - Distribuição granulométrica dos produtos de moagem e das alimentações dos estágios de flotação rougher e cleaner. 52

Figura 26 - Distribuição das formas de associação da calcopirita por fração 60

Figura 27 - Espectro de liberação da calcopirita em área - cluster A. 62

Figura 28 - Espectro de liberação da calcopirita em perímetro exposto - cluster

A

Figura 29 - Curva de distribuição acumulada de Cu versus teor de Cu- cluster

A, total acima de $0,010 \mathrm{~mm}$

Figura 30 - Distribuição das formas de associação da calcopirita por fração granulométrica - cluster D 70

Figura 31 - Espectro de liberação da calcopirita em área - cluster D 72

Figura 32 - Espectro de liberação da calcopirita em perímetro exposto - cluster

D.

Figura 33 - Curva de distribuição acumulada de Cu versus teor de $\mathrm{Cu}$ - cluster D, total acima de $0,010 \mathrm{~mm}$ 73 
Figura 34 - Distribuição das formas de associação da calcopirita por fração

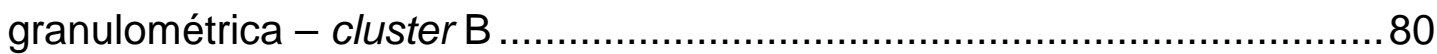

Figura 35 - Espectro de liberação da calcopirita em área - cluster B.......................82

Figura 36 - Espectro de liberação da calcopirita em perímetro exposto - cluster B

Figura 37 - Curva de distribuição acumulada de Cu versus teor de Cu - cluster

$B$, total acima de $0,010 \mathrm{~mm}$

Figura 38 - Distribuição das formas de associação da calcopirita por fração granulométrica - cluster C ..................................................................99

Figura 39 - Espectro de liberação da calcopirita em área - cluster C 92

Figura 40 - Espectro de liberação da calcopirita em perímetro exposto - cluster $\mathrm{C}$, total acima de $0,010 \mathrm{~mm}$ 92

Figura 41 - Curva de distribuição acumulada de Cu versus teor de Cu - cluster C, total acima de $0,010 \mathrm{~mm}$. 93

Figura 42 - Comparação mineralógica 96

Figura 43 - Espectros de liberação da calcopirita em área - total deslamado 97

Figura 44 - Espectros de liberação da calcopirita em perímetro exposto - total deslamado 98

Figura 45 - Espectros de liberação da calcopirita em perímetro exposto frações $+0,21 \mathrm{~mm}$ 98

Figura 46 - Curvas de distribuição acumulada de Cu versus teor de $\mathrm{Cu}$...... 99

Figura 47 - Comparações entre as composições químicas obtidas por MLA e FRX 100 


\section{LISTA DE TABELAS}

pag.

Tabela 1 - Distribuição espacial do agrupamento nos corpos Sequeirinho e Sossego.

Tabela 2 - Distribuição dos tipos litológicos nos grupos 48

Tabela 3 - Análises químicas das amostras cabeças (\% em massa) 50

Tabela 4 - Distribuição granulométrica dos produtos de moagem e das alimentações dos estágios de flotação rougher e cleaner.

Tabela 5 - Resultados de análise granuloquímica - cluster A 54

Tabela 6 - Composição mineralógica por fração granulométrica (MLA) - cluster A 55

Tabela 7 - Distribuições de Cu e S dentre os minerais portadores - cluster A........57

Tabela 8 - Distribuição das formas de associação da calcopirita (\% em massa) .....61

Tabela 9 - Grau de liberação da calcopirita - cluster A 63

Tabela 10 - Resultados de análise granuloquímica - cluster D 64

Tabela 11 - Composição mineralógica por fração granulométrica (MLA) cluster D 65

Tabela 12 - Distribuições de Cu e S dentre os minerais portadores - cluster D ......67

Tabela 13 - Distribuição das formas de associação da calcopirita (\% em massa) ....71

Tabela 14 - Grau de liberação da calcopirita - cluster D 73

Tabela 15 - Resultados de análise granuloquímica - cluster B 74

Tabela 16 - Composição mineralógica por fração granulométrica (MLA) cluster B.

Tabela 17 - Distribuições de Cu e S dentre os minerais portadores de S cluster B

Tabela 18 - Distribuição das formas de associação da calcopirita (\% em massa). 
Tabela 19 - Grau de liberação da calcopirita - cluster B

Tabela 20 - Resultados de análise granuloquímica - cluster C.

Tabela 21 - Composição mineralógica por fração granulométrica (MLA) cluster $\mathrm{C}$

Tabela 22 - Distribuições de $\mathrm{Cu}$ e $\mathrm{S}$ dentre os minerais portadores de $\mathrm{S}$ cluster $\mathrm{C}$

Tabela 23 - Distribuição das formas de associação da calcopirita (\% em massa).

Tabela 24 - Grau de liberação da calcopirita - cluster C 93

Tabela 25 - Sumário dos resultados da caracterização tecnológica. 94

Tabela 26 - Sumário dos resultados da caracterização tecnológica. 96 


\section{LISTA DE FOTOMICROGRAFIAS}

pag.

Fotomicrografia 1 - MO, cluster A, fração $-0,21+0,15$ mm...................................58

Fotomicrografia 2 - MO, cluster A, fração $-0,21+0,15$ mm.....................................58

Fotomicrografia 3 - MEV, cluster A, fração -0,21+0,15 mm...................................59

Fotomicrografia 4 - MEV, cluster A, fração $-0,21+0,15$ mm...................................59

Fotomicrografia 5 - MO, cluster D, fração $-0,21+0,15$ mm....................................... 68

Fotomicrografia 6 - MO, cluster D, fração $-0,21+0,15$ mm....................................... 68

Fotomicrografia 7 - MEV, cluster D, fração $-0,21+0,15$ mm...................................... 69

Fotomicrografia 8 - MEV, cluster D, fração $-0,21+0,15$ mm....................................69

Fotomicrografia 9 - MO, cluster B, fração $-0,21+0,15$ mm ...................................78

Fotomicrografia 10 - MO, cluster B, fração $-0,21+0,15$ mm ....................................78

Fotomicrografia 11 - MEV, cluster B, fração $-0,21+0,15$ mm ..................................79

Fotomicrografia 12 - MEV, cluster B, fração $-0,21+0,15$ mm .................................79

Fotomicrografia 13 - MO, cluster C, fração $-0,21+0,15$ mm.................................. 88

Fotomicrografia 14 - MO, cluster C, fração $-0,21+0,15$ mm................................... 88

Fotomicrografia 15 - MEV, cluster C, fração $-0,21+0,15$ mm.................................. 89

Fotomicrografia 16 - MEV, cluster C, fração $-0,21+0,15$ mm................................... 89 


\section{LISTA DE ABREVIATURAS E SIGLAS}

\begin{tabular}{ll} 
AQ & Análise química \\
BSE & Elétrons retroespalhados (backscattered electrons) \\
DRX & Difração de raios X \\
EDS & Espectrômetro por dispersão de energia (energy dispersive spectrometer) \\
FRX & Fluorescência de raios X \\
IOCG & Iron Oxide Copper Gold \\
LCT & Laboratório de Caracterização Tecnológica \\
LR & Luz refletida \\
MEV & Microscópio/microscopia eletrônico(a) de varredura \\
MLA & Mineral Liberation Analyser (software) \\
MO & Microscopia óptica \\
PAN-ICSD & PANalytical Inorganic Crystal Structure Database \\
PF & Perda ao fogo \\
PSD & Detector sensível à posição (position sensitive detector) \\
RIR & Reference Intensity Ratio \\
SDD & Silicon drift detector \\
SE & Elétrons secundários (secondary electrons) \\
\hline
\end{tabular}




\section{ÍNDICE}

pag.

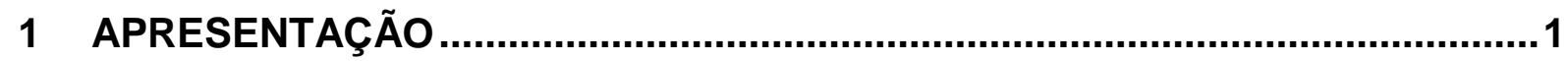

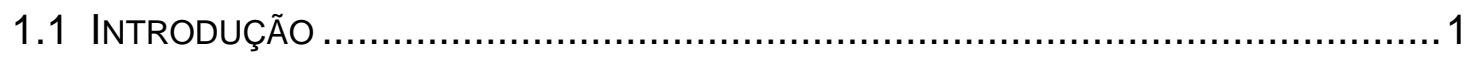

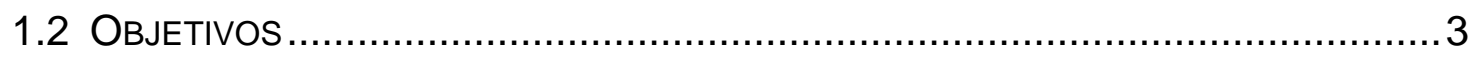

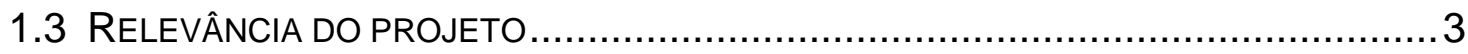

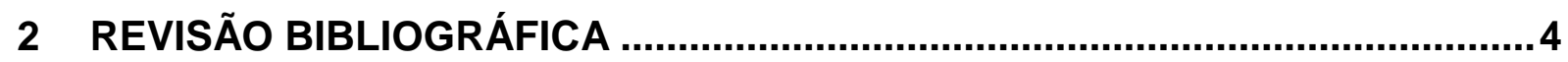

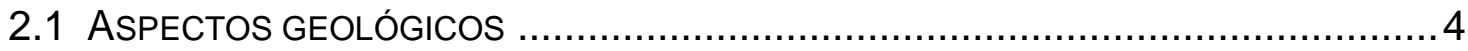

2.1.1 Considerações sobre os depósitos IOCG...................................... 4

2.1.2 Geologia da Província Mineral de Carajás.................................... 7

2.1.3 Geologia do depósito de Sossego …....................................... 10

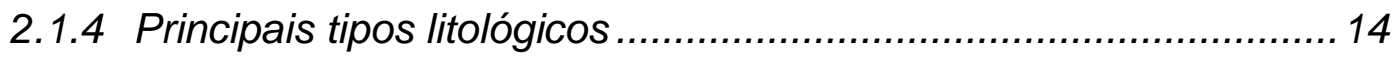

2.1.5 Beneficiamento do minério da mina de Sossego ........................... 15

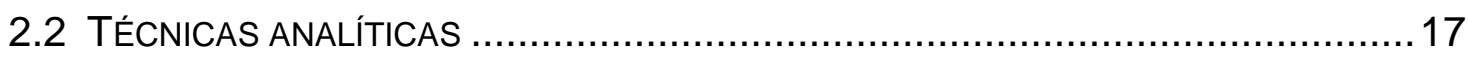

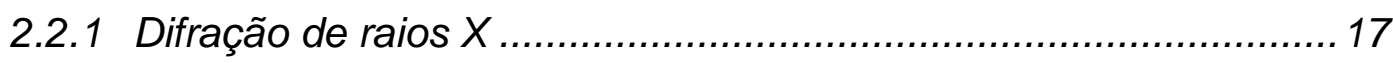

2.2.2 Análise por agrupamento (cluster analysis) com base em

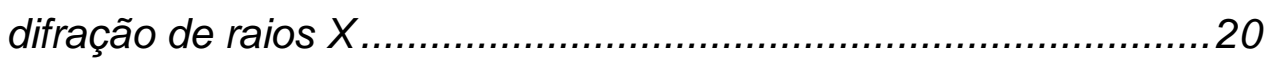

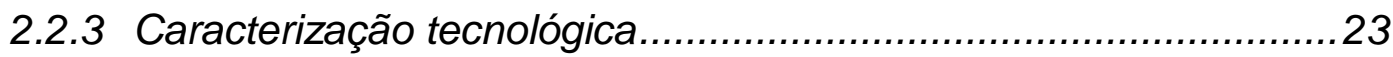

2.2.4 Mineralogia quantitativa automatizada por análise de imagens.....25

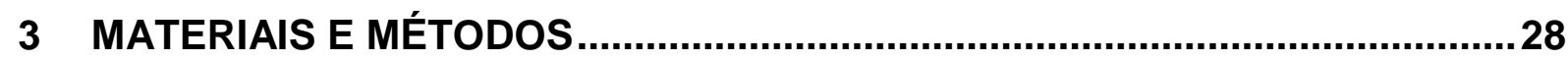

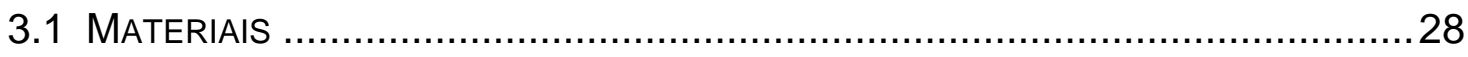

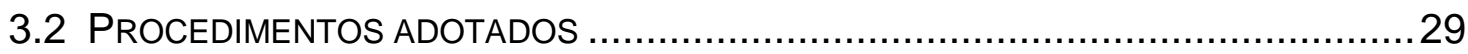

3.2.1 Primeira etapa de cominuição e homogeneização ........................ 31

3.2.2 Difração de raios $X$ e análise por agrupamento ............................ 32

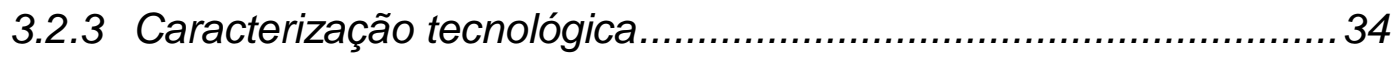

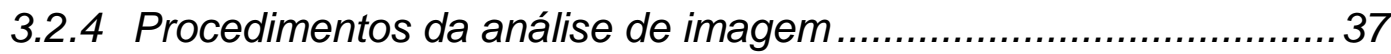


3.2.5 Atividade de campo

4 RESULTADOS E DISCUSSÃO.................................................................. 41

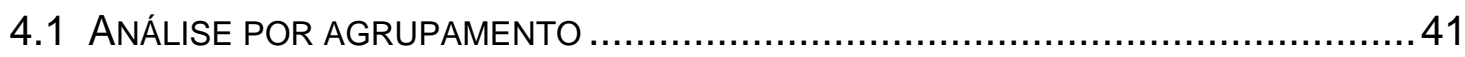

4.1.1 Relação agrupamento com a geologia da Mina do Sossego.........48

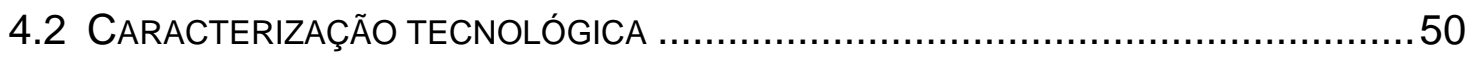

4.2.1 Composição química das amostras estudadas.........................50

4.2.2 Distribuição granulométrica das amostras estudadas..................52

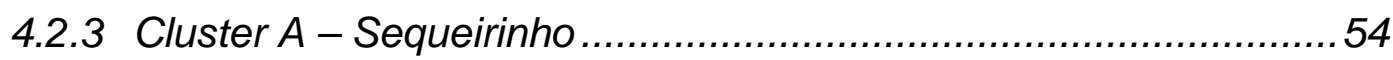

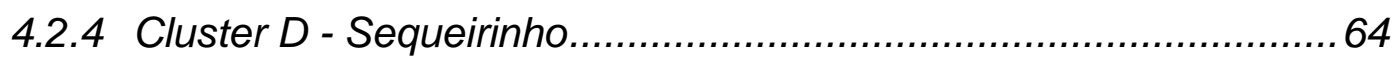

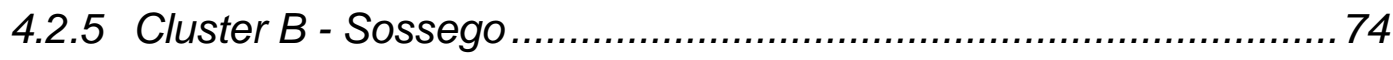

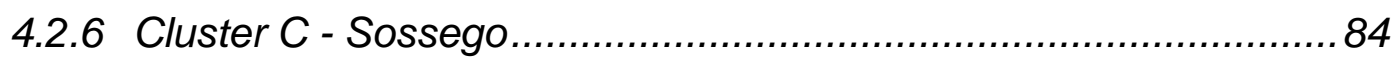

4.2.7 Sumário dos resultados de caracterização tecnológica e discussão................................................................ 94

4.2.8 Validação dos resultados de MLA.................................... 99

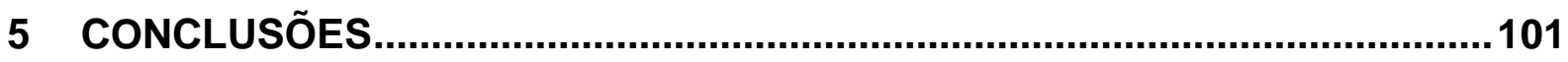

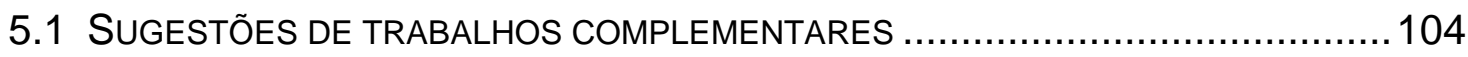

6 REFERÊNCIAS BIBLIOGRÁFICAS ..................................................... 105

\section{ANEXOS}

Anexo 1 - Relação das amostras estudadas

Anexo 2 - Difratogramas de raios $X$ das amostras mais representativas de cada grupo

Anexo 3 - Composição química das fases minerais - banco de dados MLA

Anexo 4 - Composições químicas dosadas (FRX) e calculadas (MLA) 


\section{RESUMO}

Neste trabalho é apresentada a classificação de cerca de 110 amostras de minério da Mina do Sossego com base nas ferramentas de difração de raios $X e$ análise estatística por agrupamento (cluster analysis). A comparação, baseada na posição e intensidade dos picos difratados, permitiu a distinção dos tipos de minérios, sendo que as diferenças entre os grupos referem-se às proporções dos principais minerais constituintes: quartzo, feldspato, actinolita, óxidos de ferro, mica e clorita. Observou-se forte correlação do agrupamento com a origem das amostras. Esta relação deve-se aos diferentes tipos e intensidades das alterações hidrotermais atuantes em cada corpo, que refletem na mineralogia e, consequentemente, nos difratogramas de raios $X$ das amostras.

Complementando o trabalho, foram conduzidos estudos de caracterização tecnológica em amostras compostas dos tipos identificados, os quais permitiram definir a composição mineralógica das amostras e outros parâmetros relevantes ao beneficiamento. Vários são os minerais de ganga: quartzo, plagioclásio, feldspato, anfibólio, magnetita, apatita, epídoto, clorita, escapolita, micas e calcita. A calcopirita é praticamente o único mineral de minério, e ocorre tanto na forma de microcristais inclusos nos minerais de ganga quanto como cristais maiores. Com exceção da pirita, os demais sulfetos (calcocita, siegenita e milerita) ocorrem como traços. As curvas de liberação da calcopirita demonstram que as amostras do corpo Sossego possuem maior grau de liberação do que as de Sequeirinho.

A metodologia para classificação de amostras mostrou-se bastante eficiente, possibilitando a análise de grande número de amostras, de forma objetiva e com resultado satisfatório, tendo-se verificado não só distinções mineralógicas entre estes como também características distintas frente ao processo de concentração. 


\begin{abstract}
This work presents the classification of approximately 110 copper ore samples from Sossego Mine using cluster analysis and X-ray diffraction technique. The comparison based on the position and intensity of the diffracted peaks allowed the distinction the major ore types differentiated by the proportion of major minerals: quartz, feldspar, actinolite, iron oxides, mica and chlorite. There was a strong correlation between the grouping and the location of the samples in Sequeirinho and Sossego orebodies. This relationship is due to different types and intensities of hydrothermal alteration prevailing in each body, which reflect the mineralogy and thus the X-ray diffractograms of samples.

In addition, technological characterization studies on composed samples from the defined ore types were carried out based in order to gather mineralogical composition and other relevant parameters for mineral processing. There are several gangue minerals, including: quartz, plagioclase, feldspar, amphibole, magnetite, apatite, epidote, chlorite, scapolite, mica and calcite. Chalcopyrite is essentially the only valuable mineral. It occurs both as microcrystals included in other minerals such as larger crystals. Excepting pyrite, other sulfides (chalcocite, millerite and siegenite) occur as traces. Chalcopyrite liberation curves indicate that samples from Sossego have higher liberation degree than those from Sequeirinho.

The proposed method for classification of ore samples proved to be very efficient. It enables the analysis of large numbers of samples in a short time with a satisfactory result allowing distinctions of the ore types regarding to their mineralogical composition as well as parameters for mineral processing.
\end{abstract}




\section{APRESENTAÇÃO}

\subsection{Introdução}

A Mina do Sossego, localizada na Província Mineral de Carajás no Estado do Pará, é a segunda maior reserva de cobre brasileira e contribui atualmente com cerca de $55 \%$ da produção nacional de concentrado de cobre (dados referentes a 2010 - RIBEIRO 2011). O início da explotação deu-se em 2004 e representou um marco importante para a indústria de cobre, por ser a primeira dentre vários depósitos em desenvolvimento na região a entrar em operação.

Os depósitos de Igarapé Bahia, Alemão, Cristalino, Gameleira e Alvo 118 encontram-se atualmente em desenvolvimento, e o de Salobo, recém iniciou sua operação. Todos estes depósitos, incluindo Sossego, são de porte internacional e classificados como do tipo IOCG (iron oxide cooper gold).

São características importantes destes depósitos o forte controle estrutural, alterações hidrotermais expressivas, abundância de óxidos de ferro apresentando baixo teor de Ti (magnetita e/ou hematita), mineralização de cobre com ou sem ouro associado, assinatura geoquímica distinta (elementos terras raras, $\mathrm{Co}, \mathrm{Ag}, \pm \mathrm{U}, \mathrm{P}$ ), entre outras.

A Província Mineral de Carajás está no rol dos principais distritos metalogenéticos IOCG em termos econômicos (WILLIAMS et al., 2005). Os depósitos desta região, apesar de geneticamente relacionados, possuem diferentes assembléias minerais e minerais de interesse econômico, a depender da composição das rochas hospedeiras e dos fluidos mineralizantes (MONTEIRO et al. 2008a). Possuem elevada complexidade mineralógica resultante da superimposição das alterações hidrotermais e forte controle estrutural, condições que contribuem para a elevada complexidade geológica e, consequentemente, dificultam a classificação de amostras.

Neste trabalho é apresentado um estudo de caso para avaliar o método de classificação de amostras de minério com base nas técnicas de difração de raios $\mathrm{Xe}$ análise estatística por agrupamento (cluster analysis). A comparação, baseada na 
posição e intensidade dos picos difratados, equivale à comparação entre as principais fases minerais das amostras.

Escolheu-se o caso de Sossego devido a diversos fatores: importância econômica (tanto em relação ao depósito em si quanto em relação a província metalogenética), complexidade geológica favorável para a proposta (ampla variabilidade mineralógica) e "disponibilidade" de material para estudo (material cedido pela Vale). Foram classificadas cerca de 110 amostras de minério, correspondentes a trechos de testemunhos de sondagens de frentes de lavras antigas.

Ambas as técnicas analíticas são amplamente utilizadas no setor mineral. A difração de raios $X$, geralmente associada com análises químicas, é utilizada em diversas etapas de um evento mineiro: em auxílio à exploração, lavra (blendagens), processos de beneficiamento (associação mineral), além de estudos de gênese e controles de mineralização (ANTONIASSI et al. 2008). A análise por agrupamento é muito utilizada quando se busca encontrar algum padrão de correlação entre objetos (TAN; STEINBACH; KUMAR, 2006).

Esta abordagem é recente nas áreas de geociências e tecnologia mineral e é possível através de um recurso existente em softwares atuais, que permite a classificação de dezenas a centenas de amostras em minutos, sem a necessidade da identificação das fases presentes, diminuindo drasticamente o tempo e facilitando a análise dos dados (MACCHIAROLA K. et al. 2007).

Para complementar o trabalho foram conduzidos estudos de caracterização tecnológica em amostras compostas dos tipos identificados. Por meio de análise de imagens conjugada à microscopia eletrônica de varredura, obtiveram-se informações referentes aos minerais de minério (identificação, proporção, espectro de liberação e partição do elemento de interesse) e de ganga (quantificação e formas de associação com o mineral de minério). 


\subsection{Objetivos}

Este trabalho visou avaliar a aplicabilidade da ferramenta de análise por agrupamento (cluster analysis) aliada à técnica difração de raios $\mathrm{X}$ para classificação de amostras para o caso da Mina do Sossego.

A caracterização tecnológica dos grupos de minérios objetivou 0 levantamento de informações das principais características dos litotipos definidos.

\subsection{Relevância do projeto}

A metodologia utilizada neste projeto possui grande potencial para aplicação na indústria mineira.

$O$ método de difratometria de raios $X$ tem atualmente importante papel no setor mineral, devido à simplicidade, a rapidez das análises e a confiabilidade dos resultados. Aliada à ferramenta de análise por agrupamento (cluster analysis), recurso existente em softwares atuais, é possível comparar de dezenas a milhares de difratogramas de raios $X$ em alguns minutos, sem necessidade de tratamento prévio ou identificação das fases presentes.

É possível, desta forma, a criação de um banco de dados considerável com amostras representativas do universo amostral. O procedimento pode constituir-se em uma prática rotineira em projetos de explotação ou no auxílio a exploração mineral e estudos de viabilidade econômica para uma melhor avaliação da variabilidade do depósito e definição de amostras para ensaios de processamento mineral / metalúrgicos.

O caso de Sossego é interessante tanto do ponto de vista geológico como econômico, sendo representativo de importante classe de depósitos, cuja complexidade geológica (variabilidade mineralógica e forte controle estrutural) é favorável para o estudo proposto. 


\section{REVISÃO BIBLIOGRÁFICA}

\subsection{Aspectos geológicos}

A mina do Sossego está localizada na Província Mineral de Carajás, na região de Canaã dos Carajás, sudeste do Pará (Figura 1).

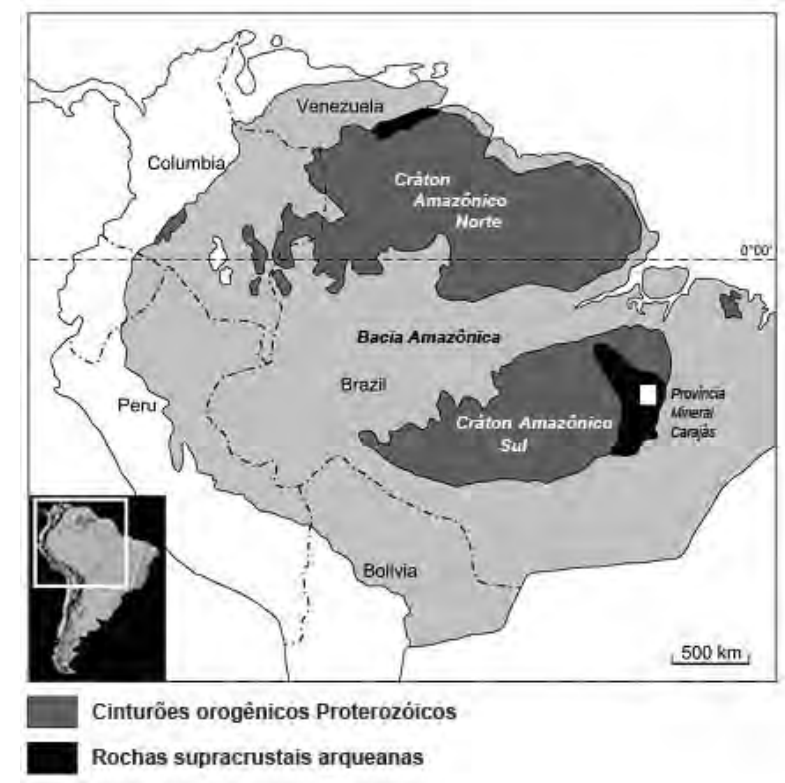

Figura 1 - Localização da Província Mineral de Carajás no Cráton Amazônico (modificado de GRAINGER et al., 2008).

O Estado do Pará abriga a maior parte das reservas brasileiras de cobre (83\% segundo estudo de RODRIGUES; HEIDER, 2009). Muito dos depósitos, incluindo Sossego, Salobo, Corpo 118, Cristalino, Alemão são do tipo óxido de Fe-Cu-Au (sigla em inglês IOCG, iron oxide copper gold).

Estão descritas, a seguir, as principais características desta classe de depósitos, além de informações sobre a Província Mineral de Carajás e do depósito de Sossego.

\subsubsection{Considerações sobre os depósitos IOCG}

Ainda não há consenso sobre as características dos sistemas e os processos geológicos que formam os depósitos em questão, uma vez que esta classe foi definida na década de 90 a partir das descobertas de Olympic Dam, La Candelaria, 
Starra, Osborne, Ernest-Henry e Alemão, o que é considerado recente (WILLIAMS et al., 2005).

Por abranger uma grande diversidade de depósitos, nenhum modelo simples pode capturar adequadamente a diversidade dos sistemas que estão incluídas nesta família (BARTON; JOHNSON, 2004).

De um modo geral, as principais características dos depósitos IOCG incluem: mineralização de cobre com ou sem ouro, controle estrutural proeminente (veios hidrotermais, brechas e outras estruturas característica de substituição) e magnetita e/ou hematita abundante aliada(s) a baixo conteúdo de Ti (WILLIAMS et al., 2005, BARTON; JOHNSON, 2004).

Outras características comuns que podem não estar presentes em todos os casos incluem: suíte distinta de elementos menores incluindo várias combinações de $\mathrm{F}, \mathrm{P}, \mathrm{Co}, \mathrm{Ni}, \mathrm{As}, \mathrm{Mo}, \mathrm{Ag}, \mathrm{Ba}, \mathrm{ETRL}, \mathrm{e} \mathrm{U}$, alteração pervasiva rica em álcalis (WILLIAMS et al., 2005, BARTON; JOHNSON, 2004).

São considerados como expressão metassomática de um evento de alteração crustal de larga escala, implantado em bacia sedimentar ou vulcanossedimentar. Estão associados com grandes descontinuidades regionais e intensa atividade magmática que permitiram intensa mobilização dos elementos (COX; SINGER, 2007; WILLIAMS et al., 2005; SKIRROW, 2004; GRAINGER et al., 2008

O faturamento hidráulico, o metassomatismo e a intensa atividade hidrotermal são os responsáveis pelas estruturas dos minérios. Estes tendem a possuir forma cônica, com mineralização em brechas, falhas e fraturas (BIONDI, 2003). As permeabilidades destas estruturas são fatores determinantes na tonelagem do depósito, o que explica a associação dos mesmos com importantes zonas de cisalhamento (COX; SINGER, 2007).

As intrusões podem ser de diferentes composições, variando amplamente entre os depósitos, desde rochas máficas como gabros e dioritos até monzonitos tonalitos, dacitos e granodioritos (COX; SINGER, 2007; WILLIAMS et al., 2005; SKIRROW, 2004; GRAINGER et al., 2008). 
Os principais distritos metalogenéticos IOCG em termos econômicos, segundo Williams et. al. (2005), estão na Austrália (Gawler Craton e Cloncurry District), Brasil (Província de Carajás), Chile e Peru (Chilean Iron Belt).

Os depósitos possuem ampla distribuição temporal (do Paleoproterozóico ao Mioceno) e tonelagem (de 3,8 bilhões de toneladas de Olympic Dam até 470 milhões de toneladas de La Candelaria no Chile) (COX; SINGER, 2007).

Apresentam, geralmente, alterações sódica (albita), sódica-cálcica (albitaoligoclásio) e potássica (biotita e K-feldspato) mais intensas e as alterações sericítica e clorítica (com quartzo acessório) menos volumosas, ocorrendo nas proximidades da mineralização (COX; SINGER, 2007; BARTON; JOHNSON, 2004). A mineralogia e geoquímica gerada pelos sistemas de alteração hidrotermal, entretanto, varia entre os depósitos, já que depende da composição das rochas hospedeiras e dos fluidos mineralizantes (SKIRROW, 2004; BARTON; JOHNSON, 1996).

Os depósitos podem apresentar zonamento vertical de regiões ricas em albita e magnetita, mais profundas, para assembléias com mais sílica, feldspato potássico e sericita em porções mais superiores. Com relação aos sulfetos de $\mathrm{Cu}$ e $\mathrm{Fe}$, observa-se a ocorrência de pirita em profundidade, calcopirita nas zonas mais próximas à superfície e bornita e calcocita em posições intermediárias (BIONDI, 2003).

A calcopirita e a pirita são as espécies minerais sulfetadas mais abundantes e sempre presentes; os outros sulfetos podem ser formados devido à ação de agentes intempéricos. No processo de alteração supérgena ocorre a dissolução dos sulfetos primários e a mobilização do Cu e do Fe na solução; o cobre é então precipitado na forma de vários minerais secundários, os quais são reflexos da composição da água e do pH e Eh ao longo do perfil de alteração (GUILBERT; PARK, 2007).

Em regiões redutoras (hipógenas) do perfil de alteração, o cobre substitui o ferro de sulfetos preexistentes (pirita e calcopirita) formando sulfetos mais ricos em $\mathrm{Cu}$, como calcocita $\left(\mathrm{Cu}_{2} \mathrm{~S}\right)$, covelita (CuS), bornita $\left(\mathrm{Cu}_{5} \mathrm{FeS}_{4}\right)$ e digenita $\left(\mathrm{Cu}_{9} \mathrm{~S}_{5}\right)$. Já em regiões mais oxidantes (mais superficiais), outros minerais de cobre podem ser formados. Estes são composicionalmente e mineralogicamente mais complexos e incluem carbonatos (malaquita e azurita), silicatos (crisocola), óxidos (cuprita), 
fosfatos (libethinita), sulfatos (brochantita, antlerita, calcantita), arsenatos (enargita), além de fases de óxi-hidróxidos (GUILBERT; PARK, 2007).

A extensão das zonas lixiviadas e enriquecidas e a natureza dos minerais formados depende da proporção de sulfetos primários na rocha e a acidez da solução percolada (GUILBERT; PARK, 2007).

Com relação aos depósitos IOCG brasileiros, uma comparação entre os mesmos é apresentada por Monteiro et al. (2008a). Para a autora e colaboradores, estes depósitos são similares quanto às (i) rochas hospedeiras variáveis (diferentes litotipos das unidades do Supergrupo Itacaiúnas); (ii) associação com zonas de cisalhamento bem como intrusões de diferentes composições; (iii) intensa alteração hidrotermal, desde inicial sódica, passando pela potássica até a mineralização dos sulfetos; (iv) amplo intervalo de temperaturas de homogeneização $\left(100-570^{\circ} \mathrm{C}\right)$ e salinidades ( 0 a $69 \%$ eq. peso $\mathrm{NaCl}$ ) em inclusões fluidas em minerais do minério, indicando a mistura de fluidos de origens diversas (MONTEIRO et al., 2008a). Para Augusto et al. (2008), além dessas características, os depósitos apresentam enriquecimentos em ETRL, P, Ni, Co e, em alguns casos, Ag, Mo, U, Th, Y, Pd, Zn, Te e Sn. Os depósitos diferem quanto às assembléias de alteração hidrotermal e os minerais de interesse econômico (calcopirita-calcocita-bornita no Salobo; calcopirita \pm calcocita-digenita-covelita no Igarapé Bahia e calcopirita-pirita nos depósitos de Sossego, Cristalino e Alvo 118) (MONTEIRO et al., 2008b; AUGUSTO et al., 2008).

\subsubsection{Geologia da Província Mineral de Carajás}

A região de Carajás abriga uma das maiores províncias minerais do mundo, apresentando jazidas de ferro, manganês, níquel, cobre, ouro, estanho, bauxita e caulim. Está localizada na porção sudeste do Cráton Amazônico e é constituída por dois compartimentos tectônicos: o Cinturão de Cisalhamento Itacaiúnas a norte e o terreno granito-greenstone Rio Maria a sul.

No compartimento Rio Maria, sequências vulcanossedimentares do tipo greenstone belts agrupadas no Supergrupo Andorinhas ocorrem como faixas anastomosadas envolvendo corpos granitóides e complexos máficos-ultramáficos. São rochas vulcânicas máficas-ultramáficas e félsicas, intercaladas com formação 
ferrífera bandada e sedimentos clásticos e vulcanoclásticos. Os complexos intrusivos máfico-ultramáficos apresentam diferenciação magmática com composições que gradam de peridotitos e dunitos para gabros e anortositos. Os granitóides intrusivos apresentam composição granodiorítica a trondhjemítica e idade de aproximadamente 2,9Ga (DOCEGEO, 1988).

No Cinturão de Cisalhamento Itacaiúnas a norte, onde se encontra o depósito de Sossego, o embasamento arqueano é representado por gnaisses e granulitos dos Complexos Xingu (2,8 Ga, MACHADO et al., 1991) e Pium ( 3,0 Ga, RODRIGUES; LAFON; SCHELLER, 1992; PIDGEON; MACAMBIRA; LAFON, 2000).

Sequências metavulcanossedimentares e sedimentares sobrejacentes aos complexos citados foram reunidas no Supergrupo Itacaiúnas, que inclui os grupos Grão do Pará, Igarapé-Salobo, Igarapé-Pojuca, Igarapé-Bahia e Buritirama (DOCEGEO, 1988). Estas unidades hospedam grande quantidade de depósitos minerais, dentre eles os depósitos de cobre e ouro de Salobo, Igarapé-Bahia, Sossego, Alvo 118 e Cristalino.

Os litotipos do Supergrupo Itacaiúnas compreendem metassedimentos detríticos, químicos e vulcanoclásticos, rochas metavulcânicas félsicas a máficas, além de formações ferríferas. Apresentam metamorfismo variando desde a fácies xisto-verde inferior (Grupos Igarapé Bahia e Grão do Pará) até anfibolito superior (Igarapé Pojuca e Igarapé Salobo), com deformação variando desde rochas com estruturas primárias preservadas até rochas com estruturas completamente obliteradas (DOCEGEO, 1988; GALARZA; MACAMBIRA; MOURA, 2003).

Sobreposto ao Supergrupo Andorinhas ocorre um pacote de rochas sedimentares terrígenas e marinhas, pouco metamorfisadas, dominadas por quartzoarenitos e pelitos da Formação Rio Fresco ou Águas Claras (NOGUEIRA 1995).

Vários eventos intrusivos de idade arqueana e paleoproterozóica afetam o Supergrupo Itacaiúnas e a Formação Águas Claras/Rio Fresco. Informações geocronológicas apontam para três intervalos magmáticos: dois no Arqueano e um no Paleoproterozóico (idades aproximadas de 2,76 Ga, 2,57 Ga e 1,88 Ga respectivamente). Vários autores apontam para a importância dos dois últimos eventos magmáticos na geração dos sistemas magmático-hidrotermais geradores dos depósitos tipo IOCG (MONTEIRO et al., 2008b). 
Dentre as intrusões arqueanas citam-se os granitóides Estrela, Plaquê, Planalto, Serra do Rabo, Cristalino, Velho Salobo e Itacaiúnas, com idades entre 2,76 e 2,56 Ga e composição alcalina e metaluminosa (NEVES, 2006). Os episódios intrusivos paleoproterozóicos $(\sim 1,88 \mathrm{Ga})$ são representados pelos granitóides Serra dos Carajás, Cigano, Pojuca, Young Salobo, Musa, Jamon, Breves, Velho e Guilherme, de composição alcalina e subalcalina e características químicas e tectônicas de granitos tipo A (NEVES, 2006; AUGUSTO et al., 2008). Ainda ocorrem intrusões máficas-ultramáficas como os Complexos Luanga, Vermelho, Onça, Jacaré e Jacarezinho.

O quadro estrutural da região pode ser dividido segundo Pinheiro \& Holdsworth (2000) em dois domínios, um de rochas de alto grau metamórfico, formadas em regime dúctil de alta temperatura, sob domínio da Zona de Cisalhamento Itacaiúnas, na qual encontram-se os gnaisses e granulitos do embasamento (Complexo Xingu e Pium), granitóides sintectônicos e algumas rochas supracrustais de alto grau (rochas vulcano-sedimentares do Grupo Igarapé Salobo; 2,76 Ga). O outro domínio é representado por rochas vulcânicas e sedimentares de baixo a muito baixo grau metamórfico, em discordância sobre as rochas do embasamento e posteriores ao evento tectônico de alta temperatura (rochas dos Grupos Igarapé-Pojuca, Grão do Pará e da Formação Águas Claras).

As grandes falhas trancorrentes E-W que cortam as rochas do Supergrupo Itacaiúnas e da Formação Águas Claras compõem a Zona de Cisalhamento Itacaiúnas que é formada pelos sistemas transcorrentes Cinzento e Carajás. O sistema Transcorrente Carajás, no qual se insere o depósito de Sossego, é marcado por uma estrutura sigmoidal e é atravessada longitudinalmente pela Falha Carajás, de direção geral WNW-ESE, que representa a estrutura mais proeminente do sistema. O fraturamento das rochas ao longo desta falha permitiu a circulação dos fluidos responsáveis pela mineralização $\mathrm{Cu}$ e $\mathrm{Au}$ (PINHEIRO; HOLDSWORTH, 2000).

A Figura 2 apresenta o mapa geológico da Província Mineral de Carajás com a localização dos principais depósitos minerais existentes. 

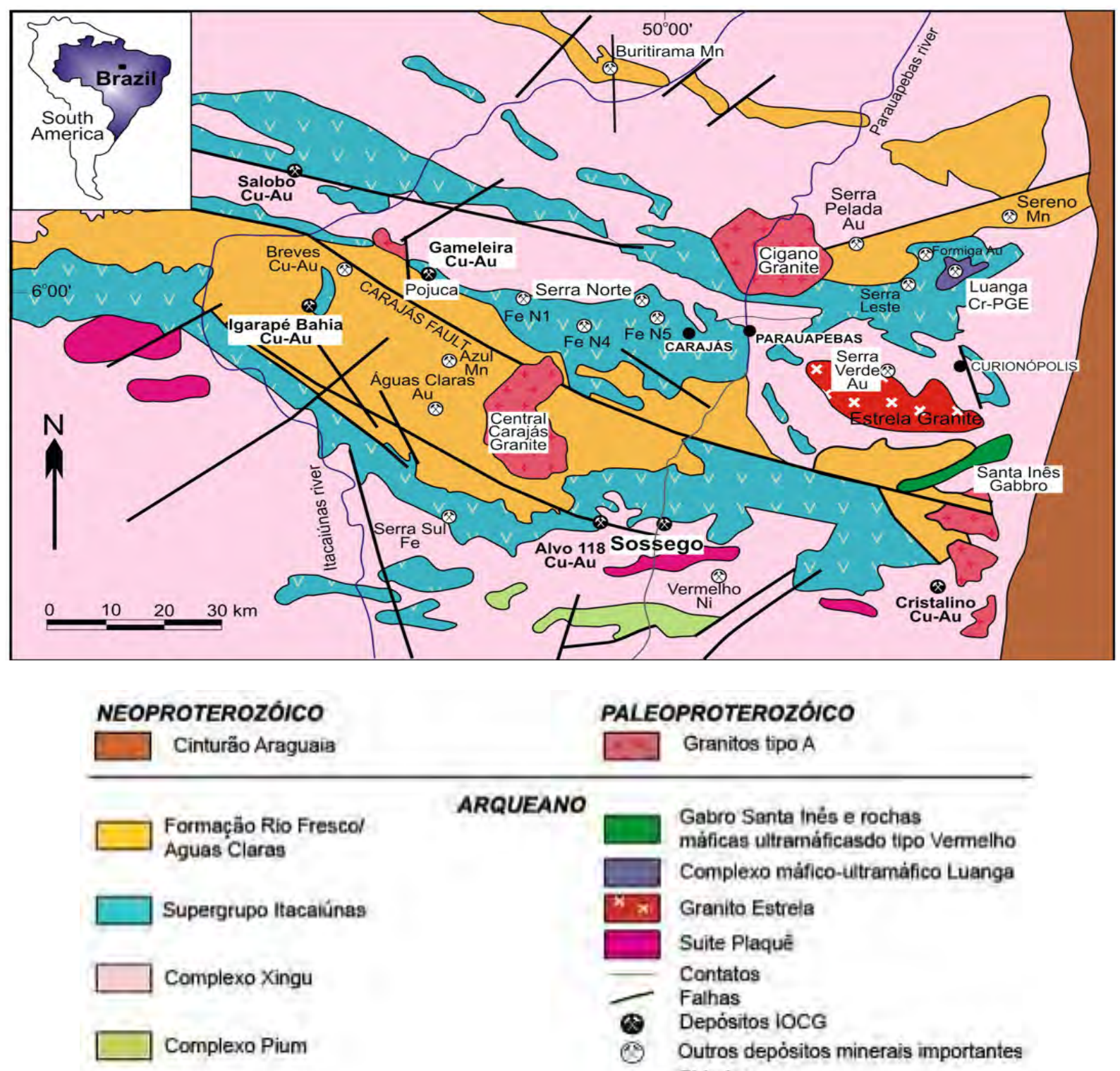

PALEOPROTEROZÓICO

$\square$ Granitos tipo A

\section{ARQUEANO}

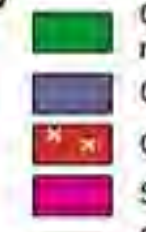

máficas ultramáficasdo tipo Vermelho

Complexo máfico-uitramàfico Luanga

Granito Estrels

Suite Plaque

Contatos

Falhas

* Depósitos 1OCG

Q Outros depósitos minerais importantes

Cidades

\section{Figura 2 - Mapa geológico da Província Mineral de Carajás (obtido de} MONTEIRO et al., 2008a)

\subsubsection{Geologia do depósito de Sossego}

Como já citado, a Mina do Sossego está localizada ao longo Zona de Cisalhamento Itacaiúnas, a qual define o contato entre as unidades metavulcanosedimentares do Supergrupo Itacaiúnas e gnaisses e migmatitos do Complexo Xingu. Ocorrem também no depósito diferentes corpos ígneos como granito, gabro e rocha metavulcânica félsica, alongados e concordantes com a estrutura regional, também afetados pelo hidrotermalismo de 2,2 Ga (MARSCHICK; LEIVEILLE, 2001).

A zona de cisalhamento em escala regional é cortada por falhas transcorrentes de direção $\mathrm{N}$ a NW, estruturas que na região do Sossego possuem 
direção EW a NE-SW e que delineiam as zonas mineralizadas, já que o intenso fraturamento permitiu a circulação dos fluidos hidrotermais.

Na Mina do Sossego, a mineralização está disposta em cincos corpos: Pista, Sequeirinho, Baiano, Sossego e Curral, sendo os mais importantes Sequeirinho e Sossego. A mineralogia destes corpos difere fortemente entre si devido ao tipo de rocha hospedeira e também do tipo e intensidade das alterações hidrotermais predominantes em cada depósito. Estas características estão ilustradas na Figura 3 e na Figura 4.

O corpo Sequeirinho está hospedado em granito, gabro e rochas metavulcânicas félsica, enquanto que as hospedeiras do corpo Sossego são granito, granito granofírico e rocha metavulcânica félsica.

Nos corpos mais a oeste, no caso Pista, Sequeirinho e Baiano, as alterações iniciais sódica e sódica-cálcica são bem desenvolvidas; já nos corpos Sossego e Curral estas alterações são pouco desenvolvidas ou quase ausentes, predominando as alterações potássica e clorítica (MONTEIRO et al., 2008a).

A alteração sódica é caracterizada pela albitização em veios e fraturas enquanto que a alteração sódica-cálcica, dominada pela actinolita e albita, substitui a assembléia anterior e está associada a corpos maciços de magnetita-(apatita) e zonas constituídas de actinolita (actinolititos) na qual a alteração foi mais intensa (MONTEIRO et al., 2008a, MONTEIRO et al., 2008b).

As alterações potássica e clorítica são mais tardias. A primeira é caracterizada pela presença de biotita, feldspato potássico, magnetita e quartzo e está associada espacialmente às zonas mineralizadas. A cloritização forma zonas ricas em clorita associada à calcita e epídoto (MONTEIRO et al., 2008a; MONTEIRO et al., 2008b). 


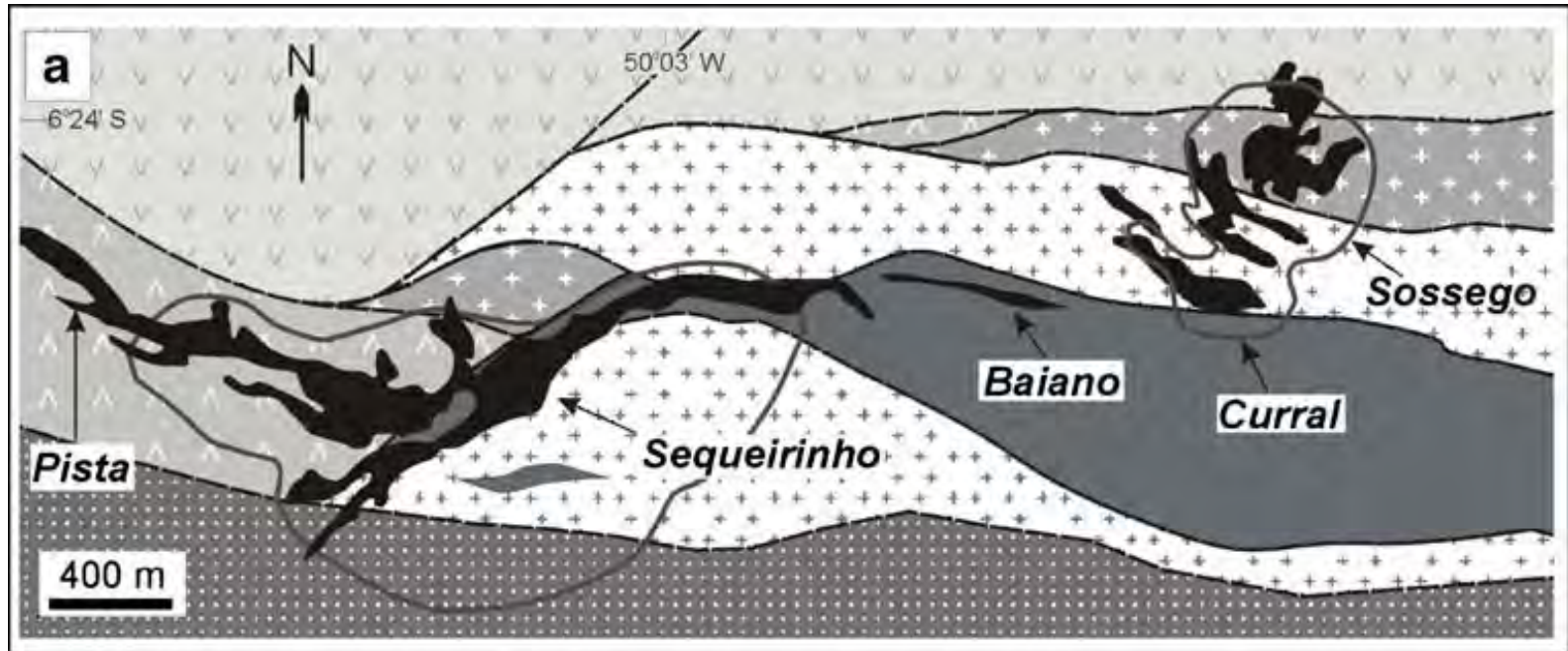

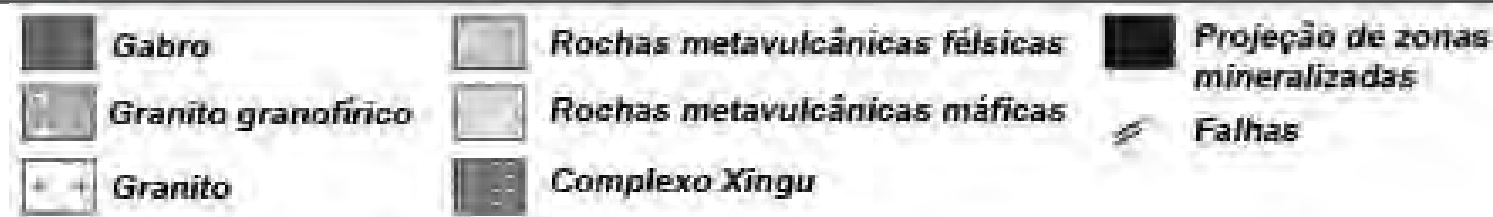

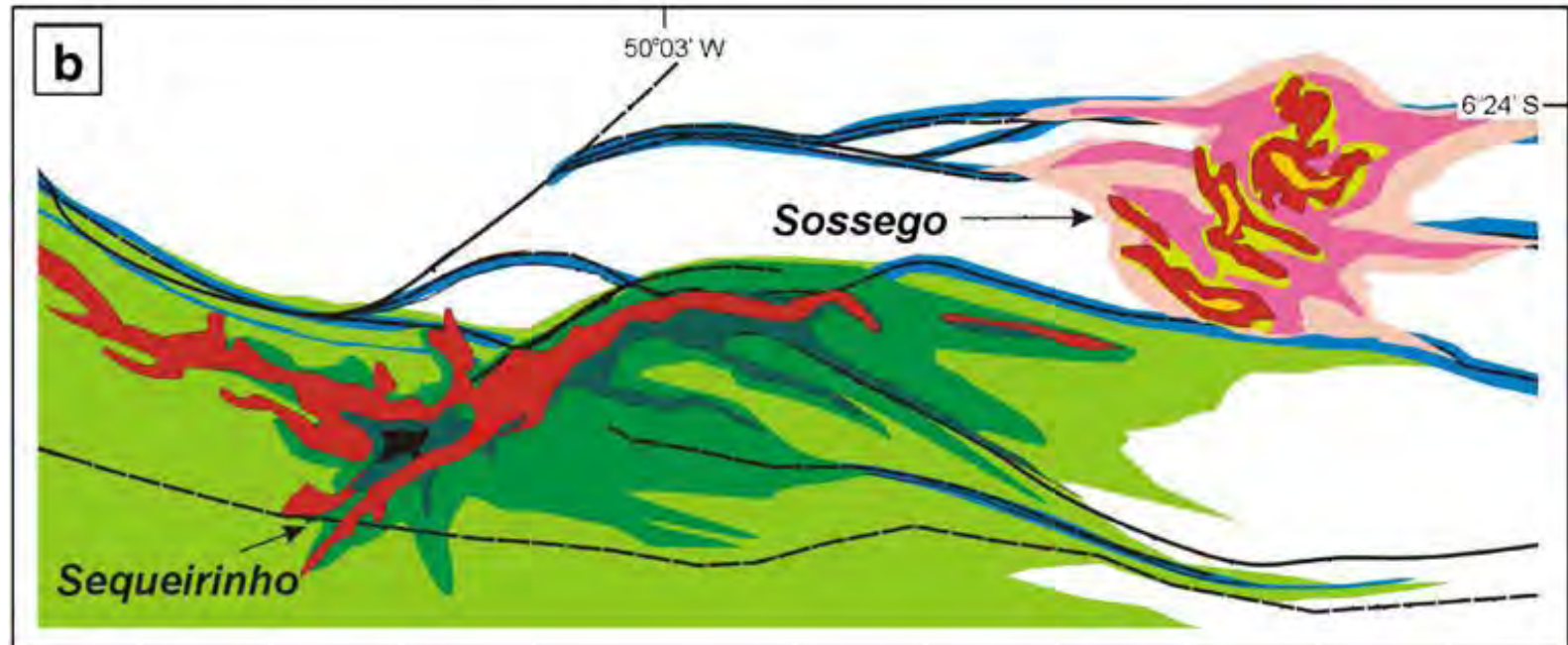

ए Silioificąão

Alteraçāo sódica

Alteraģão sódica-cálcica

Alteragào sódica-cálcica (actinolitito)

Magnetita maciça
Alteraçăo potássica

Cloritizagão

Alteraçáo cálcica tardia

Alteraģäo hidrolítica

Projeçào de zonas mineralizadas

Figura 3 - (a) Mapa geológico simplificado com a localização dos corpos Pista, Sequeirinho, Baiano, Curral e Sossego e (b) distribuição esquemática das zonas de alteração hidrotermal (modificado da Vale, obtido de MONTEIRO et al., 2008b) 


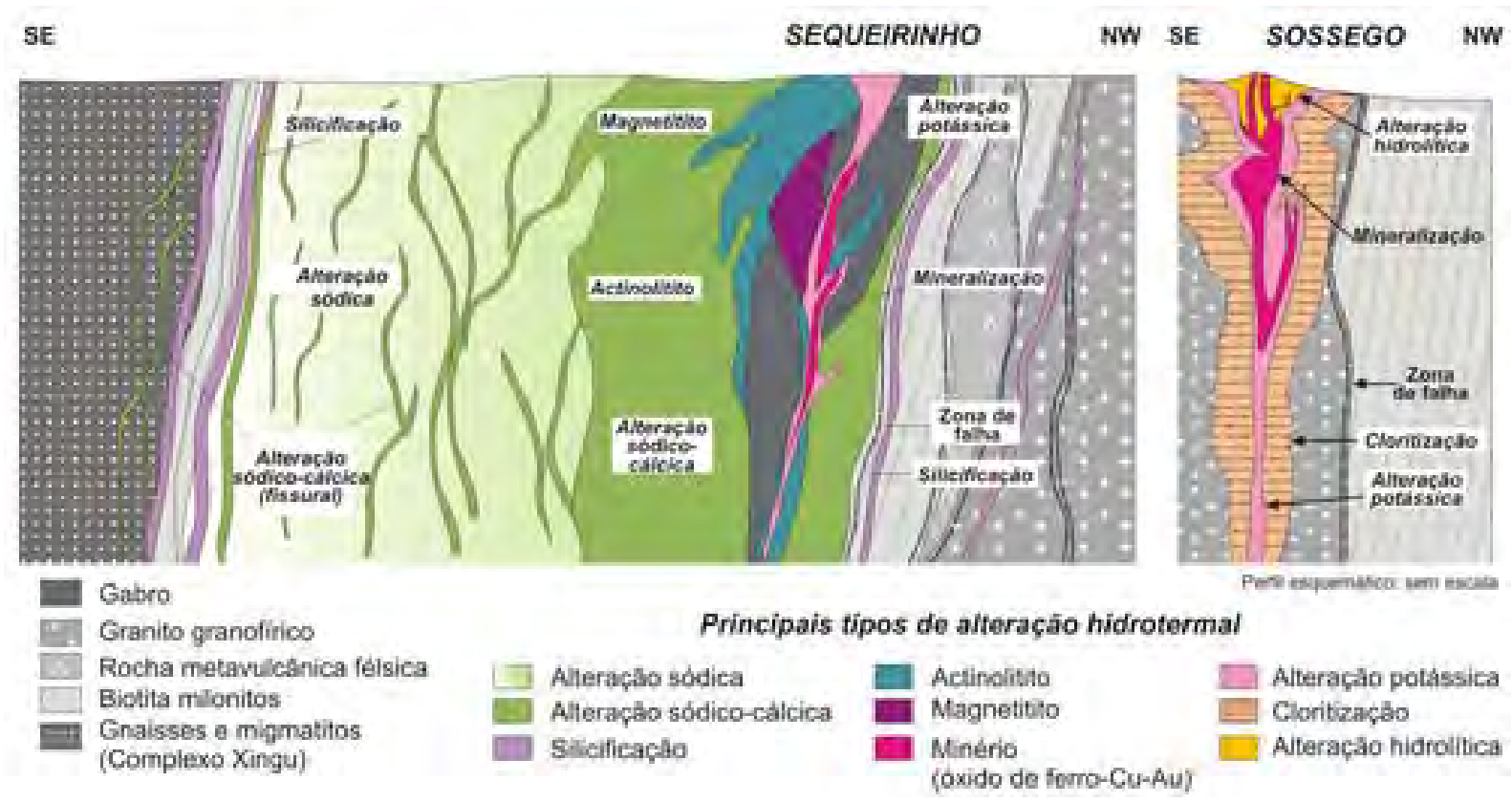

Figura 4 - Perfil esquemático mostrando a distribuição das zonas de alteração hidrotermal nos corpos Sequeirinho e Sossego (MONTEIRO et al., 2008, obtido em AUGUSTO et al., 2008)

A mineralização compreende um estágio tardio do sistema hidrotermal e é representada por sulfetos, principalmente calcopirita e, em menores quantidades, pirita, siegenita $\left((\mathrm{Ni}, \mathrm{Co})_{3} \mathrm{~S}_{4}\right)$, milerita $(\mathrm{NiS})$ e vaesita $\left(\mathrm{NiS}_{2}\right)$. Mais raramente, aparecem pirrotita, esfalerita, melonita, hessita, molibidenita e ouro nativo, na forma de pequenas inclusões na calcopirita (MONTEIRO et al., 2008a).

A calcopirita (principal mineral de minério) ocorre tanto na forma de maciça a semi-maciça, quanto disseminada, em vênulas, fraturas e stringers (stockwork), bolsões, brechas e zonas de substituição da rocha hospedeira. Também ocorre intercrescida com pirita, magnetita e/ou silicatos, podendo apresentar inclusões de magnetita e pirita (MONTEIRO et al., 2008a).

O minério do corpo Sequeirinho apresenta, em geral, aspecto brechóide; os sulfetos estão dispersos na matriz, os clastos são de actinolita, magnetita, apatita e alanita e os fragmentos são de actinolititos e magnetititos (MONTEIRO et al., 2008a). A proporção de calcopirita é muito maior do que a de siegenita e pirita (NEVES, 2006).

O minério do corpo Sossego ocorre na forma de veios e brechas. As brechas possuem clastos angulosos a arredondados, principalmente derivados de rochas 
graníticas, dispersos em matriz composta por calcopirita, magnetita, apatita, clorita e em menores quantidades muscovita, quartzo, actinolita e siegenita. O ultimo estágio do sistema hidrotermal é a alteração hidrolítica, representada pela assembléia muscovita-hematita-quarto-clorita-calcita, presente no corpo Sossego (MONTEIRO et al., 2008a; NEVES, 2006).

\subsubsection{Principais tipos litológicos}

As descrições das litologias apresentadas a seguir são baseadas em estudos petrográficos expostos em Neves (2006) e nos trabalhos de Monteiro et al. (2008a e 2008b).

As rochas félsicas estão incluídas nos litotipos granito (GRA), granito granifírico (GRF) e metavulcânicas ácidas (MVA). Nas três variedades a albitização, silicificação, epidotização e cloritização foram os processos hidrotermais mais atuantes.

Os granitos, GRA, são em geral maciços e localmente foliados e milonitizados. São constituídos de albita, quartzo, anfibólio, epidoto, clorita, calcita e feldspato potássico, tendo como minerais acessórios, titanita, alanita, zircão, apatita, magnetita, hematita e sulfetos. Os granitos granofíricos (GRF) possuem composição semelhante aos granitos, diferindo dos demais pela textura mais fina dos cristais.

A variedade metavulcânica ácida, MVA, possui fenocristais de quartzo e plagioclásio dispostos em matriz constituída de albita, epidoto, actinolita, magnetita, titanita e calcopirita.

Na brecha tipo Sossego, BHT, os clastos são derivados essencialmente de rochas graníticas e a matriz é composta por calcopirita, magnetita, apatita, clorita e em menores quantidades muscovita, quartzo, actinolita e siegenita.

O grupo de rochas máficas é representado por diabásios-gabros (GBA), actinolititos (ACT) e magnetititos (MAG). Os principais processos de alteração hidrotermal reconhecidos nessas rochas são escapolitização, anfibolitização e albitização. 
O tipo GBA é constituído principalmente por escapolita, albita, actinolita, hastingsita, epidoto, feldspato potássico e clorita, em menor quantidade, quartzo, titanita, biotita e magnetita.

Os ACT representam um caso mais extremo da alteração hidrotermal das rochas máficas, em que grande parte dos minerais preexistentes foi transformada em actinolita. Os actinolititos apresentam grandes cristais de actinolita intercrescida com magnetita e contém bolsões ricos em apatita.

Os magnetititos, MAG, são rochas maciças, de coloração escura, caracterizadas por quantidades de magnetita superiores a 50\%. Possuem, além da magnetita, calcopirita, actinolita, hastingsita, quartzo, epidoto, apatita e proporções subordinadas de albita, calcita, clorita, titanita, ilmenita e pirita.

$\mathrm{Na}$ brecha tipo Sequeirinho, BSE, os clastos são de actinolita, magnetita, apatita e alanita e os fragmentos são de actinolititos e magnetititos. A calcopirita é predominante sobre a siegenita e pirita.

\subsubsection{Beneficiamento do minério da mina de Sossego}

Em estudos de caracterização tecnológica de matérias-primas minerais, o levantamento de informações acerca do processo de beneficiamento do minério em é uma etapa importante, conforme discutido mais adiante.

Na mina do Sossego, após a lavra do minério e a britagem primária realizada nas proximidades do corpo mineralizado, o minério segue para a usina, onde passa por processos de moagem e concentração. As etapas de beneficiamento estão descritas abaixo e ilustradas na Figura 5.

$\mathrm{Na}$ usina de beneficiamento, a etapa de moagem inicia-se no moinho SAG (semi-autógeno), no qual a redução do material é realizada pela ação do próprio minério combinada com esferas de aço. A classificação da descarga do SAG é realizada por duas peneiras vibratórias. O material retido nas peneiras (acima de 13 $\mathrm{mm}$ ) é conduzido ao circuito de rebritagem em britadores cônicos, retornando ao moinho SAG; o material passante é bombeado para o circuito de classificação ciclonagem (BERGERMAN, 2009). 


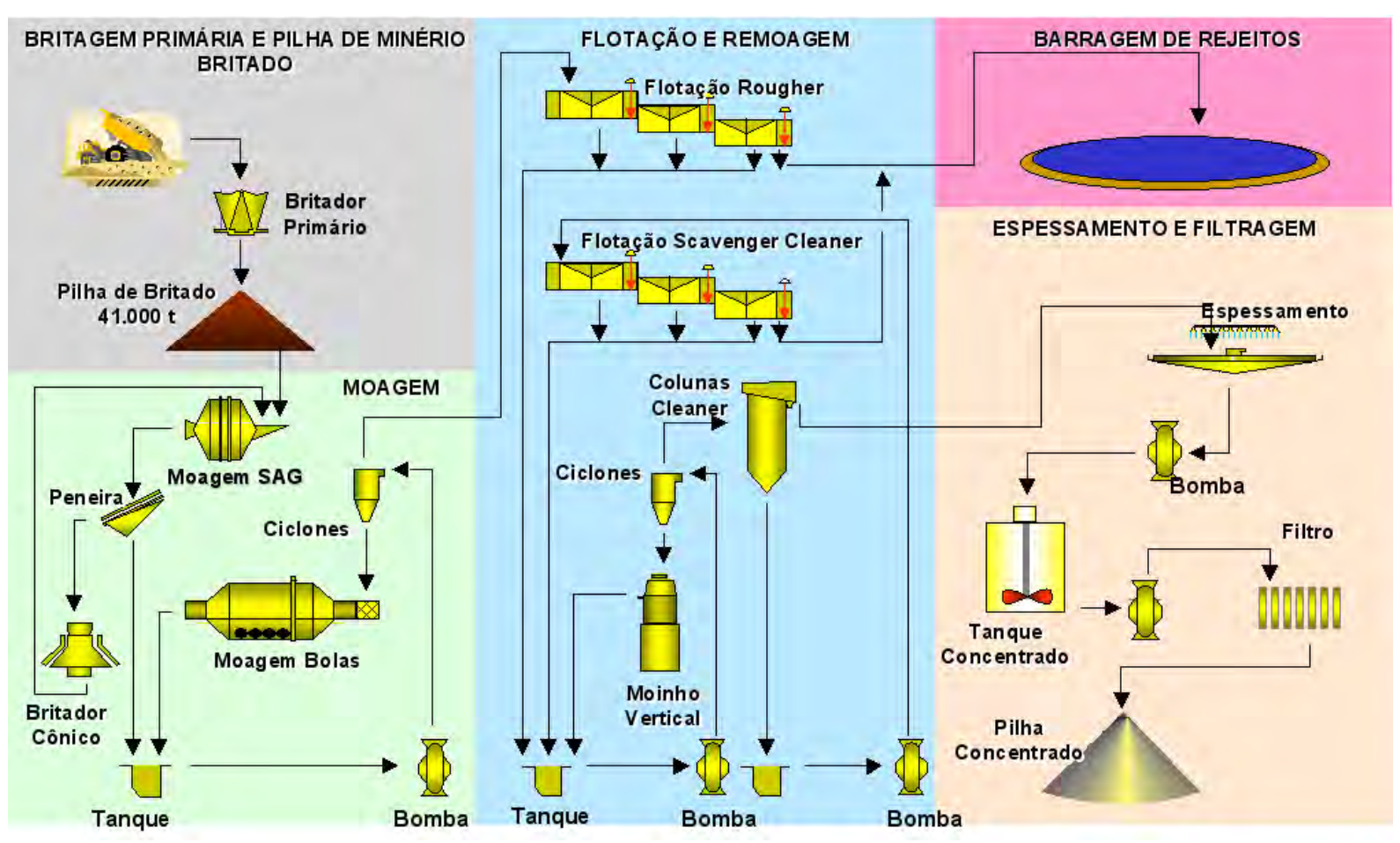

Figura 5 - Etapas do beneficiamento do minério (fluxograma cedido pela Vale)

A fração grossa do ciclone (underflow) alimenta o moinho de bolas. A descarga do moinho de bolas retorna para a ciclonagem (circuito reverso), cujo overflow (produto com $\mathrm{P}_{80}$ de $0,21 \mathrm{~mm}$ e $35 \%$ de sólidos) alimenta o circuito de flotação.

A flotação é composta por três etapas: rougher, cleaner e scavenger-cleaner. A primeira etapa de flotação é a flotação rougher. Neste processo, o rejeito é descartado por gravidade para a barragem de rejeitos e o concentrado, coletado pela espuma, é bombeado para alimentar nova etapa de ciclonagem.

O underflow dos ciclones alimenta dois moinhos verticais, que operam com bolas de aço, em circuito fechado com a ciclonagem. O overflow (material com $\mathrm{P}_{80}$ da ordem de $44 \mu \mathrm{m}$ ) é submetido à flotação cleaner (BERGERMAN, 2009).

O material flotado das colunas de flotação cleaner é o concentrado final. O rejeito das colunas permanece no circuito e alimenta a flotação scavenger cleaner, cujo concentrado se junta ao concentrado rougher (BERGERMAN, 2009).

É importante ressaltar que este processo apresenta elevada recuperação de cobre: partículas mistas com minerais portadores de cobre são concentradas nos estágios rougher e scavenger cleaner de flotação, moinhos verticais promovem a 
liberação dos minerais de minério que são concentrados no ciclo de flotação e remoagem pela espuma das colunas cleaner (REIS, 2004). Segundo Bergeman (2009), o circuito de flotação possui recuperação de cobre em torno de 93\%, podendo atingir picos de $98 \%$ em situações ótimas; o concentrado rougher apresenta teor de cobre variando entre 13 e 17\% com recuperação metalúrgica entre 94 a $96 \%$.

O concentrado final é espessado, filtrado e encaminhado para estocagem na planta antes de ser transportado até o Terminal Marítimo de Ponta da Madeira em São Luís, Maranhão, pela Estrada de Ferro de Carajás, onde é embarcado para o mercado brasileiro e mundial. A parcela destinada ao mercado nacional é refinada na usina de Caraíba Metais S.A. na Bahia (RODRIGUES; HEIDER, 2009).

\subsection{Técnicas analíticas}

A seguir é apresentada a revisão bibliográfica acerca dos métodos utilizados neste projeto: difração de raios $\mathrm{X}$, análise por agrupamento (cluster analysis), caracterização tecnológica e técnica de mineralogia quantitativa automatizada por análise de imagens.

\subsubsection{Difração de raios $X$}

A técnica de difração de raios $X$ apresenta inúmeras aplicações em diversos campos do conhecimento, sendo a identificação de fases cristalinas através de comparação com base de dados uma das mais empregadas.

Uma parcela dos raios $\mathrm{X}$, ao atingir a superfície do material, sofre espalhamento elástico sem perda de energia (dispersão ou espalhamento coerente). Caso os átomos que geram o espalhamento estejam arranjados sistematicamente, como numa estrutura cristalina, a interação das ondas eletromagnéticas com os átomos pode gerar uma interferência construtiva ou destrutiva. O fenômeno de difração dos raios $X$ irá ocorrer quando a interação for construtiva, segundo a geometria descrita pela lei de Bragg (Figura 6 , equação 1 ), que estabelece a relação entre o ângulo de incidência dos raios $X \theta$ ”, "a disância entre os planos que a originaram "d" e o comprimento de onda da radiação incidenté (" BISH; POST, 1989). 


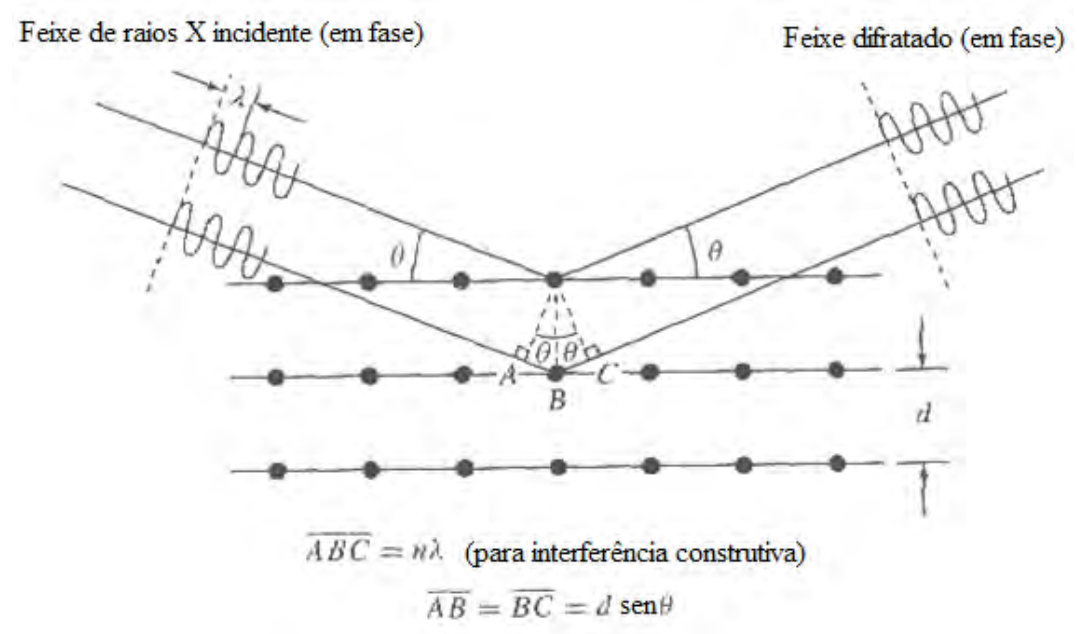

Figura 6 - Geometria que descreve o fenômeno de difração (Lei de Bragg)

Lei de Bragg: $\mathrm{n} \lambda=2 \mathrm{~d} \cdot \operatorname{sen} \theta$, onde

(equação 1)
$\lambda$ : comprimento de onda da radiação incidente,
n: número inteiro (ordem de difração)
d: distância interplanar para o conjunto de planos hkl (índice de Miller) da estrutura cristalina
$\theta$ : ângulo de incidência dos raios $X$

A intensidade do feixe difratado é dependente, dentre outros fatores, do número de elétrons presentes no plano da estrutura cristalina do mineral. Assim, cada plano cristalino, representado por uma posição angular $\theta$ no difratograma, terá uma intensidade difratada distinta. Os compostos cristalinos são identificados através das posições angulares e intensidades relativas dos picos difratados, por seu padrão difratométrico característico.

A identificação dos minerais é realizada a partir da comparação do difratograma coletado com fichas catalogadas de minerais presentes em bancos de dados disponíveis. 
A seguir, serão descritos brevemente os principais aspectos da técnica de estudo de materiais policristalinos, denominado método de difração de pó (powder diffraction).

O difratômetro de raios $X$ é composto basicamente por um sistema de geração dos raios $X$, um sistema de filtros e fendas e um sistema de detecção. A geração é dada em tubos de raios $X$, os feixes gerados são colimados por filtros e fendas $e$ incidem sobre a amostra. A interação com a amostra gera feixes difratados, que também são filtrados e captados pelo detector. De maneira simplificada pode-se dizer que os parâmetros instrumentais que influenciam no resultado da análise são: tubo gerador (tipo de anôdo, intensidade e foco), filtros (filtro $\mathrm{k} \beta$ ou monocromador), fendas (configuração) e detector utilizados.

Para uma boa análise é necessário que o difratograma coletado possua resolução adequada para o resultado esperado (quantitativo $x$ qualitativo), que é função dos instrumentos utilizados, parâmetros de coleta, preparação da amostra, além das características intrínsecas do material que se analisa.

As condições de coleta devem ser definidas de acordo com as características do material e o tipo de análise. Dentre alguns parâmetros de coleta estão: radiação empregada (tipo de anôdo e intensidade do feixe), espectro de varredura da amostra (ângulo $2 \theta$ inicial e final), modo da varredura (contínuo ou por passo), tamanho e tempo do passo e o tempo total de coleta (função das demais variáveis).

A amostragem, neste método, é de grande importância. Já que o fenômeno de difração só ocorrerá quando o cristal estiver adequadamente orientado (Lei de Bragg). Para atingir a estatística adequada, o tamanho dos cristais deve ser menor do que $30 \mu \mathrm{m}$ (para análises qualitativas) e entre 5-10 $\mu \mathrm{m}$ para análises quantitativas. Spinner é um acessório que permite a rotação da amostra, melhora a estatística dos cristais orientados.

Dentre os métodos de quantificação de fases pode-se citar: método do padrão interno, de adição, matrix-flushing e Rietveld. As análises quantitativas requerem maior precisão, ou seja, é necessário um elevado número de contagens. Atualmente, com o advento de sensores sensíveis à posição (PSD), o tempo de aquisição dos difratogramas diminuiu drasticamente, possibilitando o uso desta ferramenta em situações onde o tempo de coleta é crítico, como em controles de 
processo (MACCHIAROLA et al., 2007). Os PSD permitem a coleta simultânea de alguns graus do feixe difratado, o que também possibilita melhora na resolução do difratograma com o aumento do número de contagens, sem comprometimento do tempo de coleta.

Além da identificação e quantificação das fases minerais, a difração de raios $X$ possui diversas outras aplicações, como cálculo das dimensões da cela unitária (definir os parâmetros cristalográficos da estrutura de um mineral), determinação da cristalinidade de um material, avaliação de tamanho de cristalitos, análises sob atmosfera controlada, orientação de cristais ou textura, análise de tensão residual e espessura de filmes finos.

\subsubsection{Análise por agrupamento (cluster analysis) com base em difração de raios $X$}

A técnica de análise por agrupamento (cluster analysis) é um recurso estatístico que facilita a análise de grande quantidade de dados, estabelecendo relações de semelhança e dissimilaridades entre as amostras. Tem como objetivo classificar parâmetros em grupos de forma que os parâmetros pertencentes a um mesmo grupo sejam similares entre si com relação às variáveis (características) escolhidas e os parâmetros em grupos diferentes sejam heterogêneos (MINGOTI, 2005).

Diferentemente de outros procedimentos estatísticos, o método de análise por agrupamento é utilizado quando não há uma hipótese a priori, e a comparação entre amostras encontra-se em fase inicial. Pode ser utilizado em diversos campos do conhecimento, sempre que se quer encontrar algum padrão de correlação entre objetos (TAN; STEINBACH; KUMAR, 2006).

Nesta técnica, cada amostra é definida, através de um tratamento matemático, como um ponto no espaço multidimensional descrito pelas variáveis escolhidas no estudo. Sendo as amostras descritas como pontos no espaço, é possível calcular a distância entre todos os outros pontos, o que equivale a calcular as semelhanças/dissimilaridades entre elas (MOITA NETO; MOITA, 1998).

Existem várias maneiras de calcular a distância entre dois pontos e cabe ao interessado escolher aquela que melhor se aplica ao caso em questão. A mais conhecida e utilizada é a distância euclidiana, que corresponde ao sentido trivial de 
distância no plano. Entre outros métodos estão: distância euclidiana quadrática ou absoluta, Manhattan, Chebychev, etc. (MOITA NETO; MOITA, op.cit.).

A partir das distâncias calculadas constrói-se uma matriz de proximidade que descreve todas as distâncias entre amostras. A matriz é então utilizada para realizar o agrupamento das amostras.

As técnicas de agrupamento podem ser classificadas em dois grupos: hierárquicas e não-hierárquicas. As técnicas hierárquicas são utilizadas na maioria das vezes em análise exploratória dos dados, com intuito de identificar possíveis agrupamentos e valor provável do número de grupos. Para as técnicas não hierárquicas é preciso que o número de grupos seja pré-especificado pelo pesquisador (MINGOTI, 2005).

No método de agrupamento hierárquico os objetos podem ser tratados inicialmente como subgrupos unitários, que são agrupados a cada passo em novos subgrupos, até que apenas um grupo permanece, ou podem ser tratados inicialmente como um único grupo, que se desagrupa a cada passo (MOITA NETO; MOITA, op.cit.). A escolha do número final de grupos é subjetiva; o propósito é encontrar um número de grupos que esteja associado à partição natural dos elementos que estão sendo comparados (MINGOTI, 2005). Neste método, uma vez que um grupo é formado, ele não pode mais ser dividido, somente combinado com outros clusters (NORUSIS, 2010).

Existem diversas métodos de aglomerar matematicamente os objetos; No método de ligação simples (single linkage) a similaridade entre dois conjuntos de dados é definida pelos dois elementos mais próximos entre si (distância entre vizinhos mais próximos), enquanto que no método de ligação completa (complete linkage) pelos elementos menos semelhantes; No método da média das distâncias (average linkage), a semelhança entre dois subgrupos é a média das distâncias entre todos os pares de dados; No método do centróde (centroid method) a semelhança é dada pelos vetores médios (MINGOTI, 2005). Diferenças entre estes métodos podem ser observados na Figura 7. 


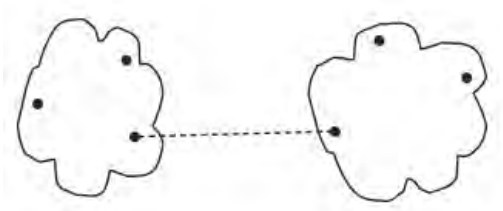

(a) Ligação Simples

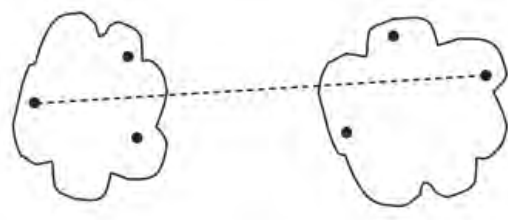

(b) Ligação Completa

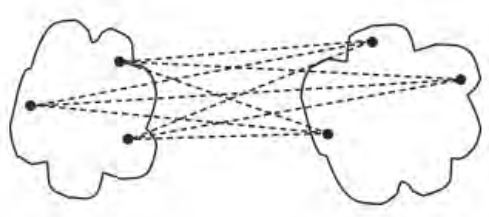

(c) Média das distâncias

Figura 7 - Definições gráficas de proximidade de métodos aglomerativos (TAN; STEINBACH; KUMAR, 2006).

O dendograma é a representação visual que ilustra o agrupamento realizado (Figura 8). Nela, objetos são representados como nós e os passos do agrupamento pela junção dos ramos no dendograma. O comprimento do ramo indica a distância entre os subgrupos quando estão unidos. Desta maneira, duas amostras próximas devem ter também valores semelhantes para as variáveis medidas, portanto, quanto maior a proximidade entre as medidas relativas às amostras, maior a similaridade entre elas. O dendrograma hierarquiza esta similaridade de modo que se pode ter uma visão bidimensional da similaridade ou dissimilaridade de todo o conjunto de amostras em estudo (MOITA NETO; MOITA, op.cit.).

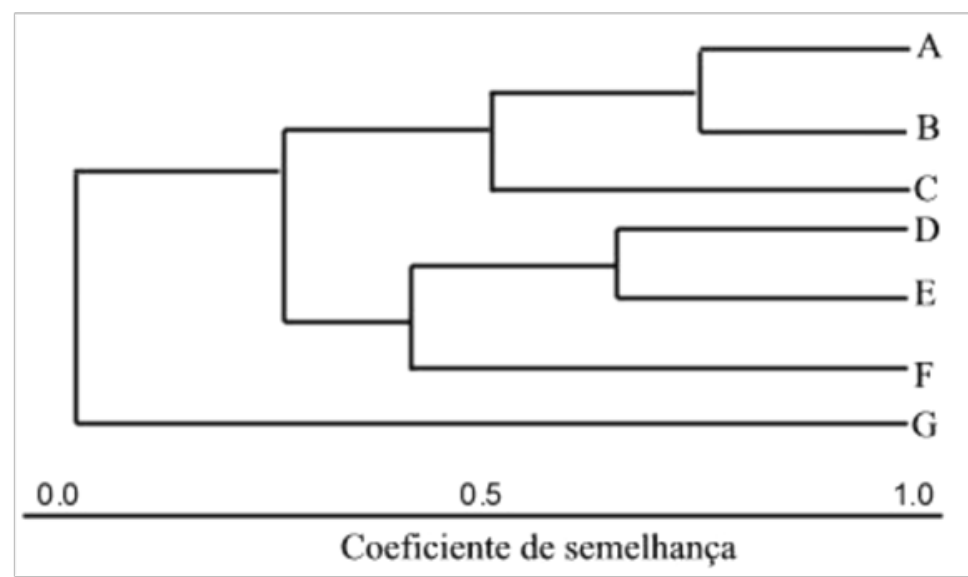

Figura 8 - Dendograma - representação gráfica de um agrupamento.

No caso da análise grupal por difratogramas de raios $\mathrm{X}$, o emprego do software X'Pert Highscore Plus (PANalytical) permite a comparação de vários espectros sem o prévio tratamento dos mesmos ou identificação das fases cristalinas presentes (MACCHIAROLA et al., 2007). 
O procedimento de classificação pode considerar a posição de picos difratados como também as respectivas intensidades difratadas, sendo que os agrupamentos resultantes retratam não só variações de assembléias mineralógicas, mas também a proporção dos minerais presentes.

O agrupamento é realizado pelo método hierárquico aglomerativo, sendo possível escolher entre diversas medidas de distâncias e modos de ligação disponíveis no software.

Posteriormente é possível ainda, a identificação dos espectros mais representativos de cada grupo e os espectros que não se encaixam em nenhuma classe entre outras opções (MACCHIAROLA et al., op.cit.).

O software também permite a análise do resultado do agrupamento a partir da ferramenta de análise estatística de componentes principais (principal component analysis - PCA). Nesta técnica as variáveis originais são reescritas em novas variáveis denominadas componentes principais. Esta transformação busca reduzir a dimensionalidade do conjunto de dados, condensando as informações nos primeiros componentes principais (MOITA NETO; MOITA, 1998). No caso o software possibilita comparar as amostras dos diferentes grupos em função de seus três primeiros principais componentes num gráfico 3D. Em um agrupamento adequado as amostras de mesmo grupo devem ocupar posições próximas no gráfico 3D, ou seja, são descritas por PCAs semelhantes.

\subsubsection{Caracterização tecnológica}

A caracterização tecnológica compreende o processo de descrição e quantificação da composição mineralógica, tamanho e forma dos grãos, associações minerais, grau de liberação, composição química, entre outros, de um material. A determinação destes parâmetros é fundamental para o aproveitamento de um recurso mineral de forma otimizada, pois fornece informações sobre o potencial de recuperação do material, além de predizer a resposta do material frente aos processos de beneficiamento (NEUMANN; SCHNEIDER; NETO, 2004). Os estudos também podem ser empregados para auxiliar na solução de problemas de um processamento já implantado. 
As técnicas tradicionais de caracterização tecnológica compreendem processos relativamente lentos e trabalhosos, que envolvem análises granulométricas e químicas, separações minerais, difração de raios $X$, conjugadas à quantificação mineralógica, microscopia óptica (MO) ou eletrônica de varredura MEV (KAHN et al., 2008). Muitos trabalhos descrevem procedimentos adotados nesse tipo de estudo, já que estes variam de acordo com o tipo de minério e com os objetivos da caracterização (PETRUK, 2000; JONES, 1987; SANT'AGOSTINO; KAHN, 1997; NEUMANN; SCHNEIDER; NETO, 2004; entre outros).

De maneira geral, a caracterização é realizada em etapas. Neumann, Schneider e Neto (2004) descrevem quatro estágios, sendo, o primeiro de fracionamento da amostra, que engloba separações granulométricas, separações por densidade, por susceptibilidade magnética, entre outros. O segundo estágio é o de identificação das fases minerais, para a qual existem diversas técnicas analíticas, como a difração de raios $X$, microscopia ótica e eletrônica de varredura, entre outras. A terceira etapa visa à quantificação e distribuição das fases existentes nos grupos fracionados (distribuição por faixa granulométrica, densitária, magnética, etc) e a última visa à determinação do grau de liberação do mineral de interesse.

A determinação do grau de liberação dos minerais de interesse é uma informação importante para o beneficiamento do minério, já que a granulação ideal da moagem implicará em redução de custos de uma sobremoagem e recuperação ótima do mineral de interesse (PETRUK, op.cit.).

Sant'Agostino e Kahn (1997) apresentam uma descrição detalhada da metodologia para a caracterização de matérias-primas, descrevendo ainda, a importância do levantamento de informações sobre o bem mineral em questão, dos processos de beneficiamento e especificações a que se destina o bem mineral, na determinação dos critérios de abordagem, metas e procedimentos.

Estudos de casos de caracterização de diferentes materiais, bem como o de mineralizações de sulfetos de metais base são apresentados em Petruk (2000). Em relação à caracterização de minérios de cobre, Petruk (op. cit.) destaca a importância da quantificação mineralógica dos minerais portadores de cobre, face às diferentes respostas destes minerais ao processo de flotação; alguns minerais de minério, como a valleriita, são dificilmente separados no processo de flotação, e 
outros facilmente flotáveis, como a bornita e a calcopirita (BULATOVIC, 2007). Além disso, a proporção destes minerais pode indicar o máximo teor de Cu recuperável (HENLEY, 1983).

Estudos de caracterização tecnológica em produtos de beneficiamento também são de grande relevância em alguns casos. Lastra (2007) descreve um exemplo em que a determinação do grau de liberação dos minerais de minério (diferentes sulfetos de cobre) e da pirita no concentrado permitiu modificações no processo de concentração. No caso, o elevado teor de cobre do concentrado, relacionado com a presença de minerais secundários, mais ricos em $\mathrm{Cu}$, mascarava a baixa eficiência do processo de concentração. Havia alta proporção de pirita no concentrado, mineral de efeito negativo no processamento, que estava relacionada a problemas de liberação.

Atualmente, a caracterização de materiais geológicos conta com ferramentas mais modernas de quantificação mineralógica automatizada, na qual são utilizadas técnicas de análise de imagens integradas a microscopia eletrônica de varredura e microanálise por EDS. Esta técnica é discutida a seguir.

\subsubsection{Mineralogia quantitativa automatizada por análise de imagens}

Ferramentas de mineralogia quantitativa automatizada através da conjugação de técnicas de análise de imagens e microscopia eletrônica de varredura e microanálise por EDS evoluíram de forma muito significativa nos últimos 20 anos possibilitando hoje gerar dados estatísticos substancialmente mais robustos. (PETRUK, 1989; SUTHERLAND; GOTTLIEB, 1991; KAHN ; MANO; TASSINARI, 2002; FANDRICH et al., 2007).

Sistemas comerciais, tais como MLA e QEM-SCAN, permitem obter em curto espaço de tempo enorme quantidade de dados mineralógicos e texturais, como composições mineralógica e química, distribuição elementar, espectros de liberação, distribuição de partículas mistas, dentre outros.

Os procedimentos de análise de imagens envolvem aquisição e tratamento adequado da imagem, segmentação das fases, identificação dos minerais, deaglomeração das partículas (para determinações do grau de liberação), manipulação dos dados e interpretação dos resultados (PETRUK, 1989). 
As imagens mais utilizadas são as de microscopia eletrônica de varredura ou óptica por luz refletida. Nas imagens provenientes de microscopia óptica (LR) os parâmetros utilizados para a discriminação dos minerais são a sua cor e reflectância. No caso do MEV são utilizadas imagens de elétrons retroespalhados (BSE) associadas com microanálises por EDS. Nas imagens de BSE o tom de cinza de cada pixel é proporcional ao número atômico médio daquele ponto. Em alguns casos essa distinção é suficiente para a discriminação dos minerais presentes; nos casos em que minerais possuem número atômico muito semelhante (caso da calcopirita e esfalerita, por exemplo) e os tons de cinza não são distinguíveis entre si, a identificação é baseada em espectros de EDS (NEUMANN; SCHNEIDER; NETO, 2004; FANDRICH et al., op.cit.).

As imagens digitais são obtidas a partir de seções polidas ou delgadas de material desagregado. A preparação das seções polidas requer cuidados como amostragem adequada, utilização de resina específica (epóxi), bom polimento, distribuição aleatória dos minerais na seção, entre outros. As imagens devem possuir alta resolução e baixo ruído para apropriada identificação e quantificação dos minerais. (FANDRICH et al., op.cit.; SUTHERLAND, GOTTLIEB, op.cit.).

No processamento das imagens, duas importantes funções do software MLA são: deaglomeração de partículas e segmentação de fases. A deaglomeração consiste em separar partículas que se tocam afim evitar resultados de liberação enviesados; o software possui um sistema automatizado que detecta partículas aglomeradas e separa-as com base em parâmetros predefinidos pelo operador. $\mathrm{Na}$ segmentação de fases, o software delimita áreas onde o nível de cinza da imagem de BSE é homogêneo e corresponde a um só mineral (FANDRICH et al., op.cit.).

O mineral correspondente a cada área é identificado com base em espectros de EDS podem ser coletados de diversas maneiras: um ponto ou área escaneada para cada área homogênea ou como um mapeamento parcial ou total da seção quando há minerais com tons de cinza semelhantes; nestes últimos casos a coleta demora muito mais tempo (FANDRICH et al., op.cit.).

Os processamentos descritos estão ilustrados na Figura 9. 


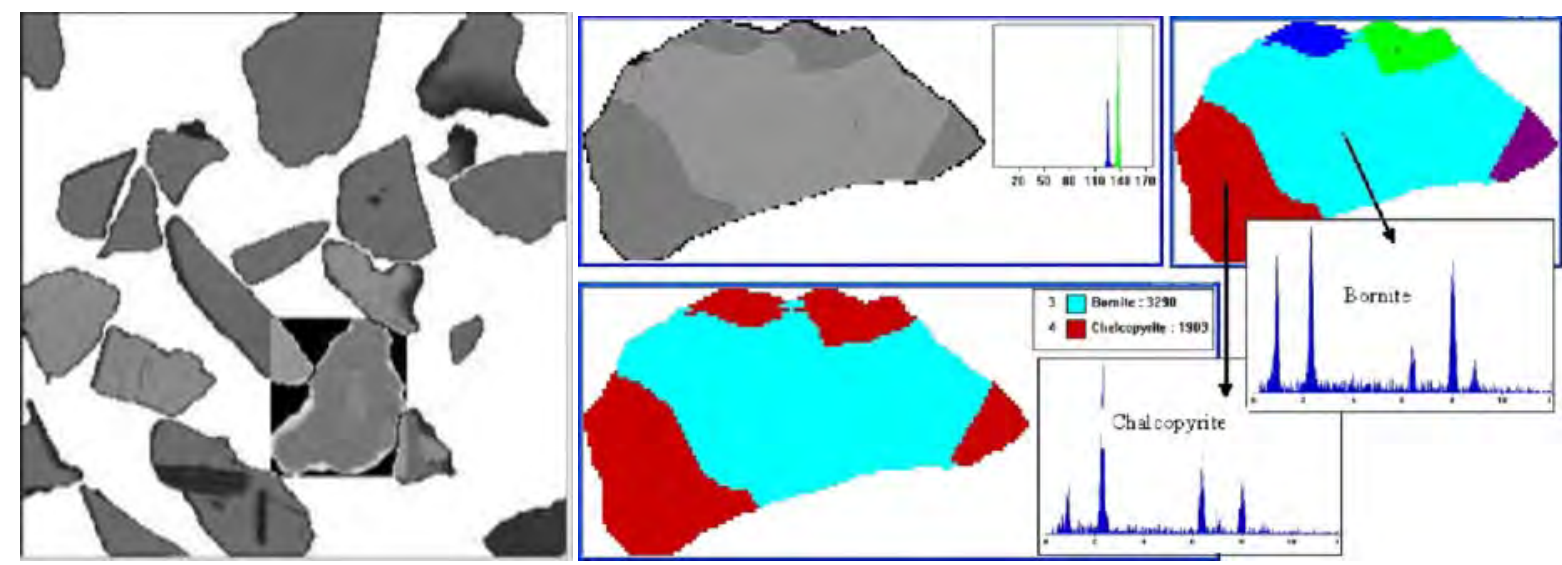

a) partículas deaglomeradas ; b) segmentação em tons de cinza homogêneos ; c) pontos de coleta de EDS em cada área segmentada ; d) partícula após classificação (comparação com o banco de dados)

Figura 9 - Processamento para análise mineralógica quantitativa automatizada (obtida de FANDRICH et al., 2007)

O banco de dados utilizado para comparação dos espectros de EDS é específico para cada conjunto de amostras, de modo a refletir as mesmas condições de coleta e características químicas das mesmas. O banco de dados deve ser criado antes das aquisições das imagens e a envolve a coleta de espectros EDS de alta resolução de cada mineral presente na amostra (FANDRICH et al., op.cit.).

Inúmeras informações sobre a amostra processada podem ser obtidas ao final do trabalho, como proporção mineralógica, distribuição granulométrica, grau de liberação mineral, associações minerais, distribuição de elementos de interesse, forma dos grãos, entre outras (NEUMANN; SCHNEIDER; NETO, 2004; FANDRICH et al., op.cit.). 


\section{MATERIAIS E MÉTODOS}

\subsection{Materiais}

As amostras utilizadas neste trabalho foram cedidas pela Vale e correspondem à contra-parte de amostras de testemunhos de sondagem utilizadas no estudo sobre geometalurgia de moagem realizado por BERGERMAN (2009).

Segundo Bergerman (op.cit.), as amostras são referentes aos planos de lavra dos anos de 2007 e 2008, para avaliação da variabilidade do minério nas cavas de Sequeirinho e Sossego.

As amostras possuiam cerca de $10 \mathrm{~kg}$ cada e foram compostas a partir de diversos fragmentos ao longo de $10 \mathrm{~m}$ de furo de sonda. A Figura 10 ilustra o metodo, denominado "B", utilizado para a composição das mesmas segundo BERGERMAN, (op.cit.). A contra-parte deste material foi objeto de estudo deste trabalho (amostras com cerca de 3,5 a $4 \mathrm{~kg}$ ).

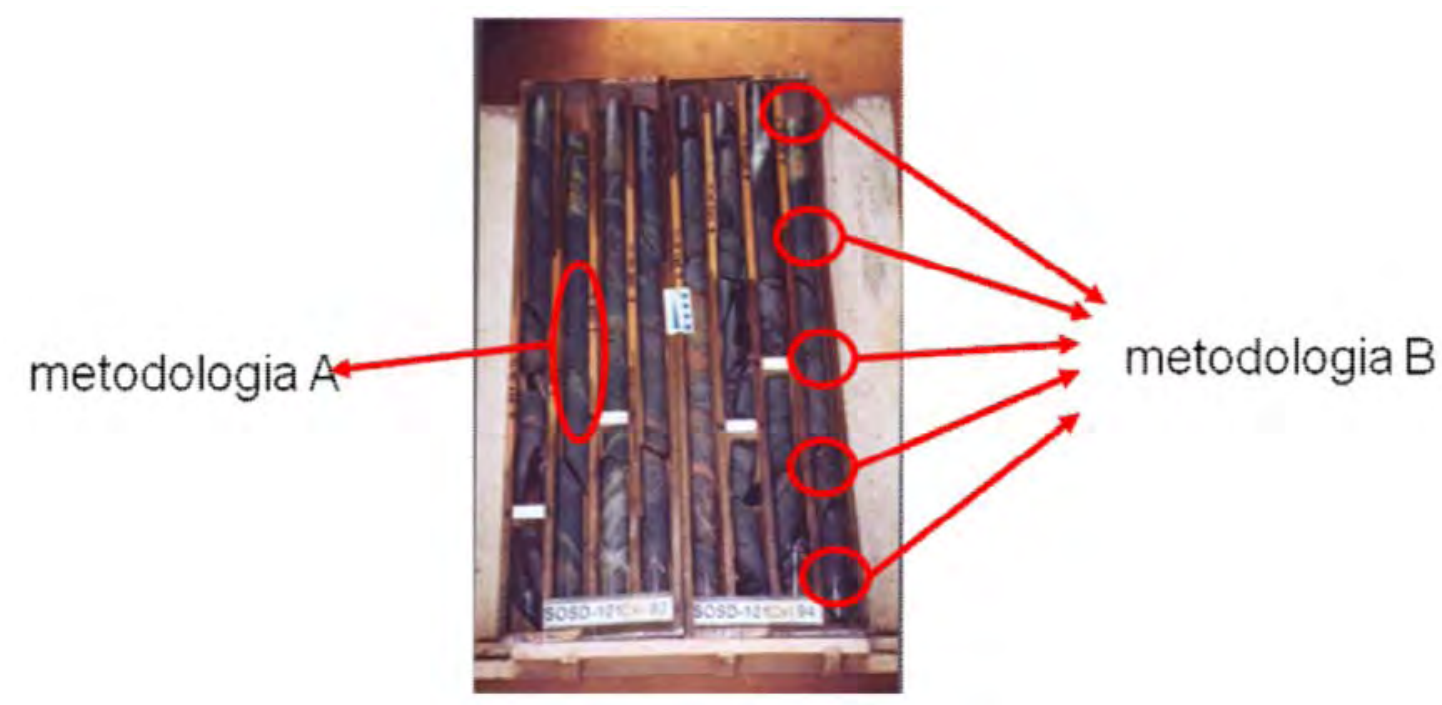

Figura 10 - Médodo B utilizado para composição das amostras (BERGERMAN, 2009)

A relação das 110 amostras recebidas é apresentada no Anexo 1; fotos de algumas amostras tal como foram enviadas ao laboratório são ilustradas na Figura 11. 

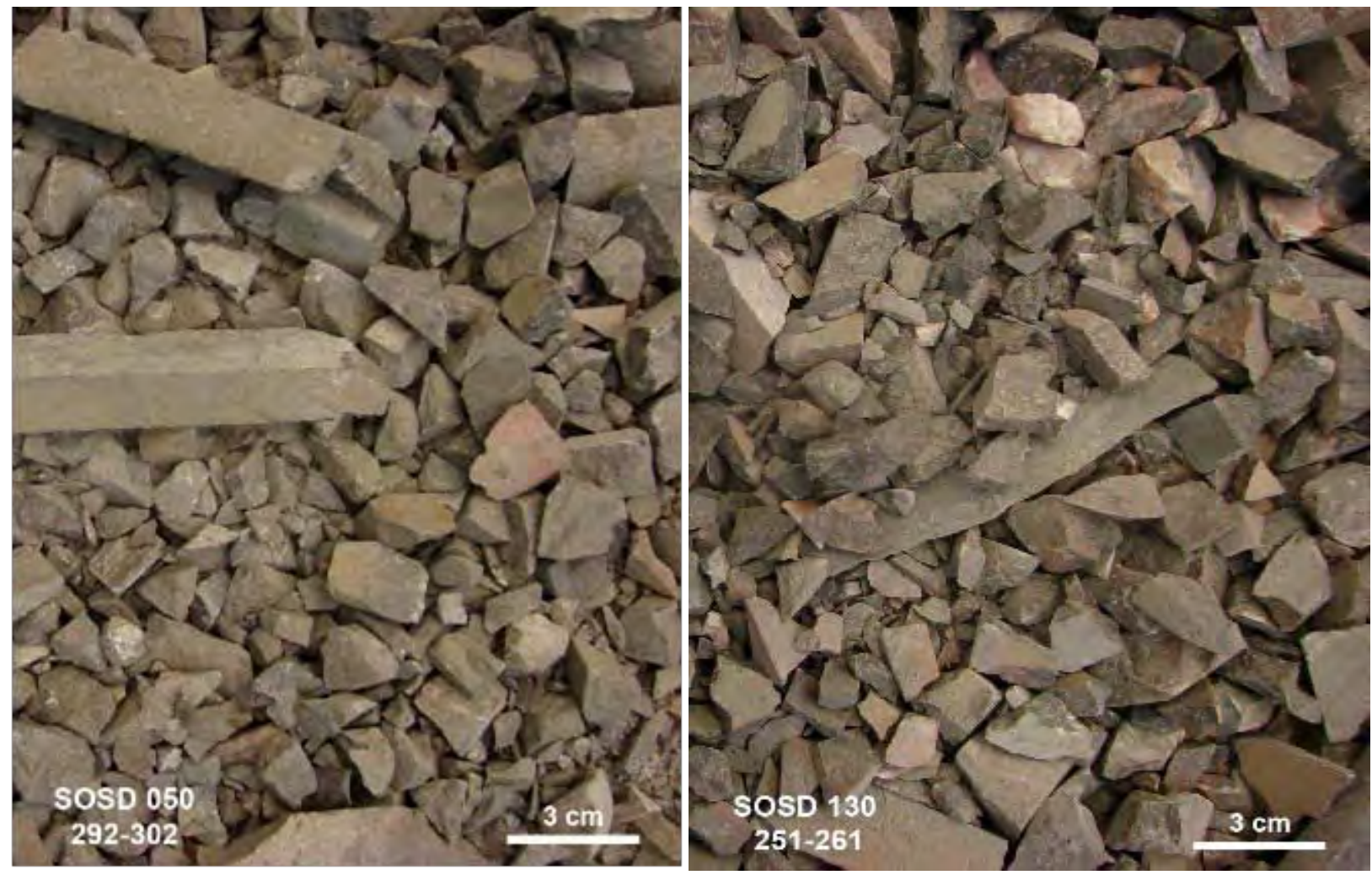

Figura 11 - Contraparte de testemunhos de sondagens, amostras tais quais

\subsection{Procedimentos adotados}

As análises laboratoriais foram desenvolvidas nas dependências do Laboratório de Caracterização Tecnológica - LCT, do Departamento de Engenharia de Minas e do Petróleo da Escola Politécnica da USP, o qual conta com procedimentos e capacitação laboratoriais (infraestrutura e pessoal) adequados à realização do projeto.

As atividades realizadas podem ser subdivididas em três etapas, conforme apresentado no fluxograma da Figura 12.

A primeira etapa envolveu cominuição e homogeneização das amostras tais quais e visou à obtenção de alíquotas representativas para os trabalhos subseqüentes.

A segunda etapa compreendeu os procedimentos de preparação das amostras para a análise de difração de raios $X$ e a classificação pela ferramenta de análise por agrupamento. 


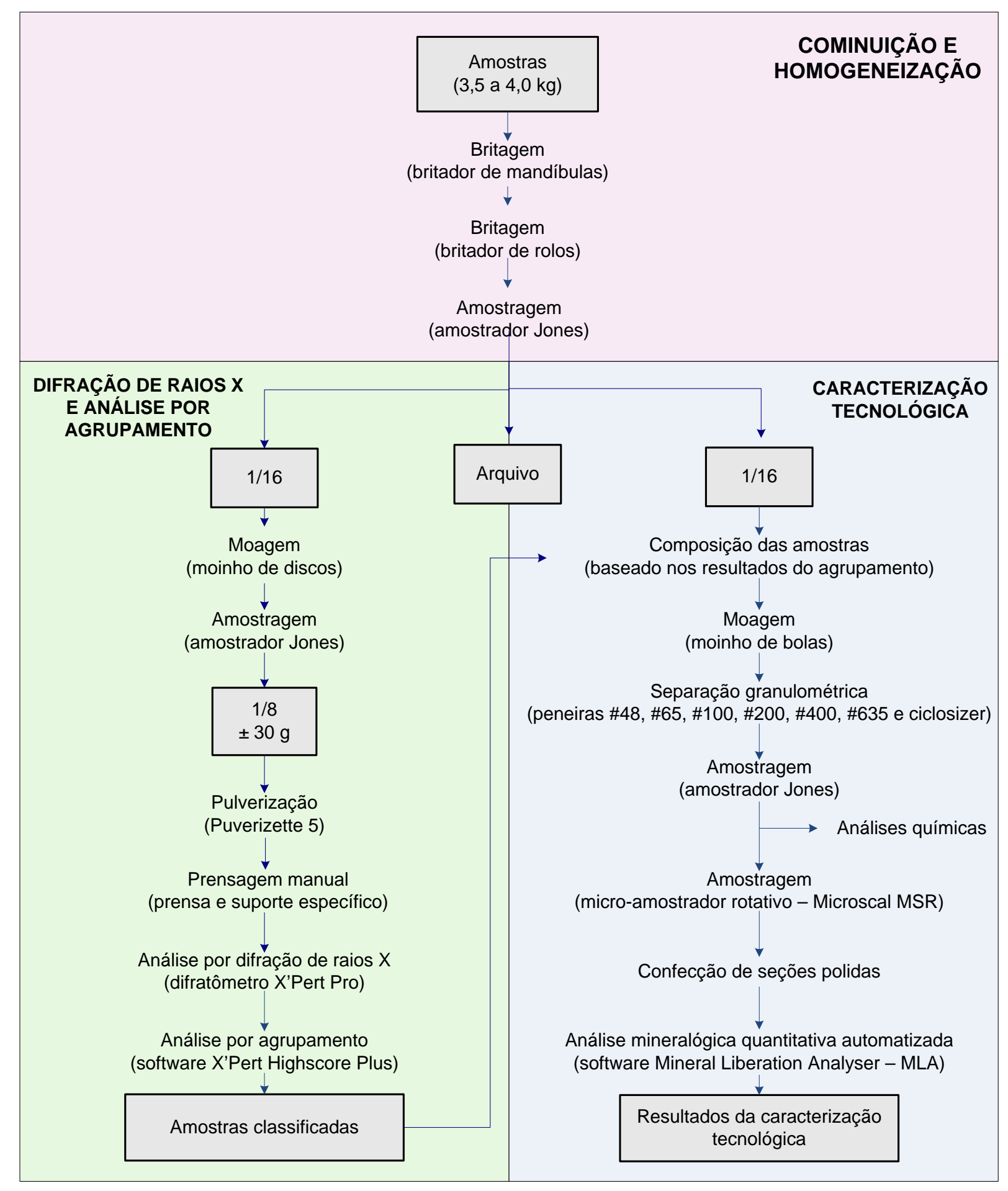

Figura 12 - Fluxograma das atividades realizadas 
$\mathrm{Na}$ terceira etapa, as alíquotas reservadas para a caracterização tecnológica foram juntadas em função do resultado do agrupamento para compor as amostras representativas dos tipos definidos; os procedimentos relativos aos estudos de caracterização tecnológica foram efetuados nestas amostras compostas. Todos os procedimentos estão detalhados a seguir.

\subsubsection{Primeira etapa de cominuição e homogeneização}

Inicialmente, o material recebido passou por uma etapa de cominuição e homogeneização, na qual foram utilizados dois britadores de mandíbulas com diferentes aberturas e um britador de rolos (Figura 13). O material obtido foi amostrado utilizando um amostrador tipo Jones, visando à redução da massa para duas alíquotas com cerca de 1/16 do total inicial (cerca de 200 a 250 g), cada qual destinada a uma etapa do projeto.

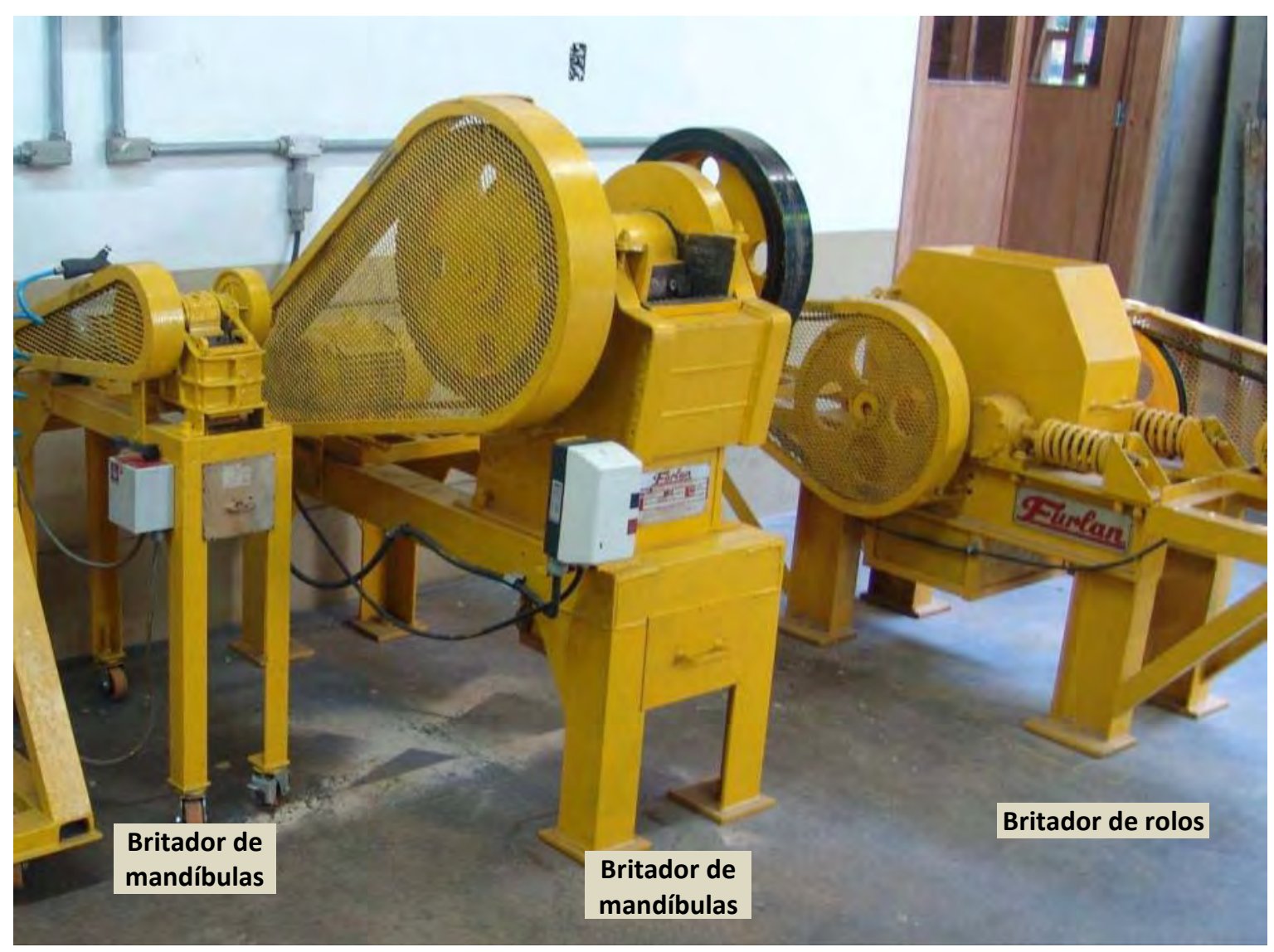

Figura 13 - Equipamentos utilizados para cominuição inicial da amostra 

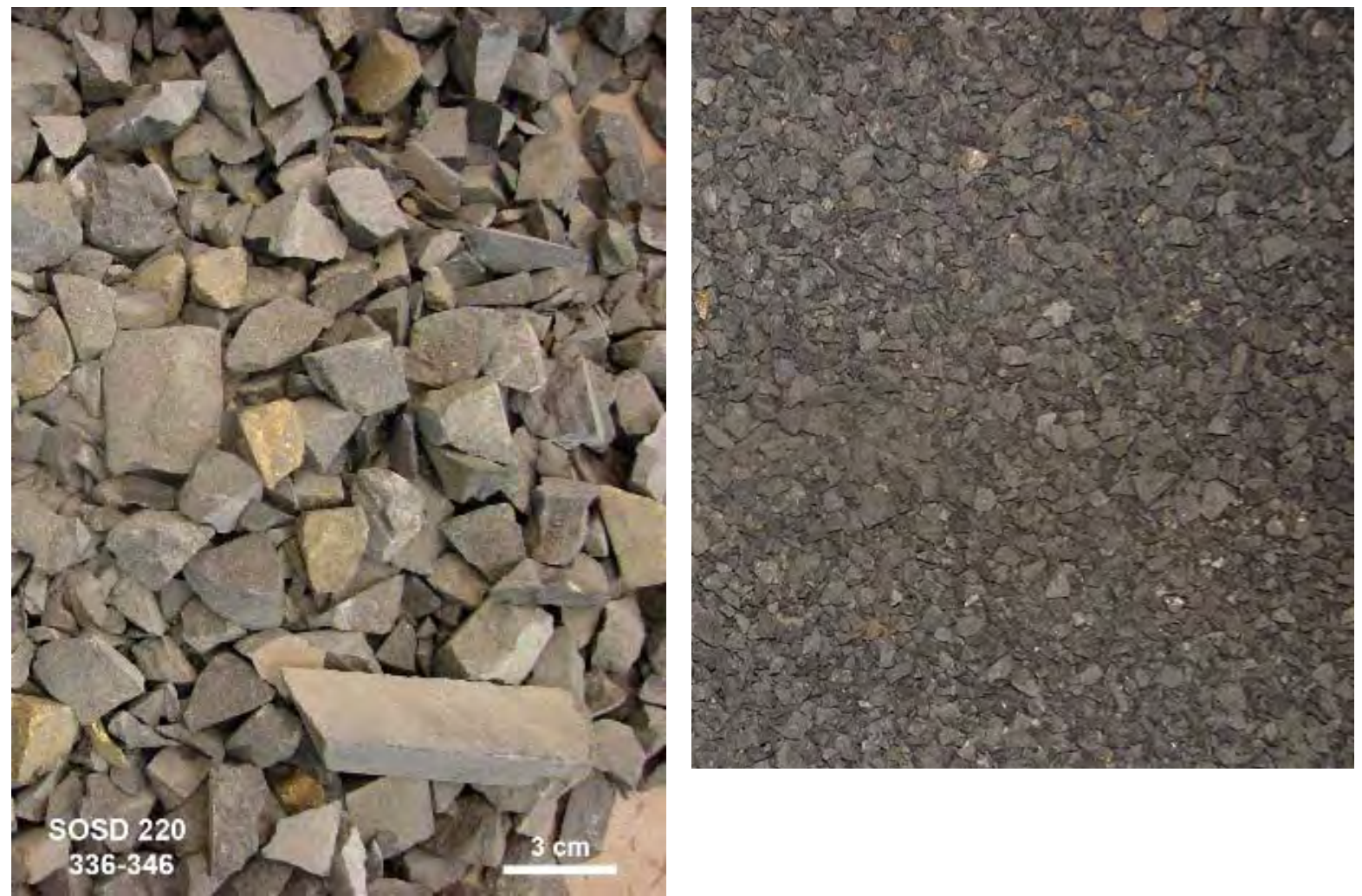

Figura 14 - Amostra antes e depois da primeira etapa de cominuição e homogeneização

\subsubsection{Difração de raios $X$ e análise por agrupamento}

A alíquota destinada à difração de raios $X$ sofreu diversos processos de cominuição e redução de massa até atingir aproximadamente $30 \mathrm{~g}$ e granulometria abaixo de $40 \mu \mathrm{m}$ (material pulverizado), condição necessária para a análise de difração de raios $X$.

A moagem no moinho de discos visou à homogeneização do material para a retirada de uma alíquota de $30 \mathrm{~g}$. Estas alíquotas foram pulverizadas em moinho planetário Pulverizette 5, marca Fritsch, de forma a se ter granulometria inferior a 40 $\mu \mathrm{m}$. Para tal, utilizaram-se panelas e bolas de aço (volume $100 \mathrm{ml}$, rotação com intensidade 7 e tempo de duração de 10 minutos).

O material pulverizado foi prensado manualmente em suportes específicos para material em pó (back loading) e então encaminhadas ao equipamento X'Pert Pro, marca PANalytical com tubo de Cu e detector sensível à posição (PSD X'Celerator), para a análise de difração de raios $X$. 


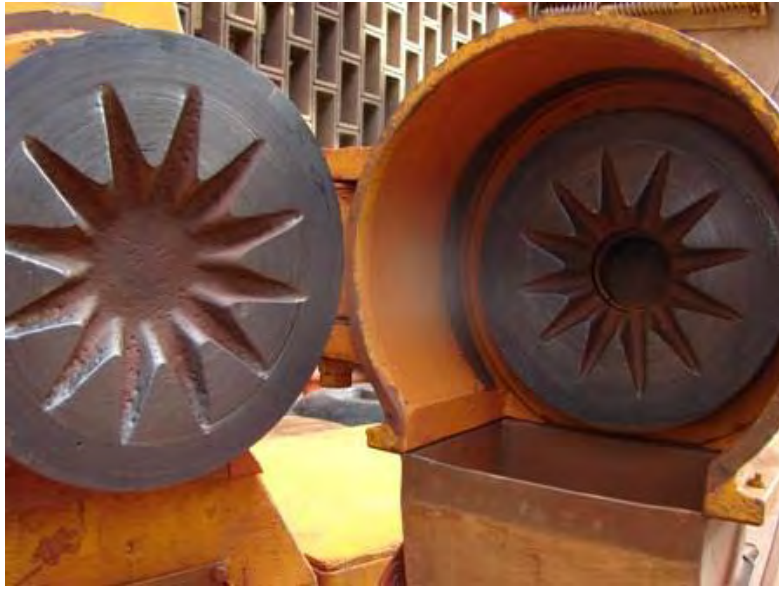

Moinho de discos

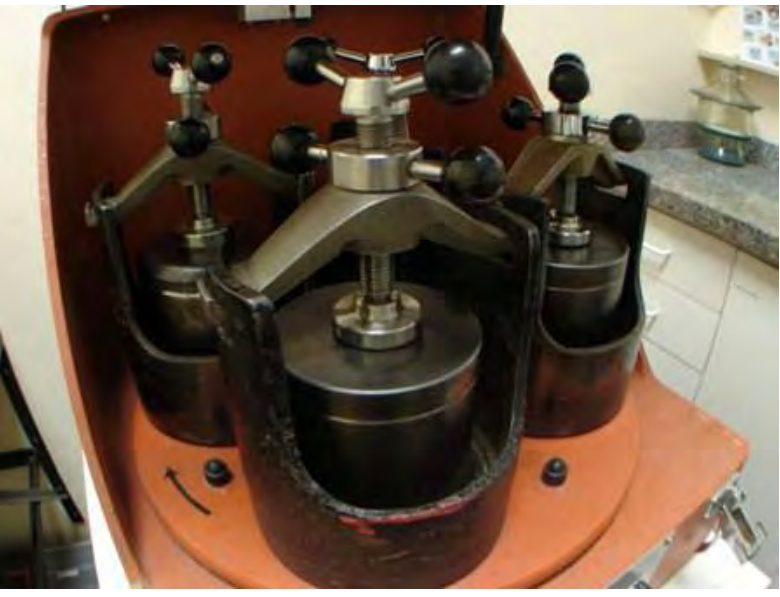

Moinho planetário Pulverizette 5, marca

Fritsch

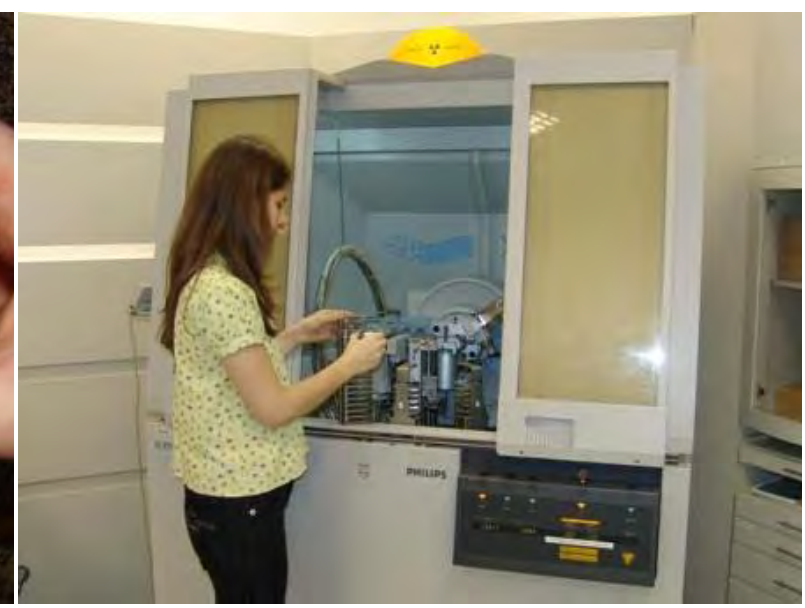

Difratômetro de raios X - X'Pert MPD, marca PANalytical
Suporte para prensagem manual de amostra para análise de DRX

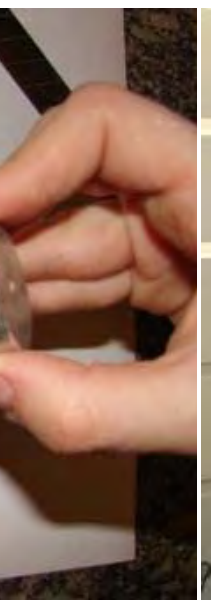

Figura 15 - Equipamentos utilizados na coleta por difração de raios $X$

As condições de coleta adotadas foram:

- Tubo de Cu, 45 kV e 40 mA, filtro de Ni no feixe difratado;

- Fenda incidente fixa de $1 / 2$ e máscara de $15 \mathrm{~mm}$;

- Rotação de 30 rpm (spinner);

- Faixa de ângulo de 3 a $70^{\circ}$, passo de $0,02^{\circ}$;

- Tempo de 10 s por passo, totalizando 5 minutos por difratograma. 
Os difratogramas obtidos foram agrupados em clusters pelo software X'Pert Highscore Plus, considerando posição e intensidade dos picos difratados (conteúdo dos minerais sem a necessidade da identificação das fases presentes).

Os principais parâmetros utilizados no agrupamento das amostras foram:

- Parâmetros de comparação:

- dados de origem considerados: picos + perfil

- tipo de comparação (FOM type): posição

- limiar de comparação (compare threshold): 40\%

- Parâmetros de agrupamento (clustering):

- medida de distância (distance measure): euclidiana

- método de ligação (linkage method): average linkage

- $\quad$ Cut-off para definição de clusters: 87

\subsubsection{Caracterização tecnológica}

Após definidos os grupos de minérios, deu-se início à etapa de caracterização tecnológica dos mesmos. As alíquotas destinadas a esta etapa foram compostas proporcionalmente, formando os quatro grupos de minério, denominados clusters $A$, $B, C$ e D.

A preparação destas quatro amostras iniciou-se com o quarteamento, visando a redução de massa e a retirada de material para arquivo. As alíquotas, com cerca de 700 a $900 \mathrm{~g}$ foram submetidas à moagem controlada em britador de rolos e moinho de bolas.

Após a cominuição, seguiu-se uma etapa de peneiramento a úmido, na qual se utilizou as peneiras 0,30 mm (48\# Tyler), 0,21 mm (65\# Tyler), 0,15 mm (100\# Tyler), 0,074 mm (200\# Tyler), 0,037 mm (400\# Tyler) e 0,020 mm (635\#). O produto abaixo de 0,020 $\mathrm{mm}$ foi reclassificado através de ciclosizer, sendo dividido em duas frações: -0,020+0,010 mm (ciclos 1 a 5 composto) e -0,010 mm (overflow). 
Todos os produtos obtidos, bem como a amostra cabeça, foram enviados para análise química para análise semiquantitativa por fluorescência de raios $\mathrm{X}$.

Foram confeccionadas seções polidas para todos os produtos obtidos, com exceção do material menor que $10 \mu \mathrm{m}$. As seções polidas foram cuidadosamente preparadas, de modo a garantir a representatividade da amostra. Inicialmente, os produtos da separação granulométrica foram quarteados em amostrador tipo Jones, visando a retirada de alíquotas com cerca de 5-10 g. Este material foi reamostrado em micro-amostrador rotativo (Microscal MSR). Para as frações acima de 0,020 mm as seções foram do tipo monocamada (o material granulado é fixado em fita dupla face de modo a formar apenas uma camada de grãos) com resina epóxi (Epofix Struers) específicas para a análise mineralógica quantitativa automatizada; para material abaixo de $0,020 \mathrm{~mm}$ optou-se por seções transversais.

Os estudos mineralógicos detalhados das formas de ocorrência e associações dos minerais de $\mathrm{Cu}$, incluindo grau de liberação por fração granulométrica e partição do elemento útil, foram efetuados de forma automatizada em seções polidas utilizando software Mineral Liberation Analyser (FEI) acoplado ao microscópio eletrônico de varredura Quanta 600 FEG (FEI) e espectrômetro por dispersão de energia (EDS) Quantax 4030 com software Esprit (Bruker). Os procedimentos adotados nesta análise são detalhados adiante.

Adicionalmente, para observação e documentação das texturas dos minerais de minério em foram confeccionadas seções polidas de material granulado acima de 0,30 mm. As seções polidas, com material embutido em resina epóxi, foram observadas em microscópio óptico de luz refletida Leica DMR. 


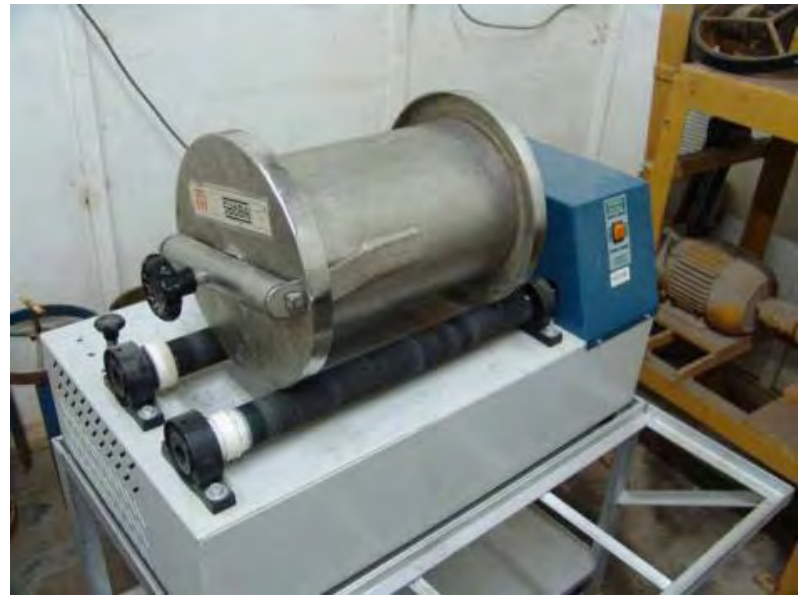

Moinho de bolas

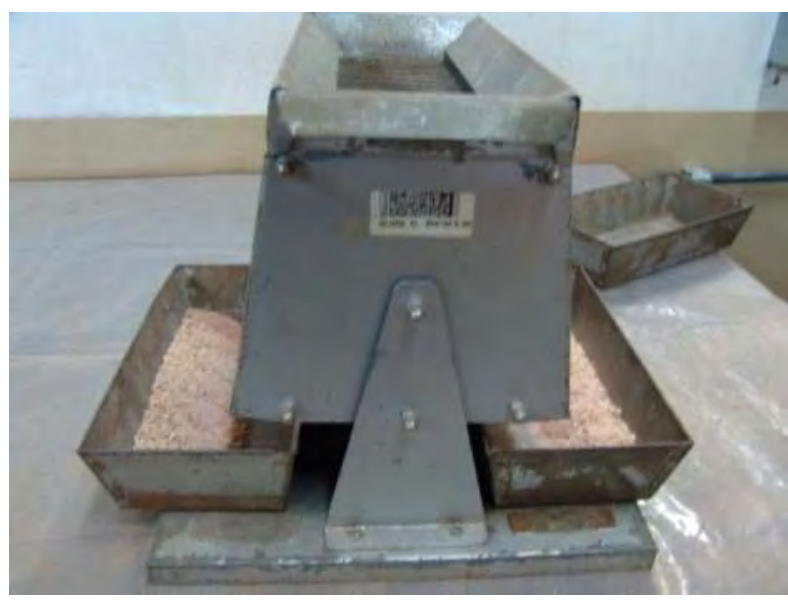

Amostrador tipo Jones

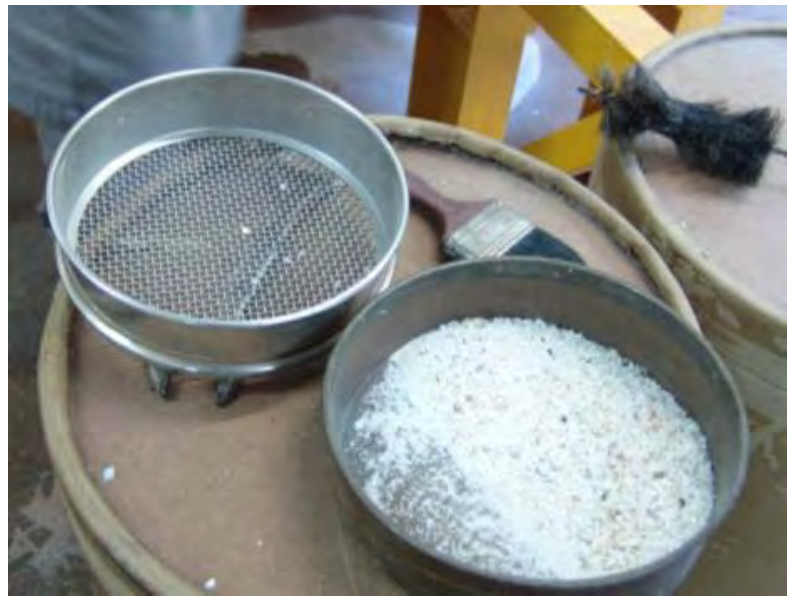

Peneiras

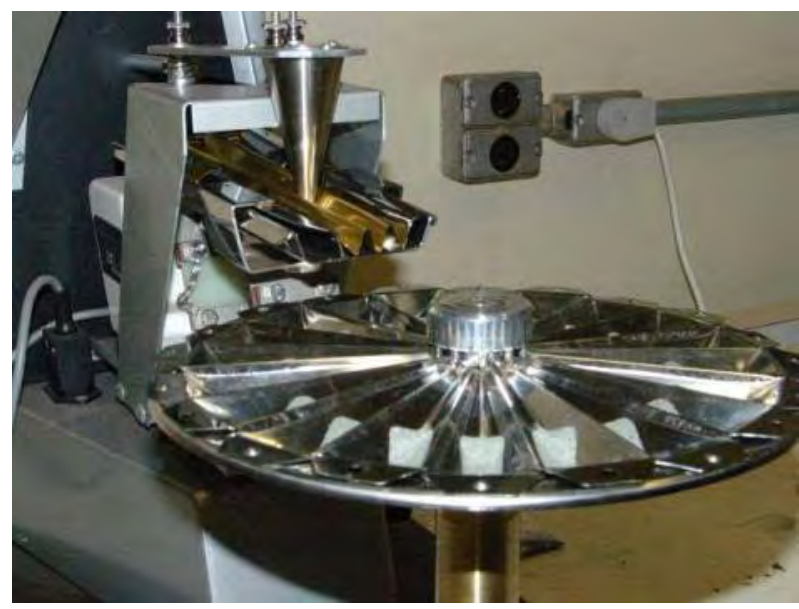

Amostrador rotativo - Microscal MSR

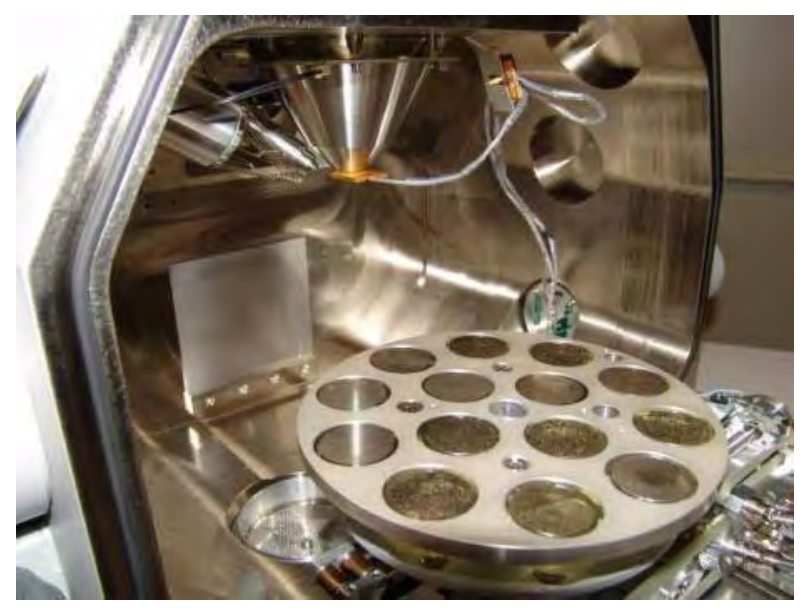

Microscópio eletrônico de varredura

Quanta 600 FEG, FEI

Figura 16 - Equipamentos utilizados na etapa de caracterização tecnológica 


\subsubsection{Procedimentos da análise de imagem}

Os procedimentos da análise mineralógica quantitativa automatizada são apresentados no fluxograma da Figura 17 e podem ser resumidos nas etapas:

- $\quad$ coleta das imagens de BSE e espectros de raios x (EDS);

- identificação das fases minerais e criação de um banco de dados preliminar;

- classificação das imagens a partir da comparação com o banco de dados preliminar;

- tratamento das imagens;

- $\quad$ identificação dos minerais e criação do banco de dados final;

- reclassificação das imagens;

- $\quad$ extração das informações;

- $\quad$ aferição dos resultados;

- tratamento dos dados. 


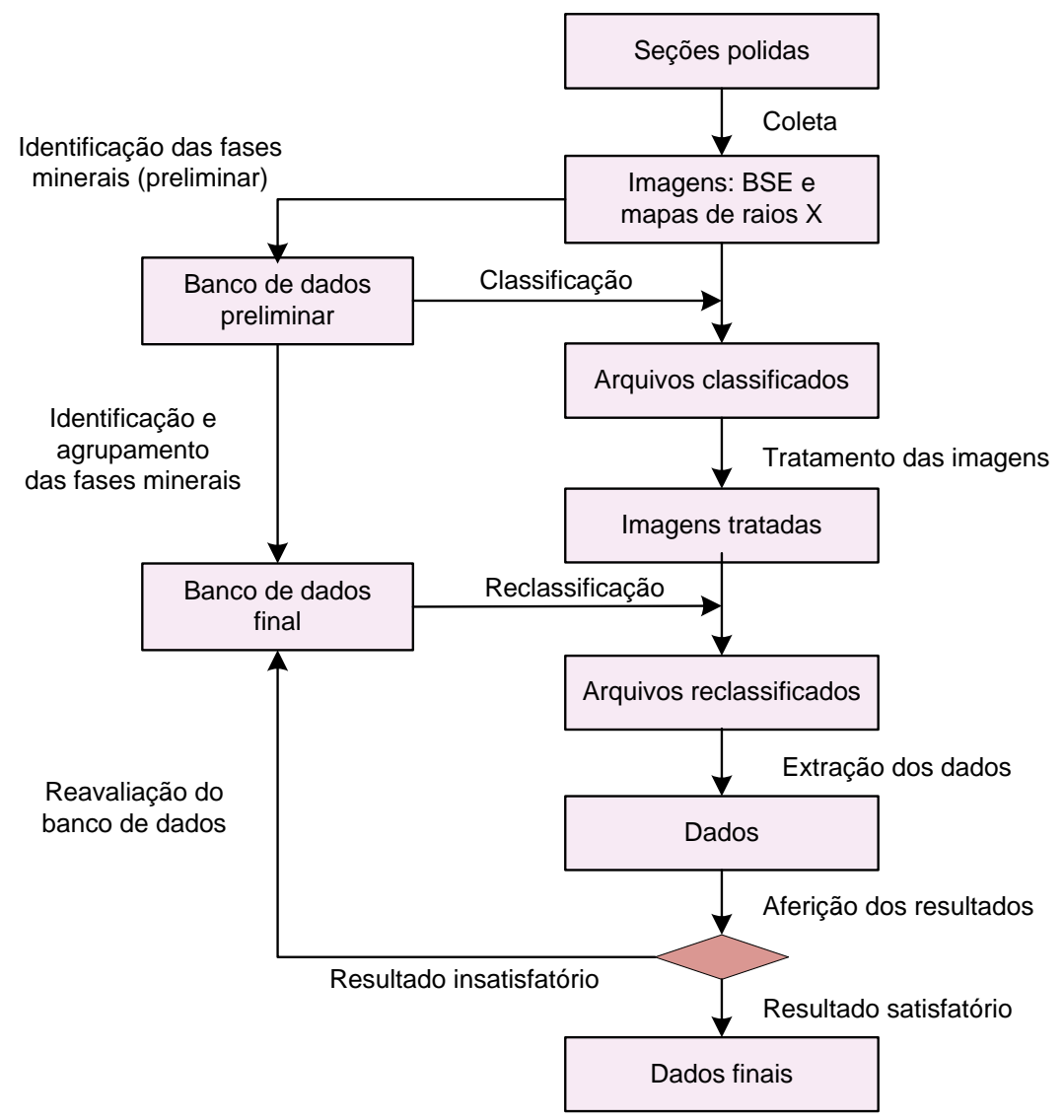

Figura 17 - Procedimentos da análise mineralógica quantitativa automatizada

$\mathrm{Na}$ etapa de coleta foram definidos os parâmetros para a aquisição das imagens, os quais: condições de brilho e contraste para uma boa descriminação dos tons de cinza, número de partículas a serem coletadas, resolução e magnificação das imagens, condições de coleta dos raios X por EDS (número de contagens por ponto, distribuição dos pontos), entre outros parâmetros.

A criação de um banco de dados foi realizada em dois momentos distintos; em primeira instância, foram identificadas todas as variações de espectro presentes nas amostras, sem que fossem atribuídos nomes definitivos aos minerais. Posteriormente, as fases foram devidamente identificadas e agrupadas com base em informações obtidas a partir de análises por difração de raios $X$ e por análises quantitativas pontuais em microscópio eletrônico de varredura/EDS.

Análises mineralógicas por difração de raios $X$ de produtos de separações minerais foram realizadas para facilitar a identificação dos minerais presentes. Em todas as amostras tomou-se uma alíquota da fração -0,074+0,037 mm para separação em líquido denso na sensidade de $2,96 \mathrm{~g} / \mathrm{cm}^{3}$ (tetra-bromo-etano) 
seguido de separação magnética do material afundado em equipamento Frantz de barreiras em intensidades de corrente de 0,0 e 0,3 A. Para identificação das fases cristalinas utilizou-se o banco de dados PAN-ICSD - PANalytical Inorganic Crystal Structure Database (2007).

A composição elementar de alguns dos minerais presentes foi efetuada por microscopia eletrônica de varredura (modelo Stereoscan 440, marca Leo), com emprego de detector de dispersão de energia (EDS) INCA, marca Oxford, com detector SDD (silicon drift detector) Inca X-act.

Minerais traços como sulfetos secundários foram identificados a partir dos espectros de EDS das partículas mapeadas.

O tratamento de imagens englobou diversas atividades, sendo a principal a deaglomeração de partículas. Neste procedimento, partículas contendo o mineral de interesse em contato com outras partículas foram ser separadas automaticamente e manualmente porque influenciariam no resultado de liberação. Neste projeto, a deaglomeração foi realizada unicamente para as partículas portadoras de sulfetos.

Ainda no tratamento de imagens existe um passo de exclusão de partículas não identificadas ou desconhecidas e de partículas com tamanho incompatível com o intervalo granulométrico da seção. Em ambos casos, a exclusão não deve influenciar no resultado, ou seja, o número de partículas excluídas deve ser muito baixo. Neste projeto as partículas não identificadas representavam menos de $0,2 \%$ do total.

Depois de terminados os tratamentos das imagens, seguiram-se as etapas de extração e análise dos dados. Para aferição dos resultados compara-se a análise química obtida do MLA com a análise química tradicional. Caso haja divergências significativas, retoma-se ao banco de dados (segunda instância) para verificar as composições químicas dos minerais utilizadas e respectivas densidades.

\subsubsection{Atividade de campo}

Foi realizada uma visita técnica à mina do Sossego no dia 06 de maio de 2010, na qual se teve a oportunidade de conhecer as cavas de Sequeirinho e Sossego (Figura 18 e Figura 19) e as instalações da usina de beneficiamento. 
As informações geológicas contribuíram para um melhor entendimento das características dos minérios, distribuição espacial e relações de contato. A visita às instalações da usina de beneficiamento foi uma oportunidade importante para o aprendizado.

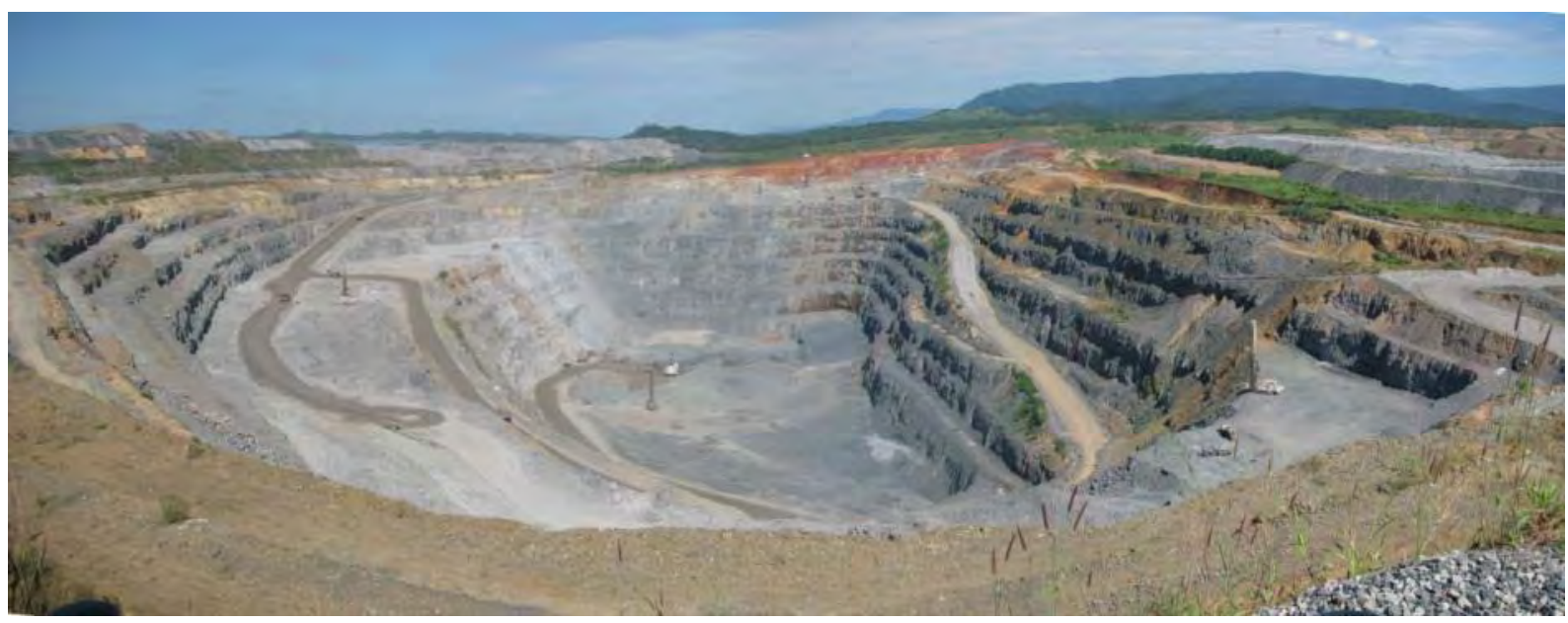

Figura 18 - Foto panorâmica da cava de Sequeirinho (foto maio 2010)

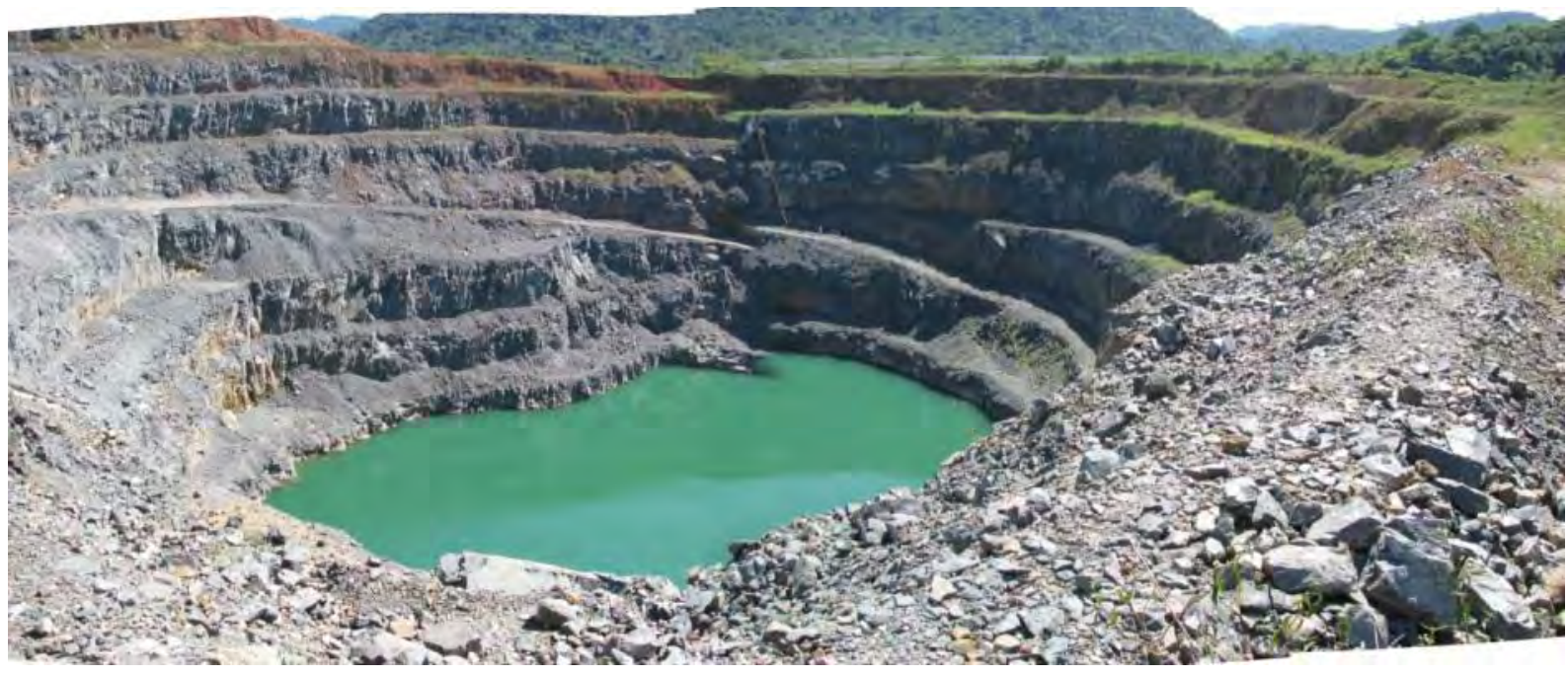

Figura 19 - Foto panorâmica da cava de Sossego (foto maio 2010) 


\section{RESULTADOS E DISCUSSÃO}

\subsection{Análise por agrupamento}

A análise por agrupamento por difração de raios $X$ considerou dois resultados distintos no que se refere ao critério de seleção adotado (cut-off), expresso no dendograma da Figura 20. Uma alternativa considera 4 classes e a outra, mais detalhada, 7 grupos. Para ambos os processamentos adotou-se a medida de distância Euclidiana e o método de linkagem por média, que considerou nos agrupamentos a posição dos picos (ver materiais e métodos).

O dendograma da Figura 20 é a principal maneira de visualizar os agrupamentos realizados. Nele as distâncias entre as amostras refletem as semelhanças entre as mesmas e os ramos os passos do agrupamento. Os traços pontilhados verticais indicam os cortes adotados nos dois processamentos, que

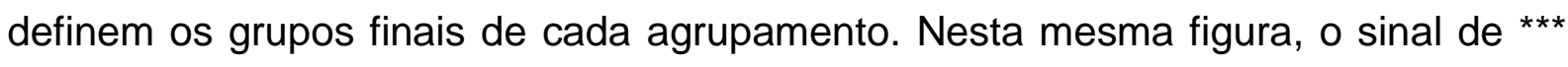
depois da identificação da amostra aponta para a amostra mais representativa de cada grupo (identificada automaticamente pelo software), e o sinal de + para a mais distinta.

A partir do dendograma pode-se compreender as diferenças entre os dois critérios adotados. No agrupamento com quatro classes de minério, as amostras dos grupos 1 e 2 são reunidas no cluster A, as dos grupos 3 e 4 no cluster B e as dos grupos 6 e 7 no cluster D.

Outra maneira de verificar a qualidade do agrupamento é através da análise por principal componente (PCA - principal component analysis). A técnica independe da análise por agrupamento, sendo utilizada como complemento para análise do conjunto de dados.

Para o conjunto de amostras, os três primeiros componentes principais descrevem cerca de $85 \%$ das informações. O posicionamento das amostras em função destas variáveis, sob diferentes pontos de visada, é apresentado na Figura 21. Nota-se que os grupos ocupam regiões distintas do cubo (em perspectiva 3D), indicando que o agrupamento foi satisfatório. 

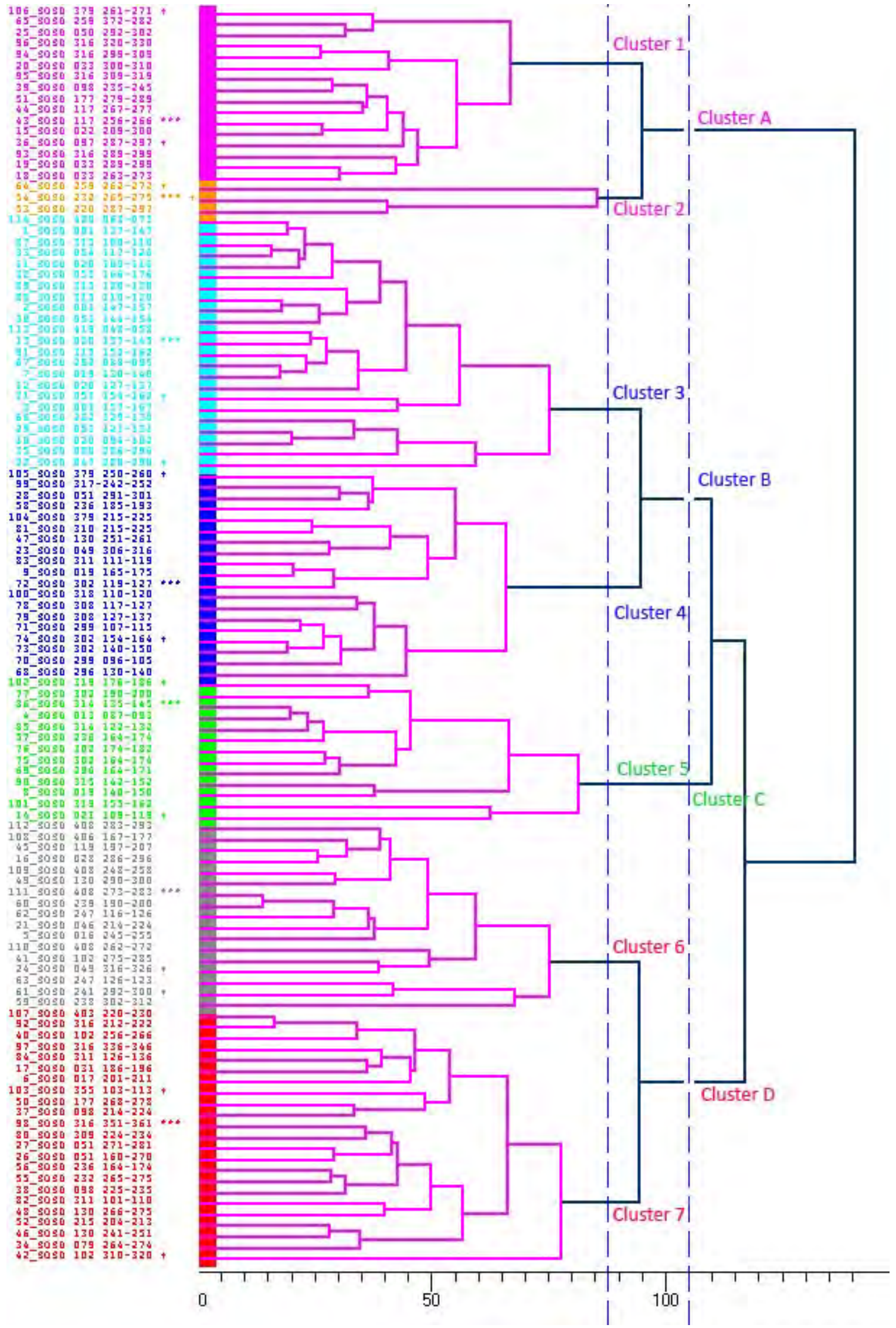

Figura 20 - Dendograma indicando o agrupamento das amostras. 

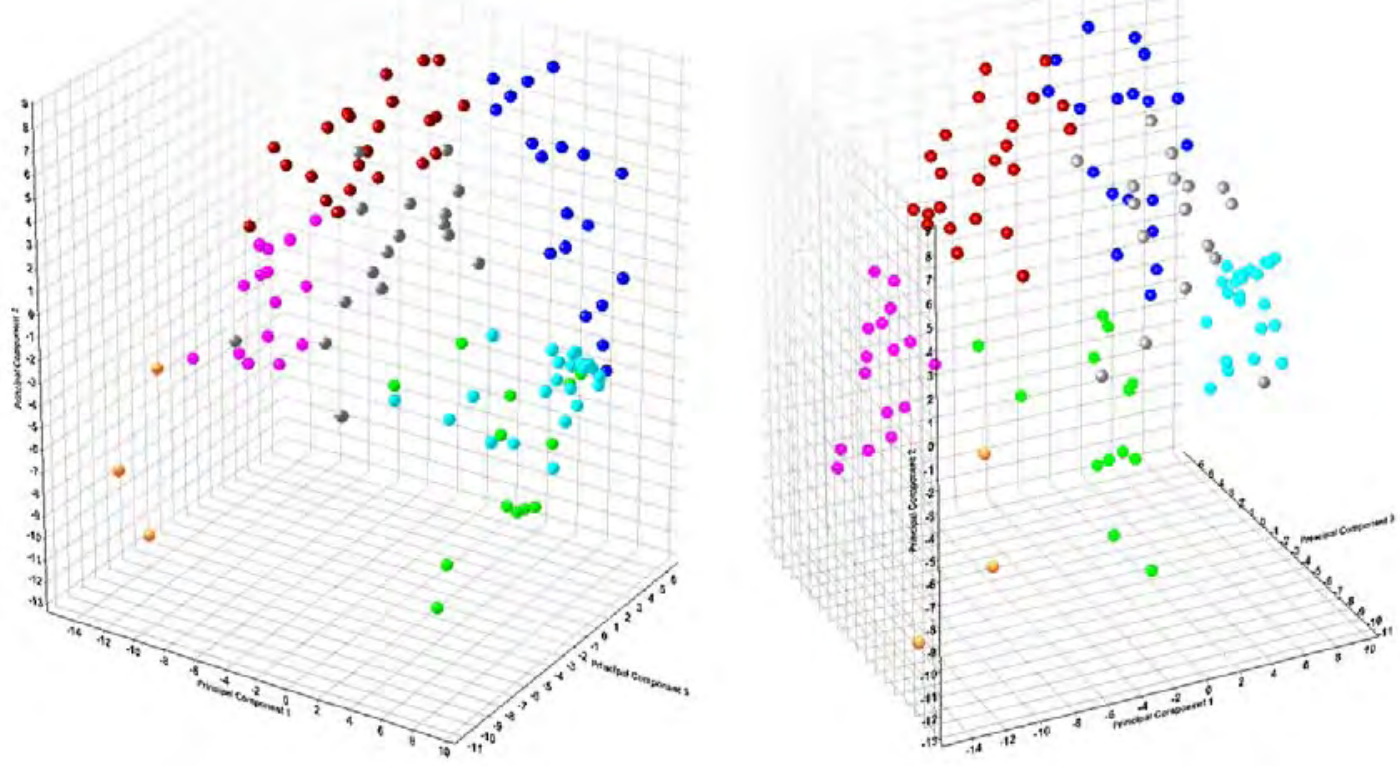

Nota: Análise por principal componente do agrupamento relativo a sete amostras

Legenda: rosa (cluster 1), laranja (cluster 2), azul claro (cluster 3), azul escuro (cluster 4), verde (cluster 5), cinza (cluster 6) e vermelho (cluster 7).
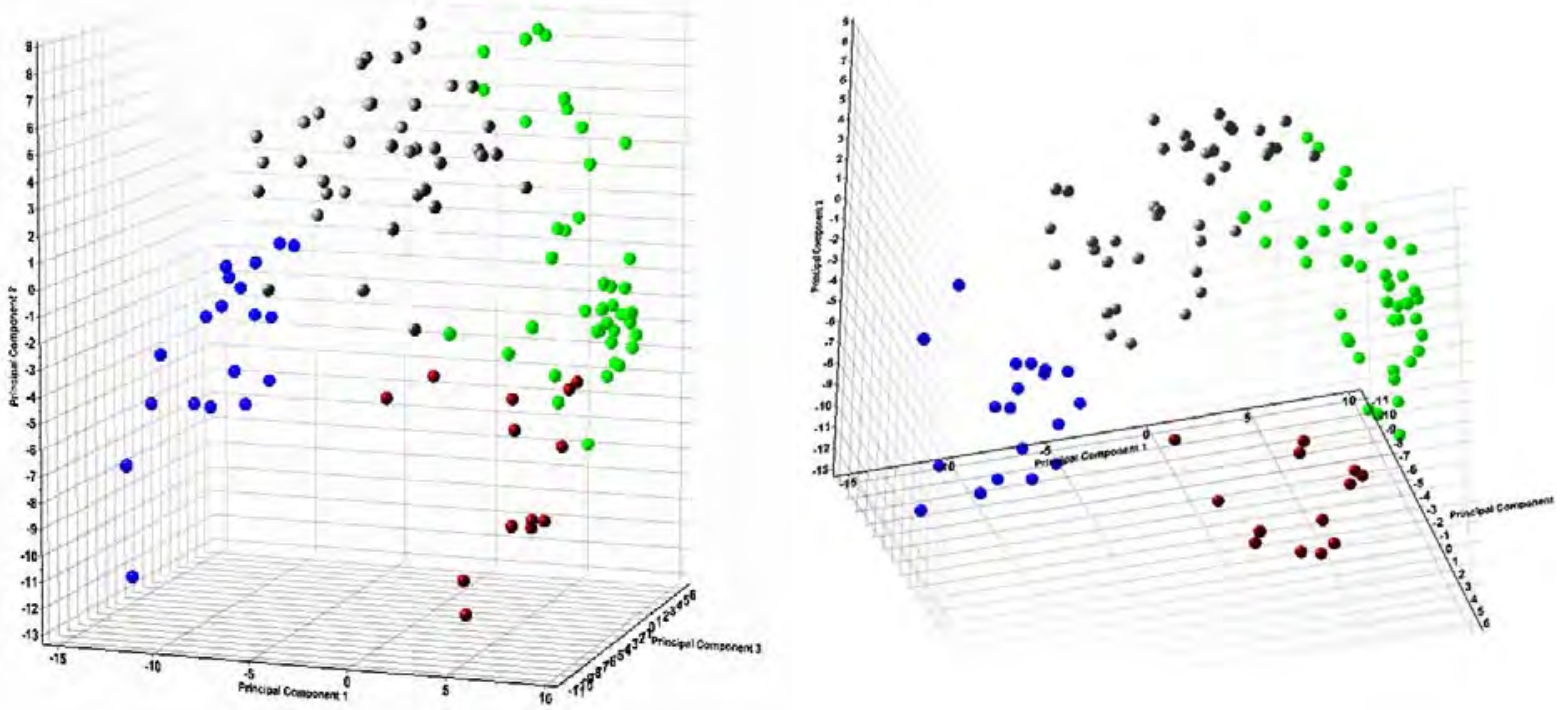

Nota:Análise por principal componente do agrupamento relativo a sete amostras

Legenda: azul (cluster A), verde (cluster B), vermelho (cluster C) e cinza (cluster D).

Figura 21 - Distribuição espacial dos agrupamentos de amostras segundo análise de componente principal (PCA), sob diferentes pontos de visada - 7 e 4 grupos. 
A distribuição das amostras de cada grupo nos corpos Sequeirinho e Sossego é apresentada na Tabela 1. Nota-se boa correlação do agrupamento com a origem das amostras: os clusters 1, 2, 6 e 7 (A e D) são compostos majoritariamente por amostras do corpo Sequeirinho enquanto que os clusters 3 e 5 (B e C) de amostras do corpo Sossego. O cluster 4 reúne amostras de ambos corpos. Algumas amostras não possuem informações sobre procedência.

\section{Tabela 1 - Distribuição espacial do agrupamento nos corpos Sequeirinho e Sossego}

\begin{tabular}{ccccc}
\hline & Número de amostras & & \\
& Sequeirinho & Sossego & Sem identificação & Total \\
\hline Cluster 1 & 15 & 0 & 1 & 16 \\
Cluster 2 & 3 & 0 & 0 & 3 \\
Cluster 3 & 2 & 19 & 2 & 23 \\
Cluster 4 & 6 & 11 & 1 & 18 \\
Cluster 5 & 0 & 11 & 2 & 13 \\
Cluster 6 & 8 & 0 & 7 & 15 \\
Cluster 7 & 18 & 2 & 2 & 22 \\
\hline
\end{tabular}

Outra maneira de se analisar a qualidade do agrupamento é verificar as semelhanças entre os difratogramas de cada grupo. Na Figura 22 é apresentado um comparativo entre todos os difratogramas de raios $X$ das amostras estudadas, classificados quanto ao grupo ao qual pertencem e com a identificação das principais fases minerais.

O padrão difratométrico de cada cluster pode ser visualizado também na Figura 23, a partir dos difratogramas das amostras mais representativas de cada grupo, identificadas automaticamente pelo software. As interpretações dos DRXs destas amostras encontram-se no anexo 2.

Devido à dificuldade para estimar a proporção de fases minerais com estruturas cristalinas semelhantes em amostras complexas a partir da difração de raios $X$, alguns minerais como albita e feldspato potássico são apresentados como única fase (Alb-Kfs), bem como magnetita e hematita (Mag-Hem) e biotita e muscovita (Bt-Ms). 

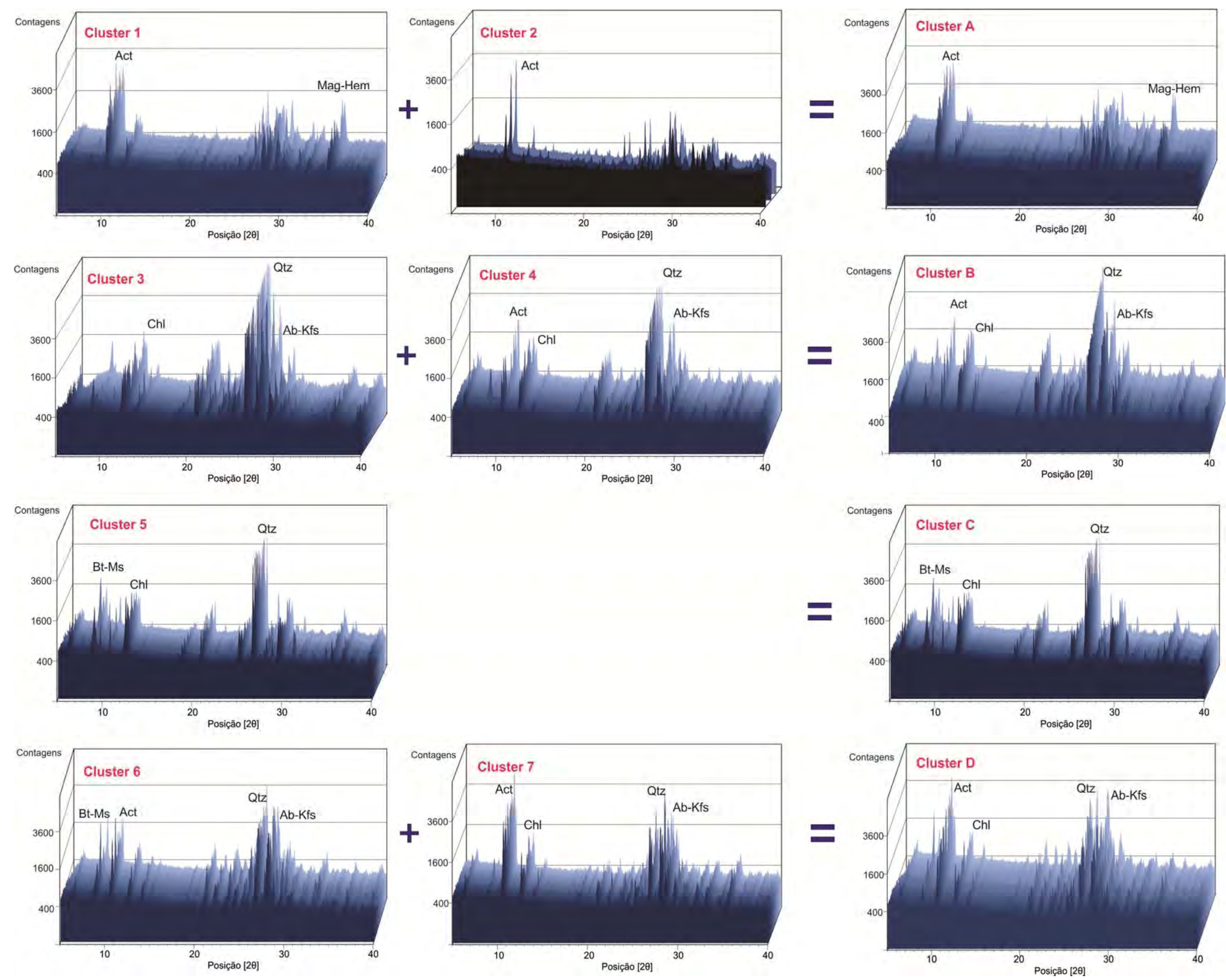

Legenda: $\mathrm{Qtz}=$ quartzo, Ab-Kfs = albita-feldspato potássico, Act = actinolita, Mag-Hem = magnetita-hematita, $\mathrm{Chl}=$ clorita, Bt-Ms = biotita- muscovita.

Figura 22 - Comparativo entre os difratogramas 


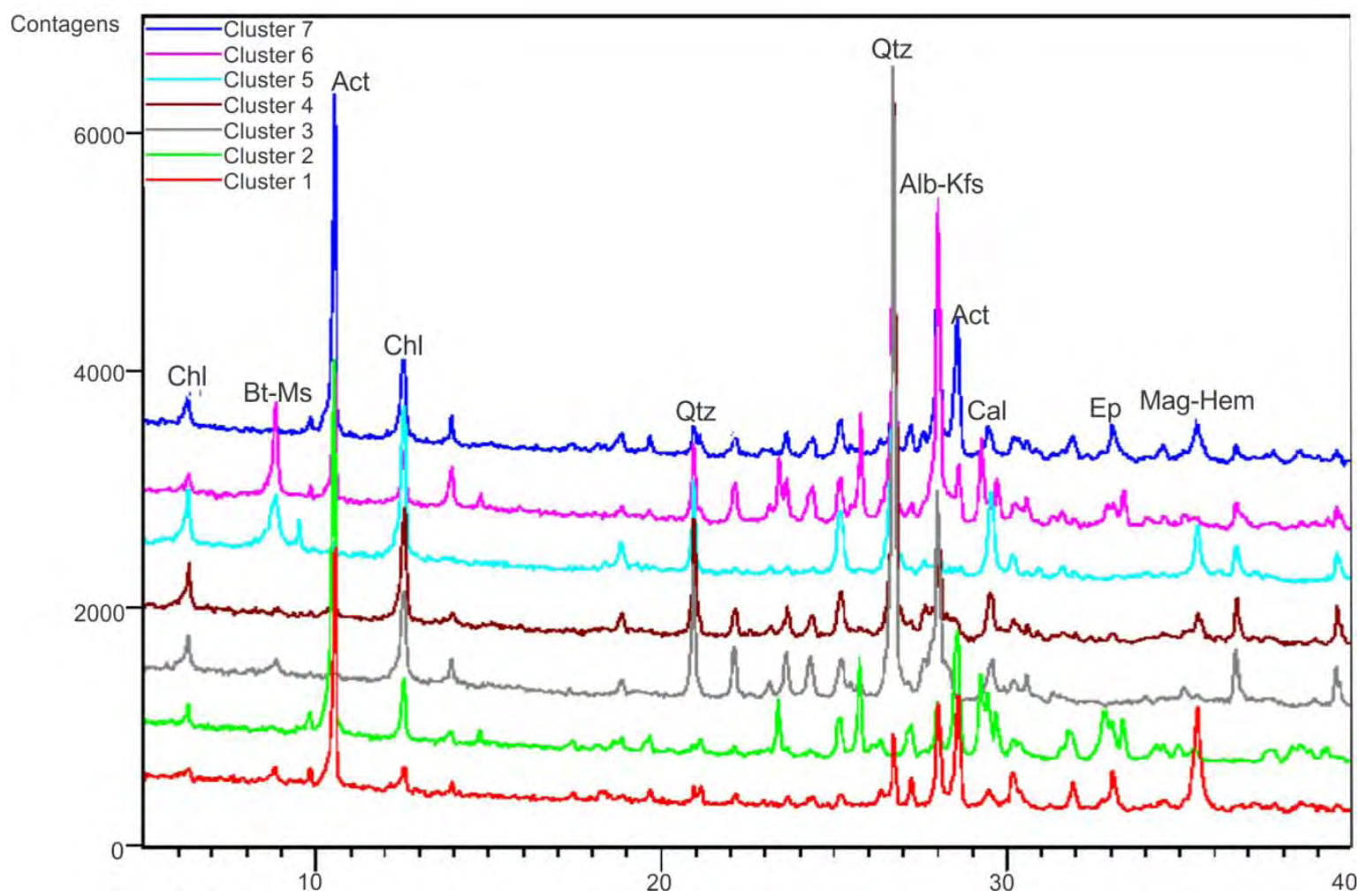

Legenda: Qtz = quartzo, Ab-Kfs = albita-feldspato potássico, Act = actinolita, Mag-Hem = magnetita-hematita, Chl =clorita, BtMs = biotita - muscovita, $\mathrm{Cal}=$ calcita, $\mathrm{Ep}=$ epídoto.

Figura 23 - Comparação entre difratogramas mais representativos de cada grupo

Analisando os padrões difratométricos dos grupos, verifica-se que as amostras dos clusters 1 e 2 (A) possuem em comum elevada proporção de actinolita e menor conteúdo de quartzo e feldspato, sendo que as do grupo 1 possuem pico de magnetita-hematita, ausente no grupo 2.

As amostras dos grupos 3, 4 (B) e 5 (C) são mais ricas em quartzo. O cluster 5 (C) se diferencia por apresentar menor proporção de feldspato em relação às demais. Os clusters 3 e 4 (B) distinguem-se em relação à proporção de quartzo e actinolita.

As amostras dos clusters 6 e 7 (D) contém actinolita, quartzo e feldspato, sendo o grupo 6 distinto do grupo 7 em relação às proporções de mica e clorita.

Variações nas proporções minerais entre amostras de mesmo grupo (diferenças nas intensidades dos picos) são compatíveis com a gênese do depósito, de evolução hidrotermal. 
A distribuição dos teores de $\mathrm{Cu}$ das amostras de cada grupo é apresentada na Figura 24. Verifica-se uma tendência de algumas amostras dos grupos A e C possuírem teores de Cu mais elevados que as demais.
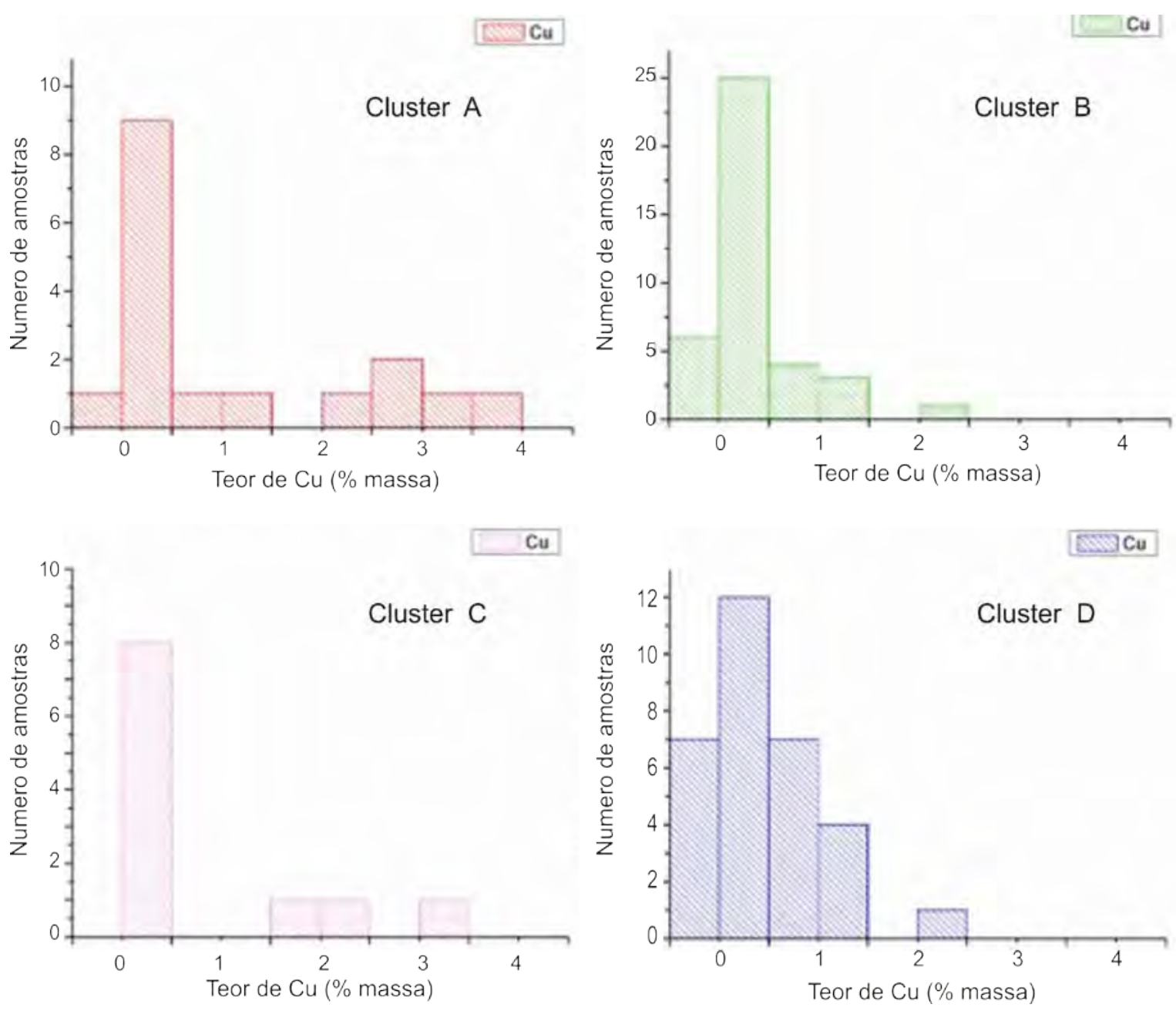

Figura 24 - Teores de Cu nos grupos definidos (\% massa)

Quanto à distribuição dos litotipos nos grupos, apresentada na Tabela 2, não é possível estabelecer uma correlação imediata. Pode-se dizer de maneira grosseira que o grupo A, pertencente ao corpo Sequeirinho, é composto por rochas máficas GBA (gabro), ACT (actinolititos) e MAG (magnetititos), além do tipo BSE (brecha tipo Sequeirinho). Já o grupo $\mathrm{D}$, referente ao mesmo corpo de minério, é composto tanto por rochas máficas como por rochas granitóides, como GRF (granófiro), GRA (granito) e MVA (metavulcânica félsica). 
Os grupos B e C, referentes às amostras do corpo Sossego, são compostos por rochas predominantemente félsicas (GRF, GRA e MVA) além do tipo BHT (brecha heterolítica), descrita somente para o corpo Sossego.

Tabela 2 - Distribuição dos tipos litológicos nos grupos

\begin{tabular}{|c|c|c|c|c|c|c|c|c|c|}
\hline \multicolumn{10}{|c|}{ Litotipos } \\
\hline & GBA & ACT & MAG & BSE & GRF & GRA & MVA & BHT & TOTAL \\
\hline & gabro & actinolitito & magnetitito & $\begin{array}{c}\text { brecha } \\
\text { Sequeirinho }\end{array}$ & $\begin{array}{c}\text { granito } \\
\text { granofírico }\end{array}$ & granito & $\begin{array}{l}\text { metavulcânica } \\
\text { félsica }\end{array}$ & $\begin{array}{c}\text { brecha } \\
\text { heterolítica }\end{array}$ & \\
\hline Cluster A & 2 & 6 & 7 & 2 & 0 & 0 & 0 & 0 & 17 \\
\hline Cluster B & 1 & 3 & 0 & 0 & 17 & 3 & 1 & 14 & 39 \\
\hline Cluster C & 0 & 0 & 0 & 0 & 7 & 0 & 0 & 4 & 11 \\
\hline Cluster D & 4 & 13 & 0 & 1 & 2 & 4 & 7 & 0 & 31 \\
\hline
\end{tabular}

\subsubsection{Relação agrupamento com a geologia da Mina do Sossego}

Existem algumas dificuldades para estabelecer relações diretas entre o agrupamento e a geologia da Mina do Sossego, parte delas deve-se à indiferenciação das proporções de albita/feldspato potássico, magnetita/hematita e biotita/muscovita, outra parte deve-se a própria complexidade mineralógica, estruturação do depósito (superposição dos estágios de alteração hidrotermal) e dificuldades da equipe de geologia de campo na classificação dos litotipos a partir de testemunhos de sondagens.

A partir da análise dos resultados, apresentada a seguir, pode-se dizer que o agrupamento refletiu os diferentes ambientes geológicos de formação, agrupando as amostras de acordo com a(s) alteração(ões) hidrotermal(is) predominante(s).

As relações a seguir se baseiam nas interpretações sobre a distribuição regional dos estágios de alteração hidrotermal apontadas por Monteiro et.al. (2008 vide item 2.1.3 e Figura 3), informações de localização e principais fases minerais constituintes dos grupos (padrão difratométrico dos clusters): 
- As amostras do cluster 1 e 2 (A) são provenientes do corpo Sequeirinho. As principais fases minerais, actinolita e magnetita ${ }^{1}$, são características de regiões onde a alteração sódica-cálcica foi mais intensa e houve a formação de corpos de actinolititos e magnetititos.

- Os clusters 6 e 7 (D) também são compostos majoritariamente por amostras do corpo Sequeirinho, entretanto as principais fases minerais são actinolita e feldspato (no caso albita), também características dos estágios de alteração sódica-cálcica e sódica. Possivelmente a proporção de clorita no cluster 7 deve-se à maior influência de alteração clorítica e a de mica no cluster 6 pode representar influência tanto alteração potássica (biotita) quanto hidrolítica (muscovita).

- Os clusters 3 e 5 (parte do B e C) englobam amostras do corpo Sossego. No cluster 5 , a associação de quarto, mica, óxido de ferro (possivelmente hematita), clorita e calcita caracteriza a assembléia de alteração hidrolítica. O cluster 3 , composto por elevada proporção de quartzo, clorita e feldspatos, pode representar amostras sob maior influência da alteração clorítica.

- Provavelmente as amostras do cluster 4 (parte do B) representam litotipos formados em ambiente transicional, sob influência de diversas alterações hidrotermais e por isso reúne amostras de ambos corpos.

\footnotetext{
${ }^{1}$ Amostra com elevada proporção de magnetita, observável em imã de mão.
} 


\subsection{Caracterização tecnológica}

As informações obtidas não apontam para diferenças substanciais entre os dois resultados de agrupamentos (quatro e sete clusters). Por este motivo e considerando o escopo deste projeto, os estudos de caracterização tecnológica apresentados a seguir foram conduzidos com base no resultado relativo a quatro grupos de amostras. Os resultados serão apresentados na seguinte ordem: "cluster A", "cluster D" (referentes ao corpo Sequeirinho) e "cluster B" e "cluster C" (corpo Sossego).

\subsubsection{Composição química das amostras estudadas}

Foram efetuadas análises químicas semi-quantitativas por fluorescência de raios $\mathrm{X}$ para todas as amostras cabeças (tais quais). Os resultados obtidos são apresentados na Tabela 3.

Tabela 3 - Análises químicas das amostras cabeças (\% em massa)

\begin{tabular}{|c|cccc|}
\hline & \multicolumn{4}{|c|}{ Teor (\% em massa) } \\
\hline Elemento/ & \multicolumn{2}{|c|}{ Sequeirinho } & \multicolumn{2}{c|}{ Sossego } \\
Composto & Cluster A & Cluster D & Cluster B & Cluster C \\
\hline $\mathrm{Cu}$ & 2,09 & 0,92 & 0,66 & 1,23 \\
$\mathrm{~S}$ & 2,26 & 1,01 & 0,69 & 1,30 \\
$\mathrm{SiO}_{2}$ & 38,7 & 55,7 & 62,8 & 49,3 \\
$\mathrm{Fe}_{2} \mathrm{O}_{3}$ & 27,5 & 12,2 & 9,94 & 18,5 \\
$\mathrm{Al}_{2} \mathrm{O}_{3}$ & 5,69 & 9,92 & 9,12 & 6,26 \\
$\mathrm{CaO}$ & 8,49 & 6,00 & 4,55 & 6,73 \\
$\mathrm{MgO}$ & 5,71 & 4,07 & 2,52 & 4,60 \\
$\mathrm{Na}_{2} \mathrm{O}$ & 1,58 & 3,69 & 2,87 & 0,82 \\
$\mathrm{~K}_{2} \mathrm{O}$ & 0,44 & 1,03 & 1,60 & 1,34 \\
$\mathrm{TiO}_{2}$ & 0,42 & 0,51 & 0,45 & 0,40 \\
$\mathrm{P}_{2} \mathrm{O}_{5}$ & 3,85 & 1,42 & 0,96 & 1,37 \\
$\mathrm{PF}$ & 1,63 & 2,49 & 3,38 & 7,34 \\
$\mathrm{Total}$ & $\mathbf{9 8 , 4}$ & $\mathbf{9 9 , 0}$ & $\mathbf{9 9 , 5}$ & $\mathbf{9 9 , 2}$ \\
\hline
\end{tabular}


Observa-se a partir dos dados apresentados, que o teor de Cu nas amostras varia de 0,66 e 2,09\%, sendo o cluster A aquele com mais alto teor, seguido do cluster C, com 1,23\% e do cluster D (0,92\%). O teor de S encontra-se entre 0,69 e 2,26\% com ocorrência proporcional à do $\mathrm{Cu}$.

Em todos os clusters a sílica é predominante. Entretanto, a proporção de $\mathrm{SiO}_{2}$ varia amplamente entre as amostras: o cluster A é o mais pobre com $38,7 \%$ de $\mathrm{SiO}_{2,}$, seguido do cluster C $(49,3 \%)$, do D $(55,7 \%)$ e por fim do $\mathrm{B}$, com $62,8 \%$.

O $\mathrm{Fe}_{2} \mathrm{O}_{3}$ é o segundo composto mais abundante, com teores entre 9,94\% (cluster B) e 27,5\% (cluster A). A ocorrência segue padrão oposto ao da sílica: as amostras mais ricas em $\mathrm{SiO}_{2}$ possuem teores mais baixos de $\mathrm{Fe}_{2} \mathrm{O}_{3}$.

$\mathrm{O}$ teor de $\mathrm{Al}_{2} \mathrm{O}_{3}$ nas amostras situa-se entre 5,69 e 9,92\%; os cluster com teores de $\mathrm{Al}_{2} \mathrm{O}_{3}$ próximos a 9-10\% são aqueles com teor de $\mathrm{SiO}_{2}$ mais elevado ( $\mathrm{B}$ e D). O teor de CaO está compreendido entre 4,55 e 8,49\%.

$\mathrm{O} \mathrm{MgO}$ apresenta-se de modo semelhante ao do $\mathrm{Fe}_{2} \mathrm{O}_{3}$ : as amostras mais ricas em $\mathrm{MgO}$ são aquelas com mais $\mathrm{Fe}_{2} \mathrm{O}_{3}$. Os valores de $\mathrm{MgO}$ situam-se entre 2,52 e $5,71 \%$.

Quanto ao teor de $\mathrm{P}_{2} \mathrm{O}_{5}$, verifica-se que a amostra $A$ possui teor bem mais elevado, com $3,85 \%$ do total; nos outros clusters permanece entre $0,96 \%$ (B) e $1,42 \%$ (D).

Em resumo, tem-se que o cluster A é o que possui os menores teores de $\mathrm{SiO}_{2}$ $(38,7 \%)$ e $\mathrm{Al}_{2} \mathrm{O}_{3}(5,69 \%)$ e os maiores teores de $\mathrm{Fe}_{2} \mathrm{O}_{3}(27,5 \%), \mathrm{MgO}(5,71 \%)$ e $\mathrm{CaO}$ (8,49\%), além de $\mathrm{P}_{2} \mathrm{O}_{5}$ elevado. O cluster B é o oposto, apresentando os maiores teores de $\mathrm{SiO}_{2}(62,8 \%)$ e $\mathrm{Al}_{2} \mathrm{O}_{3}(9,94 \%)$ e os menores teores de $\mathrm{Fe}_{2} \mathrm{O}_{3}(9,94 \%)$, MgO (2,52\%) e CaO (4,55\%), além de $\mathrm{Na}_{2} \mathrm{O}$ e $\mathrm{K}_{2} \mathrm{O}(1,57 \%)$ elevado. Os clusters $\mathrm{C}$ e D possuem composição intermediária entre as amostras A e B, sendo o cluster C mais próximo do A e o cluster D, mais próximo do B. 


\subsubsection{Distribuição granulométrica das amostras estudadas}

A moagem realizada em laboratório em moinho de bolas visou à geração de produtos com distribuição granulométrica semelhante à da alimentação da flotação rougher da usina de beneficiamento.

Os resultados das moagens, bem como as distribuições granulométricas das alimentações da flotação rougher e cleaner são apresentados a seguir, na Figura 25 e Tabela 4.

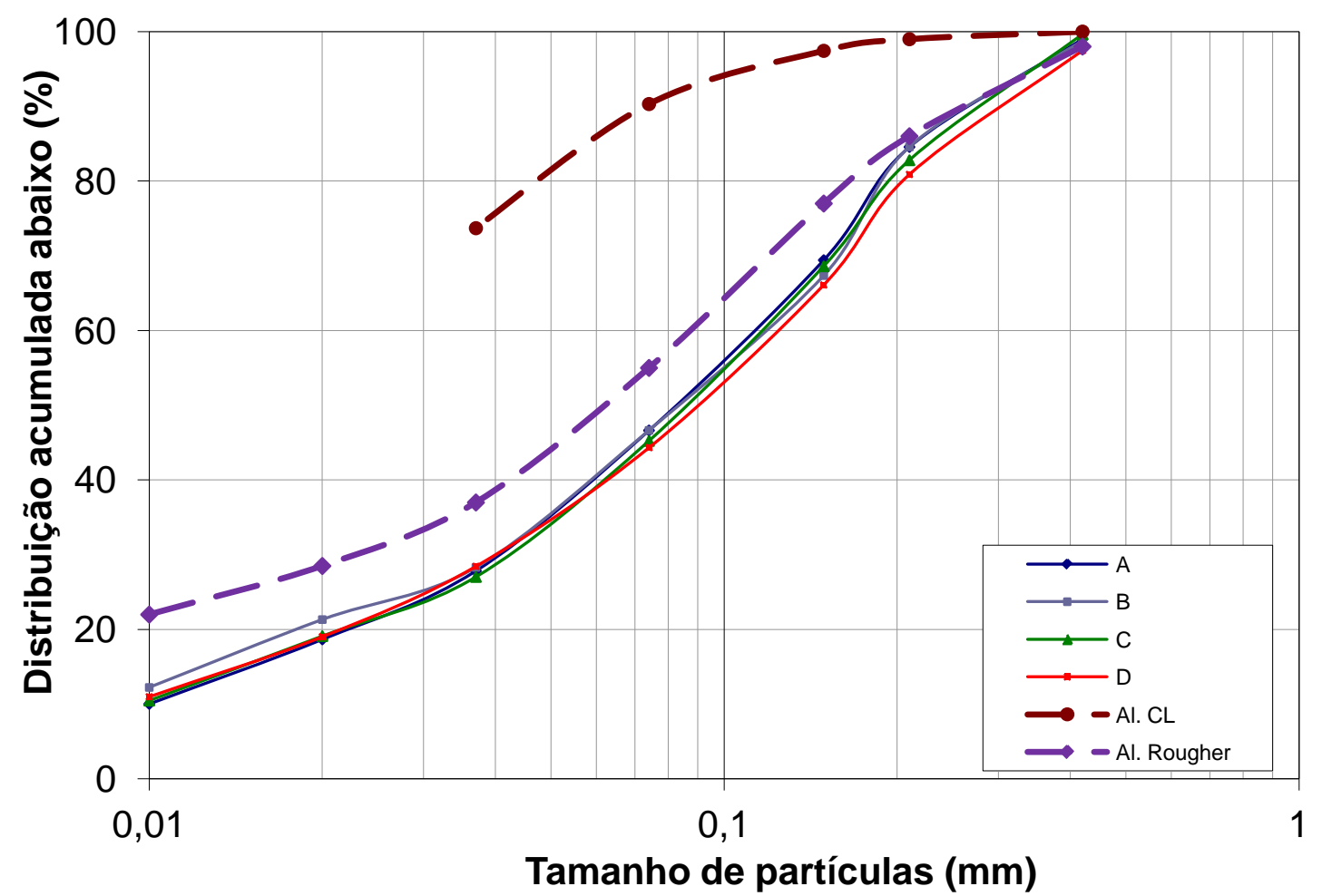

Figura 25 - Distribuição granulométrica dos produtos de moagem e das alimentações dos estágios de flotação rougher e cleaner. 
Tabela 4 - Distribuição granulométrica dos produtos de moagem e das alimentações dos estágios de flotação rougher e cleaner.

\begin{tabular}{lcccccc}
\hline & \multicolumn{6}{c}{ \% em massa acumulada abaixo } \\
Abertura (mm) & Cluster A & Cluster D & Cluster B & Cluster C & $\begin{array}{c}\text { Alim. } \\
\text { routher }\end{array}$ & $\begin{array}{c}\text { Alim. } \\
\text { cleaner }\end{array}$ \\
\hline $0,21 \mathrm{~mm}$ & 85 & 81 & 85 & 83 & 86 & 99 \\
$0,149 \mathrm{~mm}$ & 69 & 66 & 67 & 69 & 77 & 97 \\
$0,074 \mathrm{~mm}$ & 47 & 44 & 47 & 45 & 55 & 90 \\
$0,037 \mathrm{~mm}$ & 28 & 28 & 28 & 27 & 37 & 74 \\
$0,020 \mathrm{~mm}$ & 19 & 19 & 21 & 19 & 28 & \\
$0,010 \mathrm{~mm}$ & 10 & 11 & 12 & 10 & 22 & \\
\hline
\end{tabular}

Para as condições de moagem empregadas, cerca de 80 a $85 \%$ em massa das amostras possui granulação abaixo de 0,21 mm. As frações abaixo de 0,020 mm representam 19 a $21 \%$ do total.

A distribuição granulométrica aproximada da alimentação da flotação rougher, descrita em BERGERMAN (2009), indica que $86 \%$ do material está abaixo de 0,21 $\mathrm{mm}$, sendo que a fração abaixo de $0,020 \mathrm{~mm}$ corresponde a aproximadamente $28 \%$ do total.

Já a distribuição granulométrica da alimentação flotação cleaner, última etapa de flotação do circuito de beneficiamento, possui 99\% em massa abaixo de 0,21 mm e $74 \%$ abaixo de $0,037 \mathrm{~mm}$.

É importante ressaltar que os resultados de caracterização tecnológica apresentados por fração granulométrica, a seguir, referem-se às condições de moagem empregadas neste trabalho. Assim, os resultados apresentados não podem ser empregados diretamente para análises de produtos de moagem da usina de beneficiamento, sendo necessários ajustes que reflitam a diferença entre as moagens do laboratório e a da usina (com maior conteúdo de finos). 


\subsubsection{Cluster A - Sequeirinho}

\subsubsection{Análise granuloquímica}

A distribuição granulométrica da amostra cominuída e a composição química (teores dosados) por fração granulométrica para o cluster A é exposta na Tabela 5.

\section{Tabela 5 - Resultados de análise granuloquímica - cluster A}

\begin{tabular}{|c|c|c|c|c|c|c|c|c|c|c|c|c|c|c|c|c|c|c|c|c|}
\hline \multirow{2}{*}{$\begin{array}{c}\text { Fração } \\
\text { mm }\end{array}$} & \multirow{2}{*}{\multicolumn{2}{|c|}{$\begin{array}{c}\text { \%\% massa } \\
\text { retida acum. }\end{array}$}} & \multicolumn{12}{|c|}{ Teores (\% em massa) } & \multicolumn{6}{|c|}{ Distribuição no ensaio (\%) } \\
\hline & & & $\mathrm{Cu}$ & $\mathbf{S}$ & $\mathrm{SiO}_{2}$ & $\mathrm{Fe}_{2} \mathrm{O}_{3}$ & $\mathrm{Al}_{2} \mathrm{O}_{3}$ & $\mathrm{CaO}$ & MgO & $\mathrm{Na}_{2} \mathrm{O}$ & $\mathrm{K}_{2} \mathrm{O}$ & $\mathrm{TiO}_{2}$ & $\mathbf{P}_{2} \mathrm{O}_{5}$ & PF & $\mathrm{Cu}$ & $\mathbf{S}$ & $\mathrm{SiO}_{2}$ & $\mathrm{Fe}_{2} \mathrm{O}_{3}$ & $\mathrm{Al}_{2} \mathrm{O}_{3}$ & $\mathrm{CaO}$ \\
\hline$+0,210$ & 15,4 & 15,4 & 1,18 & 1,44 & 44,2 & 23,2 & 6,59 & 8,17 & 6,02 & 2,07 & 0,51 & 0,43 & 3,23 & 1,66 & 9,7 & 10,5 & 17,2 & 13,9 & 17,3 & 14,8 \\
\hline$-0,210+0,150$ & 15,1 & 30,6 & 1,48 & 1,82 & 40,4 & 26,3 & 6,07 & 8,43 & 5,75 & 1,83 & 0,44 & 0,43 & 4,00 & 1,58 & 12,0 & 13,0 & 15,5 & 15,4 & 15,6 & 15,0 \\
\hline$-0,150+0,074$ & 22,8 & 53,4 & 1,76 & 2,19 & 38,4 & 27,7 & 5,55 & 8,63 & 5,75 & 1,72 & 0,37 & 0,37 & 4,57 & 1,52 & 21,4 & 23,6 & 22,1 & 24,5 & 21,6 & 23,1 \\
\hline$-0,074+0,037$ & 18,8 & 72,2 & 2,24 & 2,63 & 36,6 & 28,4 & 5,06 & 8,80 & 5,85 & 1,40 & 0,39 & 0,39 & 4,49 & 2,04 & 22,5 & 23,4 & 17,4 & 20,7 & 16,2 & 19,4 \\
\hline$-0,037+0,020$ & 9,16 & 81,3 & 2,63 & 3,08 & 36,3 & 27,2 & 5,37 & 8,34 & 6,13 & 1,33 & 0,44 & 0,35 & 4,27 & 2,66 & 12,9 & 13,4 & 8,4 & 9,6 & 8,4 & 9,0 \\
\hline Under $+0,010$ & 8,64 & 90,0 & 2,61 & 2,06 & 37,7 & 26,6 & 5,54 & 8,92 & 6,36 & 1,30 & 0,40 & 0,36 & 4,89 & 1,88 & 12,1 & 8,4 & 8,2 & 8,9 & 8,1 & 9,0 \\
\hline Over & 10,0 & 100,0 & 1,77 & 1,60 & 44,6 & 17,9 & 7,47 & 8,31 & 7,45 & 1,85 & 0,60 & 0,37 & 3,80 & 3,03 & 9,5 & 7,6 & 11,3 & 7,0 & 12,8 & 9,8 \\
\hline Total calc. & 100 & & 1,87 & 2,11 & 39,6 & 25,8 & 5,87 & 8,53 & 6,07 & 1,67 & 0,44 & 0,39 & 4,19 & 1,93 & 100 & 100 & 100 & 100 & 100 & 100 \\
\hline Total dos. & 100 & & 2,09 & 2,26 & 38,7 & 27,5 & 5,69 & 8,49 & 5,71 & 1,58 & 0,44 & 0,42 & 3,85 & 1,63 & & & & & & \\
\hline
\end{tabular}

A análise granulométrica indica que cerca de 15,4\% em massa estão retidos em 0,21 m e aproximadamente $18,7 \%$ estão abaixo de $0,020 \mathrm{~mm}$ para as condições de moagem empregadas.

Os teores de Cu variam de 1,18 a 2,63\%, aumentando progressivamente até o intervalo $+0,020 \mathrm{~mm}$, a partir do qual decresce novamente. Os teores de S situamse entre 1,44 e 3,08\%, apresentando ocorrência semelhante ao cobre. Os teores de $\mathrm{SiO}_{2}$ variam de 36,3 a 44,6\%, enquanto que os de $\mathrm{Fe}_{2} \mathrm{O}_{3}$ de 23,2 e 28,4\%. Em menores proporções, ocorrem teores médio de $\mathrm{CaO}$ ao redor de 8-9\%, $\mathrm{Al}_{2} \mathrm{O}_{3}$ entre 5,06 e 7,47\% e $\mathrm{MgO}$ entre 5,75 a 7,45\%. Além de 3-4\% de $\mathrm{P}_{2} \mathrm{O}_{5}$ e 1-2\% de $\mathrm{Na}_{2} \mathrm{O}$.

\subsubsection{Composição mineralógica por fração granulométrica (MLA)}

A composição mineralógica do Cluster A para as frações acima de 0,010 mm, apresentada na Tabela 6, foi determinada através do sistema de análise de imagens MLA, com apoio de identificação das fases por DRX além de MEV. 
Tabela 6 - Composição mineralógica por fração granulométrica (MLA) - cluster

A

\begin{tabular}{|l|ccccccc|}
\hline \multirow{2}{*}{ Mineral } & \multicolumn{7}{c}{ Fração (mm) - \% em massa } \\
& $\mathbf{+ 0 , 2 1 0}$ & $\begin{array}{r}\mathbf{- 0 , 2 1 0} \\
\mathbf{+ 0 , 1 5 0}\end{array}$ & $\mathbf{- 0 , 1 5 0}$ & $\mathbf{+ 0 , 0 7 4}$ & $\mathbf{- 0 . 0 3 7}$ & $\mathbf{- 0 , 0 2 0}$ & Total \\
\hline calcopirita & 3,6 & 4,4 & 4,9 & $\mathbf{+ 0 , 0 3 7}$ & $\mathbf{+ 0 , 0 2 0}$ & $\mathbf{+ 0 , 0 1 0}$ & $\mathbf{+ 0 , 0 1 0}$ \\
pirita & 0,5 & 0,4 & 0,4 & 0,6 & 0,3 & 0,4 & $\mathbf{0 , 5}$ \\
outros sulfetos* & $<0,1$ & $<0,1$ & $<0,1$ & $<0,1$ & 0,1 & $<0,1$ & $<\mathbf{0 , 1}$ \\
\hline anfibólio & 33 & 30 & 28 & 30 & 29 & 36 & $\mathbf{3 1}$ \\
magnetita & 18 & 23 & 26 & 25 & 25 & 19 & $\mathbf{2 3}$ \\
plagioclásio & 12 & 11 & 9 & 8 & 7 & 7 & $\mathbf{9}$ \\
apatita & 6 & 7 & 8 & 8 & 8 & 8 & $\mathbf{8}$ \\
quartzo & 6 & 6 & 6 & 5 & 4 & 4 & $\mathbf{5}$ \\
epídoto & 6 & 6 & 5 & 4 & 4 & 3 & $\mathbf{5}$ \\
clorita & 4 & 4 & 4 & 5 & 7 & 6 & $\mathbf{5}$ \\
escapolita & 4 & 3 & 3 & 2 & 2 & 2 & $\mathbf{3}$ \\
mica & 2 & 2 & 2 & 2 & 3 & 3 & $\mathbf{2}$ \\
k-feldspato & 1 & 1 & 1 & 1 & 0,9 & 0,9 & $\mathbf{1}$ \\
outros & 2 & 2 & 2 & 2 & 2 & 2 & $\mathbf{2}$ \\
\hline
\end{tabular}

Nota: outros sulfetos* = calcocita, milerita e siegenita, anfibólio = actinolita \pm hastingsita; plagioclásio = albita \pm plagioclásio sódico com cálcio, clorita = Fe-clinocloro, mica = biotita/flogopita e muscovita, outros = piroxênio + calcita + titanita +rutilo +zircão +alanita +monazita +ilmenita +thorita +uraninita.

Considerando-se o intervalo granulométrico $+0,010 \mathrm{~mm}$, o cluster A é composto predominantemente por anfibólio (31\%) e magnetita (23\%), além de plagioclásio (9\%), apatita (8\%), quartzo $(5 \%)$, epídoto $(5 \%)$ e clorita $(5 \%)$. Em menores proporções estão presentes escapolita (3\%) e micas (2\%). Os minerais acessórios (inferiores a 1\%) são: piroxênio, calcita, titanita, rutilo, zircão, alanita, monazita, ilmenita, thorita e uraninita.

Os conteúdos de calcopirita variam de 3,6 a 9,3\%, elevando-se progressivamente em direção aos finos. A pirita representa cerca de $0,5 \%$ da amostra, variando de 0,3 a $0,6 \%$. Os outros sulfetos são calcocita, milerita e siegenita, que juntos perfazem menos de $0,1 \%$ do total.

O anfibólio predominante é a actinolita, podendo ocorrer a hastingsita também; os conteúdos variam de 29 a 33\%. As proporções de magnetita situam-se entre 18 e $26 \%$, com tendência de aumento nas frações intermediárias. A albita é o 
plagioclásio predominante com conteúdos que variam de 7 a 12\%, diminuindo em direção às frações mais finas.

A apatita situa-se entre 6 e 8\%, o quartzo entre 4-6\%, o epídoto entre 3-6\% e a clorita entre $4-7 \%$. A escapolita varia de $2-4 \%$ e a mica de $2-4 \%$.

Os difratogramas interpretados de amostras representativas deste cluster são apresentados no anexo 2. Os teores médios considerados para as composições dos minerais presentes e respectivas massas específicas são expostos no anexo 3 (banco de dados do MLA), bem como a comparação entre as composições químicas dosadas por FRX e as calculadas a partir do MLA, indicando elevadas correlações e validando os resultados da análise de imagens (anexo 4).

\subsubsection{Partição do Cu e S}

As distribuições de $\mathrm{Cu}$ e $\mathrm{S}$ dentre os minerais portadores é apresentada na Tabela 7.

No cluster A, o cobre está presente quase que em sua totalidade na forma de calcopirita (99,5\%), sendo o restante referente ao cobre da calcocita. O enxofre está presente em sua maioria na calcopirita (89\%) e na pirita (10\%); nos demais minerais portadores (calcocita, milerita e siegenita) perfaz cerca de $1 \%$ do total presente na amostra. 
Tabela 7 - Distribuições de Cu e S dentre os minerais portadores - cluster A

\begin{tabular}{|c|c|c|c|c|c|c|}
\hline & \multirow{2}{*}{ Fração } & \multicolumn{5}{|c|}{ Distribuição (\%) } \\
\hline & & calcopirita & calcocita & pirita & milerita & siegenita \\
\hline \multirow{7}{*}{$\mathrm{Cu}$} & $+0,210$ & 99,3 & 0,8 & - & - & - \\
\hline & $-0,210+0,150$ & 99,9 & 0,1 & - & - & - \\
\hline & $-0,150+0,074$ & 100 & - & - & - & - \\
\hline & $-0,074+0,037$ & 98,8 & 1,2 & - & - & - \\
\hline & $-0,037+0,020$ & 99,7 & 0,3 & - & - & - \\
\hline & $-0,020+0,010$ & 99,7 & 0,3 & - & - & - \\
\hline & Total $+0,010$ & 99,5 & 0,5 & - & - & - \\
\hline \multirow{7}{*}{$\mathrm{s}$} & $+0,210$ & 82,7 & 0,2 & 16,1 & 0,2 & 0,8 \\
\hline & $-0,210+0,150$ & 86,6 & - & 12,4 & 0,8 & 0,3 \\
\hline & $-0,150+0,074$ & 87,9 & - & 11,5 & - & 0,6 \\
\hline & $-0,074+0,037$ & 86,6 & 0,3 & 12,8 & 0,3 & - \\
\hline & $-0,037+0,020$ & 93,1 & 0,1 & 5,6 & 0,6 & 0,6 \\
\hline & $-0,020+0,010$ & 92,6 & 0,1 & 6,8 & 0,2 & 0,4 \\
\hline & Total $+\mathbf{0 , 1 0}$ & 88,4 & 0,1 & 10,8 & 0,3 & 0,4 \\
\hline
\end{tabular}

\subsubsection{Caracterização da calcopirita}

Os principais aspectos texturais da calcopirita observados sob microscopia óptica de luz refletida, em relação à sua forma de ocorrência e associações com a ganga presente, são ilustrados na Fotomicrografia 1 e na Fotomicrografia 2.

Na primeira imagem é apresentado um aspecto geral da fração 0,21+0,15 $\mathrm{mm}$, onde nota-se a presença dos minerais opacos: essencialmente magnetita (cinza claro) e calcopirita (levemente amarelado).

A calcopirita ocorre tanto na forma de microcristais inclusos nos minerais de ganga quanto como cristais maiores. Detalhes destas texturas podem ser mais bem observados na Fotomicrografia 2.

Os mesmos aspectos texturais podem ser observados na Fotomicrografia 3 e na Fotomicrografia 4, obtidas em microscópio eletrônico de varredura (MEV). 


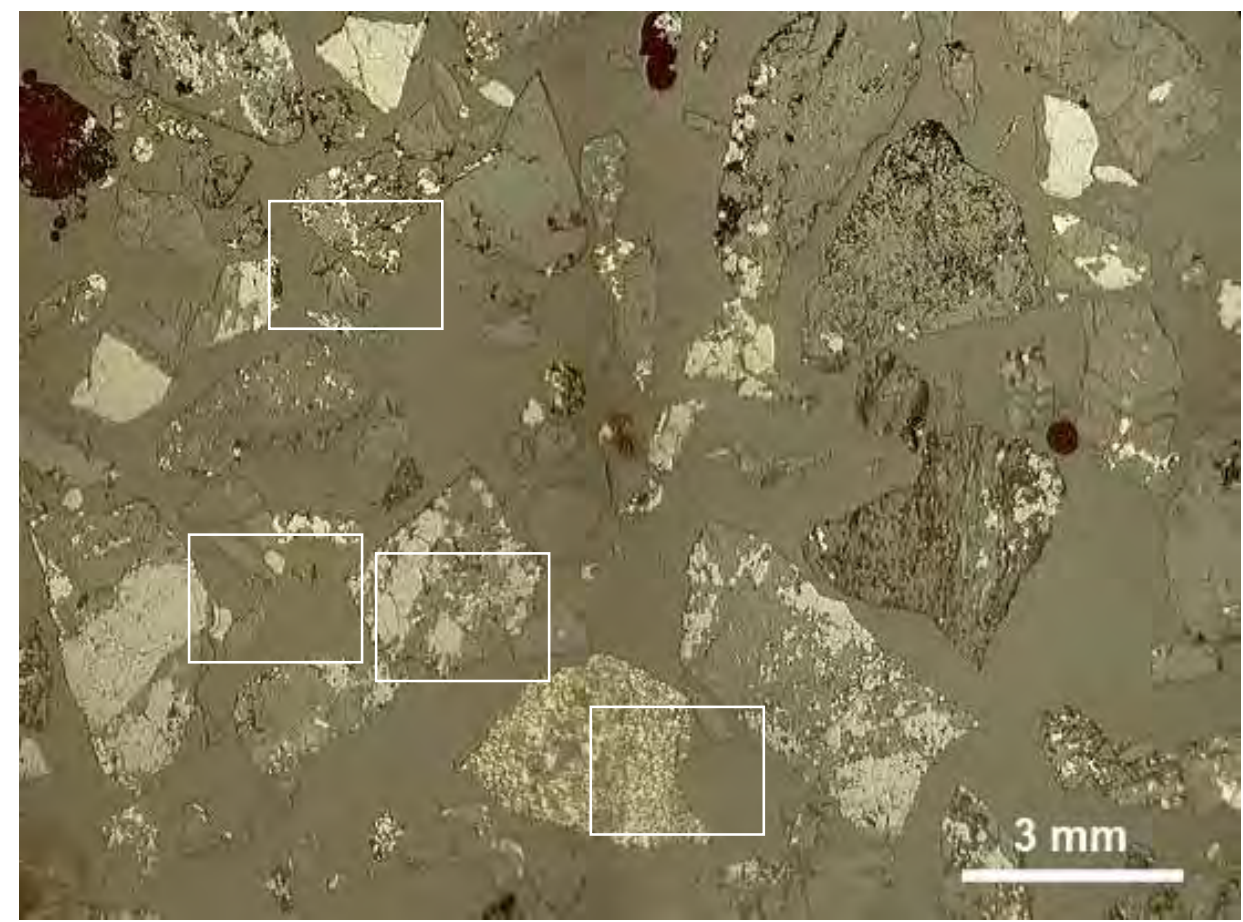

Fotomicrografia 1 - MO, cluster A, fração -0,21+0,15 mm.

Aspecto geral da amostra Cluster A. Os minerais opacos são essencialmente magnetita e calcopirita. A calcopirita ocorre muitas vezes como pequenas inclusões nos minerais de ganga

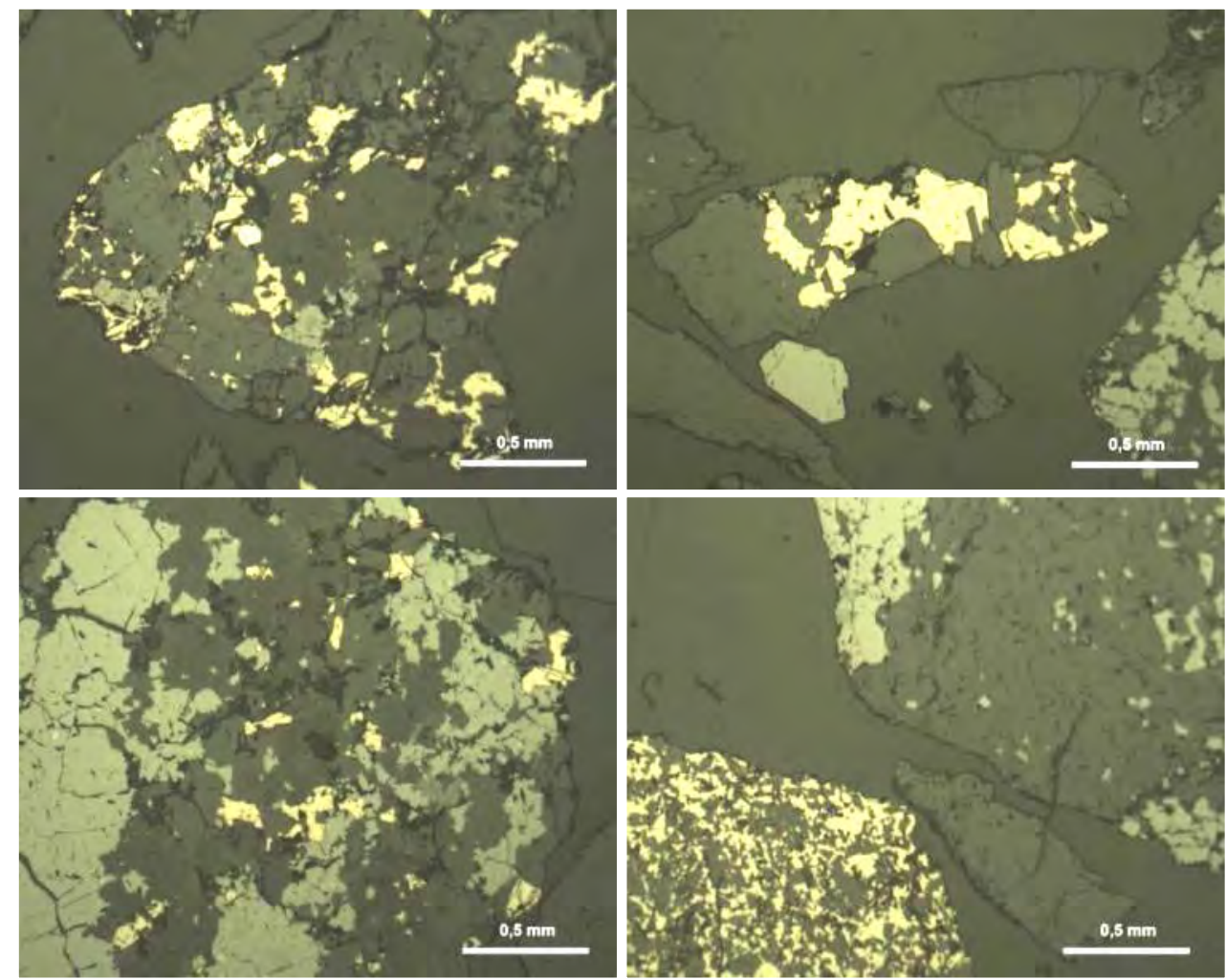

Fotomicrografia 2 - MO, cluster A, fração -0,21+0,15 mm.

Detalhe de algumas partículas: (a), (c) e (d) calcopirita e magnetita na forma de pequenas inclusões nos demais minerais de ganga; (b) cristal maior de calcopirita. 


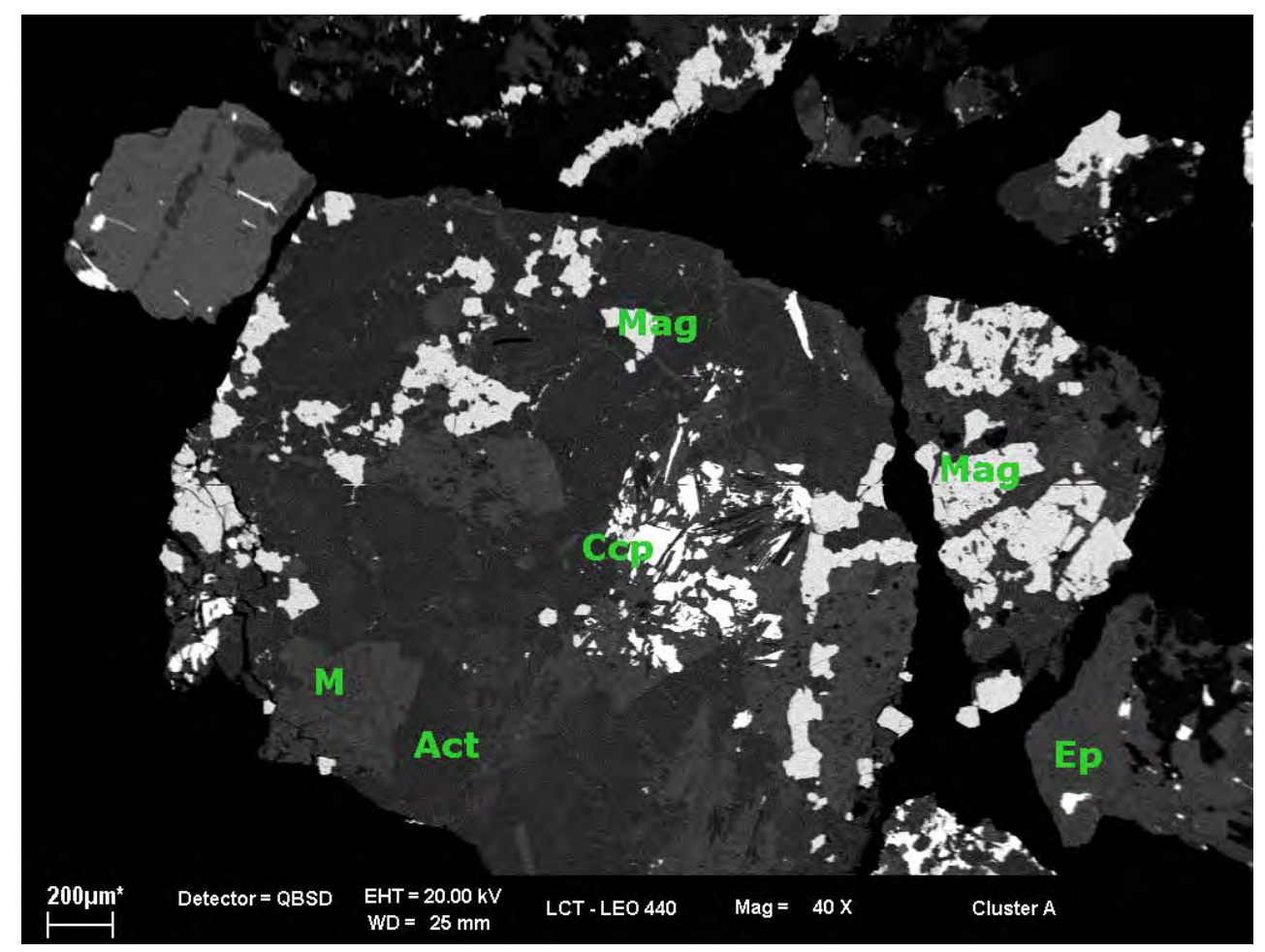

Fotomicrografia 3 - MEV, cluster A, fração -0,21+0,15 mm.

Minúsculos cristais de calcopirita inclusos em minerais de ganga na partícula maior ao centro.

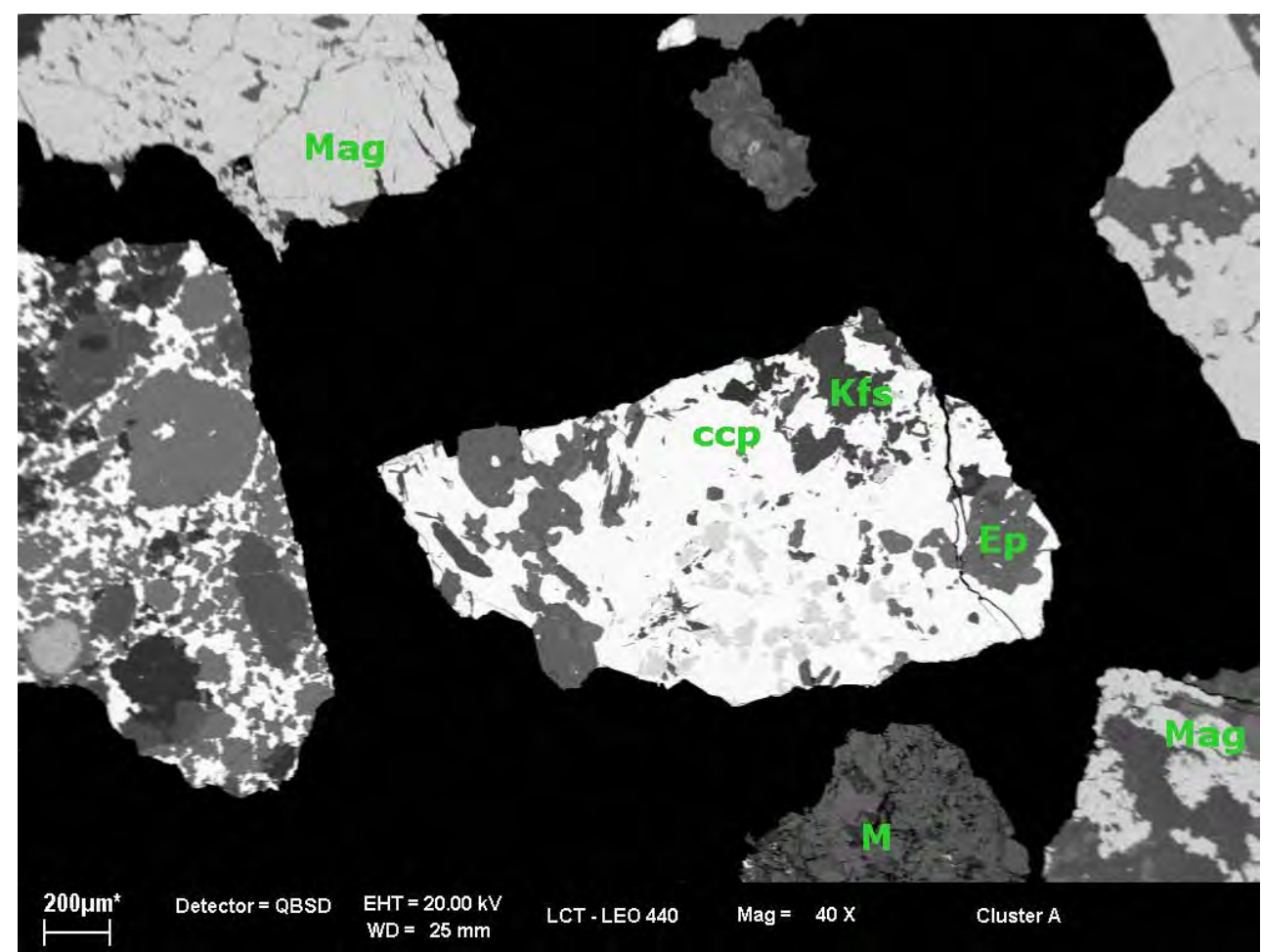

Fotomicrografia 4 - MEV, cluster A, fração -0,21+0,15 mm.

Detalhe de partícula composta majoritariamente por calcopirita (tom mais claro da imagem). 


\subsubsection{Características da calcopirita}

A caracterização das principais associações da calcopirita foi efetuada por microscopia eletrônica de varredura MEV/EDS aliada ao sistema de análise de imagens Mineral Liberation Analyser (MLA).

A Figura 26 e a Tabela 8 apresentam um sumário das formas de associação da calcopirita (\% em massa), entre partículas livres (>95\% do mineral de interesse), mistas em partículas binárias (2 fases minerais) e mistas em partículas ternárias (3 ou mais fases), para as frações acima de 0,010 mm.

A calcopirita apresenta liberação global de 74\%, aumentando de 33 a 92\% conforme diminui a granulação. Abaixo de 0,037 mm, quando atinge liberação de 90\%, as associações binárias perfazem 8\% da fração, enquanto que as ternárias cerca de 1\%. Nas partículas binárias, as associações mais frequentes são com anfibólios, apatita, clorita e magnetita.

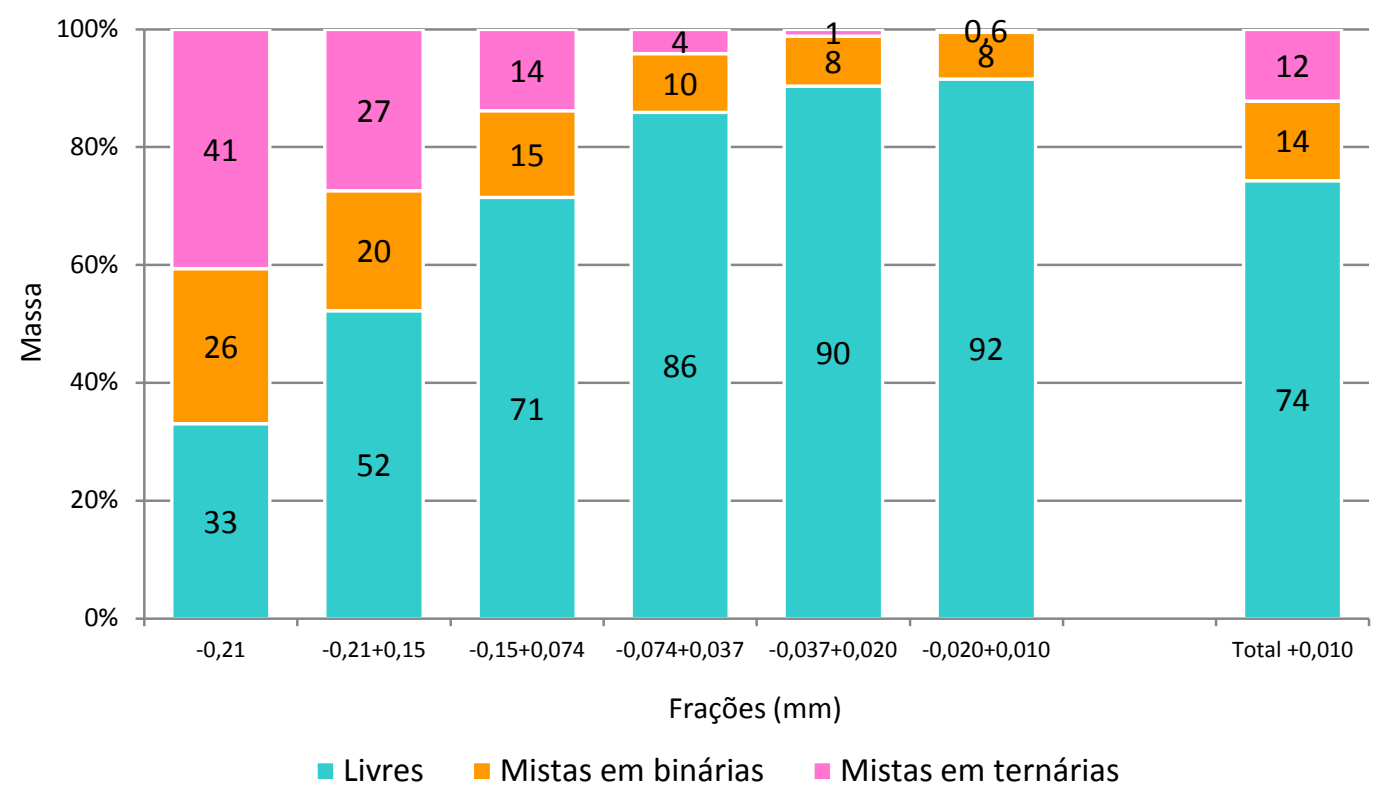

Figura 26 - Distribuição das formas de associação da calcopirita por fração granulométrica - cluster A 
Tabela 8 - Distribuição das formas de associação da calcopirita (\% em massa)

\begin{tabular}{|c|c|c|c|c|c|c|c|c|c|}
\hline \multirow[b]{2}{*}{ Fração (mm) } & \multicolumn{9}{|c|}{ Sumário da distribuição da calcopirita (\% em massa) } \\
\hline & \multicolumn{3}{|c|}{ Livre } & \multicolumn{3}{|c|}{ Mista em binárias } & \multicolumn{3}{|c|}{ Mista em ternárias } \\
\hline$+0,210$ & \multicolumn{3}{|c|}{33} & \multicolumn{3}{|c|}{26} & \multicolumn{3}{|c|}{41} \\
\hline$-0,210+0,150$ & \multicolumn{3}{|c|}{52} & \multicolumn{3}{|c|}{20} & \multicolumn{3}{|c|}{27} \\
\hline$-0,150+0,074$ & \multicolumn{3}{|c|}{71} & \multicolumn{3}{|c|}{15} & \multicolumn{3}{|c|}{14} \\
\hline$-0,074+0,037$ & \multicolumn{3}{|c|}{86} & \multicolumn{3}{|c|}{10} & \multicolumn{3}{|c|}{4} \\
\hline$-0,037+0,020$ & \multicolumn{3}{|c|}{90} & \multicolumn{3}{|c|}{8} & \multicolumn{3}{|c|}{1} \\
\hline$-0,020+0,010$ & \multicolumn{3}{|c|}{92} & \multicolumn{3}{|c|}{8} & \multicolumn{3}{|c|}{0,6} \\
\hline \multirow[t]{2}{*}{ Total $+\mathbf{0 , 0 1 0}$} & \multicolumn{3}{|c|}{74} & \multicolumn{3}{|c|}{14} & \multicolumn{3}{|c|}{12} \\
\hline & \multicolumn{9}{|c|}{ Associações da calcopirita em partículas binárias (\% em massa) } \\
\hline Fração (mm) & anfibólio & apatita & clorita & mag. & pirita & epidoto & plagioc. & outros* & Total \\
\hline$+0,210$ & 6 & 6 & 3 & 2 & 5 & 1 & 1 & 2 & 26 \\
\hline$-0,210+0,150$ & 5 & 5 & 4 & 2 & 2 & 2 & $\operatorname{tr}$ & 1 & 20 \\
\hline$-0,150+0,074$ & 3 & 3 & 3 & 1 & 1 & 1 & 1 & 1 & 15 \\
\hline$-0,074+0,037$ & 2 & 1 & 3 & 2 & 1 & 1 & $\operatorname{tr}$ & 1 & 10 \\
\hline$-0,037+0,020$ & 1 & 1 & 2 & 2 & $\operatorname{tr}$ & $\operatorname{tr}$ & $\operatorname{tr}$ & 1 & 8 \\
\hline$-0,020+0,010$ & 3 & 1 & 1 & 2 & $\operatorname{tr}$ & 1 & $\operatorname{tr}$ & 1 & 8 \\
\hline Total $+0,010$ & 3 & 3 & 2 & 2 & 1 & 1 & $\operatorname{tr}$ & 1 & 14 \\
\hline
\end{tabular}

Associações da calcopirita em partículas ternárias (\% em massa)

Fração (mm) anfibólio apatita clorita mag. pirita epidoto plagioc. outros* Total

\begin{tabular}{ccccccccccc}
\hline$+0,210$ & 9 & 6 & 3 & 1 & 4 & 4 & 4 & 7 & 41 \\
$-0,210+0,150$ & 7 & 4 & 2 & 1 & 4 & 3 & 3 & 4 & 27 \\
$-0,150+0,074$ & 3 & 2 & 2 & $\operatorname{tr}$ & 2 & 1 & 1 & 3 & 14 \\
$-0,074+0,037$ & 1 & $\operatorname{tr}$ & $\operatorname{tr}$ & - & 1 & 1 & 1 & 1 & 4 \\
$-0,037+0,020$ & $\operatorname{tr}$ & - & $\operatorname{tr}$ & $\operatorname{tr}$ & $\operatorname{tr}$ & $\operatorname{tr}$ & - & $\operatorname{tr}$ & 1 \\
$-0,020+0,010$ & $\operatorname{tr}$ & - & $\operatorname{tr}$ & $\operatorname{tr}$ & - & - & $\operatorname{tr}$ & $\operatorname{tr}$ & 0,6 \\
Total $+0,010$ & 3 & 2 & 2 & 1 & $\operatorname{tr}$ & 1 & 1 & 2 & 12 \\
\hline
\end{tabular}

Notas: 1 abreviaturas: $\operatorname{mag}=$ magnetita; plagioc = plagioclásio

2. $\left(^{\star}\right)=$ outros minerais presentes
3. $t r=$ fases com até $0,5 \%$ em massa

A partir das imagens digitais (MLA) calcula-se a fração de mineral útil para cada partícula, bem como a sua respectiva área ou perímetro exposto. $\mathrm{O}$ processamento desses dados permite determinar a distribuição em frequência do mineral de interesse segundo sua área ou superfície nas partículas. As curvas de espectro de liberação da calcopirita considerando as frações em área e em "superfície livre" (parcela de calcopirita exposta no perímetro de cada partícula) são apresentadas respectivamente na Figura 27 e na Figura 28. 


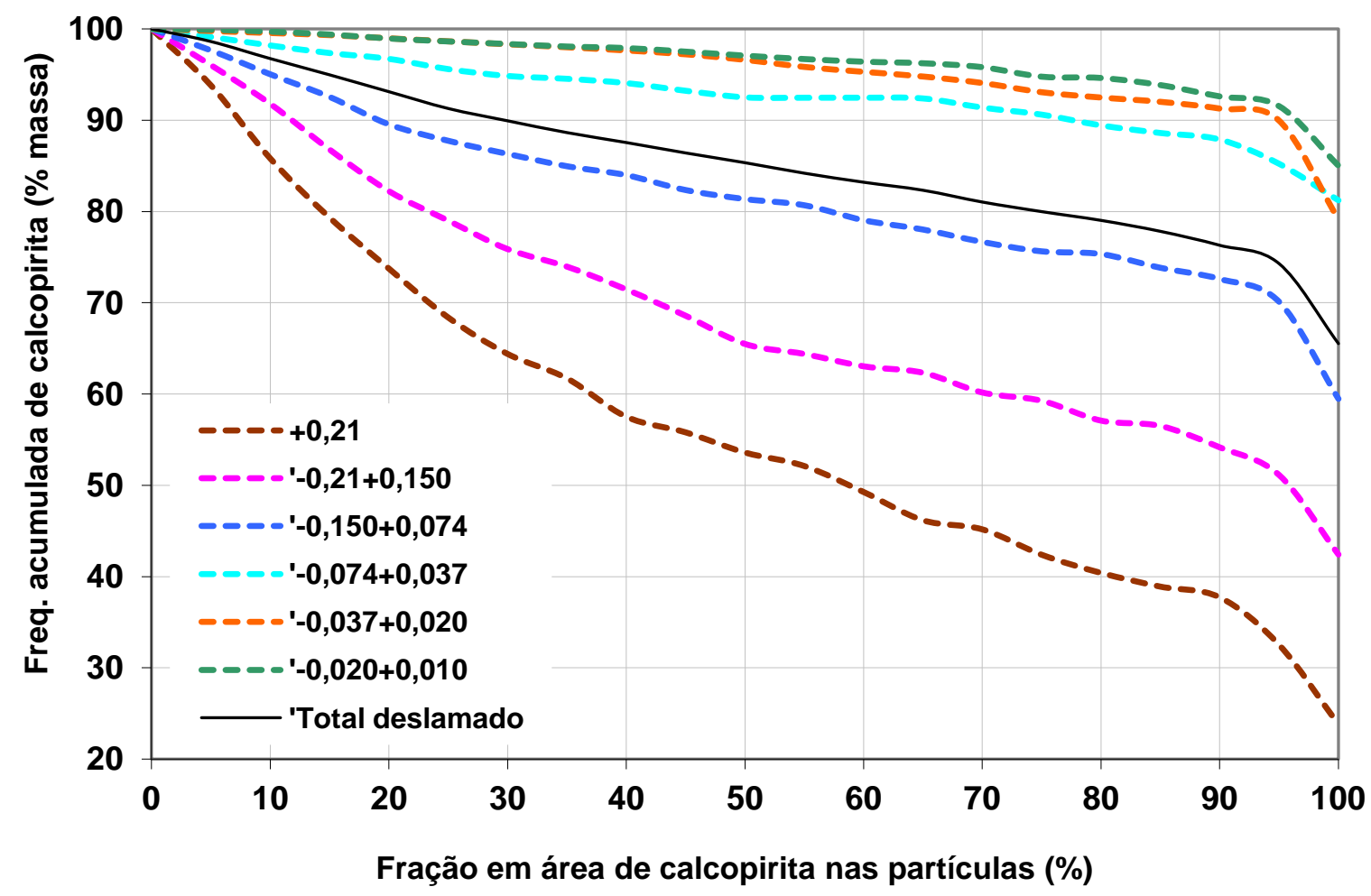

Figura 27 - Espectro de liberação da calcopirita em área - cluster A

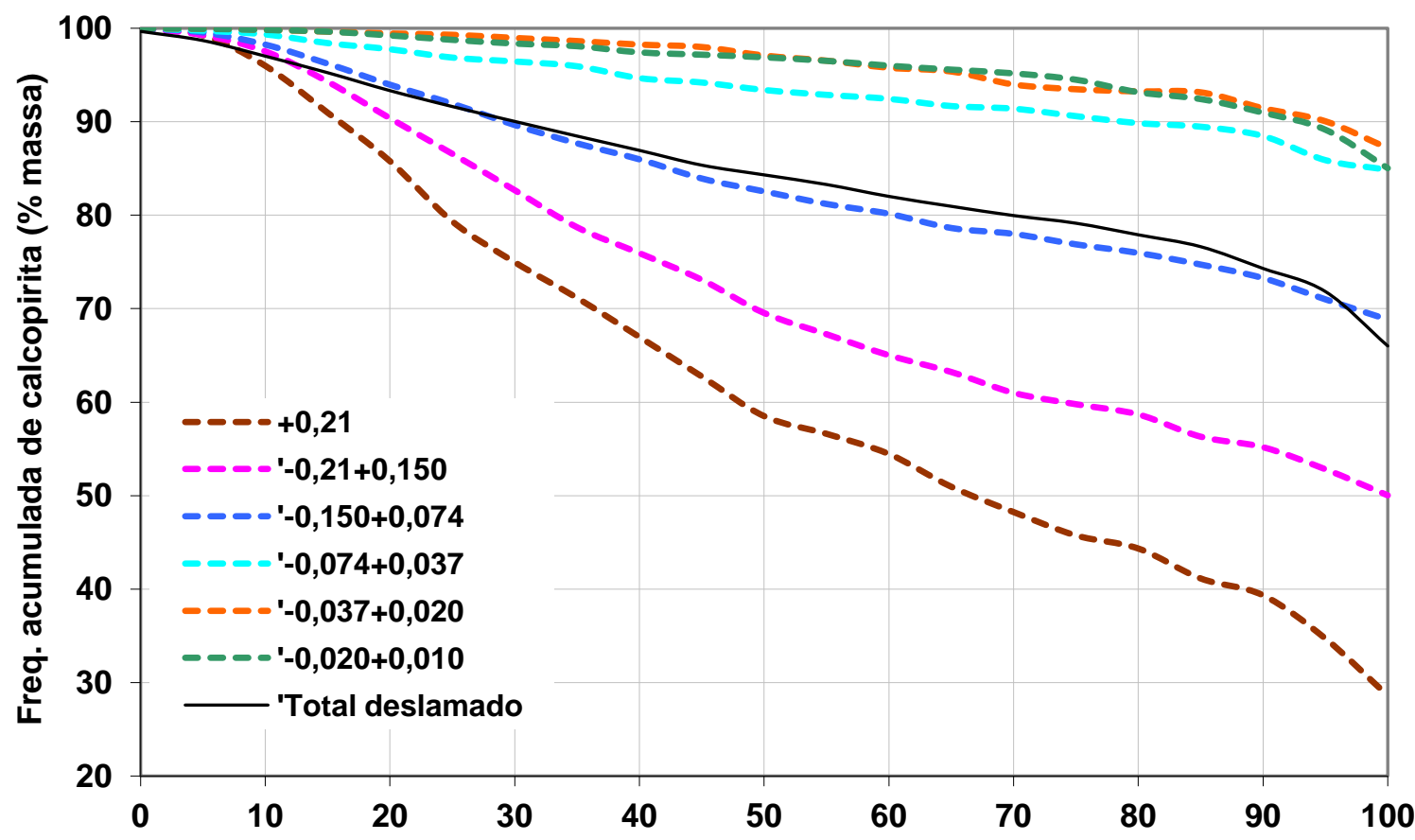

Fração em perímetro exposto de calcopirita nas partículas (\%)

Figura 28 - Espectro de liberação da calcopirita em perímetro exposto - cluster A 
A Tabela 9 apresenta os valores de liberação considerando como partícula liberada aquelas com no mínimo 85\%, 90\%, 95\% e 100\% de calcopirita (valores extraídos da curva de espectro de liberação do total $+0,010 \mathrm{~mm}$, em termos de porcentagem em área e em superfície exposta).

Tabela 9 - Grau de liberação da calcopirita - cluster A

\begin{tabular}{ccccc}
\hline Fração de mineral útil na partícula (\%) & $\mathbf{2 8 5}$ & $\mathbf{2 9 0}$ & $\mathbf{2 9 5}$ & $\mathbf{1 0 0}$ \\
\hline Grau de liberação da calcopirita (\% em área) & 78 & 76 & 74 & 65 \\
Grau de liberação da calcopirita (\% em perímetro exposto) & 77 & 74 & 72 & 66 \\
\hline
\end{tabular}

\subsubsection{Curvas de distribuição versus teores de Cu}

A curva de distribuição acumulada (recuperação potencial base 2D) versus teor de $\mathrm{Cu}$ (obtida nos estudos de MLA) para o material acumulado acima de 0,10 $\mathrm{mm}$, no intervalo considerado, é apresentada na Figura 29. Os estudos mostram que, teoricamente, para as condições de cominuição empregadas um teor entre $13 \mathrm{e}$ $17 \%$ de $\mathrm{Cu}$ (valores típicos dos produtos da etapa rougher segundo Bergeman 2009), seria possível recuperar mais de $99 \%$ do total de Cu já na granulometria de moagem da etapa rougher de flotação.

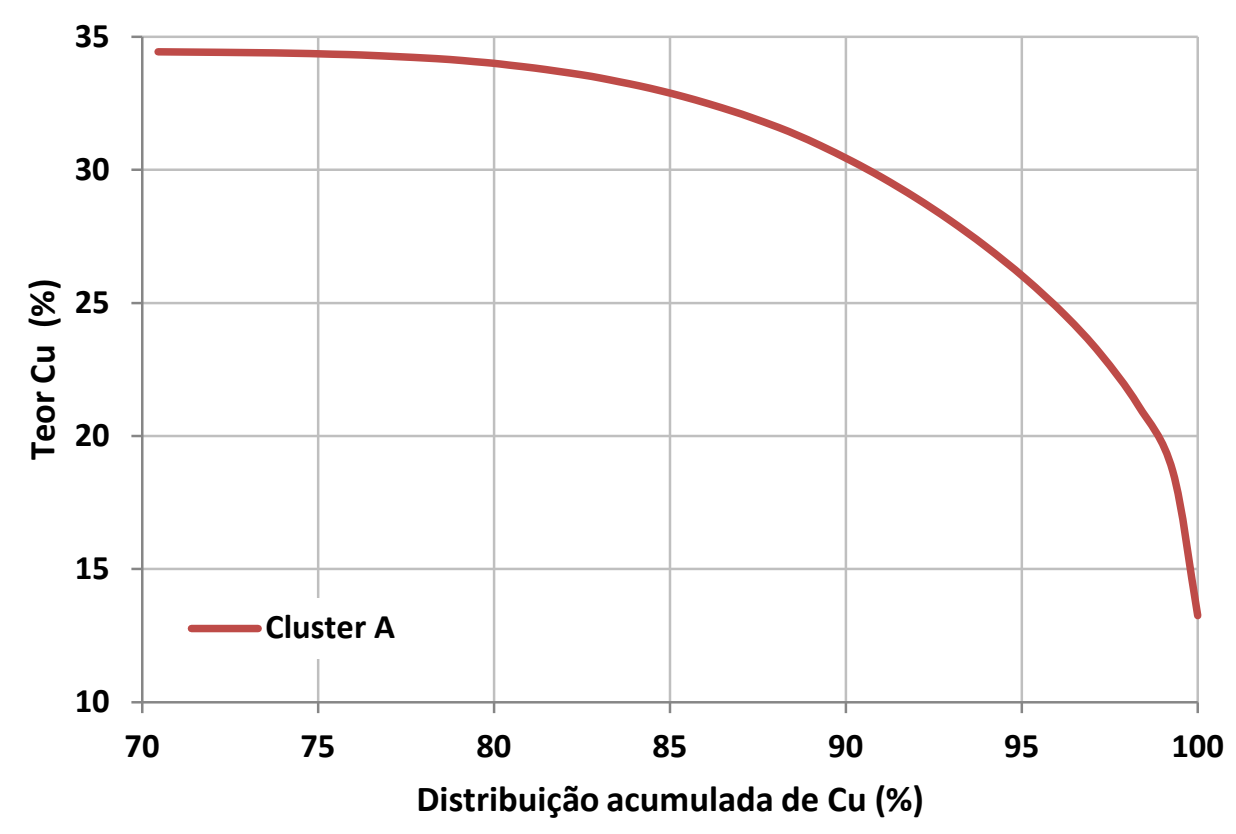

Figura 29 - Curva de distribuição acumulada de $\mathrm{Cu}$ versus teor de $\mathrm{Cu}$ - cluster A, total acima de $0,010 \mathrm{~mm}$ 


\subsubsection{Cluster D - Sequeirinho}

\subsubsection{Distribuição dos elementos por fração}

A distribuição granulométrica da amostra cominuída e a composição química (teores dosados) por fração granulométrica para o cluster D é exposta na Tabela 10.

\section{Tabela 10 - Resultados de análise granuloquímica - cluster D}

\begin{tabular}{|c|c|c|c|c|c|c|c|c|c|c|c|c|c|c|c|c|c|c|c|c|}
\hline \multirow{2}{*}{$\begin{array}{c}\text { Fração } \\
\text { mm }\end{array}$} & \multirow{2}{*}{\multicolumn{2}{|c|}{$\begin{array}{c}\text { ‘\% massa } \\
\text { retida acum. }\end{array}$}} & \multirow[b]{2}{*}{$\mathrm{Cu}$} & \multicolumn{11}{|c|}{ Teores (\% em massa) } & \multicolumn{6}{|c|}{ Distribuição no ensaio (\%) } \\
\hline & & & & $\mathbf{S}$ & $\mathrm{SiO}_{2}$ & $\mathrm{Fe}_{2} \mathrm{O}_{3}$ & $\mathrm{Al}_{2} \mathrm{O}_{3}$ & $\mathrm{CaO}$ & MgO & $\mathrm{Na}_{2} \mathrm{O}$ & $\mathrm{K}_{2} \mathrm{O}$ & $\mathrm{TiO}_{2}$ & $\mathrm{P}_{2} \mathrm{O}_{5}$ & PF & $\mathrm{Cu}$ & $\mathbf{S}$ & $\mathrm{SiO}_{2}$ & $\mathrm{Fe}_{2} \mathrm{O}_{3}$ & $\mathrm{Al}_{2} \mathrm{O}_{3}$ & $\mathrm{CaO}$ \\
\hline$+0,210$ & 19,1 & 19,1 & 0,48 & 0,56 & 59,9 & 9,5 & 10,7 & 5,32 & 3,98 & 4,12 & 1,12 & 0,53 & 0,90 & 1,96 & 10,2 & 11,1 & 20,5 & 15,3 & 20,3 & 17,0 \\
\hline$-0,210+0,150$ & 14,8 & 33,9 & 0,61 & 0,72 & 58,0 & 10,6 & 10,4 & 5,59 & 3,98 & 4,02 & 1,07 & 0,53 & 1,16 & 2,30 & 10,1 & 11,1 & 15,4 & 13,2 & 15,4 & 13,8 \\
\hline$-0,150+0,074$ & 21,8 & 55,7 & 0,84 & 0,99 & 56,0 & 11,8 & 9,98 & 6,11 & 4,08 & 3,81 & 1,00 & 0,52 & 1,67 & 2,18 & 20,5 & 22,5 & 21,9 & 21,6 & 21,6 & 22,3 \\
\hline$-0,074+0,037$ & 15,9 & 71,5 & 1,23 & 1,36 & 53,2 & 13,5 & 9,44 & 6,43 & 4,28 & 3,50 & 0,92 & 0,47 & 1,93 & 2,61 & 21,8 & 22,6 & 15,1 & 18,0 & 14,9 & 17,1 \\
\hline$-0,037+0,020$ & 9,4 & 81,0 & 1,39 & 1,59 & 52,0 & 13,8 & 9,21 & 6,52 & 4,77 & 3,31 & 0,91 & 0,47 & 1,90 & 2,86 & 14,7 & 15,7 & 8,8 & 10,9 & 8,6 & 10,3 \\
\hline Under $+0,010$ & 8,0 & 89,0 & 1,40 & 1,02 & 52,1 & 15,1 & 9,05 & 6,89 & 4,77 & 3,24 & 0,92 & 0,49 & 2,14 & 1,87 & 12,6 & 8,6 & 7,5 & 10,2 & 7,2 & 9,3 \\
\hline Over & 11,0 & 100,0 & 0,82 & 0,73 & 54,6 & 11,7 & 10,9 & 5,53 & 5,03 & 3,64 & 1,27 & 0,46 & 1,52 & 2,80 & 10,2 & 8,4 & 10,8 & 10,8 & 12,0 & 10,2 \\
\hline Total calc. & 100 & & 0,92 & 0,98 & 55,6 & 12,0 & 10,0 & 6,02 & 4,31 & 3,72 & 1,02 & 0,50 & 1,57 & 2,34 & 100 & 100 & 100 & 100 & 100 & 100 \\
\hline Total dos. & 100 & & 0,92 & 1,01 & 55,7 & 12,2 & 9,92 & 6,00 & 4,07 & 3,69 & 1,03 & 0,51 & 1,42 & 2,49 & & & & & & \\
\hline
\end{tabular}

A análise granulométrica do cluster D indica que cerca de $19 \%$ em massa estão retidos em 0,21 mm, enquanto que 19\% constituem material abaixo de 0,020 $\mathrm{mm}$, para as condições de moagem empregadas.

Os teores de Cu variam de 0,48 a 1,40\%, sendo mais elevados no intervalo 0,074+0,010 mm. Observa-se um aumento dos teores com o decréscimo na granulometria, exceto no overflow. O teor de $S$ encontra-se entre 0,56 e 1,59\%, aumentando progressivamente até o intervalo $+0,020 \mathrm{~mm}$, a partir do qual ocorre decréscimo.

Os teores de $\mathrm{SiO}_{2}$ variam de 50,1 a 59,2\%; os teores de $\mathrm{Fe}_{2} \mathrm{O}_{3}$ entre 9,4 e $14,8 \%$ e os de $\mathrm{Al}_{2} \mathrm{O}_{3}$, entre 8,83 e 10,7\%. Ainda permanecem 5-6\% de $\mathrm{CaO}, 4-5 \%$ de $\mathrm{MgO}$ e 3-4\% de $\mathrm{Na}_{2} \mathrm{O}$. Além de $\mathrm{P}_{2} \mathrm{O}_{5}(1,5 \%), \mathrm{K}_{2} \mathrm{O}(1 \%), \mathrm{Cl}(0,5 \%)$ e $\mathrm{TiO}_{2}(0,5 \%)$. 


\subsubsection{Composição mineralógica por fração granulométrica (MLA)}

A composição mineralógica do cluster D para as frações acima de $0,010 \mathrm{~mm}$, exposta na Tabela 11, foi determinada através do sistema de análise de imagens MLA, com apoio de identificação das fases por DRX além de MEV.

Tabela 11 - Composição mineralógica por fração granulométrica (MLA) cluster D

\begin{tabular}{|l|ccccccc|}
\hline & \multicolumn{7}{|c|}{ Fração (mm) - \% em massa } \\
Minerais & $\mathbf{+ 0 , 2 1 0}$ & $\mathbf{- 0 , 2 1 0}$ & $\mathbf{- 0 , 1 5 0}$ & $\mathbf{- 0 , 0 7 4}$ & $\mathbf{- 0 . 0 3 7}$ & $\mathbf{- 0 , 0 2 0}$ & Total \\
& & $\mathbf{+ 0 , 1 5 0}$ & $\mathbf{+ 0 , 0 7 4}$ & $\mathbf{+ 0 , 0 3 7}$ & $\mathbf{+ 0 , 0 2 0}$ & $\mathbf{+ 0 , 0 1 0}$ & $\mathbf{+ 0 , 0 1 0}$ \\
\hline calcopirita & 1,2 & 1,7 & 2,3 & 3,5 & 4,4 & 4,9 & $\mathbf{2 , 6}$ \\
pirita & 0,1 & 0,2 & 0,4 & 0,2 & 0 & 0,2 & $\mathbf{0 , 2}$ \\
outros sulfetos & $<0,1$ & $<0,1$ & $<0,1$ & $<0,1$ & $<0,1$ & $<0,1$ & $<\mathbf{0 , 1}$ \\
\hline plagioclásio & 30 & 29 & 26 & 25 & 20 & 19 & $\mathbf{2 6}$ \\
anfibólio & 21 & 21 & 22 & 22 & 26 & 28 & $\mathbf{2 3}$ \\
quartzo & 12 & 12 & 11 & 11 & 9 & 9 & $\mathbf{1 1}$ \\
escapolita & 9 & 9 & 8 & 7 & 8 & 6 & $\mathbf{8}$ \\
epidoto & 6 & 6 & 6 & 6 & 5 & 4 & $\mathbf{6}$ \\
magnetita & 3 & 5 & 6 & 6 & 8 & 7 & $\mathbf{5}$ \\
k-feldspato & 5 & 5 & 5 & 5 & 4 & 3 & $\mathbf{5}$ \\
clorita & 4 & 5 & 5 & 5 & 7 & 7 & $\mathbf{5}$ \\
mica & 3 & 3 & 3 & 3 & 4 & 4 & $\mathbf{3}$ \\
apatita & 2 & 2 & 3 & 3 & 4 & 4 & $\mathbf{3}$ \\
outros & 2 & 2 & 3 & 3 & 3 & 3 & $\mathbf{3}$ \\
\hline
\end{tabular}

Nota: outros sulfetos = calcocita, milerita e siegenita, anfibólio = actinolita \pm hastingsita; plagiocláio = albita \pm plagioclásio sódico com cálcio, clorita = Fe-clinocloro, mica = biotita/flogopita e muscovita, outros = carbonatos + piroxênio + titanita +rutilo +zircão +alanita +monazita +ilmenita +thorita +uraninita.

Considerando-se o intervalo granulométrico $+0,010 \mathrm{~mm}$, o cluster $\mathrm{D}$ é composto predominantemente por plagioclásio (26\%), anfibólio (23\%) e quartzo (11\%), além de escapolita (8\%), epídoto (6\%), magnetita (5\%), K-feldspato (5\%) e clorita (5\%). Em menor quantidade estão presentes mica e apatita. Os minerais acessórios (inferiores a 1\%) são: piroxênio, calcita, titanita, rutilo, zircão, alanita, monazita, ilmenita, thorita e uraninita

Os conteúdos de calcopirita variam de 1,2 a 4,9\%, elevando-se progressivamente em direção aos finos. A pirita representa cerca de $0,2 \%$ da 
amostra, variando de 0 a $0,4 \%$. Os outros sulfetos (calcocita, milerita e siegenita) perfazem menos de $0,1 \%$ do total.

A albita é o plagioclásio predominante, variando de 30 a 19\% em direção às frações mais finas. O anfibólio segue tendência contrária, aumentando de 21 a 28\% em direção aos finos; a actinolita é o anfibólio predominante, ocorrendo secundariamente a hastingsita.

O quartzo, a escapolita, o epídoto e o K-feldspato decrescem em direção aos finos, variando de 9 a 12\% (quartzo), 6 a 9\% (escapolita), 4 a 6\% (epídoto) e 3 a 5\% (K-feldspato). A magnetita, clorita (Fe-clinocloro), mica (biotita/flogopita e muscovita) e apatita seguem tendência oposta, aumentando em direção aos finos.

Os difratogramas interpretados de amostras representativas deste cluster são apresentados no anexo 2. Os teores médios considerados para as composições dos minerais presentes e respectivas massas específicas são expostos nos anexos 3 (banco de dados do MLA), bem como a comparação entre as composições químicas dosadas por FRX e as calculadas a partir do MLA, indicando elevadas correlações e validando os resultados da análise de imagens (anexo 4).

\subsubsection{Partição do Cu e S}

As distribuições de Cu e $\mathrm{S}$ dentre os minerais portadores é apresentada na Tabela 12.

No cluster D, o cobre está presente quase que em sua totalidade na forma de calcopirita $(98,7 \%)$, sendo o restante referente ao cobre da calcocita $(1,4 \%)$. O enxofre está presente em sua maioria na calcopirita $(88,3 \%)$ e na pirita $(10,8 \%)$. conteúdo de enxofre nos demais minerais portadores (calcocita, milerita e siegenita) perfaz cerca de $1 \%$ do total presente na amostra. 
Tabela 12 - Distribuições de Cu e S dentre os minerais portadores - cluster D

\begin{tabular}{|c|c|c|c|c|c|c|}
\hline & \multirow{2}{*}{ Fração } & \multicolumn{5}{|c|}{ Distribuição (\%) } \\
\hline & & calcopirita & calcocita & pirita & milerita & siegenita \\
\hline \multirow{7}{*}{$\mathrm{Cu}$} & $+0,210$ & 92,5 & 7,5 & - & - & - \\
\hline & $-0,210+0,150$ & 99,5 & 0,6 & - & - & - \\
\hline & $-0,150+0,074$ & 99,9 & 0,1 & - & - & - \\
\hline & $-0,074+0,037$ & 100 & - & - & - & - \\
\hline & $-0,037+0,020$ & 98,2 & 1,8 & - & - & - \\
\hline & $-0,020+0,010$ & 98,9 & 1,1 & - & - & - \\
\hline & Total $+0,010$ & 98,6 & 1,4 & - & - & - \\
\hline \multirow{7}{*}{$\mathrm{s}$} & $+0,210$ & 84,3 & 1,7 & 13,9 & - & 0,1 \\
\hline & $-0,210+0,150$ & 85,9 & 0,1 & 13,5 & 0,3 & 0,1 \\
\hline & $-0,150+0,074$ & 77,5 & - & 21,2 & 0,9 & 0,4 \\
\hline & $-0,074+0,037$ & 91,6 & - & 7,6 & 0,4 & 0,4 \\
\hline & $-0,037+0,020$ & 99,3 & 0,5 & 0,1 & - & 0,2 \\
\hline & $-0,020+0,010$ & 93,6 & 0,3 & 5,7 & 0,2 & 0,2 \\
\hline & Total $+\mathbf{0 , 1 0}$ & 88,3 & 0,3 & 10,8 & 0,4 & 0,3 \\
\hline
\end{tabular}

\subsubsection{Caracterização da calcopirita}

Os principais aspectos texturais da calcopirita observados sob microscopia óptica de luz refletida, em relação à sua forma de ocorrência e associações com a ganga presente, são ilustrados na Fotomicrografia 5 e na Fotomicrografia 6.

$\mathrm{Na}$ primeira imagem é apresentado um aspecto geral da fração $0,21+0,15$ $\mathrm{mm}$, onde nota-se a presença dos minerais opacos: essencialmente magnetita (cinza claro) e calcopirita (levemente amarelado).

A calcopirita ocorre tanto na forma de microcristais inclusos nos minerais de ganga quanto como cristais maiores. Detalhes destas texturas podem ser mais bem observados na Fotomicrografia 6.

Os mesmos aspectos texturais podem ser observados na Fotomicrografia $7 \mathrm{e}$ na Fotomicrografia 8, obtidas em microscópio eletrônico de varredura (MEV). 


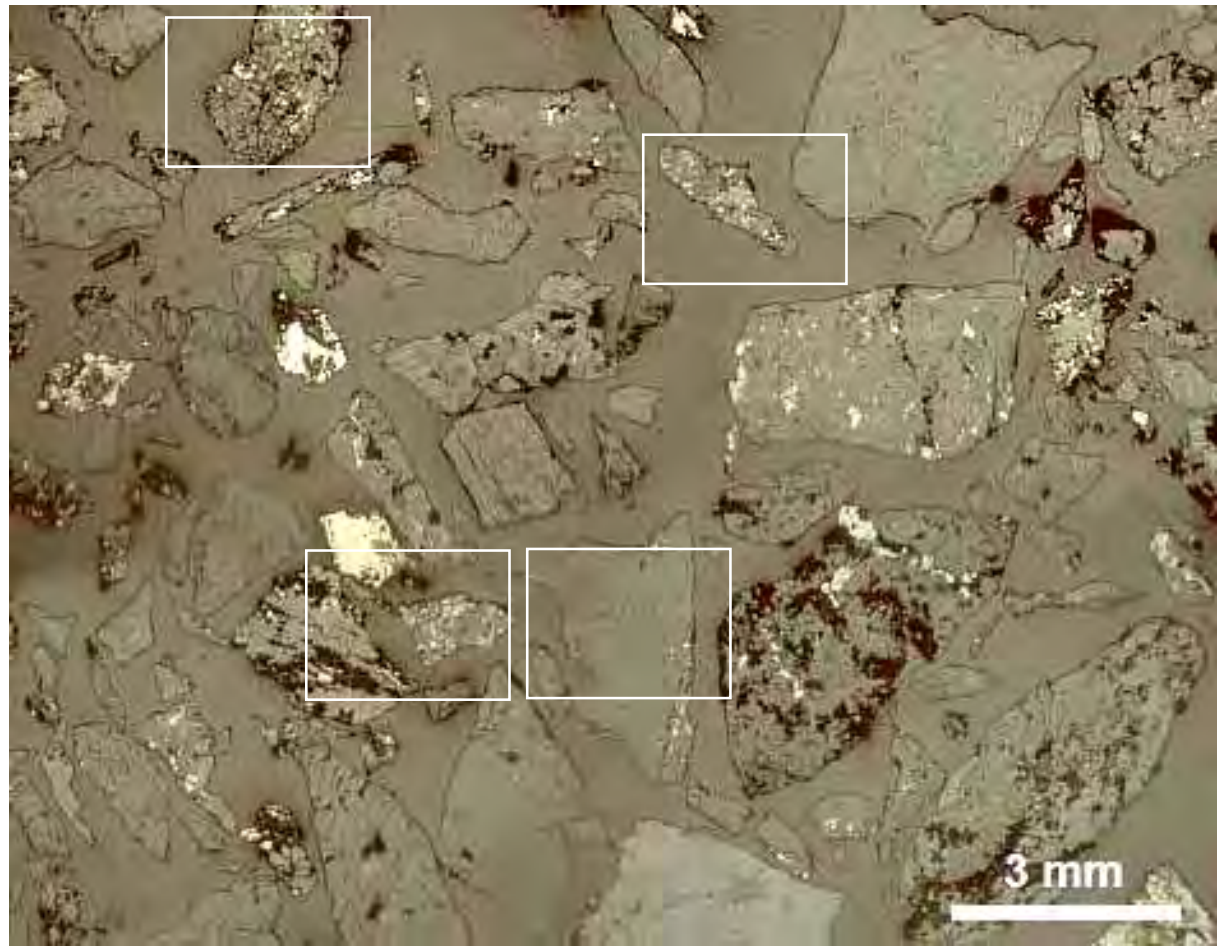

Fotomicrografia 5 - MO, cluster D, fração -0,21+0,15 mm.

Aspecto geral da amostra Cluster D. Os minerais opacos são essencialmente magnetita, calcopirita e pirita. A calcopirita ocorre muitas vezes como pequenas inclusões nos minerais de ganga
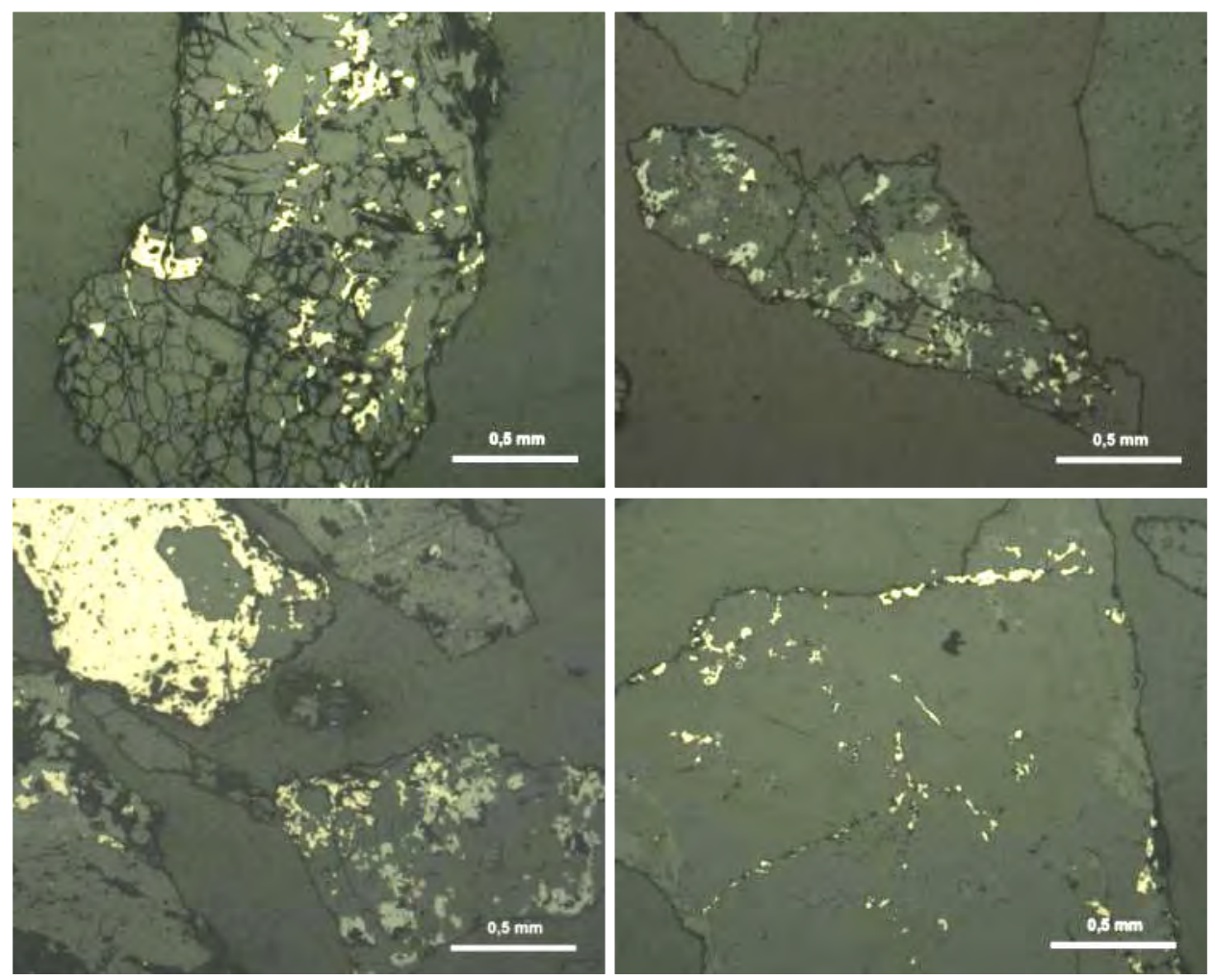

Fotomicrografia 6 - MO, cluster D, fração -0,21+0,15 mm.

Detalhe das partículas com calcopirita: (a), (b) e (d) calcopirita disseminada, como pequenas inclusões nos demais minerais de ganga e (c) calcopirita na forma de 


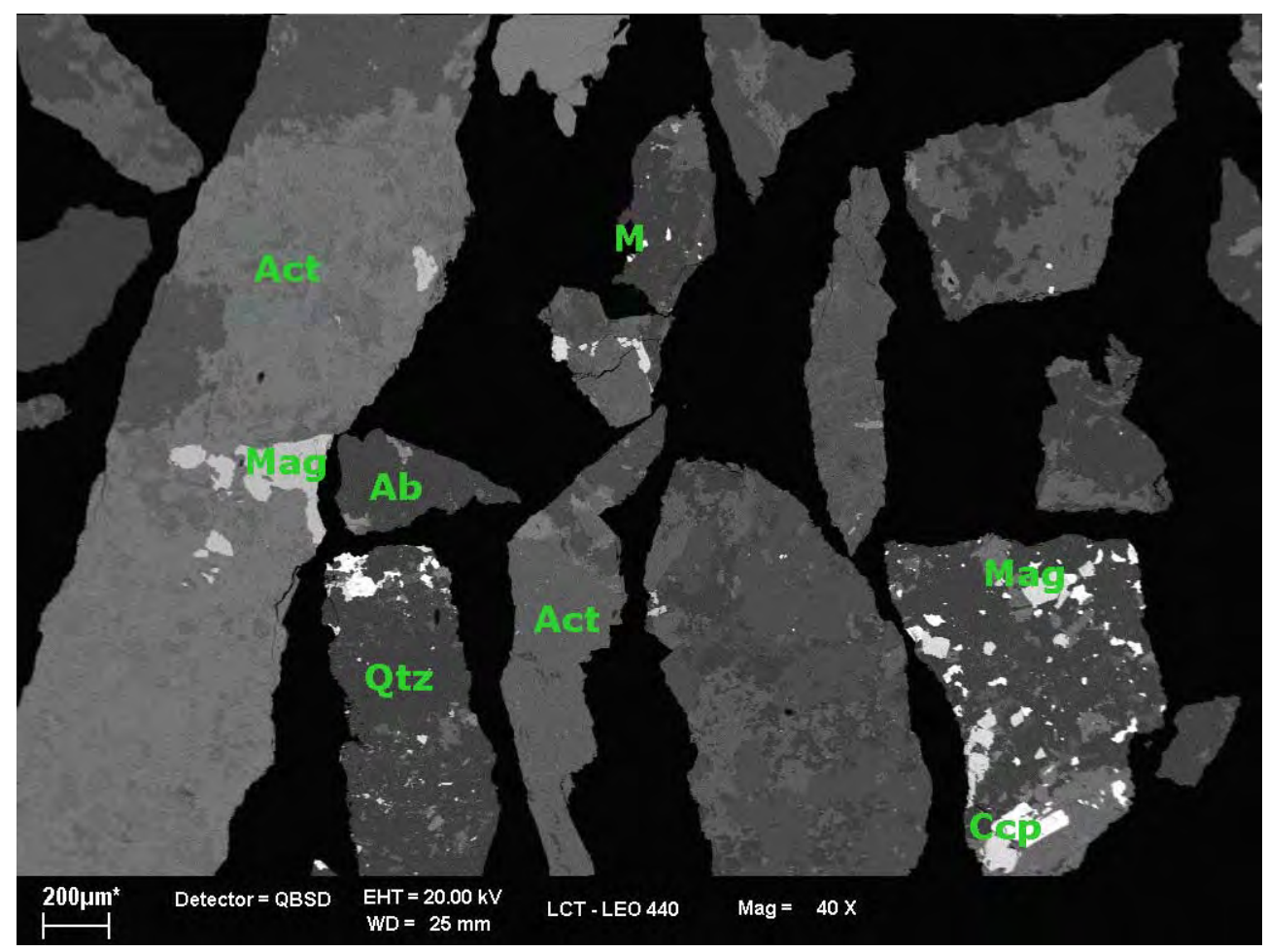

Fotomicrografia 7 - MEV, cluster D, fração -0,21+0,15 mm.

Aspecto textural da calcopirita: minúsculo cristal de calcopirita e sua associação com a ganga.

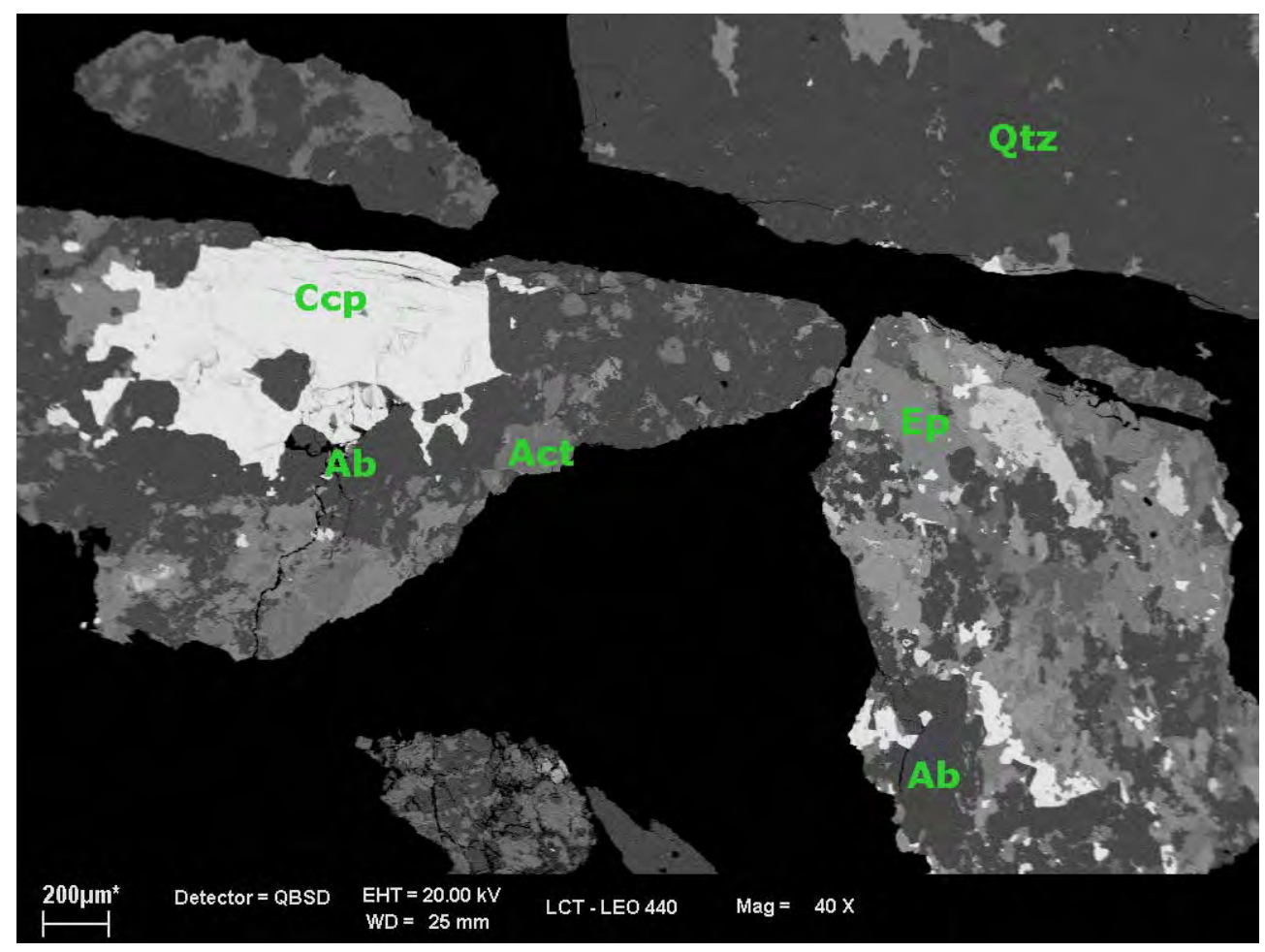

Fotomicrografia 8 - MEV, cluster D, fração -0,21+0,15 mm.

Formas de ocorrência da calcopirita. 


\subsubsection{Características da calcopirita}

A caracterização das principais associações da calcopirita foi efetuada por microscopia eletrônica de varredura MEV/EDS aliada ao sistema de análise de imagens Mineral Liberation Analyser (MLA).

A Figura 30 e a Tabela 13 apresentam um sumário das formas de associação da calcopirita (\% em massa), entre partículas livres (>95\% do mineral de interesse), mistas em partículas binárias (2 fases minerais) e mistas em partículas ternárias (3 ou mais fases), para as frações acima de 0,010 $\mathrm{mm}$.

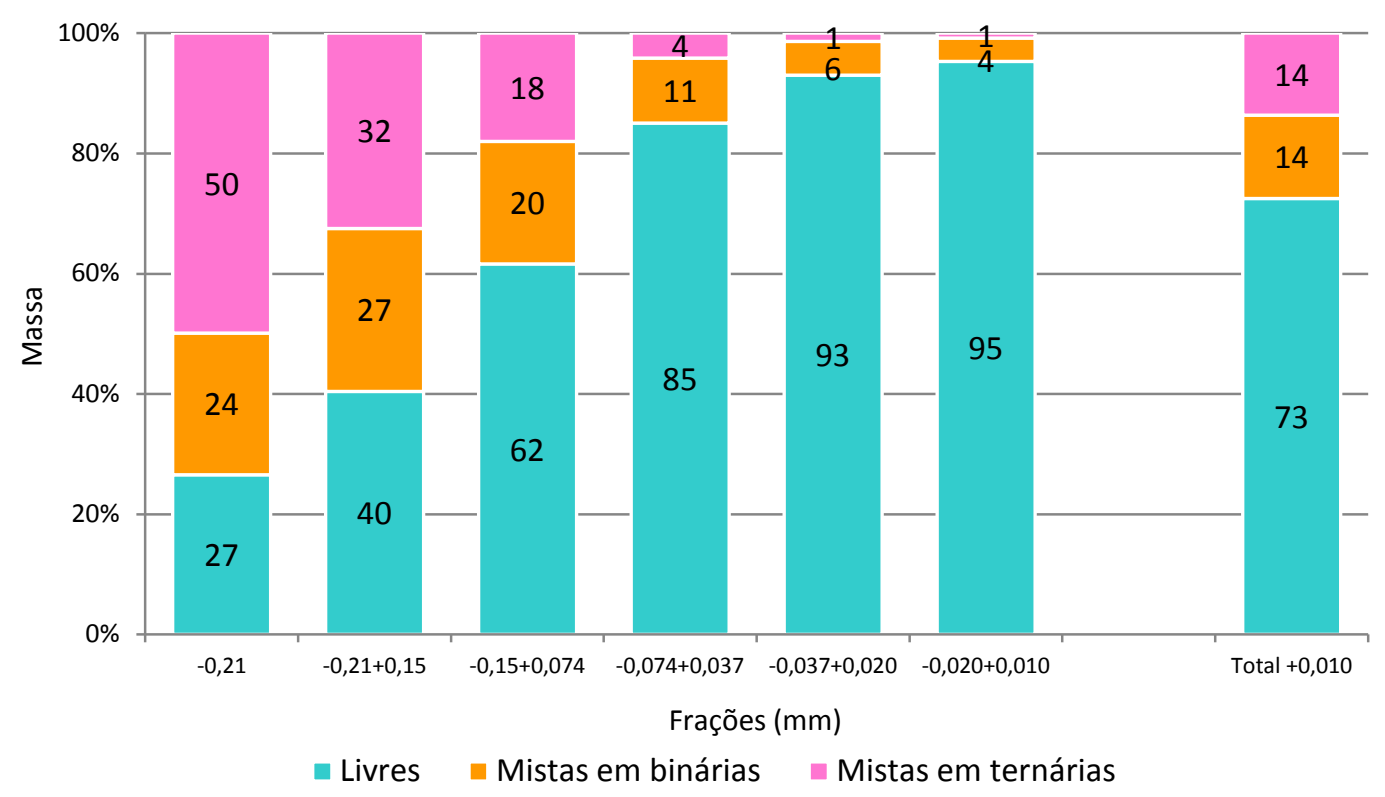

Figura 30 - Distribuição das formas de associação da calcopirita por fração granulométrica - cluster D

A calcopirita apresenta liberação global de 73\%, variando de 27 a 95\% nas frações, aumentando progressivamente em direção aos finos. Abaixo de 0,037 mm, quando atinge liberação acima de $90 \%$, a calcopirita mista ocorre principalmente na forma de partículas binárias, que perfazem de 4-6\% da fração, enquanto que as ternárias correspondem a cerca de 1\%. Nas partículas binárias, as associações mais frequentes são com clorita, anfibólio, plagioclásio, apatita, entre outros. 
Tabela 13 - Distribuição das formas de associação da calcopirita (\% em massa)

\begin{tabular}{|c|c|c|c|c|c|c|c|c|c|}
\hline \multirow[b]{2}{*}{ Fração (mm) } & \multicolumn{9}{|c|}{ Sumário da distribuição da calcopirita (\% em massa) } \\
\hline & \multicolumn{3}{|c|}{ Livre } & \multicolumn{3}{|c|}{ Mista em binárias } & \multicolumn{3}{|c|}{ Mista em ternárias } \\
\hline$+0,210$ & \multicolumn{3}{|c|}{27} & \multicolumn{3}{|c|}{24} & \multicolumn{3}{|c|}{50} \\
\hline$-0,210+0,150$ & \multicolumn{3}{|c|}{40} & \multicolumn{3}{|c|}{27} & \multicolumn{3}{|c|}{32} \\
\hline$-0,150+0,074$ & \multicolumn{3}{|c|}{62} & \multicolumn{3}{|c|}{20} & \multicolumn{3}{|c|}{18} \\
\hline$-0,074+0,037$ & \multicolumn{3}{|c|}{85} & \multicolumn{3}{|c|}{11} & \multicolumn{3}{|c|}{4} \\
\hline$-0,037+0,020$ & \multicolumn{3}{|c|}{93} & \multicolumn{3}{|c|}{6} & \multicolumn{3}{|c|}{1} \\
\hline$-0,020+0,010$ & \multicolumn{3}{|c|}{95} & \multicolumn{3}{|c|}{4} & \multicolumn{3}{|c|}{1} \\
\hline \multirow[t]{2}{*}{ Total $+0,010$} & \multicolumn{3}{|c|}{73} & \multicolumn{3}{|c|}{14} & \multicolumn{3}{|c|}{14} \\
\hline & \multicolumn{9}{|c|}{ Associações da calcopirita em partículas binárias (\% em massa) } \\
\hline Fração (mm) & clorita & anfib. & plagioc & apatita & pirita & quartzo & epidoto & outros* & Total \\
\hline$+0,210$ & 3 & 4 & 4 & 3 & 1 & 2 & 3 & 4 & 24 \\
\hline$-0,210+0,150$ & 7 & 4 & 7 & 1 & 1 & 1 & 1 & 4 & 27 \\
\hline$-0,150+0,074$ & 4 & 3 & 2 & 4 & 4 & 1 & 1 & 2 & 20 \\
\hline$-0,074+0,037$ & 3 & 2 & 1 & 2 & $\operatorname{tr}$ & $\operatorname{tr}$ & $\operatorname{tr}$ & 2 & 11 \\
\hline$-0,037+0,020$ & 1 & 1 & 1 & $\operatorname{tr}$ & - & $\operatorname{tr}$ & 1 & 2 & 6 \\
\hline$-0,020+0,010$ & 1 & 1 & 1 & - & $\operatorname{tr}$ & $\operatorname{tr}$ & $\operatorname{tr}$ & 1 & 4 \\
\hline \multirow[t]{2}{*}{ Total $+0,010$} & 3 & 2 & 2 & 2 & 1 & 1 & 1 & 2 & 14 \\
\hline & \multicolumn{9}{|c|}{ Associações da calcopirita em partículas ternárias (\% em massa) } \\
\hline Fração (mm) & clorita & anfib. & plagioc & apatita & pirita & quartzo & epidoto & outros* & Total \\
\hline$+0,210$ & 6 & 8 & 13 & 4 & $\operatorname{tr}$ & 5 & 6 & 8 & 50 \\
\hline$-0,210+0,150$ & 4 & 7 & 7 & 3 & $\operatorname{tr}$ & 3 & 3 & 7 & 32 \\
\hline$-0,150+0,074$ & 1 & 3 & 3 & 1 & 1 & 2 & 1 & 6 & 18 \\
\hline$-0,074+0,037$ & 1 & 1 & 1 & $\operatorname{tr}$ & - & $\operatorname{tr}$ & $\operatorname{tr}$ & 1 & 4 \\
\hline$-0,037+0,020$ & $\operatorname{tr}$ & $\operatorname{tr}$ & $\operatorname{tr}$ & $\operatorname{tr}$ & - & $\operatorname{tr}$ & $\operatorname{tr}$ & 1 & 1 \\
\hline$-0,020+0,010$ & $\operatorname{tr}$ & $\operatorname{tr}$ & $\operatorname{tr}$ & $\operatorname{tr}$ & $\operatorname{tr}$ & - & $\operatorname{tr}$ & $\operatorname{tr}$ & 1 \\
\hline Total $+\mathbf{0 , 0 1 0}$ & 2 & 2 & 3 & 1 & $\operatorname{tr}$ & 1 & 1 & 3 & 14 \\
\hline
\end{tabular}

Notas: 1. abreviaturas: anfib = anfibólio; plagioc = plagioclásio
2. $\left(^{\star}\right)=$ outros minerais presentes
3. $t r=$ fases com até $0,5 \%$ em massa

A partir das imagens digitais (MLA) calcula-se a fração de mineral útil para cada partícula, bem como a sua respectiva área ou perímetro exposto. O processamento desses dados permite determinar a distribuição em frequência do mineral de interesse segundo sua área ou superfície nas partículas. As curvas de espectro de liberação da calcopirita considerando as frações em área e em 
"superfície livre" (parcela de calcopirita exposta no perímetro de cada partícula). são apresentadas respectivamente na Figura 31 e na Figura 32.

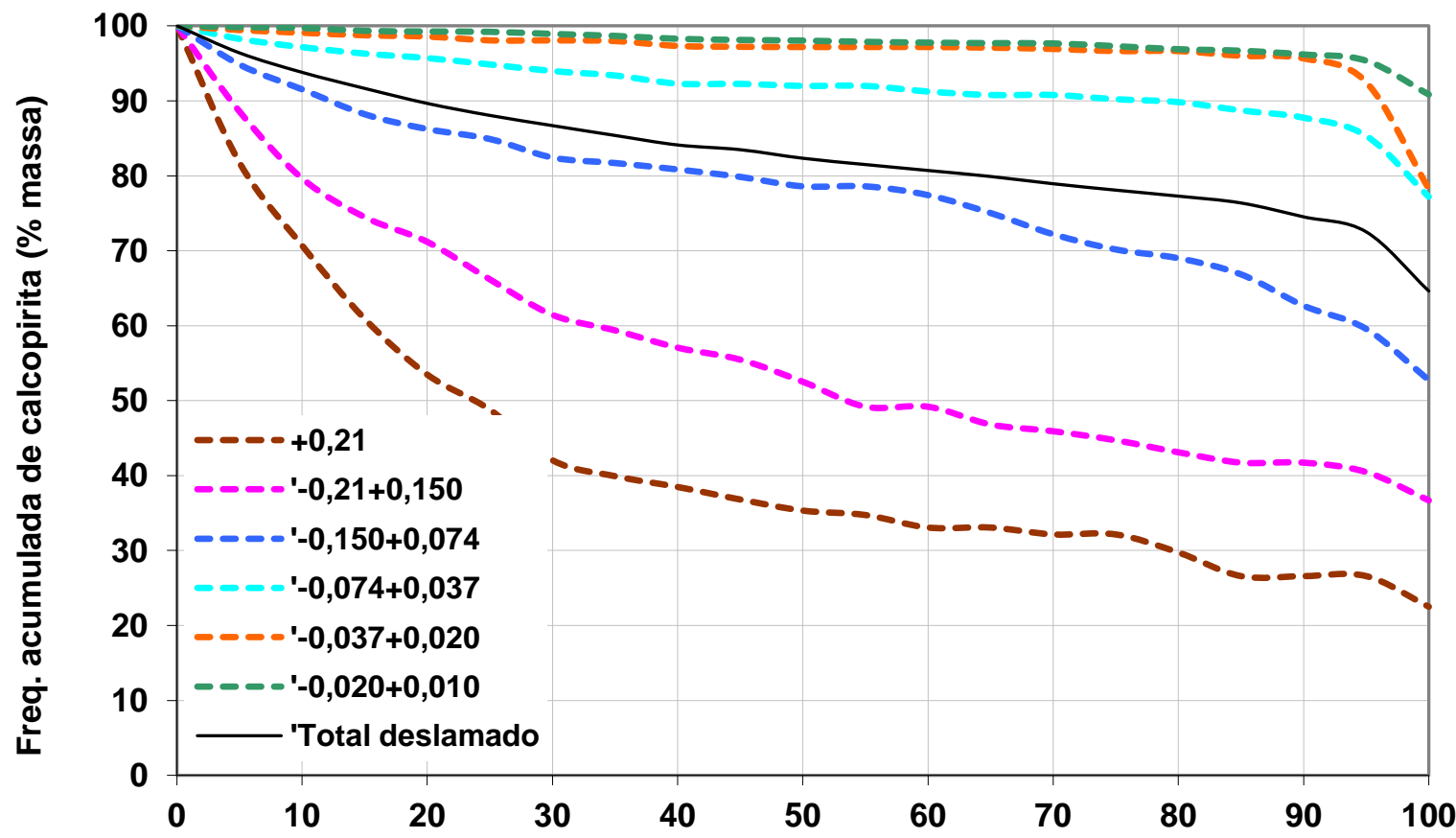

Fração em área de calcopirita nas partículas (\%)

Figura 31 - Espectro de liberação da calcopirita em área - cluster D

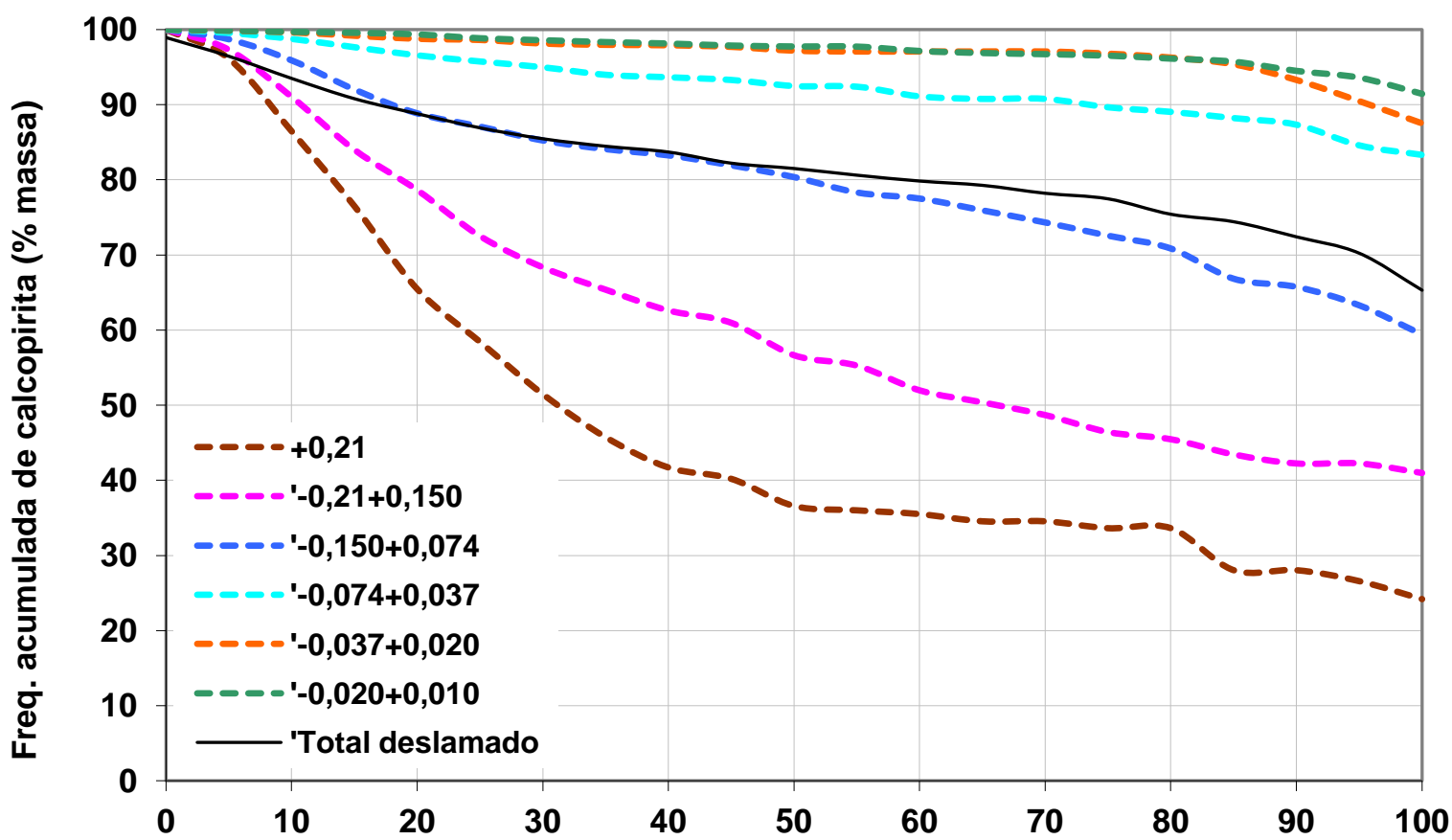

Fração em perímetro exposto de calcopirita nas partículas (\%)

Figura 32 - Espectro de liberação da calcopirita em perímetro exposto - cluster D 
A Tabela 14 apresenta os valores de liberação considerando como partícula liberada aquelas com no mínimo 85\%, 90\%, 95\% e 100\% de calcopirita (valores extraídos das curvas de espectro de liberação do total deslamado, em termos de porcentagem em área e em superfície exposta).

Tabela 14 - Grau de liberação da calcopirita - cluster D

\begin{tabular}{ccccc}
\hline Fração de mineral útil na partícula (\%) & $\geq 85$ & $\geq 90$ & $\geq 95$ & 100 \\
\hline Grau de liberação da calcopirita (\% em área) & 76 & 74 & 72 & 65 \\
Grau de liberação da calcopirita (\% em perímetro exposto) & 74 & 72 & 70 & 65 \\
\hline
\end{tabular}

\subsubsection{Curvas de distribuição versus teores de cobre}

A curva de distribuição acumulada versus teor de $\mathrm{Cu}$ (obtida nos estudos de MLA) para o material acumulado acima de 0,10 mm, no intervalo considerado, é apresentada na Figura 33. Os estudos mostram que, teoricamente, nas condições de moagem empregadas para um teor entre 13 e 17\% de Cu (valores típicos dos produtos da etapa rougher segundo Bergeman 2009), seria possível recuperar cerca de $97-98 \%$ do total de Cu já na granulometria de moagem da etapa rougher de flotação.

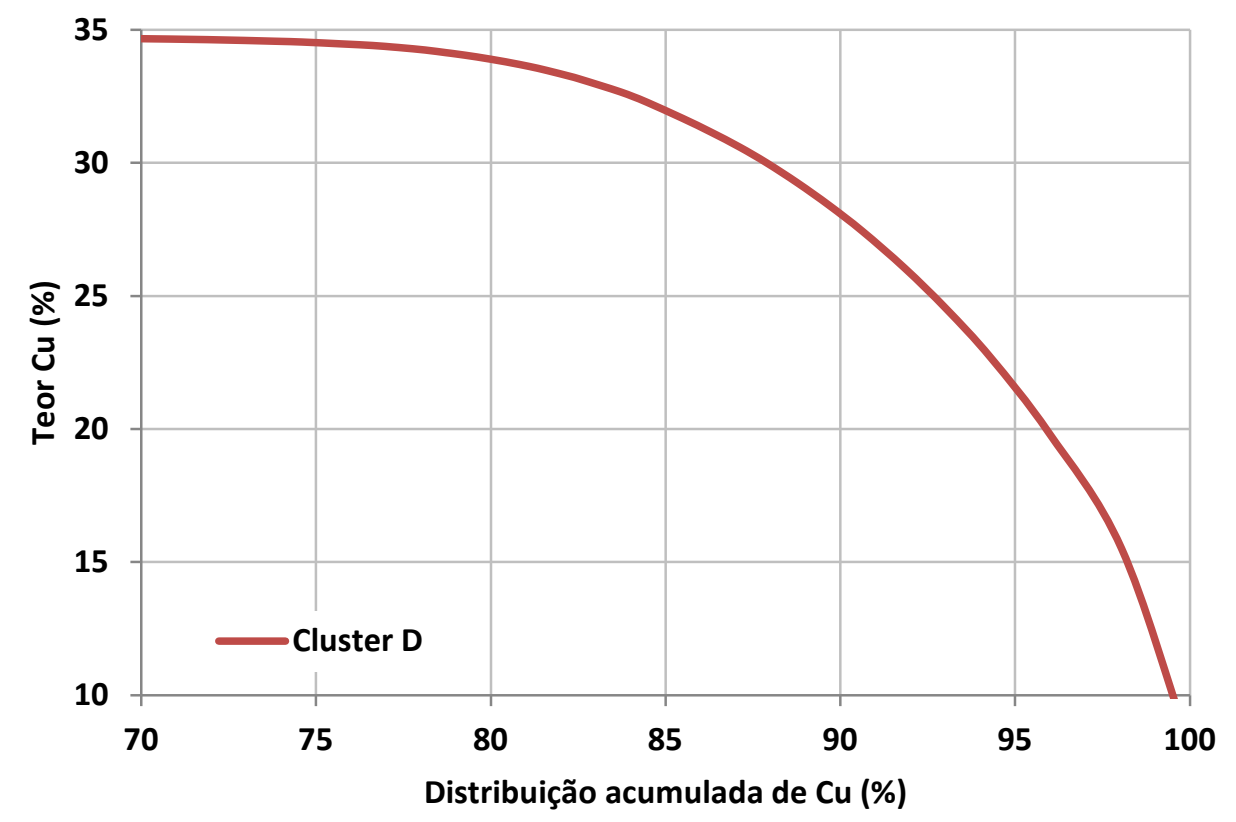

Figura 33 - Curva de distribuição acumulada de $\mathrm{Cu}$ versus teor de $\mathrm{Cu}$ - cluster D, total acima de $0,010 \mathrm{~mm}$ 


\subsubsection{Cluster B - Sossego}

\subsubsection{Distribuição dos elementos por fração}

A distribuição de teores por fração granulométrica para o cluster B é exposta na Tabela 15.

\section{Tabela 15 - Resultados de análise granuloquímica - cluster B}

\begin{tabular}{|c|c|c|c|c|c|c|c|c|c|c|c|c|c|c|c|c|c|c|c|c|}
\hline \multirow{2}{*}{$\begin{array}{c}\text { Fração } \\
\text { mm }\end{array}$} & \multirow{2}{*}{\multicolumn{2}{|c|}{$\begin{array}{c}\text { ‘\% massa } \\
\text { retida acum. }\end{array}$}} & \multirow[b]{2}{*}{$\mathrm{Cu}$} & \multicolumn{11}{|c|}{ Teores (\% em massa) } & \multicolumn{6}{|c|}{ Distribuição no ensaio (\%) } \\
\hline & & & & $\mathbf{S}$ & $\mathrm{SiO}_{2}$ & $\mathrm{Fe}_{2} \mathrm{O}_{3}$ & $\mathrm{Al}_{2} \mathrm{O}_{3}$ & $\mathrm{CaO}$ & MgO & $\mathrm{Na}_{2} \mathrm{O}$ & $\mathrm{K}_{2} \mathrm{O}$ & $\mathrm{TiO}_{2}$ & $\mathrm{P}_{2} \mathrm{O}_{5}$ & PF & $\mathrm{Cu}$ & $\mathbf{S}$ & $\mathrm{SiO}_{2}$ & $\mathrm{Fe}_{2} \mathrm{O}_{3}$ & $\mathrm{Al}_{2} \mathrm{O}_{3}$ & $\mathrm{CaO}$ \\
\hline$+0,210$ & 15,4 & 15,4 & 0,37 & 0,40 & 67,5 & 7,40 & 9,64 & 2,96 & 2,20 & 3,32 & 1,74 & 0,45 & 0,64 & 3,00 & 8,4 & 8,6 & 16,5 & 12,1 & 16,2 & 10,2 \\
\hline$-0,210+0,150$ & 17,2 & 32,6 & 0,55 & 0,64 & 65,5 & 8,19 & 9,30 & 3,57 & 2,32 & 3,14 & 1,69 & 0,43 & 0,88 & 3,42 & 13,7 & 15,2 & 17,9 & 15,0 & 17,5 & 13,7 \\
\hline$-0,150+0,074$ & 20,7 & 53,4 & 0,75 & 0,85 & 64,9 & 8,95 & 9,23 & 4,30 & 2,46 & 3,06 & 1,65 & 0,40 & 1,18 & 1,71 & 22,8 & 24,5 & 21,4 & 19,7 & 20,9 & 19,9 \\
\hline$-0,074+0,037$ & 18,3 & 71,7 & 0,86 & 0,99 & 61,0 & 9,97 & 8,64 & 4,88 & 2,70 & 2,73 & 1,46 & 0,43 & 1,21 & 4,54 & 23,1 & 25,1 & 17,8 & 19,4 & 17,3 & 20,0 \\
\hline$-0,037+0,020$ & 7,0 & 78,7 & 1,05 & 1,14 & 58,2 & 11,4 & 8,45 & 5,40 & 2,91 & 2,47 & 1,40 & 0,42 & 1,25 & 5,33 & 10,7 & 11,0 & 6,4 & 8,5 & 6,4 & 8,4 \\
\hline Under $+0,010$ & 9,1 & 87,8 & 0,93 & 0,66 & 60,0 & 12,2 & 8,22 & 6,13 & 2,81 & 2,45 & 1,35 & 0,45 & 1,46 & 2,94 & 12,3 & 8,3 & 8,7 & 11,8 & 8,1 & 12,4 \\
\hline Over & 12,3 & 100,0 & 0,50 & 0,42 & 58,1 & 10,4 & 10,1 & 5,60 & 3,57 & 2,82 & 1,70 & 0,43 & 0,98 & 4,88 & 8,9 & 7,2 & 11,3 & 13,5 & 13,5 & 15,3 \\
\hline Total calc. & 100 & & 0,70 & 0,74 & 63,0 & 9,44 & 9,12 & 4,48 & 2,63 & 2,92 & 1,59 & 0,43 & 1,07 & 3,46 & 100 & 100 & 100 & 100 & 100 & 100 \\
\hline Total dos. & 100 & & 0,66 & 0,69 & 62,8 & 9,94 & 9,12 & 4,55 & 2,52 & 2,87 & 1,60 & 0,45 & 0,96 & 3,38 & & & & & & \\
\hline
\end{tabular}

A análise granulométrica do cluster B indica que cerca de $15 \%$ em massa estão retidos em 0,21 mm, enquanto que $21 \%$ constituem material abaixo de 0,020 $\mathrm{mm}$, para as condições de moagem empregadas.

Os teores de Cu variam de 0,37 até 1,05\%, com tendência de aumento em direção aos finos, com exceção do overflow. O teor de S encontra-se entre 0,40 e 1,14\% com tendência semelhante ao do cobre.

A sílica representa cerca de 63\% da amostra, variando de 58,1 a 67,5\% nas frações (com tendência de diminuição para os finos). $\mathrm{O} \mathrm{Fe}_{2} \mathrm{O}_{3}$ constitui por volta $10 \%$ da amostra, variando de 7,4 até $12,2 \%$, com tendência de aumento para os finos. O teor de $\mathrm{Al}_{2} \mathrm{O}_{3}$ situa-se entre 8,22 e 10,1\%, representando 9\% da amostra. $\mathrm{O}$ teor médio calculado de $\mathrm{CaO}$ é 4,5\% e o de $\mathrm{MgO}$ 2,6\%. Ainda permanecem cerca de $3 \%$ de $\mathrm{Na}_{2} \mathrm{O}, 1,5 \% \mathrm{~K}_{2} \mathrm{O}, 0,4 \%$ de $\mathrm{TiO}_{2}$ e $1 \% \mathrm{P}_{2} \mathrm{O}_{5}$, 


\subsubsection{Composição mineralógica por fração granulométrica (MLA)}

A composição mineralógica do cluster B para as frações acima de $0,010 \mathrm{~mm}$, exposta na Tabela 16, foi determinada através do sistema de análise de imagens MLA, com apoio de identificação das fases por DRX além de MEV.

Tabela 16 - Composição mineralógica por fração granulométrica (MLA) cluster B

\begin{tabular}{|c|c|c|c|c|c|c|c|}
\hline \multirow[b]{2}{*}{ Minerais } & \multicolumn{7}{|c|}{ Fração (mm) - \% em massa } \\
\hline & $+0,210$ & $\begin{array}{l}-0,210 \\
+0,150\end{array}$ & $\begin{array}{r}-0,150 \\
+0,074\end{array}$ & $\begin{array}{l}-0,074 \\
+0,037\end{array}$ & $\begin{array}{l}-0.037 \\
+0,020\end{array}$ & $\begin{array}{r}-0,020 \\
+0,010\end{array}$ & $\begin{array}{c}\text { Total } \\
+0,010\end{array}$ \\
\hline calcopirita & 0,9 & 1,8 & 2,1 & 2,7 & 3,5 & 3,1 & 2,2 \\
\hline pirita & 0,1 & 0,1 & 0 & 0 & 0,1 & 0,1 & 0,1 \\
\hline outros sulfetos & $<0,1$ & $<0,1$ & $<0,1$ & $<0,1$ & 0,1 & $<0,1$ & $<0,1$ \\
\hline quartzo & 34 & 33 & 32 & 32 & 27 & 26 & 31 \\
\hline plagioclásio & 28 & 27 & 26 & 24 & 21 & 22 & 25 \\
\hline k-feldspato & 11 & 11 & 10 & 9 & 8 & 8 & 10 \\
\hline clorita & 8 & 9 & 10 & 11 & 13 & 13 & 10 \\
\hline anfibólio & 4 & 5 & 5 & 5 & 5 & 7 & 5 \\
\hline magnetita & 3 & 2 & 4 & 4 & 6 & 4 & 4 \\
\hline carbonato & 3 & 3 & 4 & 5 & 7 & 7 & 4 \\
\hline mica & 3 & 3 & 3 & 3 & 3 & 3 & 3 \\
\hline apatita & 1 & 1 & 2 & 2 & 2 & 3 & 2 \\
\hline epídoto & 1 & 1 & 1 & 1 & 1 & 1 & 1 \\
\hline outros & 2 & 2 & 2 & 2 & 3 & 2 & 2 \\
\hline
\end{tabular}

Considerando-se o intervalo granulométrico $+0,010 \mathrm{~mm}$, o cluster B é composto predominantemente por quartzo (31\%) e feldspatos (25\% de plagioclásio e $10 \%$ de K-feldspato), com menores proporções de clorita (10\%), anfibólios (5\%;

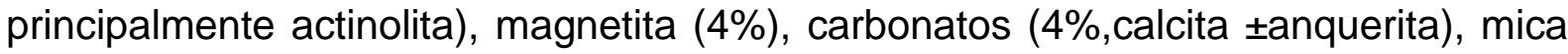
(3\%) apatita (2\%), e epídoto (1\%). Outros minerais acessórios (inferiores a 1\%) são: piroxênio, escapolita, titanita, rutilo, zircão, alanita, monazita, ilmenita, thorita e uraninita. 
Os conteúdos de calcopirita variam de 1 a 3\%, elevando-se progressivamente em direção aos finos; a pirita representa cerca de 0,1\% da amostra, enquanto que os outros sulfetos (calcocita, milerita e siegenita) perfazem menos de $0,1 \%$ do total.

O conteúdo de quartzo está compreendido entre 26 e 34\%, com tendência a diminuir em direção aos finos. A proporção de plagioclásio (principalmente albita e secundariamente plagioclásio sódico com cálcio) situa-se entre 21 a $28 \%$ e o Kfeldspato entre 8 e 11\%; ambos diminuem progressivamente em direção às frações mais finas.

As proporções de clorita (Fe-clinocloro), anfibólio (actinolita e secundariamente hastingsita), magnetita, carbonato (calcita, além de anquerita) e apatita aumentam em direção aos finos, variando de 8 a 13\% (clorita), 4 a 7\% (anfibólio), 3 a 6\% (magnetita) e 3 a 7\% (carbonato) e 1 a 3\% (apatita). A quantidade de mica (biotita/flogopita e muscovita) e epídoto permance constante nas frações: 3 e $1 \%$ respectivamente.

Os difratogramas interpretados de amostras representativas deste cluster são apresentados no anexo 2. Os teores médios considerados para as composições dos minerais presentes e respectivas massas específicas são expostos nos anexos 3 (banco de dados do MLA), bem como a comparação entre as composições químicas dosadas por FRX e as calculadas a partir do MLA, indicando elevadas correlações e validando os resultados da análise de imagens (anexo 4).

\subsubsection{Partição do Cu e S}

As distribuições Cu e S dentre os minerais portadores de S é apresentada na Tabela 17.

O cobre está presente quase que em sua totalidade na forma de calcopirita (96\%), sendo o restante referente ao cobre da calcocita. O enxofre está presente em sua maioria na calcopirita (95\%) e na pirita (4\%); a parcela de enxofre nos demais minerais portadores (calcocita, milerita e siegenita) perfaz cerca de $1 \%$ do total presente na amostra. 
Tabela 17 - Distribuições de Cu e S dentre os minerais portadores de S cluster B

\begin{tabular}{|c|c|c|c|c|c|c|}
\hline & \multirow{2}{*}{ Fração } & \multicolumn{5}{|c|}{ Distribuição (\%) } \\
\hline & & calcopirita & calcocita & pirita & milerita & siegenita \\
\hline \multirow{7}{*}{$\mathrm{Cu}$} & $+0,210$ & 93,4 & 6,6 & - & - & - \\
\hline & $-0,210+0,150$ & 98,8 & 1,2 & - & - & - \\
\hline & $-0,150+0,074$ & 95,7 & 4,3 & - & - & - \\
\hline & $-0,074+0,037$ & 98,6 & 1,4 & - & - & - \\
\hline & $-0,037+0,020$ & 92,8 & 7,2 & - & - & - \\
\hline & $-0,020+0,010$ & 95,5 & 4,5 & - & - & - \\
\hline & Total $+\mathbf{0 , 0 1 0}$ & 96,3 & 3,7 & - & - & - \\
\hline \multirow{7}{*}{ S } & $+0,210$ & 89,8 & 1,6 & 8,7 & - & - \\
\hline & $-0,210+0,150$ & 91,7 & 0,3 & 8,0 & - & - \\
\hline & $-0,150+0,074$ & 96,0 & 1,1 & 2,9 & - & - \\
\hline & $-0,074+0,037$ & 97,8 & 0,3 & 1,9 & - & - \\
\hline & $-0,037+0,020$ & 95,7 & 1,8 & 2,3 & - & 0,2 \\
\hline & $-0,020+0,010$ & 95,8 & 1,1 & 2,8 & - & 0,3 \\
\hline & Total $+\mathbf{0 , 1 0}$ & 95,2 & 0,9 & 3,8 & - & 0,1 \\
\hline
\end{tabular}

\subsubsection{Caracterização microestrutural}

Os principais aspectos texturais da calcopirita observados sob microscopia óptica de luz refletida, em relação à sua forma de ocorrência e associações com a ganga presente, são ilustrados na Fotomicrografia 9 e Fotomicrografia 10.

$\mathrm{Na}$ primeira imagem é apresentado um aspecto geral da fração $0,21+0,15$ $\mathrm{mm}$, onde nota-se a presença dos minerais opacos: essencialmente magnetita (cinza claro) e calcopirita (levemente amarelado).

A calcopirita ocorre tanto na forma de microcristais inclusos nos minerais de ganga quanto como cristais maiores. Detalhes destas texturas podem ser mais bem observados na Fotomicrografia 10.

Os mesmos aspectos texturais podem ser observados na Fotomicrografia $11 \mathrm{e}$ na Fotomicrografia 12, obtidas em microscópio eletrônico de varredura (MEV). 


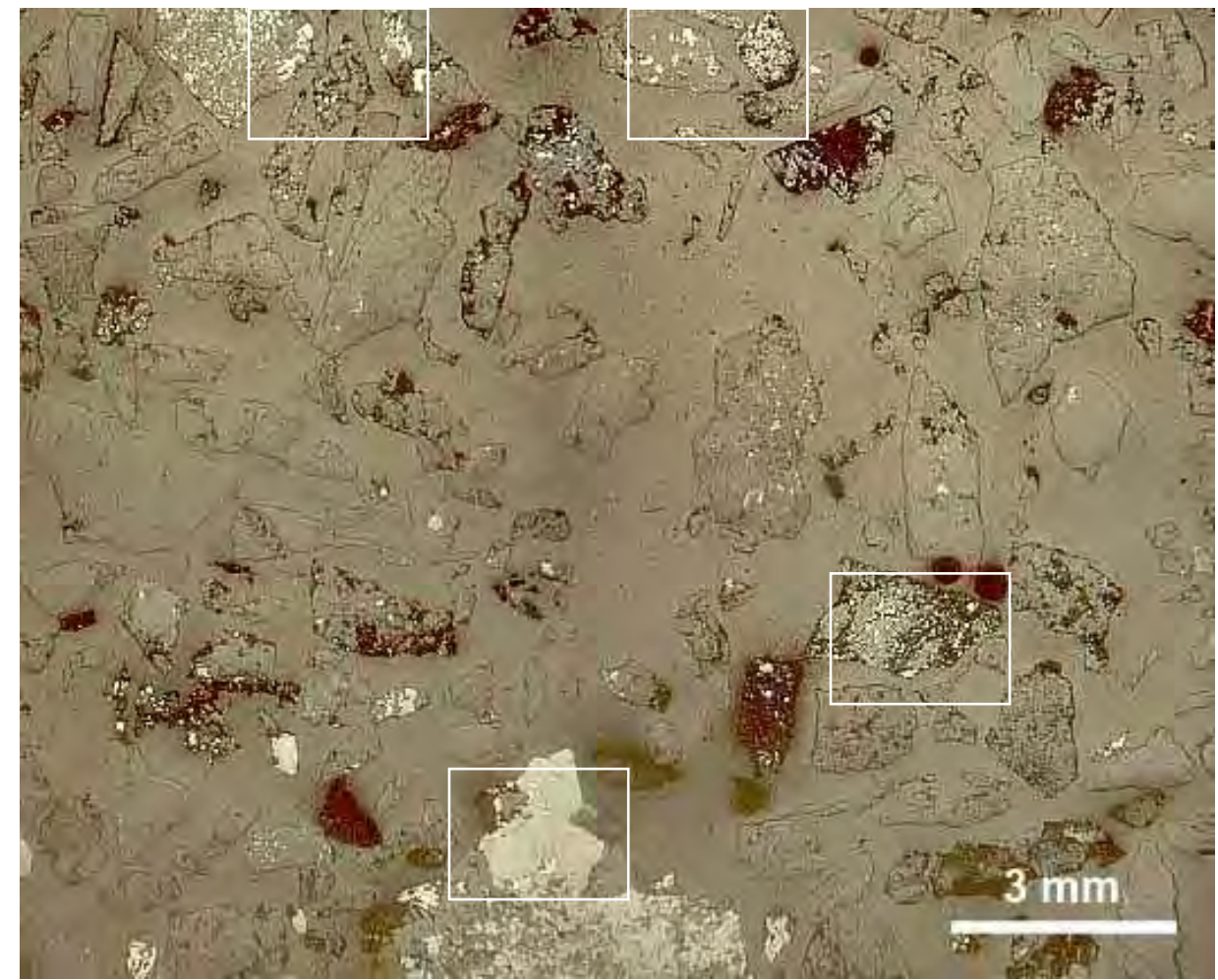

\section{Fotomicrografia 9 - MO, cluster $B$, fração $-0,21+0,15$ mm}

Aspecto geral da amostra Cluster B. Os minerais opacos são essencialmente magnetita, calcopirita e pirita.
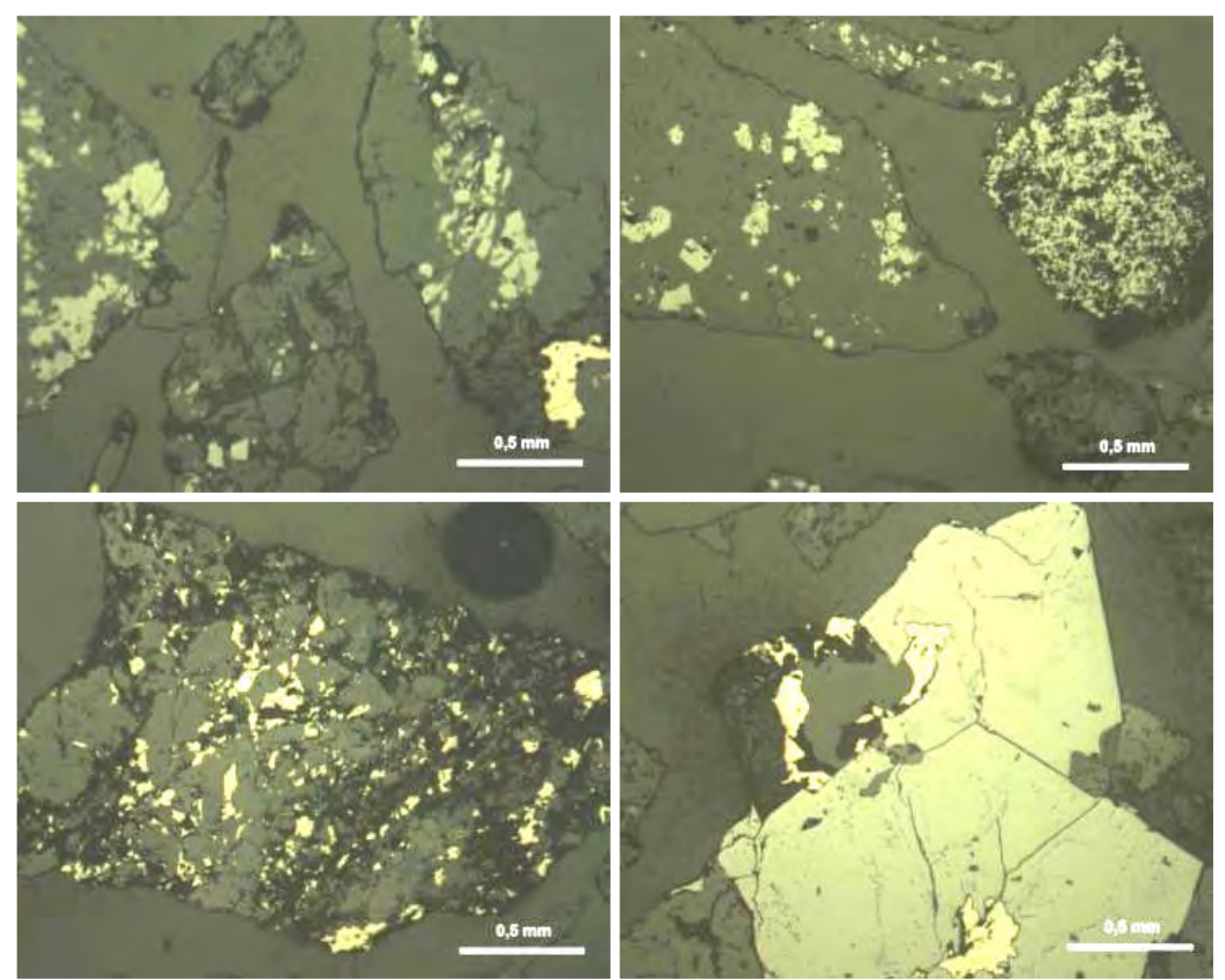

Fotomicrografia 10 - MO, cluster $B$, fração -0,21+0,15 mm

Detalhe das partículas com calcopirita disseminada (a), (b) e (c) e cristais maiores (d). 


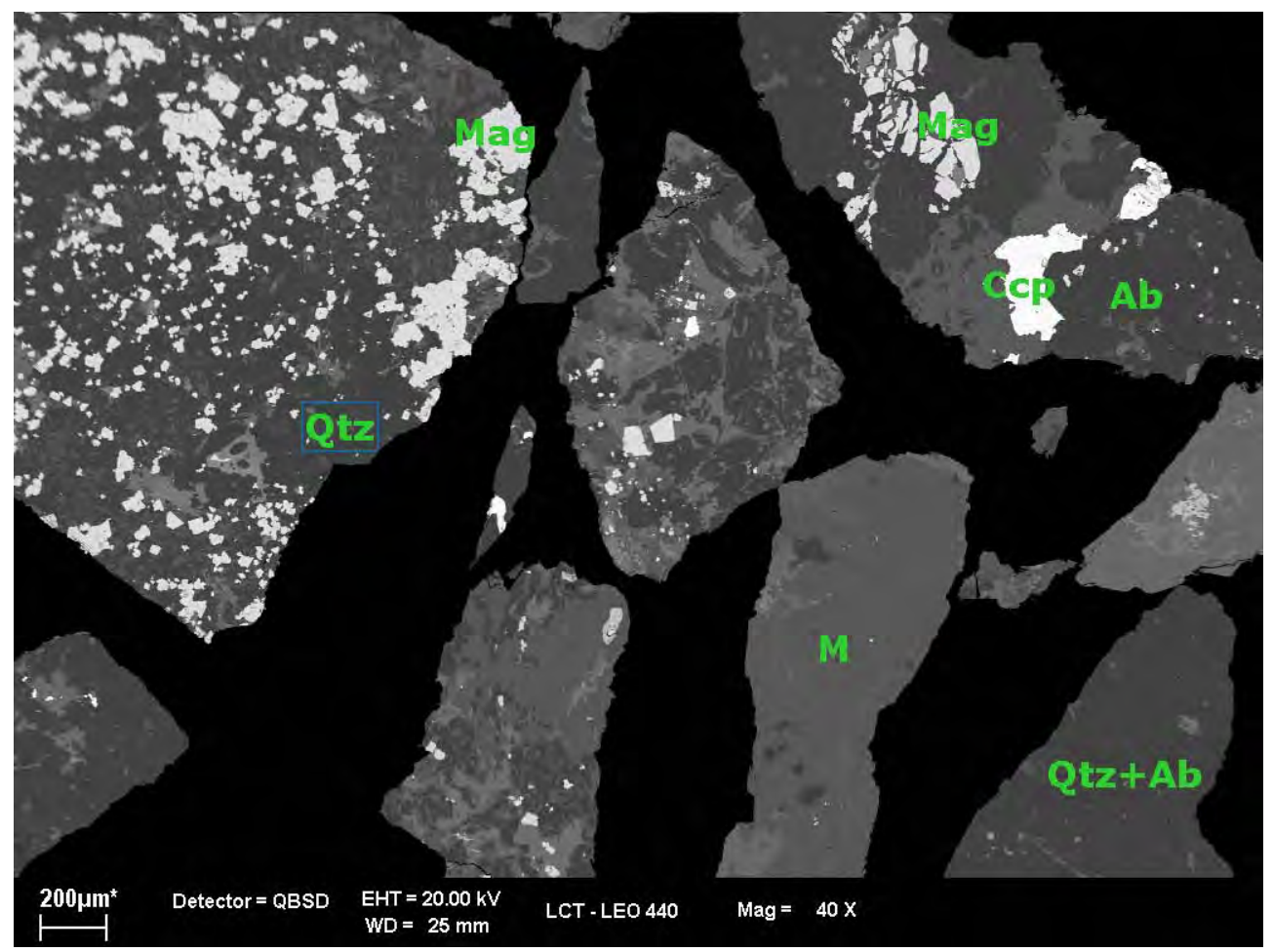

Fotomicrografia 11 - MEV, cluster B, fração -0,21+0,15 mm

Aspecto textural da calcopirita: cristais de calcopirita e sua associação com a ganga.

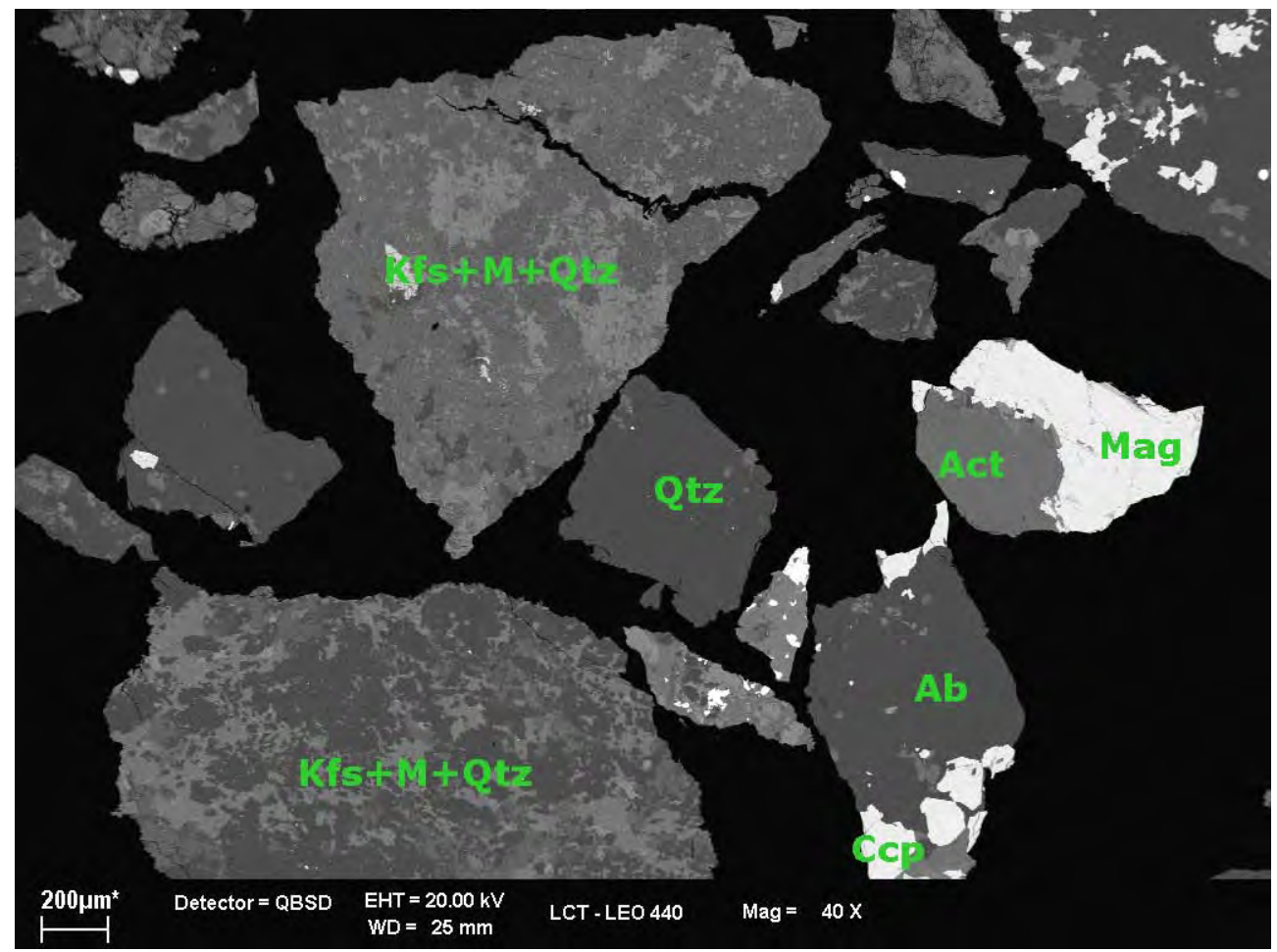

Fotomicrografia 12 - MEV, cluster B, fração -0,21+0,15 mm

Cristais de calcopirita maiores (em relação à forma disseminada). 


\subsubsection{Características da calcopirita}

A caracterização das principais associações da calcopirita foi efetuada por microscopia eletrônica de varredura MEV/EDS aliada ao sistema de análise de imagens Mineral Liberation Analyser (MLA).

A Figura 34 e a Tabela 18 apresentam a distribuição das formas de associação da calcopirita (\% em massa), entre partículas livres (>95\% do mineral de interesse), mistas em partículas binárias (2 fases minerais) e mistas em partículas ternárias (3 ou mais fases), para as frações acima de 0,010 mm.

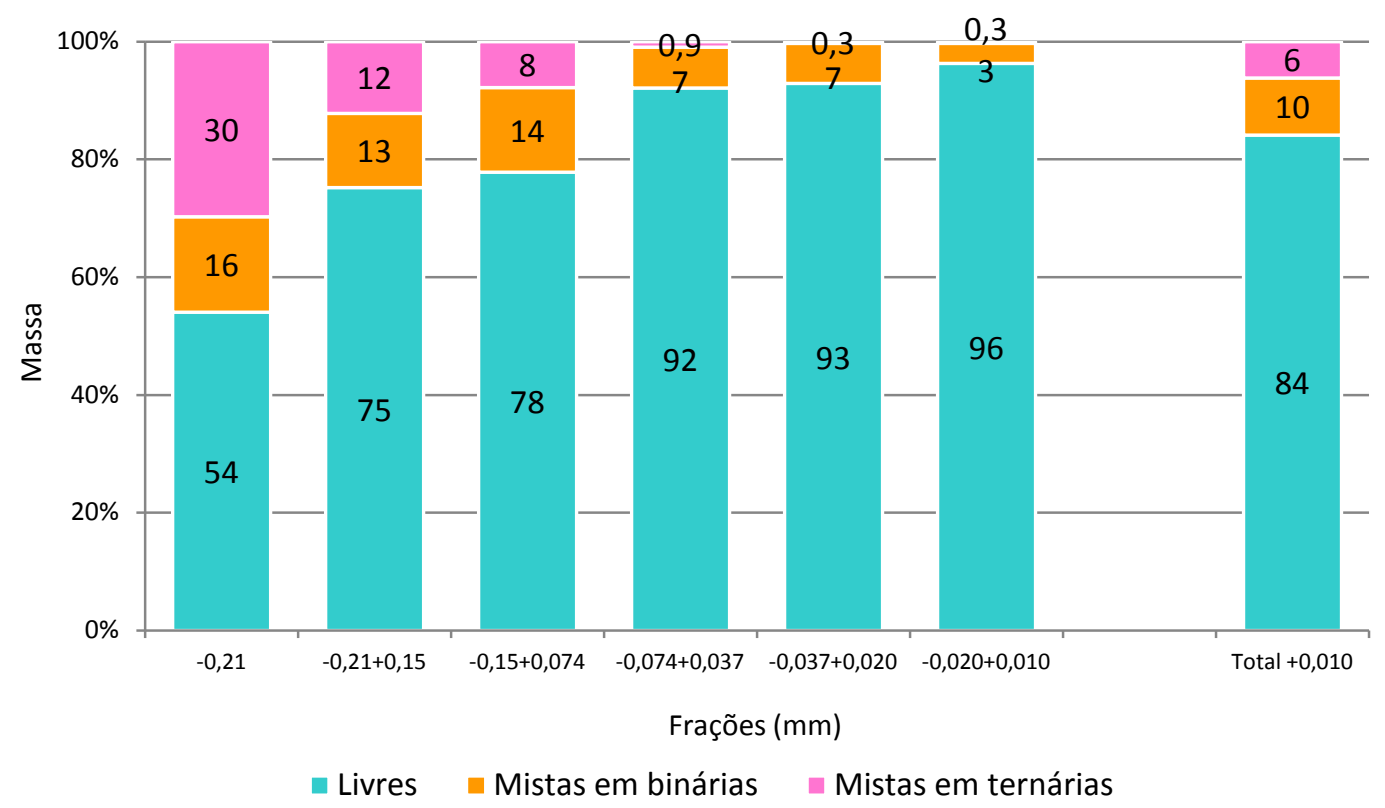

Figura 34 - Distribuição das formas de associação da calcopirita por fração granulométrica - cluster B

A calcopirita apresenta liberação global de 84\%, variando de 54 a $96 \%$ nas frações, aumentando progressivamente em direção aos finos. Abaixo de 0,074 mm, quando atinge liberação acima de 90\%, a calcopirita mista ocorre principalmente na forma de partículas binárias, que perfazem de 3 a $7 \%$ da fração. Nas partículas binárias a calcopirita ocorre associada principalmente com a clorita, quartzo e magnetita. 
Tabela 18 - Distribuição das formas de associação da calcopirita (\% em massa)

\begin{tabular}{cccc}
\hline Fração $(\mathbf{m m})$ & \multicolumn{3}{c}{ Sumário da distribuição da calcopirita (\% em massa) } \\
Mista em binárias & Mista em ternárias \\
\hline$+0,210$ & $\mathbf{5 4}$ & 16 & 30 \\
$-0,210+0,150$ & $\mathbf{7 5}$ & 13 & 12 \\
$-0,150+0,074$ & $\mathbf{7 8}$ & 14 & 8 \\
$-0,074+0,037$ & $\mathbf{9 2}$ & 7 & 1 \\
$-0,037+0,020$ & $\mathbf{9 3}$ & 7 & 0,3 \\
$-0,020+0,010$ & $\mathbf{9 6}$ & 3 & 0,3 \\
Total +0,010 & $\mathbf{8 4}$ & $\mathbf{1 0}$ & $\mathbf{6}$ \\
\hline
\end{tabular}

Associações da calcopirita em partículas binárias (\% em massa)

Fração $(\mathrm{mm})$ clorita quartzo apatita mag. plagio. carbon. K-felds. outros* Total

\begin{tabular}{cccccccccc}
\hline$+0,210$ & 4 & 4 & 1 & $\operatorname{tr}$ & 2 & 2 & 1 & 2 & 16 \\
$-0,210+0,150$ & 4 & 4 & $\operatorname{tr}$ & 2 & 1 & 1 & - & 1 & 13 \\
$-0,150+0,074$ & 6 & 2 & 1 & 2 & 1 & 1 & $\operatorname{tr}$ & 1 & 14 \\
$-0,074+0,037$ & 2 & 1 & $\operatorname{tr}$ & 2 & $\operatorname{tr}$ & 1 & 1 & $\operatorname{tr}$ & 7 \\
$-0,037+0,020$ & 2 & $\operatorname{tr}$ & 1 & 1 & $\operatorname{tr}$ & $\operatorname{tr}$ & 1 & 2 & 7 \\
$-0,020+0,010$ & $\operatorname{tr}$ & $\operatorname{tr}$ & 1 & 1 & 1 & - & $\operatorname{tr}$ & $\operatorname{tr}$ & 3 \\
Total +0,010 & $\mathbf{3}$ & $\mathbf{2}$ & $\mathbf{1}$ & $\mathbf{2}$ & $\mathbf{1}$ & $\mathbf{1}$ & $\operatorname{tr}$ & $\mathbf{1}$ & $\mathbf{1 0}$ \\
\hline
\end{tabular}

Associações da calcopirita em partículas ternárias (\% em massa)

Fração $(\mathrm{mm})$ clorita quartzo apatita mag. plagio. carbon. K-felds. outros* Total

\begin{tabular}{cccccccccc}
\hline$+0,210$ & 5 & 6 & 4 & 1 & 4 & 1 & 3 & 7 & 30 \\
$-0,210+0,150$ & 2 & 1 & 1 & 1 & 2 & 1 & 2 & 2 & 12 \\
$-0,150+0,074$ & 1 & 1 & 1 & 1 & 1 & 1 & 1 & 1 & 8 \\
$-0,074+0,037$ & $\operatorname{tr}$ & $\operatorname{tr}$ & - & - & $\operatorname{tr}$ & - & - & $\operatorname{tr}$ & 1 \\
$-0,037+0,020$ & $\operatorname{tr}$ & - & - & - & - & - & - & $\operatorname{tr}$ & $\operatorname{tr}$ \\
$-0,020+0,010$ & - & - & - & $\operatorname{tr}$ & $\operatorname{tr}$ & - & - & $\operatorname{tr}$ & $\operatorname{tr}$ \\
Total $+\mathbf{0}, \mathbf{0 1 0}$ & $\mathbf{1}$ & $\mathbf{1}$ & $\mathbf{1}$ & $\operatorname{tr}$ & $\mathbf{1}$ & $\mathbf{1}$ & $\mathbf{1}$ & $\mathbf{1}$ & $\mathbf{6}$ \\
\hline
\end{tabular}

Notas: 1. abreviaturas: $m a g=$ magnetita; plagioc $=$ plagioclásio, carbon=carbonatos, $\boldsymbol{K}$-felds $=\boldsymbol{K}$-feldspato

2. $\left({ }^{*}\right)=$ outros minerais presentes

$3, \mathrm{tr}=$ fases com até $0,5 \%$ em massa

A partir das imagens digitais (MLA) calcula-se a fração de mineral útil para cada partícula, bem como a sua respectiva área ou perímetro exposto. O processamento desses dados permite determinar a distribuição em frequência do mineral de interesse segundo sua área ou superfície nas partículas. As curvas de espectro de liberação da calcopirita considerando as frações em área e em 
"superfície livre" (parcela de calcopirita exposta no perímetro de cada partícula) são apresentadas respectivamente na Figura 35 e na Figura 36.

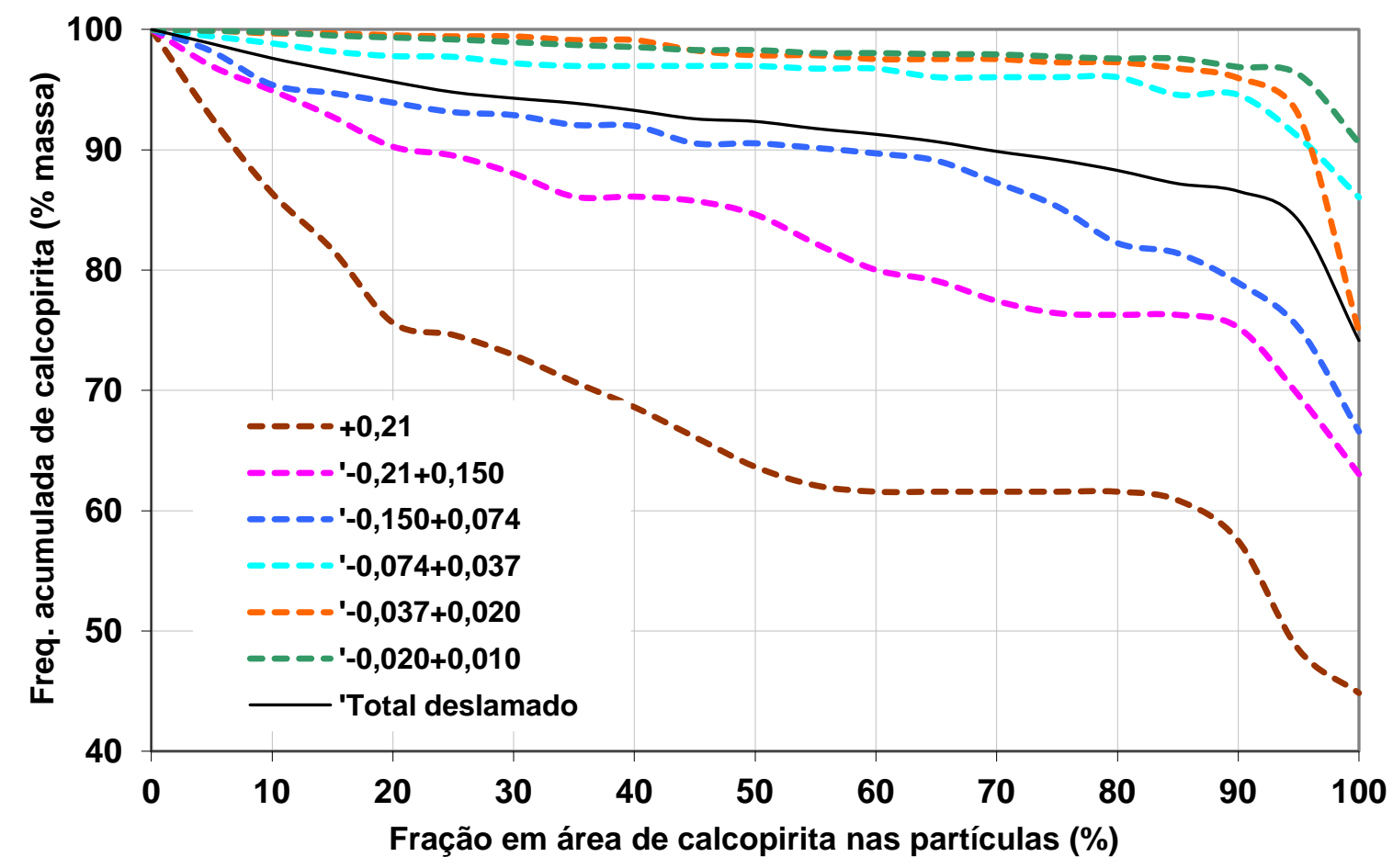

Figura 35 - Espectro de liberação da calcopirita em área - cluster B

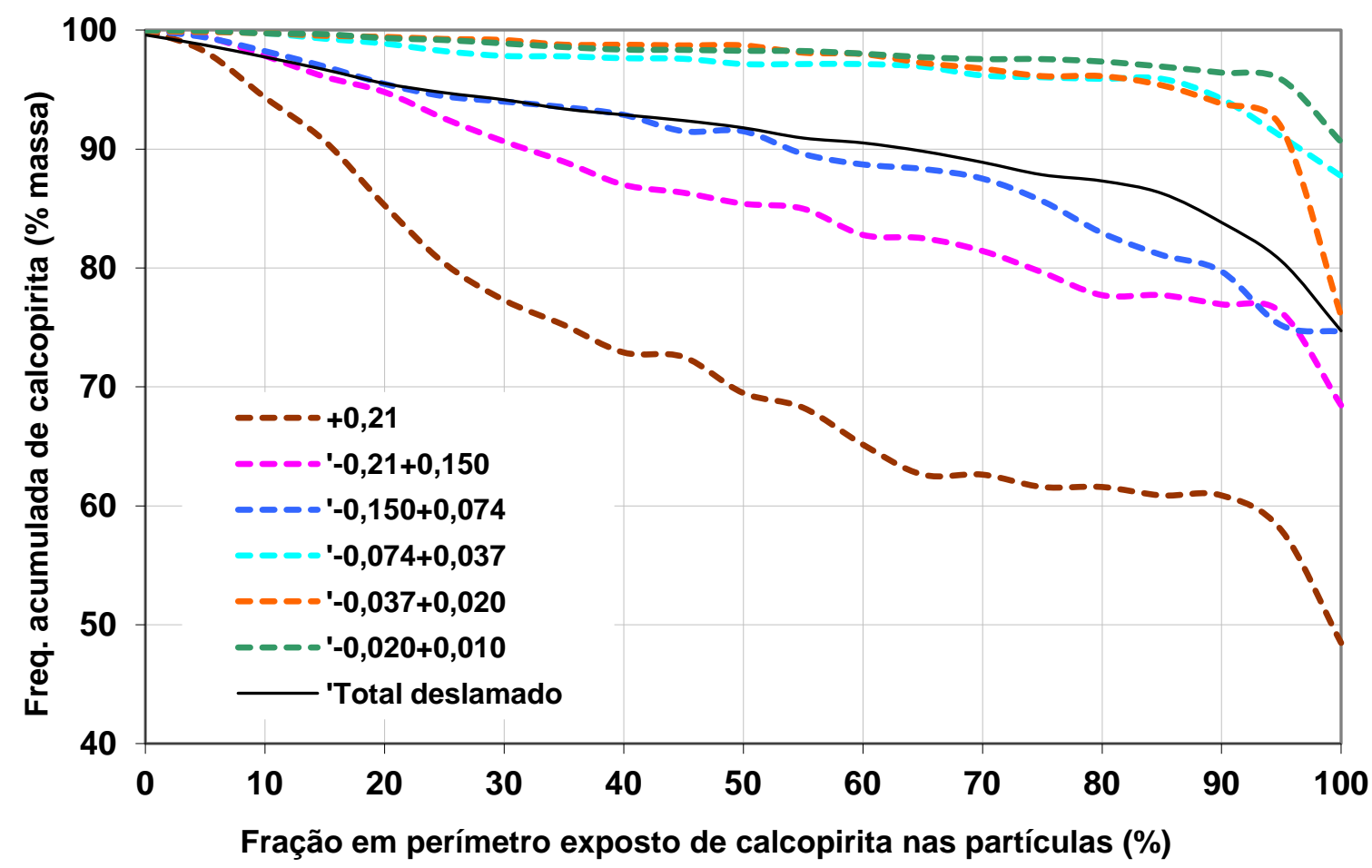

Figura 36 - Espectro de liberação da calcopirita em perímetro exposto - cluster B 
A Tabela 19 apresenta os valores de liberação considerando como partícula liberada aquelas com no mínimo 85\%, 90\%, 95\% e 100\% de calcopirita (valores extraídos das curvas de espectro de liberação do total deslamado, em termos de porcentagem em área e em superfície exposta).

Tabela 19 - Grau de liberação da calcopirita - cluster B

\begin{tabular}{ccccc}
\hline Fração de mineral útil na partícula (\%) & $\geq 85$ & $\geq 90$ & $\geq 95$ & 100 \\
\hline Grau de liberação da calcopirita (\% em área) & 87 & 86 & 84 & 74 \\
Grau de liberação da calcopirita (\% em perímetro exposto) & 86 & 84 & 81 & 74 \\
\hline
\end{tabular}

\subsubsection{Curvas de distribuição versus teores de cobre}

A curva de recuperação versus teor de Cu (obtida nos estudos de MLA) para o material acumulado acima de 0,10 mm, no intervalo considerado, é apresentada na Figura 37. Os estudos mostram que, teoricamente, nas condições de moagem empregadas para um teor entre 13 e 17\% de Cu (valores típicos dos produtos da etapa rougher segundo Bergeman 2009), seria possível recuperar mais de 99\% do total de Cu já na granulometria de moagem da etapa rougher de flotação.

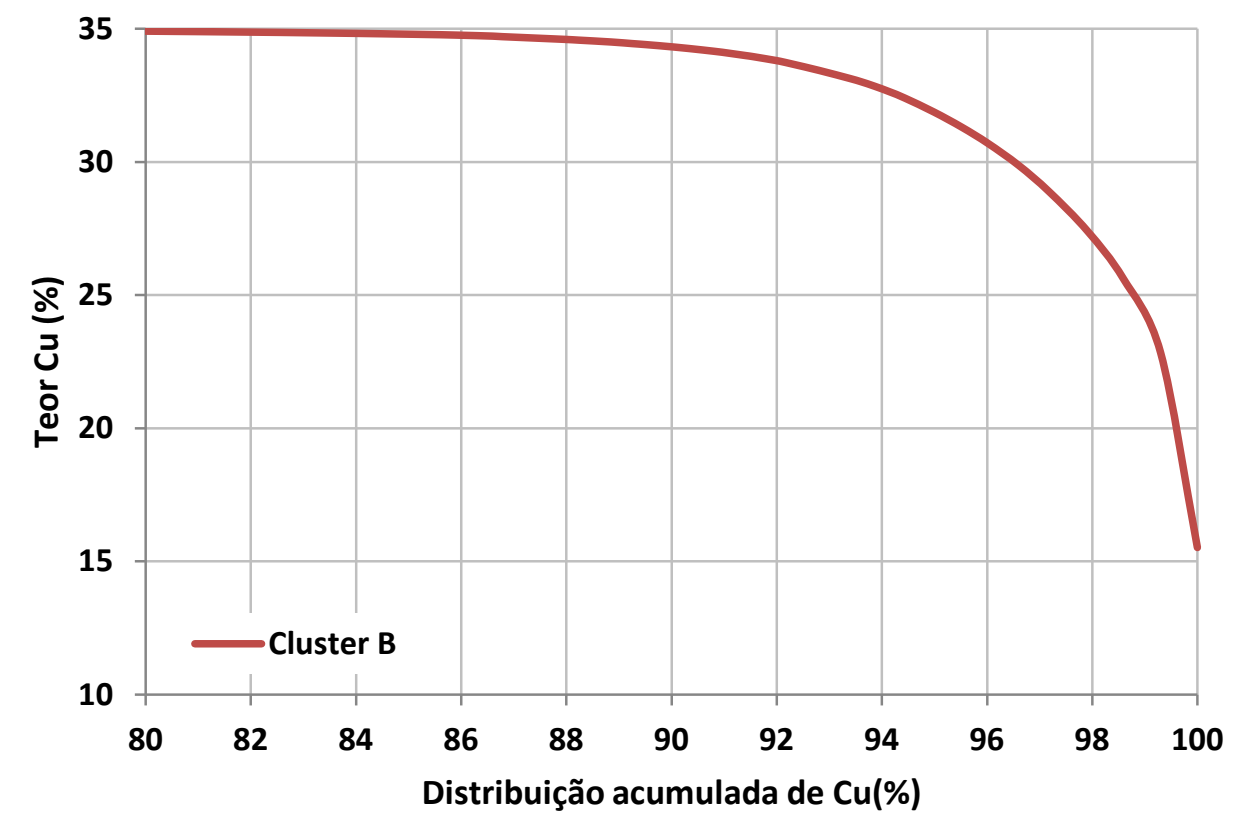

Figura 37 - Curva de distribuição acumulada de $\mathrm{Cu}$ versus teor de $\mathrm{Cu}$ - cluster $B$, total acima de $0,010 \mathrm{~mm}$ 


\subsubsection{Cluster C - Sossego}

\subsubsection{Distribuição dos elementos por fração}

A distribuição de teores por fração granulométrica para o cluster C é exposta na Tabela 20.

\section{Tabela 20 - Resultados de análise granuloquímica - cluster C}

\begin{tabular}{|c|c|c|c|c|c|c|c|c|c|c|c|c|c|c|c|c|c|c|c|c|}
\hline \multirow{2}{*}{$\begin{array}{c}\text { Fração } \\
\text { mm }\end{array}$} & \multirow{2}{*}{\multicolumn{2}{|c|}{$\begin{array}{c}\text { ‘\% massa } \\
\text { retida acum. }\end{array}$}} & \multirow[b]{2}{*}{$\mathrm{Cu}$} & \multicolumn{11}{|c|}{ Teores (\% em massa) } & \multicolumn{6}{|c|}{ Distribuição no ensaio (\%) } \\
\hline & & & & $\mathbf{S}$ & $\mathrm{SiO}_{2}$ & $\mathrm{Fe}_{2} \mathrm{O}_{3}$ & $\mathrm{Al}_{2} \mathrm{O}_{3}$ & $\mathrm{CaO}$ & MgO & $\mathrm{Na}_{2} \mathrm{O}$ & $\mathrm{K}_{2} \mathrm{O}$ & $\mathrm{TiO}_{2}$ & $\mathrm{P}_{2} \mathrm{O}_{5}$ & PF & $\mathrm{Cu}$ & $\mathbf{S}$ & $\mathrm{SiO}_{2}$ & $\mathrm{Fe}_{2} \mathrm{O}_{3}$ & $\mathrm{Al}_{2} \mathrm{O}_{3}$ & $\mathrm{CaO}$ \\
\hline$+0,210$ & 17,2 & 17,2 & 0,88 & 0,93 & 54,6 & 15,6 & 6,81 & 5,76 & 4,49 & 0,98 & 1,46 & 0,40 & 1,12 & 6,38 & 13,0 & 13,3 & 18,8 & 14,9 & 18,0 & 14,3 \\
\hline$-0,210+0,150$ & 14,2 & 31,4 & 1,20 & 1,31 & 52,1 & 16,7 & 6,48 & 6,26 & 4,48 & 0,94 & 1,32 & 0,38 & 1,35 & 6,72 & 14,6 & 15,4 & 14,8 & 13,2 & 14,1 & 12,8 \\
\hline$-0,150+0,074$ & 23,4 & 54,8 & 1,37 & 1,48 & 50,1 & 17,7 & 6,25 & 6,90 & 4,47 & 0,84 & 1,29 & 0,40 & 1,58 & 6,80 & 27,5 & 28,8 & 23,5 & 23,0 & 22,4 & 23,3 \\
\hline$-0,074+0,037$ & 18,2 & 73,0 & 1,42 & 1,54 & 47,1 & 19,9 & 6,26 & 6,93 & 4,79 & 0,72 & 1,20 & 0,38 & 1,62 & 7,22 & 22,2 & 23,3 & 17,2 & 20,2 & 17,5 & 18,2 \\
\hline$-0,037+0,020$ & 7,9 & 80,9 & 1,27 & 1,34 & 45,3 & 21,0 & 6,53 & 7,05 & 5,33 & 0,63 & 1,27 & 0,40 & 1,50 & 7,45 & 8,6 & 8,8 & 7,2 & 9,3 & 7,9 & 8,1 \\
\hline under & 8,6 & 89,5 & 1,15 & 0,79 & 47,6 & 22,0 & 5,97 & 8,31 & 4,82 & 0,72 & 1,21 & 0,46 & 1,65 & 4,73 & 8,5 & 5,7 & 8,2 & 10,6 & 7,9 & 10,3 \\
\hline over & 10,5 & 100,0 & 0,62 & 0,54 & 48,7 & 14,9 & 7,58 & 8,57 & 6,16 & 0,87 & 1,39 & 0,40 & 1,18 & 8,38 & 5,6 & 4,7 & 10,3 & 8,7 & 12,2 & 13,0 \\
\hline Total calc. & 100 & & 1,17 & 1,21 & 49,7 & 18,0 & 6,51 & 6,94 & 4,82 & 0,83 & 1,31 & 0,40 & 1,44 & 6,84 & 100 & 100 & 100 & 100 & 100 & 100 \\
\hline Total dos. & 100 & & 1,23 & 1,30 & 49,3 & 18,5 & 6,26 & 6,73 & 4,60 & 0,82 & 1,34 & 0,40 & 1,37 & 7,34 & & & & & & \\
\hline
\end{tabular}

A análise granulométrica do cluster C indica que cerca de $17 \%$ em massa estão retidos em 0,21 mm, enquanto que $19 \%$ constituem material abaixo de 0,020 $\mathrm{mm}$, para as condições de moagem empregadas.

Os teores de Cu variam de 0,62 e 1,42\% e os de S encontram-se entre 0,54 e 1,54\%. Ambos apresentam tendência semelhante, aumentando progressivamente até o intervalo $+0,037 \mathrm{~mm}$, a partir do qual ocorre decréscimo.

Os teores de $\mathrm{SiO}_{2}$ variam de 45,3 a 54,6\%, com teor médio de 49\%. Os teores de $\mathrm{Fe}_{2} \mathrm{O}_{3}$ situam-se entre 14,9 e 22,0\%, e os de $\mathrm{Al}_{2} \mathrm{O}_{3}$, entre 5,53 e 7,58\%. Ainda permanecem cerca de $7 \%$ de $\mathrm{CaO}$ e $5 \%$ de $\mathrm{MgO}$, além de $0,8 \%$ de $\mathrm{Na}_{2} \mathrm{O}, 1,3 \%$ de $\mathrm{K}_{2} \mathrm{O}(1 \%), 0,4 \%$ de $\mathrm{TiO}_{2}$ e $1,4 \%$ de $\mathrm{P}_{2} \mathrm{O}_{5}$. 


\subsubsection{Composição mineralógica por fração granulométrica (MLA)}

A composição mineralógica das frações acima de $0,010 \mathrm{~mm}$, calculada através do sistema de análise de imagens Mineral Liberation Analyser (MLA-FEI), está exposta na Tabela 21.

Tabela 21 - Composição mineralógica por fração granulométrica (MLA) cluster C

\begin{tabular}{|c|c|c|c|c|c|c|c|}
\hline \multirow[b]{2}{*}{ Minerais } & \multicolumn{7}{|c|}{ Fração $(\mathrm{mm})$ - \% em massa } \\
\hline & $+0,210$ & $\begin{array}{r}-0,210 \\
+0,150\end{array}$ & $\begin{array}{r}-0,150 \\
+0,074\end{array}$ & $\begin{array}{r}-0,074 \\
+0,037\end{array}$ & $\begin{array}{r}-0.037 \\
+0,020\end{array}$ & $\begin{array}{r}-0,020 \\
+0,010\end{array}$ & $\begin{array}{c}\text { Total } \\
+0,010\end{array}$ \\
\hline calcopirita & 2,7 & 3,4 & 4,3 & 5,1 & 3,6 & 3,8 & 3,9 \\
\hline pirita & $<0,1$ & - & $<0,1$ & - & - & $<0,1$ & $<0,1$ \\
\hline outros sulfetos & - & - & - & - & - & - & - \\
\hline quartzo & 33 & 32 & 29 & 27 & 22 & 23 & 29 \\
\hline clorita & 15 & 15 & 16 & 16 & 17 & 16 & 16 \\
\hline magnetita & 8 & 9 & 12 & 12 & 18 & 14 & 12 \\
\hline carbonatos & 7 & 9 & 9 & 9 & 10 & 11 & 9 \\
\hline mica & 8 & 8 & 7 & 8 & 10 & 11 & 8 \\
\hline plagioclásio & 7 & 7 & 6 & 6 & 5 & 5 & 6 \\
\hline K-feldspato & 6 & 6 & 5 & 5 & 3 & 4 & 5 \\
\hline anfibólio & 6 & 5 & 4 & 4 & 4 & 6 & 5 \\
\hline apatita & 2 & 2 & 3 & 4 & 3 & 3 & 3 \\
\hline epídoto & 1 & 1 & 1 & 1 & 1 & 1 & 1 \\
\hline outros & 3 & 3 & 3 & 3 & 3 & 3 & 3 \\
\hline
\end{tabular}

Considerando-se o intervalo granulométrico $+0,010 \mathrm{~mm}$, o cluster C é composto predominantemente por quartzo (29\%), clorita (16\%) e magnetita (12\%), além de carbonatos (9\%), micas (8\%), plagioclásio (6\%), K-feldspato (5\%), anfibólios (5\%), apatita (3\%) e epídoto (1\%). Os minerais traços (menos de 1\%) são: piroxênio, escapolita, titanita, rutilo, zircão, alanita, monazita, ilmenita, thorita e uraninita

Os conteúdos de calcopirita variam de 2,7 a 5,1\%. A pirita representa menos de $0,1 \%$ do total e os demais sulfetos (calcocita, milerita e siegenita) não foram encontrados nesta amostra. 
A proporção de quartzo situa-se entre 22 e 33\%, diminuindo progressivamente em direção aos finos. O conteúdo de clorita (Fe-clinocloro) permanece ao redor de $15-17 \%$ ao longo de todo intervalo granulométrico, enquanto que o de magnetita varia de 8 a 18\%, aumentando em direção às frações finas.

Os carbonatos (calcita e secundariamente anquerita) e micas (biotita/flogopita e muscovita) aumentam em direção aos finos, variando de 7 a 11\% (carbonatos) e 7 a 11\% (micas). Já os feldspatos decrescem nas frações mais finas, de 7 a 5\% (plagioclásio) e de 6 a 3\% (K-feldspato). O anfibólio e a apatita não apresentam tendência definida.

Os difratogramas interpretados de amostras representativas deste cluster são apresentados no anexo 2. Os teores médios considerados para as composições dos minerais presentes e respectivas massas específicas são expostos nos anexos 3 (banco de dados do MLA), bem como a comparação entre as composições químicas dosadas por FRX e as calculadas a partir do MLA, indicando elevadas correlações e validando os resultados da análise de imagens (anexo 4).

\subsubsection{Partição do Cu e S}

As distribuições Cu e S dentre os minerais portadores de S é apresentada na Tabela 22. No cluster C, o cobre está presente em sua totalidade na forma de calcopirita. Praticamente todo o enxofre da amostra está na forma de calcopirita (99\%) e o restante associado à pirita (<1\%). 
Tabela 22 - Distribuições de Cu e S dentre os minerais portadores de S cluster C

\begin{tabular}{|c|c|ccccc|}
\hline \multirow{4}{*}{ Fração } & \multicolumn{5}{c}{ Distribuição (\%) } & \\
& calcopirita & calcocita & pirita & milerita & siegenita \\
\hline \multirow{5}{*}{ Cu } & $+0,210$ & 100 & - & - & - & - \\
& $-0,210+0,150$ & 100 & - & - & - & - \\
& $-0,150+0,074$ & 100 & - & - & - & - \\
& $-0,074+0,037$ & 100 & - & - & - & - \\
& $-0,037+0,020$ & 100 & - & - & - & - \\
& $-0,020+0,010$ & 100 & - & - & - & - \\
& Total +0,010 & $\mathbf{1 0 0}$ & - & - & - & - \\
\hline \multirow{5}{*}{$\mathbf{S}$} & $+0,210$ & 97,3 & - & 2,7 & - & - \\
& $-0,210+0,150$ & 100 & - & - & - & - \\
& $-0,150+0,074$ & 98,9 & - & 1,1 & - & - \\
& $-0,074+0,037$ & 100,0 & - & - & - & - \\
& $-0,037+0,020$ & 100,0 & - & - & - & - \\
\hline
\end{tabular}

\subsubsection{Caracterização microestrutural da calcopirita}

Os principais aspectos texturais da calcopirita observados sob microscopia óptica de luz refletida, em relação à sua forma de ocorrência e associações com a ganga presente, são ilustrados na Fotomicrografia 13 e na Fotomicrografia 14.

$\mathrm{Na}$ primeira imagem é apresentado um aspecto geral da fração 0,21+0,15 $\mathrm{mm}$, onde nota-se a presença dos minerais opacos: essencialmente magnetita (cinza claro) e calcopirita (levemente amarelado).

A calcopirita ocorre tanto na forma de microcristais inclusos nos minerais de ganga quanto como cristais maiores. Detalhes destas texturas podem ser mais bem observados na Fotomicrografia 14.

Os mesmos aspectos texturais podem ser observados na Fotomicrografia 15 e na Fotomicrografia 16, obtidas em microscópio eletrônico de varredura (MEV). 


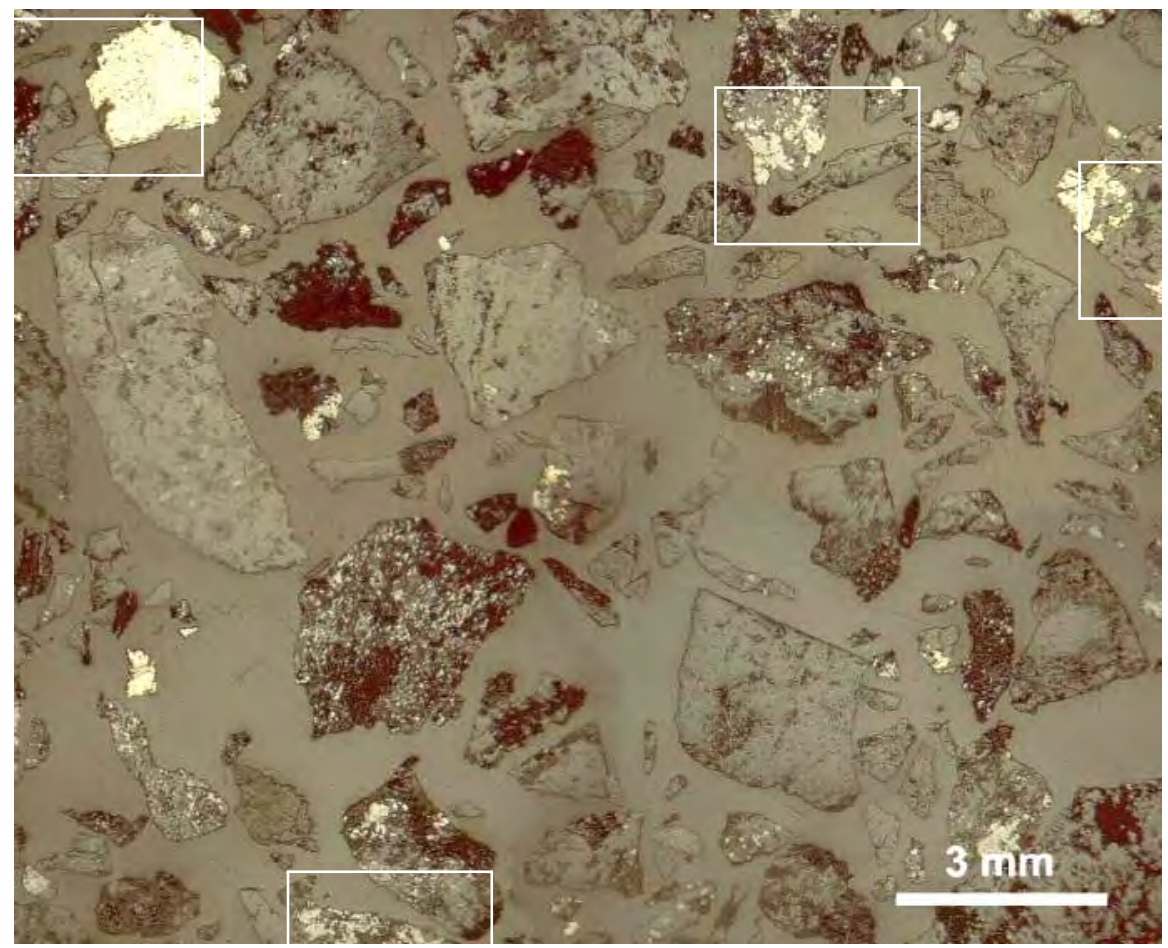

Fotomicrografia 13 - MO, cluster C, fração -0,21+0,15 mm

Aspecto geral da amostra cluster C. Os minerais opacos são essencialmente magnetita, calcopirita e pirita.
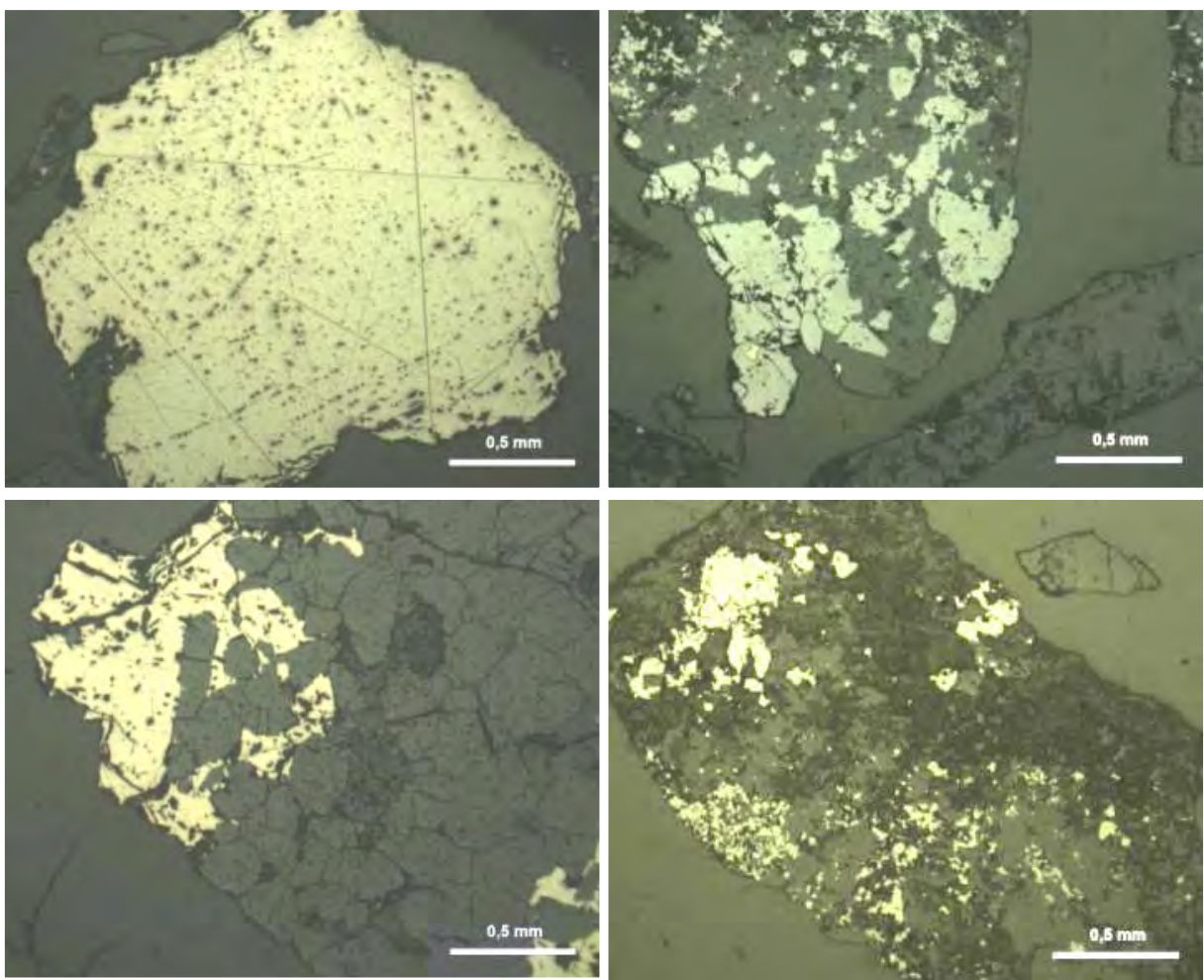

Fotomicrografia 14 - MO, cluster C, fração -0,21+0,15 mm

Detalhe de partículas com calcopirita disseminada (d), com cristais maiores (a) e (c). (d) Partícula com magnetita. 


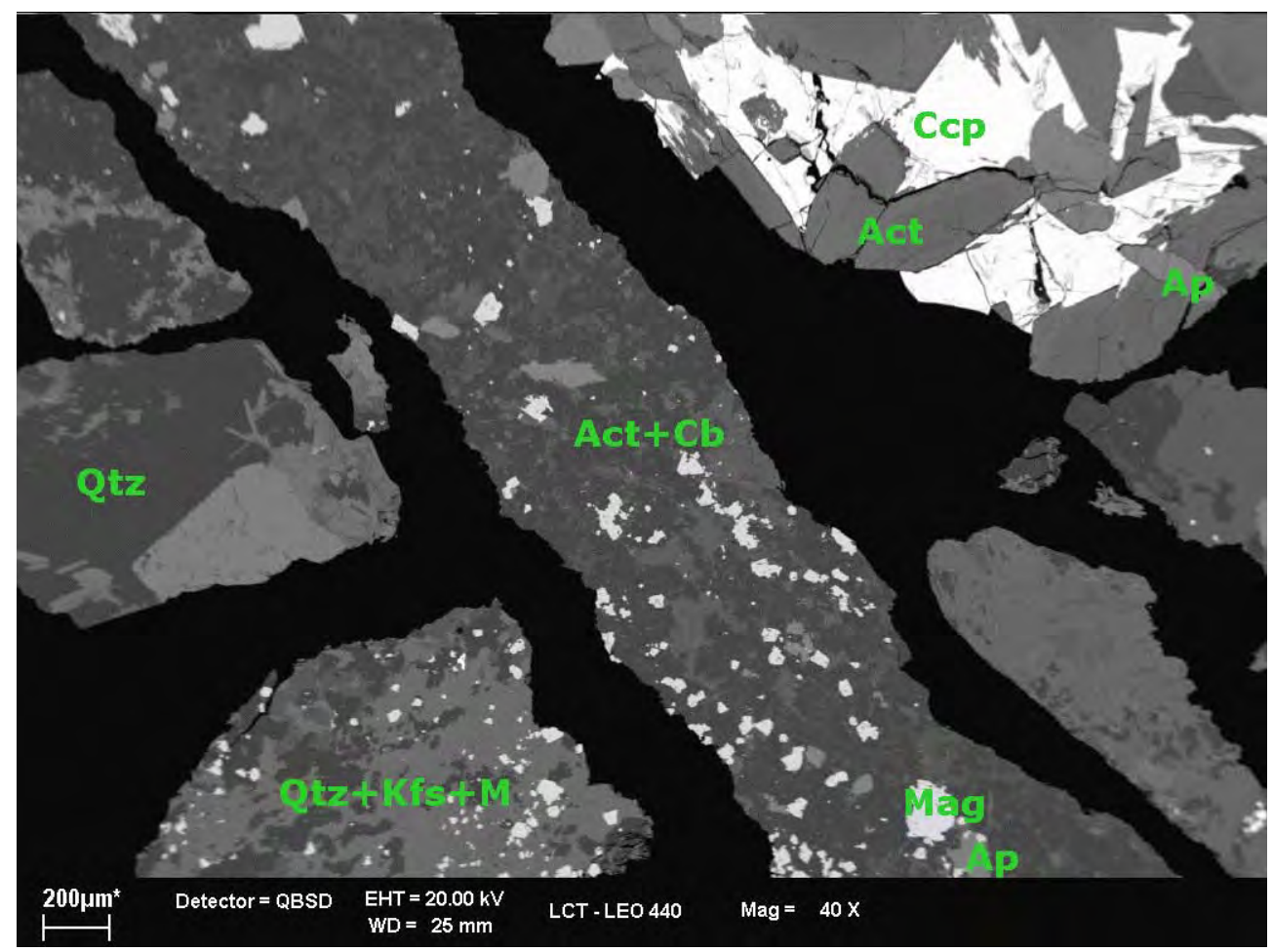

Fotomicrografia 15 - MEV, cluster C, fração -0,21+0,15 mm

Cristais de calcopirita maiores (em relação à forma disseminada), na partícula à direita.

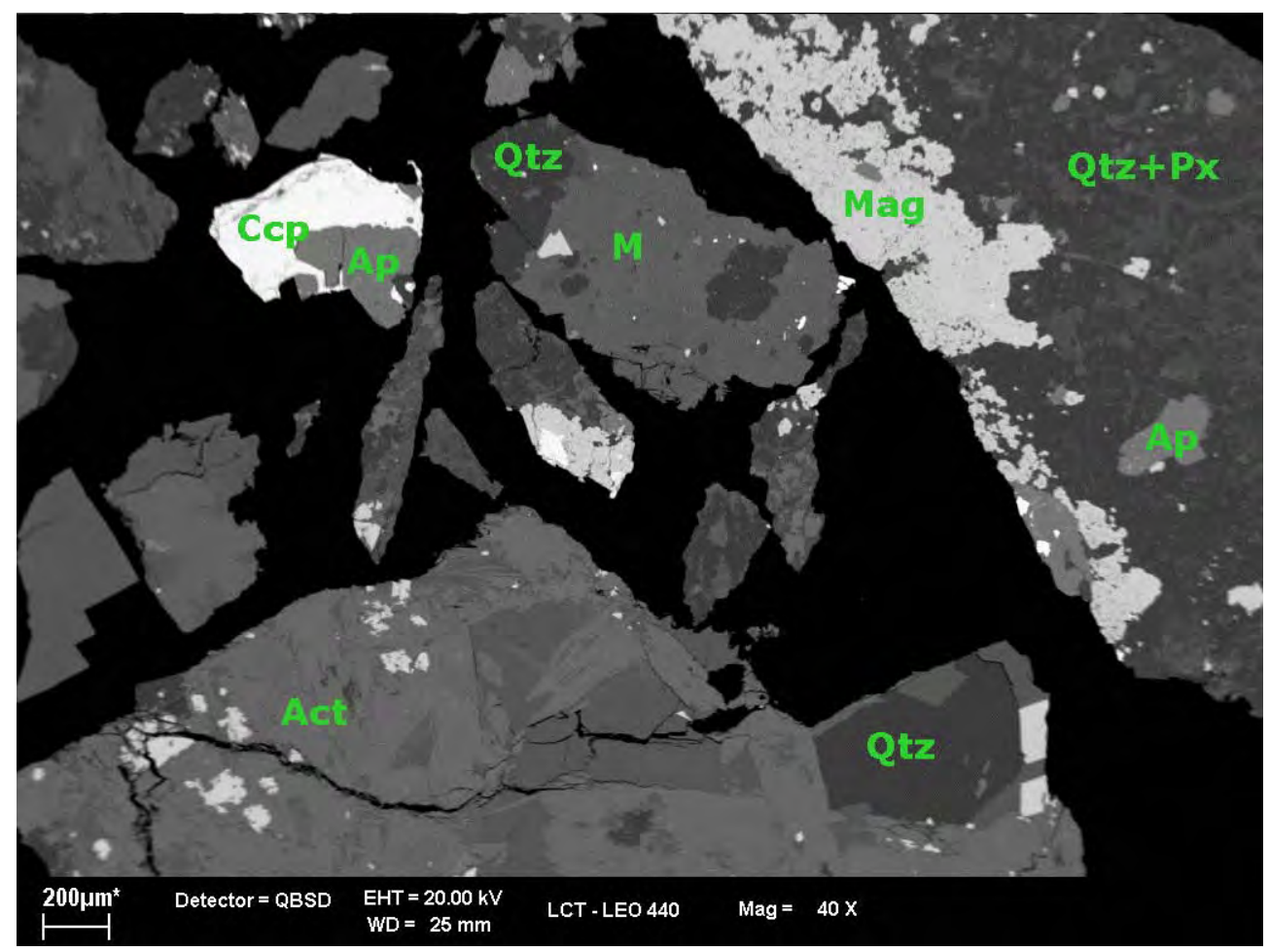

Fotomicrografia 16 - MEV, cluster C, fração -0,21+0,15 mm

Cristais de calcopirita maiores (em relação à forma disseminada). 


\subsubsection{Características da calcopirita}

A caracterização das principais associações da calcopirita foi efetuada por microscopia eletrônica de varredura MEV/EDS aliada ao sistema de análise de imagens Mineral Liberation Analyser (MLA).

A Figura 38 e a Tabela 23 apresentam a distribuição das formas de associação da calcopirita (\% em massa), entre partículas livres (>95\% do minerais de interesse), mistas em partículas binárias (2 fases minerais) e mistas em partículas ternárias (3 ou mais fases), para as frações acima de 0,010 mm.

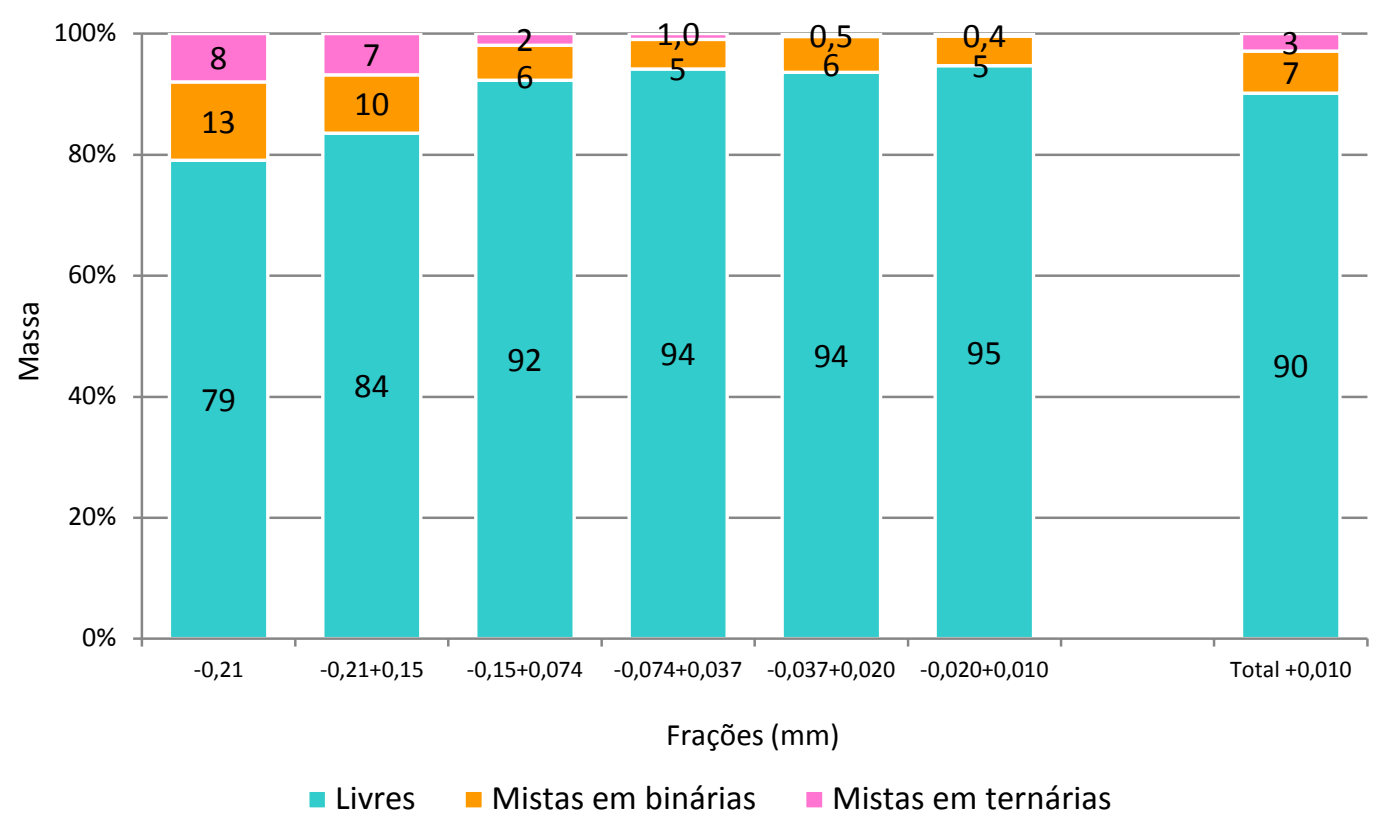

Figura 38 - Distribuição das formas de associação da calcopirita por fração granulométrica - cluster $\mathrm{C}$

A calcopirita apresenta liberação global de 90\%, variando de 79 a 95\% nas frações e aumentando progressivamente em direção aos finos. Abaixo de 0,150 mm, quando atinge liberação acima de 90\%, a calcopirita mista ocorre principalmente na forma de partículas binárias, que perfazem de 5 a $6 \%$ da fração, enquanto que as ternárias correspondem a 1\% ou menos do total. Nas partículas binárias a calcopirita ocorre associada principalmente com magnetita e clorita. 
Tabela 23 - Distribuição das formas de associação da calcopirita (\% em massa)

\begin{tabular}{|c|c|c|c|c|c|c|c|c|c|}
\hline \multirow{2}{*}{ Fração (mm) } & \multicolumn{9}{|c|}{ Sumário da distribuição da calcopirita (\% em massa) } \\
\hline & \multicolumn{3}{|c|}{ Livre } & \multicolumn{3}{|c|}{ Mista em binárias } & \multicolumn{3}{|c|}{ Mista em ternárias } \\
\hline$+0,210$ & \multicolumn{3}{|c|}{79} & \multicolumn{3}{|c|}{13} & \multicolumn{3}{|c|}{8} \\
\hline$-0,210+0,150$ & \multicolumn{3}{|c|}{84} & \multicolumn{3}{|c|}{10} & \multicolumn{3}{|c|}{7} \\
\hline$-0,150+0,074$ & \multicolumn{3}{|c|}{92} & \multicolumn{3}{|c|}{6} & \multicolumn{3}{|c|}{2} \\
\hline$-0,074+0,037$ & \multicolumn{3}{|c|}{94} & \multicolumn{3}{|c|}{5} & \multicolumn{3}{|c|}{1} \\
\hline$-0,037+0,020$ & \multicolumn{3}{|c|}{94} & \multicolumn{3}{|c|}{6} & \multicolumn{3}{|c|}{0,5} \\
\hline$-0,020+0,010$ & \multicolumn{3}{|c|}{95} & \multicolumn{3}{|c|}{5} & \multicolumn{3}{|c|}{0,4} \\
\hline Total $+0,010$ & \multicolumn{3}{|c|}{90} & \multicolumn{3}{|c|}{7} & \multicolumn{3}{|c|}{3} \\
\hline & \multicolumn{9}{|c|}{ Associações da calcopirita em partículas binárias (\% em massa) } \\
\hline Fração (mm) & mag. & clorita & pirox. & carbon. & quartzo & anfib. & apatita & outros* & Total \\
\hline$+0,210$ & 3 & 2 & 3 & 1 & 2 & $\operatorname{tr}$ & $\operatorname{tr}$ & 2 & 13 \\
\hline$-0,210+0,150$ & 2 & 2 & 3 & 2 & 1 & $\operatorname{tr}$ & 1 & - & 10 \\
\hline$-0,150+0,074$ & 2 & 1 & 1 & 1 & $\operatorname{tr}$ & $\operatorname{tr}$ & - & $\operatorname{tr}$ & 6 \\
\hline$-0,074+0,037$ & 2 & 2 & 1 & $\operatorname{tr}$ & 1 & - & - & $\operatorname{tr}$ & 5 \\
\hline$-0,037+0,020$ & 1 & 2 & 1 & - & 1 & 1 & - & 1 & 6 \\
\hline$-0,020+0,010$ & 1 & 1 & $\operatorname{tr}$ & 1 & 1 & $\operatorname{tr}$ & $\operatorname{tr}$ & 1 & 5 \\
\hline \multirow[t]{2}{*}{ Total $+0,010$} & 2 & 2 & 1 & 1 & 1 & $\operatorname{tr}$ & $\operatorname{tr}$ & $\operatorname{tr}$ & 7 \\
\hline & \multicolumn{9}{|c|}{ Associações da calcopirita em partículas ternárias (\% em massa) } \\
\hline Fração (mm) & mag. & clorita & pirox. & carbon. & quartzo & anfib. & apatita & outros* & Total \\
\hline$+0,210$ & 2 & 1 & $\operatorname{tr}$ & 1 & 2 & $\operatorname{tr}$ & 1 & 1 & 8 \\
\hline$-0,210+0,150$ & 1 & 1 & $\operatorname{tr}$ & 2 & 2 & 1 & $\operatorname{tr}$ & 1 & 7 \\
\hline$-0,150+0,074$ & $\operatorname{tr}$ & $\operatorname{tr}$ & $\operatorname{tr}$ & $\operatorname{tr}$ & 1 & - & - & 1 & 2 \\
\hline$-0,074+0,037$ & - & $\operatorname{tr}$ & - & $\operatorname{tr}$ & $\operatorname{tr}$ & - & - & $\operatorname{tr}$ & 1 \\
\hline$-0,037+0,020$ & - & $\operatorname{tr}$ & - & - & - & - & - & $\operatorname{tr}$ & 0,5 \\
\hline$-0,020+0,010$ & $\operatorname{tr}$ & $\operatorname{tr}$ & - & - & - & - & - & $\operatorname{tr}$ & 0,4 \\
\hline Total $+0,010$ & 1 & $\operatorname{tr}$ & $\operatorname{tr}$ & $\operatorname{tr}$ & 1 & $\operatorname{tr}$ & $\operatorname{tr}$ & $\operatorname{tr}$ & 3 \\
\hline
\end{tabular}

Notas: 1. abreviaturas: mag = magnetita, pirox. piroxênio, carbon = carbonatos e anfib = anfibólio

\footnotetext{
2. $\left(^{*}\right)=$ outros minerais presentes

3. $t r=$ fases com até $0,5 \%$ em massa
}

A partir das imagens digitais (MLA) calcula-se a fração de mineral útil para cada partícula, bem como a sua respectiva área ou perímetro exposto. O processamento desses dados permite determinar a distribuição em frequência do mineral de interesse segundo sua área ou superfície nas partículas. As curvas de espectro de liberação da calcopirita considerando as frações em área e em 
"superfície livre" (parcela de calcopirita exposta no perímetro de cada partícula). são apresentadas respectivamente na Figura 39 e na Figura 40.

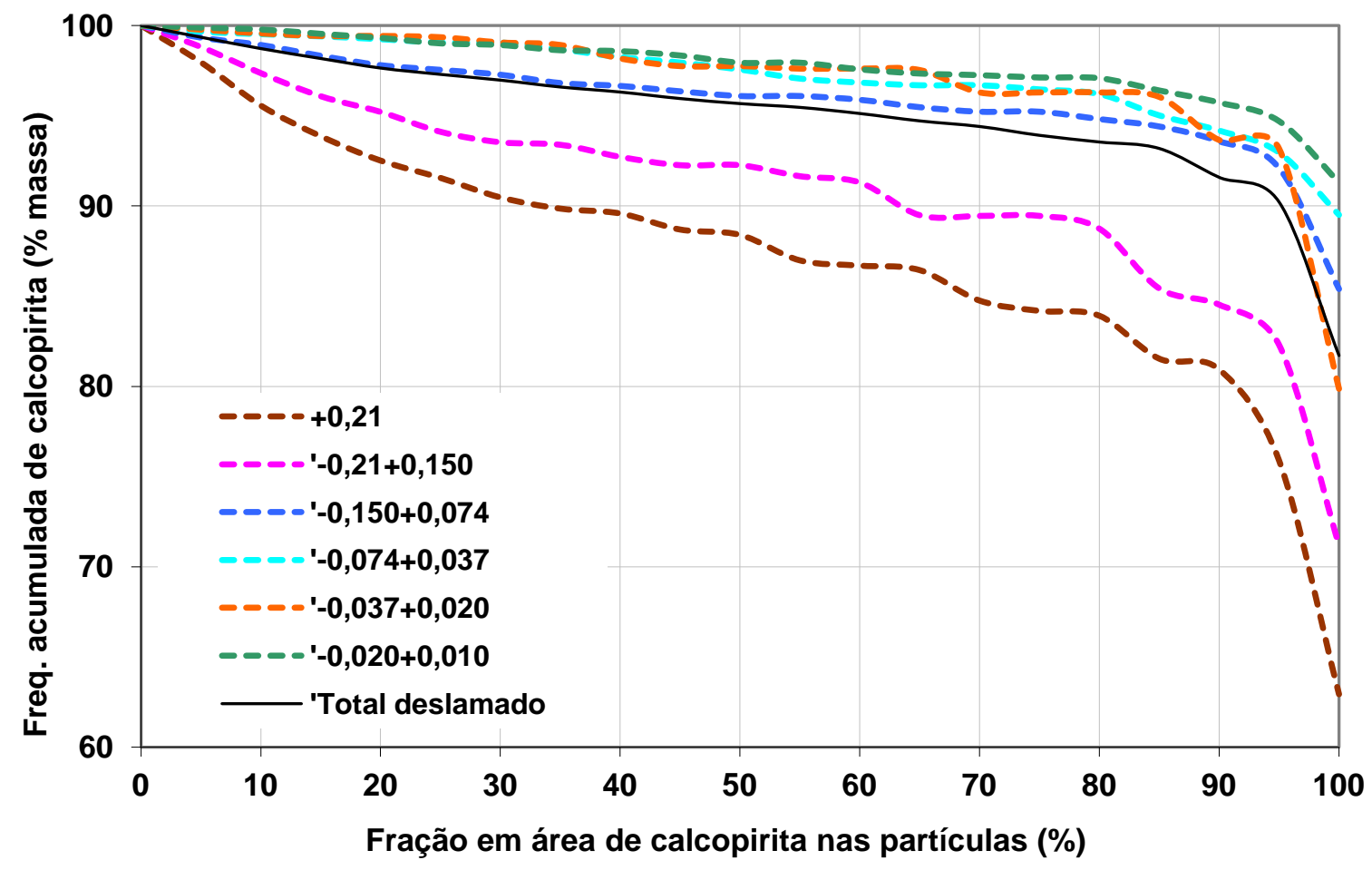

Figura 39 - Espectro de liberação da calcopirita em área - cluster C

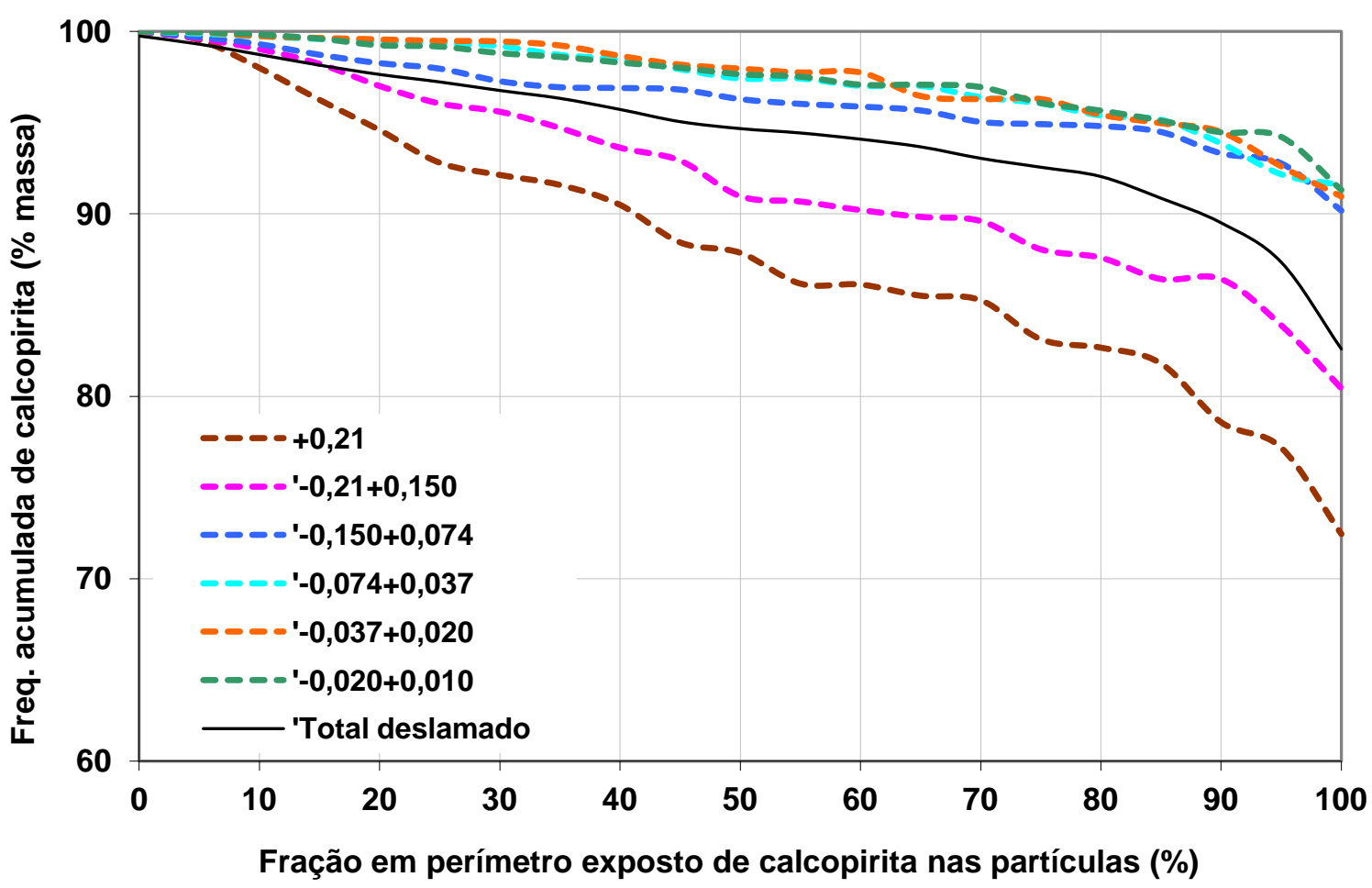

Figura 40 - Espectro de liberação da calcopirita em perímetro exposto - cluster C, total acima de $0,010 \mathrm{~mm}$ 
A Tabela 24 apresenta os valores de liberação considerando como partícula liberada aquelas com no mínimo 85\%, 90\%, 95\% e 100\% de calcopirita (valores extraídos das curvas de espectro de liberação do total deslamado, em termos de porcentagem em área e em superfície exposta).

Tabela 24 - Grau de liberação da calcopirita - cluster C

\begin{tabular}{ccccc}
\hline Fração de mineral útil na partícula (\%) & $\geq 85$ & $\geq 90$ & $\geq 95$ & 100 \\
\hline Grau de liberação da calcopirita (\% em área) & 93 & 92 & 90 & 82 \\
Grau de liberação da calcopirita (\% em perímetro exposto) & 91 & 89 & 87 & 83 \\
\hline
\end{tabular}

\subsubsection{Curvas de distribuição versus teores de cobre}

A curva de distribuição acumulada versus teor de $\mathrm{Cu}$ (obtida nos estudos de MLA) para o material acumulado acima de 0,10 mm, no intervalo considerado, é apresentada na Figura 41. Os estudos mostram que, teoricamente, nas condições de moagem empregadas para um teor entre 13 e 17\% de Cu (valores típicos dos produtos da etapa rougher segundo Bergeman 2009), seria possível recuperar 100\% do total de Cu já na granulometria de moagem da etapa rougher de flotação.

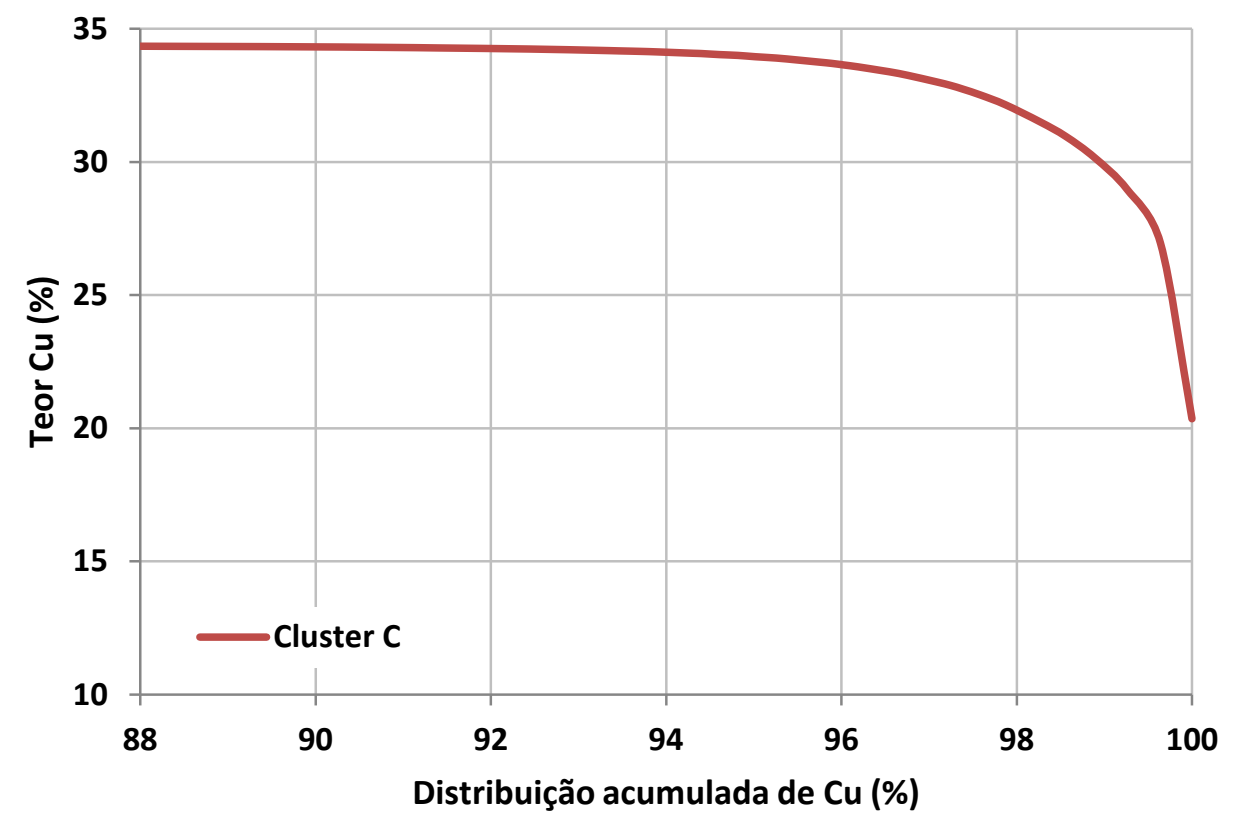

Figura 41 - Curva de distribuição acumulada de Cu versus teor de Cu - cluster C, total acima de $0,010 \mathrm{~mm}$ 


\subsubsection{Sumário dos resultados de caracterização tecnológica e discussão}

É apresentado nesta seção um sumário comparativo entre os resultados obtidos nos estudos de caracterização tecnológica. Alguns destes resultados encontram-se expostos na Tabela 25.

Tabela 25 - Sumário dos resultados da caracterização tecnológica

\begin{tabular}{|c|c|c|c|c|}
\hline & \multicolumn{2}{|c|}{ Sequeirinho } & \multicolumn{2}{|c|}{ Sossego } \\
\hline & Cluster A & Cluster D & Cluster B & Cluster C \\
\hline \multicolumn{5}{|c|}{ \% Massa acumulada abaixo } \\
\hline $0,21 \mathrm{~mm}$ & 85 & 81 & 85 & 83 \\
\hline $0,149 \mathrm{~mm}$ & 69 & 66 & 67 & 69 \\
\hline $0,074 \mathrm{~mm}$ & 47 & 44 & 47 & 45 \\
\hline $0,037 \mathrm{~mm}$ & 28 & 28 & 28 & 27 \\
\hline $0,020 \mathrm{~mm}$ & 19 & 19 & 21 & 19 \\
\hline $0,010 \mathrm{~mm}$ & 10 & 11 & 12 & 10 \\
\hline \multicolumn{5}{|c|}{ Composição química (\% em massa; principais compostos) } \\
\hline $\mathrm{Cu}$ & 2,09 & 0,92 & 0,66 & 1,23 \\
\hline $\mathrm{s}$ & 2,26 & 1,01 & 0,69 & 1,30 \\
\hline $\mathrm{SiO}_{2}$ & 38,7 & 55,7 & 62,8 & 49,3 \\
\hline $\mathrm{Fe}_{2} \mathrm{O}_{3}$ & 27,5 & 12,2 & 9,94 & 18,5 \\
\hline $\mathrm{Al}_{2} \mathrm{O}_{3}$ & 5,69 & 9,92 & 9,12 & 6,26 \\
\hline $\mathrm{CaO}$ & 8,49 & 6,00 & 4,55 & 6,73 \\
\hline $\mathrm{MgO}$ & 5,71 & 4,07 & 2,52 & 4,60 \\
\hline $\mathrm{Na}_{2} \mathrm{O}$ & 1,58 & 3,69 & 2,87 & 0,82 \\
\hline $\mathrm{K} 2 \mathrm{O}$ & 0,44 & 1,03 & 1,60 & 1,34 \\
\hline \multicolumn{5}{|c|}{ Partição do Cu e S nos minerais portadores (\%) } \\
\hline \multicolumn{5}{|c|}{$\mathrm{Cu}$} \\
\hline calcopirita & 99,5 & 98,6 & 96,3 & 100 \\
\hline outros sulfetos & 0,5 & 1,4 & 3,7 & 0 \\
\hline \multicolumn{5}{|l|}{$\mathbf{S}$} \\
\hline calcopirita & 88,4 & 88,3 & 95,2 & 99,3 \\
\hline pirita & 10,8 & 10,8 & 3,8 & 0,7 \\
\hline outros sulfetos & 0,8 & 0,9 & 1,0 & $\operatorname{Tr}$ \\
\hline
\end{tabular}

Para as condições de moagem empregadas, cerca de 81 a 85\% em massa das amostras possui granulação abaixo de 0,21 mm; as frações abaixo de 0,020 mm representam 19 a $21 \%$ do total. 
O cluster A possui o maior teor de cobre (2,09\%), seguido do cluster C $(1,23 \%)$. Em resumo, tem-se que o cluster A é o que possui os menores teores de $\mathrm{SiO}_{2}(38,7 \%)$ e $\mathrm{Al}_{2} \mathrm{O}_{3}(5,69 \%)$ e os maiores teores de $\mathrm{Fe}_{2} \mathrm{O}_{3}(27,5 \%), \mathrm{MgO}(5,71 \%)$ e $\mathrm{CaO}(8,49 \%)$, além de $\mathrm{P}_{2} \mathrm{O}_{5}$ elevado. O cluster B é o oposto, apresentando os maiores teores de $\mathrm{SiO}_{2}(62,8 \%)$ e $\mathrm{Al}_{2} \mathrm{O}_{3}(9,94 \%)$ e os menores teores de $\mathrm{Fe}_{2} \mathrm{O}_{3}$ (9,94\%), MgO (2,52\%) e $\mathrm{CaO}(4,55 \%)$, além de $\mathrm{Na}_{2} \mathrm{O}$ e $\mathrm{K}_{2} \mathrm{O}(1,57 \%)$ elevado. Os clusters C e D possuem composição intermediária entre as amostras A e B, sendo o cluster C mais próximo do A e o cluster D, mais próximo do B.

As distribuições de $\mathrm{Cu}$ e $\mathrm{S}$ dentre os minerais portadores indicam que a $\mathrm{o}$ cobre está presente quase que em sua totalidade na calcopirita (96-100\%), sendo o restante referente ao cobre da calcocita. O enxofre está em sua maioria na calcopirita (88-99\%) e na pirita (1-11\%); nos demais sulfetos - calcocita $\left(\mathrm{Cu}_{2} \mathrm{~S}\right)$, milerita $(\mathrm{NiS})$ e siegenita $\left.(\mathrm{Ni}, \mathrm{Co})_{3} \mathrm{~S}_{4}\right)$ - perfaz $0-1 \%$ do total presente na amostra.

A composição mineralógica das amostras totais $+0,020 \mathrm{~mm}$ é apresentada comparativamente na Tabela 26 e na Figura 42. Vários são os minerais de ganga, os quais: quartzo, plagioclásio (albita tplagioclásio sódico com cálcio), K-feldspato, anfibólio (actinolita \pm hastingsita), magnetita, apatita, epídoto, clorita, escapolita, micas (biotita/flogopita e muscovita) e calcita. Os minerais acessórios são: piroxênio, titanita, rutilo, zircão, alanita, monazita, ilmenita, thorita e uraninita.

Com relação à composição mineralógica, tem-se que, comparativamente:

- O cluster A possui elevada proporção de anfibólio (31\%) e magnetita ${ }^{2}$ (23\%), além de plagioclásio (9\%), apatita (8\%), epídoto (5\%) e quartzo (5\%).

- O cluster D apresenta considerável proporção de anfibólio (23\%) e plagioclásio (26\%), além de quartzo (11\%) e escapolita (8\%).

- O cluster B é composto de essencialmente por quartzo (31\%), plagioclásio (25\%), k-feldspato (10\%) e clorita (10\%).

- O cluster C possui quartzo (29\%), clorita (16\%), magnetita-hematita ${ }^{3}(12 \%)$, além de carbonatos (9\%), micas (8\%) e feldspatos (11\%).

\footnotetext{
${ }^{2}$ Estima-se que para o Cluster A, a proporção de magnetita seja predominante sobre a hematita.

${ }^{3}$ Não foi possível estabelecer as proporções entre estes minerais.
} 
Tabela 26 - Sumário dos resultados da caracterização tecnológica

\begin{tabular}{lcccc}
\hline Minerais & \multicolumn{2}{c}{ Sequeirinho } & \multicolumn{2}{c}{ Sossego } \\
(\% em massa) & Cluster A & Cluster D & Cluster B & Cluster C \\
\hline calcopirita & 5,6 & 2,6 & 2,2 & 3,9 \\
pirita & 0,5 & 0,2 & 0,1 & $<0,1$ \\
outros sulfetos & $*$ & $*$ & $*$ & $*$ \\
quartzo & 5 & 11 & 31 & 29 \\
plagioclásio & 9 & 26 & 25 & 6 \\
K-feldspato & 1 & 5 & 10 & 5 \\
mica & 2 & 3 & 3 & 8 \\
clorita & 5 & 5 & 10 & 16 \\
anfibólio & 31 & 23 & 5 & 5 \\
epidoto & 5 & 6 & 1 & 1 \\
magnetita/hematita & 23 & 5 & 4 & 12 \\
carbonatos & $* *$ & $* *$ & 4 & 9 \\
apatita & 8 & 3 & 2 & 3 \\
escapolita & 3 & 8 & $*$ & $*$ \\
outros & 2 & 3 & 2 & 3 \\
\hline
\end{tabular}

Notas: *proporções menores que 0,1; **mineral traço contabilizado em outros.
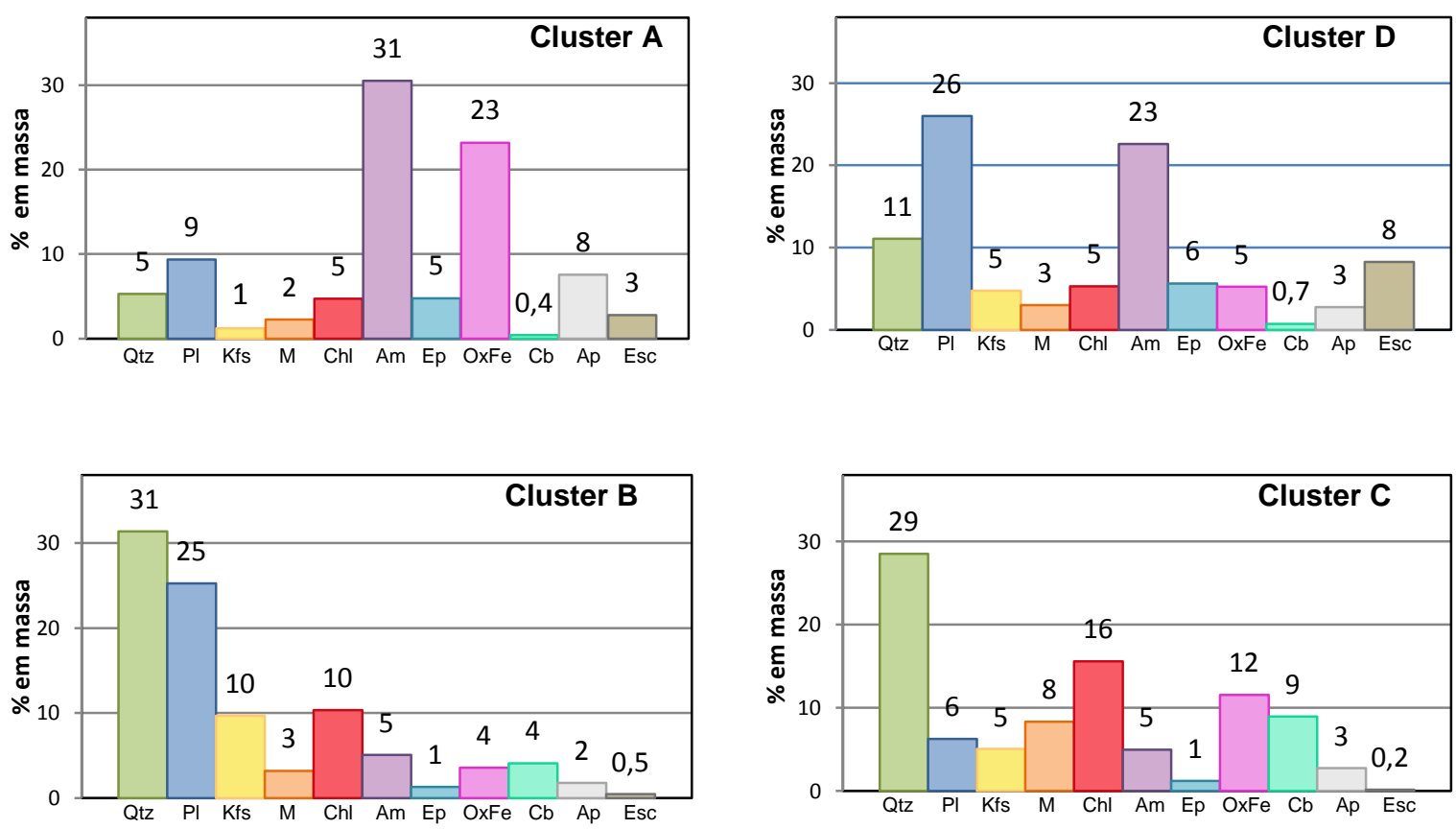

Figura 42 - Comparação mineralógica 
As curvas de liberação da calcopirita em área e perímetro exposto (Figura 43 e Figura 44 respectivamente) demonstram que as amostras do corpo Sossego (clusters B e C) possuem maior grau de liberação da calcopirita para amostra total deslamada nas condições de moagem empregadas. Considerando partículas livres aquelas que possuem $90 \%$ de calcopirita em perímetro exposto, tem-se $90 \%$ de liberação para o cluster C, 84\% para o B e cerca de $75 \%$ para A e D.

A liberação da calcopirita expressa em perímetro exposto é sistematicamente menor em relação à liberação expressa em área, com diferenças de 2 a 3\% nas amostras. A liberação em perímetro exposto é a mais apropriada para análise, visto que o processo de concentração por flotação depende da acessibilidade do coletor à superfície das partículas de calcopirita.

Analisando comportamento de liberação das frações mais grossas $(+0,21 \mathrm{~mm})$ na Figura 45 e admitindo 90\% em perímetro exposto para partículas livres, observase que somente aproximadamente $28 \%$ das partículas encontram-se liberadas no cluster D; 40\% no cluster A e, 61 e 78\% dos clusters B e C. Estes resultados podem indicar as possíveis perdas de minerais de cobre em partículas mistas mais grossas, principalmente nos clusters A e D, durante o processo de flotação.

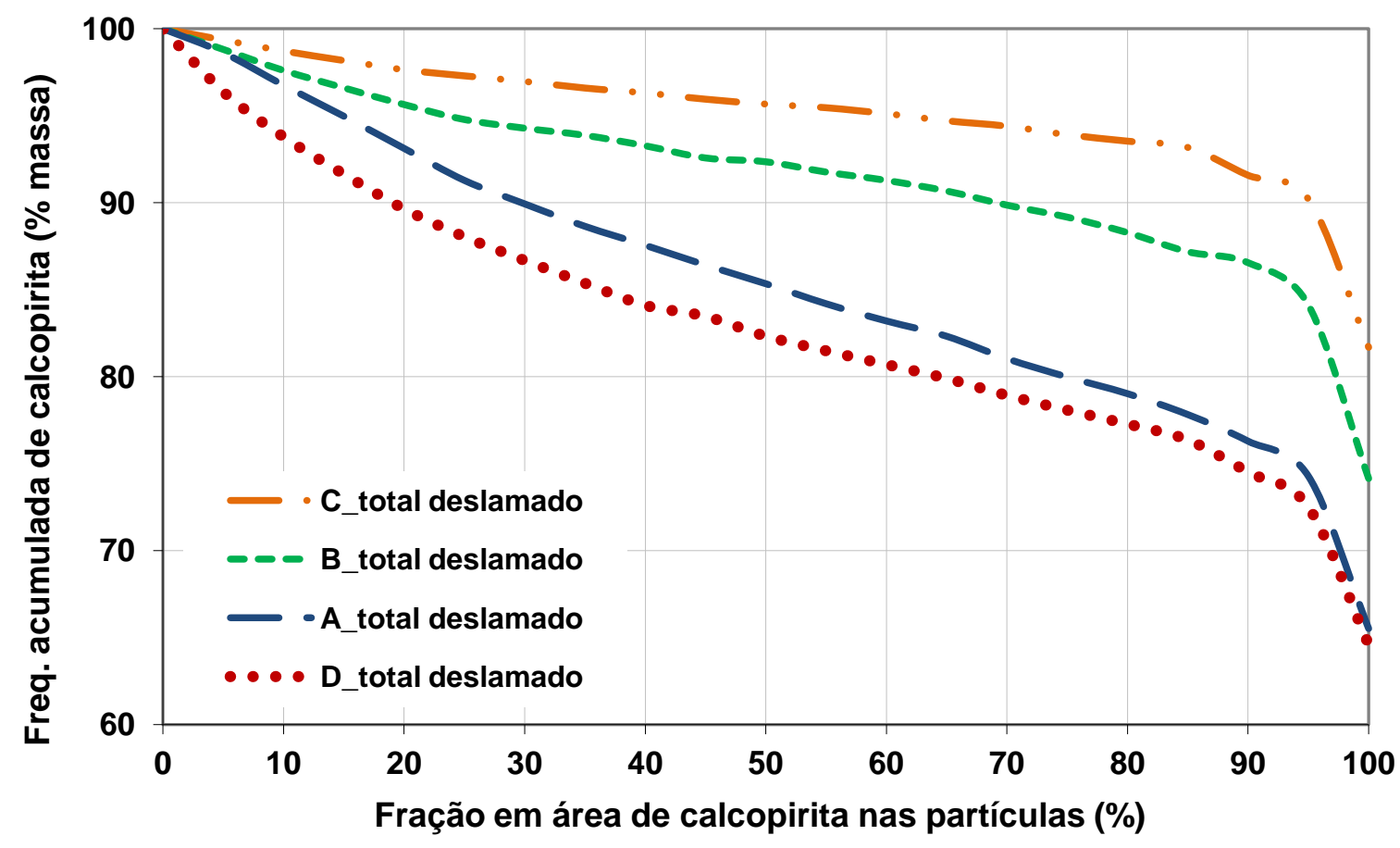

Figura 43 - Espectros de liberação da calcopirita em área - total deslamado 


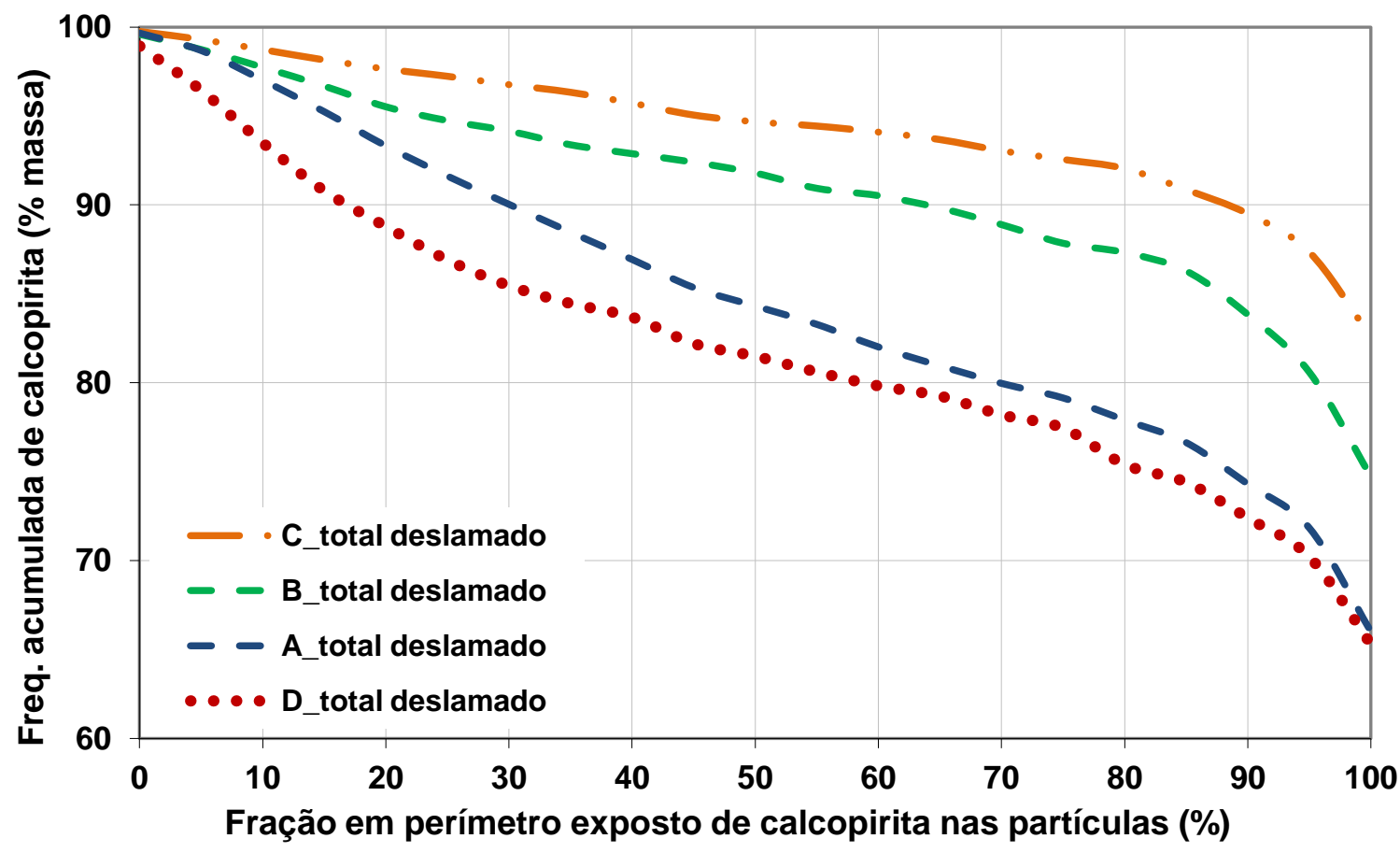

Figura 44 - Espectros de liberação da calcopirita em perímetro exposto - total deslamado

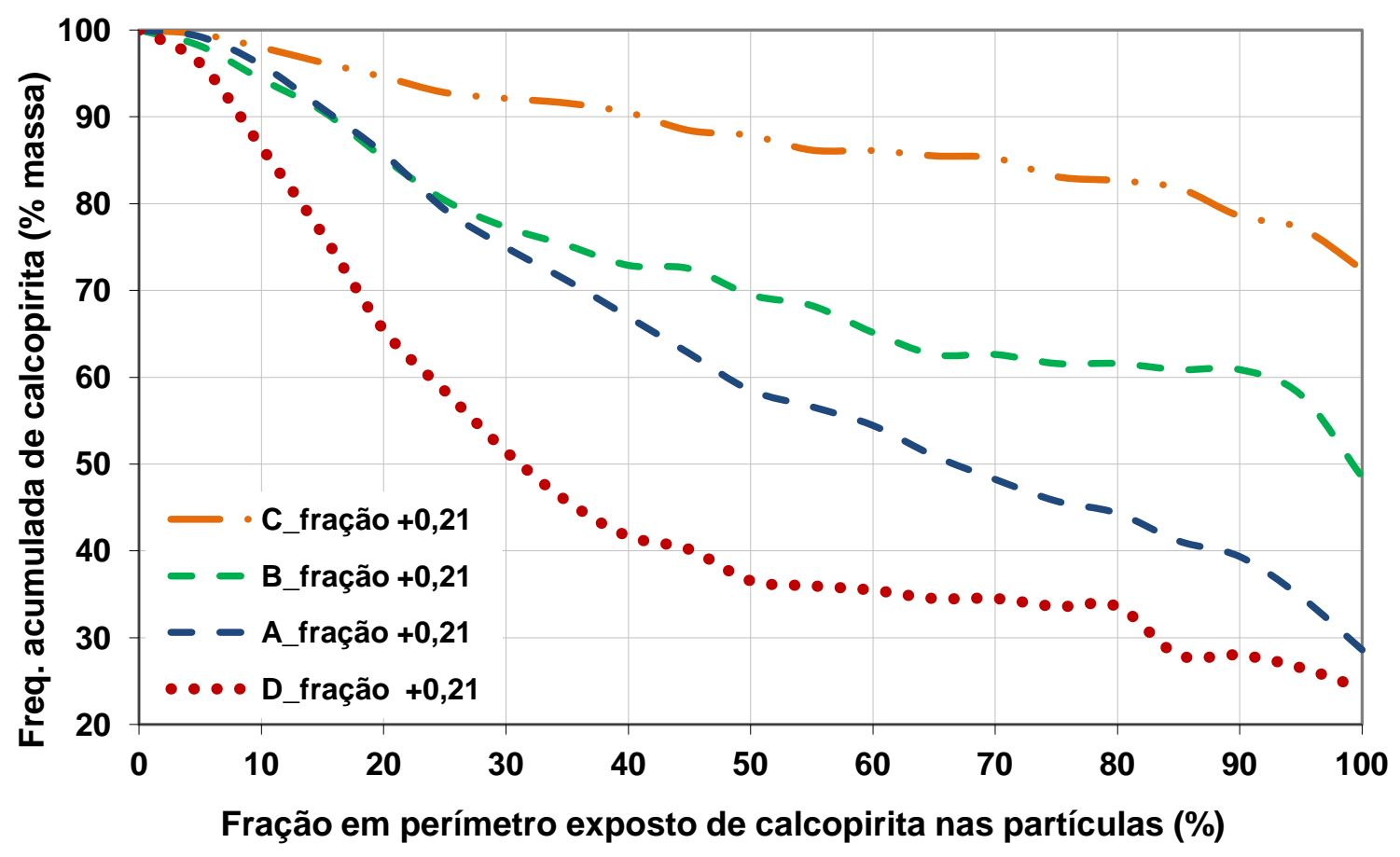

Figura 45 - Espectros de liberação da calcopirita em perímetro exposto frações $+0,21 \mathrm{~mm}$ 
As curvas de distribuição acumulada versus teor de $\mathrm{Cu}$ para o material acumulado acima de 0,10 mm, apresentadas na Figura 46, mostram que, teoricamente, para as condições de cominuição empregadas e um teor entre 13 e $17 \%$ de $\mathrm{Cu}$ (valores típicos dos produtos da etapa rougher segundo Bergeman 2009), as recuperações seriam da ordem de 97 a 100\% já na granulometria de moagem da etapa rougher de flotação.

Já em se considerando teores do concentrado final (30\% de $\mathrm{Cu}$ ) estas recuperações seriam da ordem de 99\%, 97\%, 91\% e 87\%, respectivamente para os clusters C, B (Sossego), A e D (Sequeirinho).

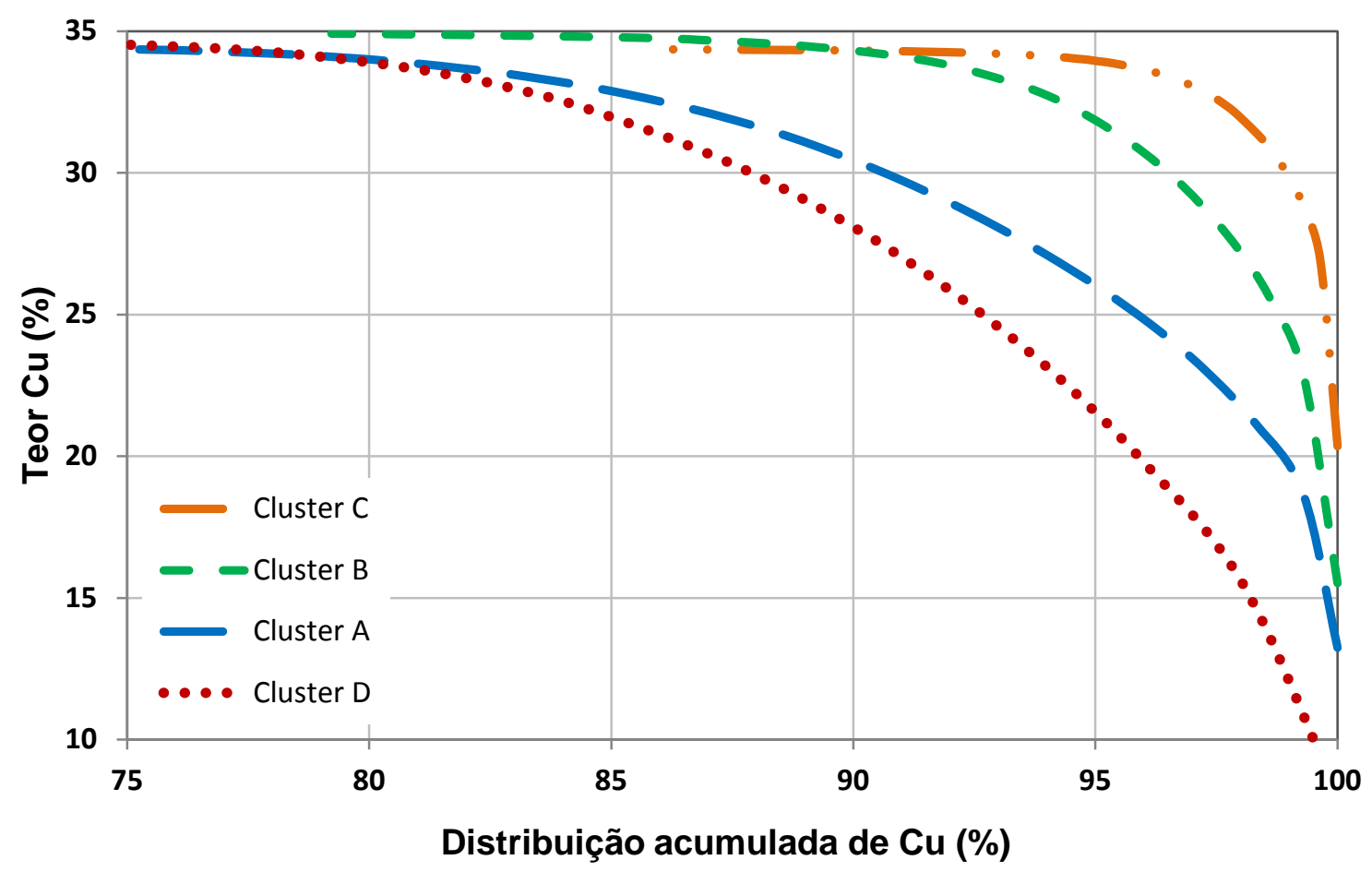

Figura 46 - Curvas de distribuição acumulada de Cu versus teor de $\mathrm{Cu}$

\subsubsection{Validação dos resultados de MLA}

A validação dos resultados da caracterização mineralógica quantitativa automatizada (MLA) foi realizada a partir do confronto com os dados da análise química (FRX). A comparação está apresentada no anexo 4 e Figura 47. O banco de dados utilizado no projeto encontra-se no anexo 3. 
Houve boa correlação entre as composições químicas obtidas pela análise química tradicional (FRX) e os resultados obtidos pelo MLA, indicando que a amostragem para a confecção das seções polidas foi bem realizada e o banco de dados utilizado está coerente.
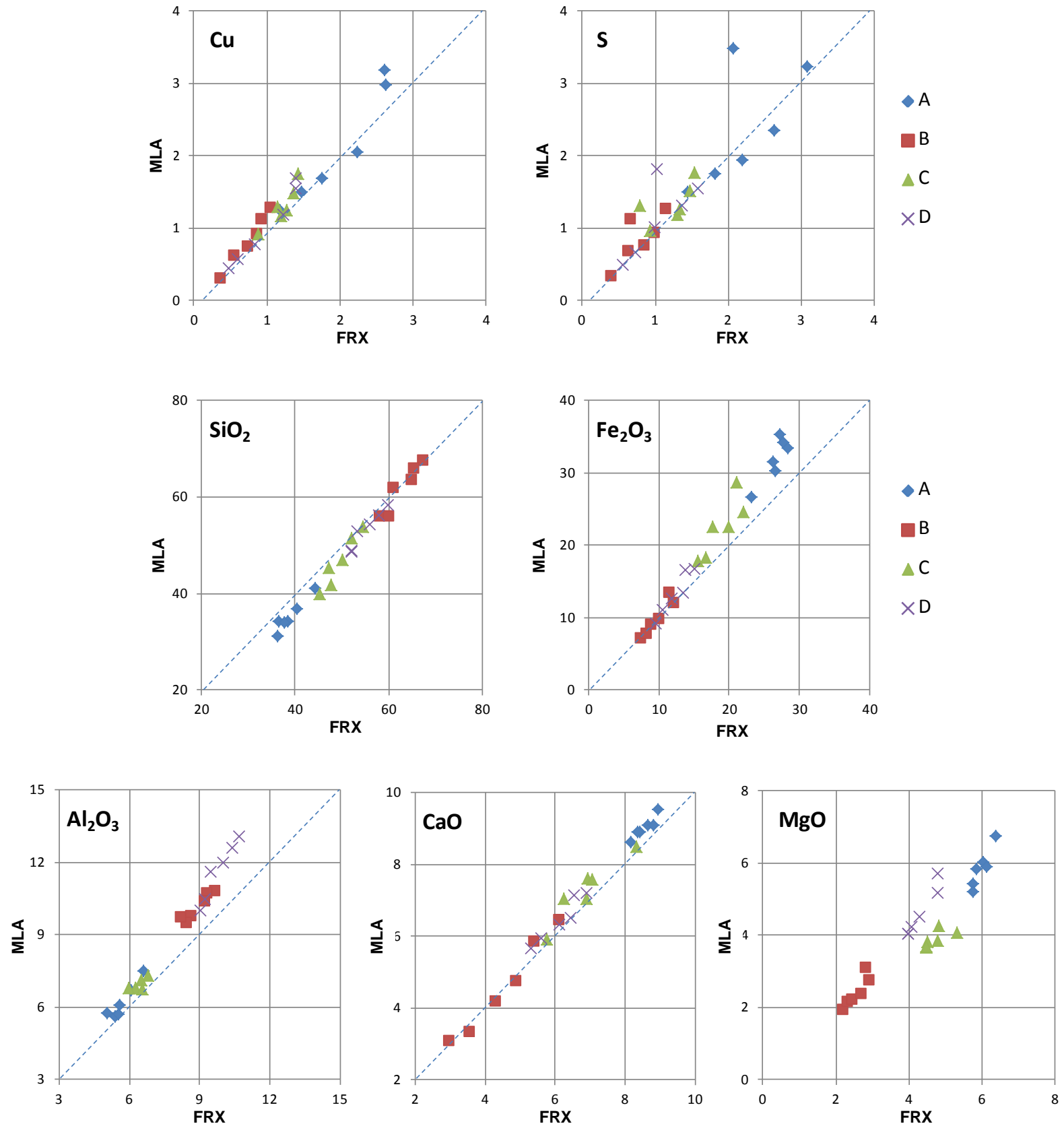

Nota: Cada ponto é representativo de uma fração granulométrica dos quatro clusters

Figura 47 - Comparações entre as composições químicas obtidas por MLA e FRX 


\section{CONCLUSÕES}

As amostras de minério de cobre da Mina do Sossego foram classificadas a partir da análise por agrupamento dos difratogramas de raios $X$, resultando na distinção de sete ou quatro tipos de minério, a depender do nível de refinamento desejado (cut off). Para ambos os processamentos adotou-se a medida de distância Euclidiana e o método de linkagem por média, que considerou nos agrupamentos a posição dos picos.

Houve forte correlação entre os grupos com a localização das amostras: os clusters 1, 2, 6 e 7 são compostos majoritariamente por amostras do corpo Sequeirinho enquanto que os clusters 3 e 5 de amostras do corpo Sossego. O cluster 4 reúne amostras de ambos corpos. Esta correlação deve-se aos diferentes tipos e intensidades das alterações hidrotermais predominantes em cada corpo, que refletem na mineralogia e consequentemente nos difratogramas de raios $X$ das amostras.

Os clusters se diferenciam a partir das proporções das seguintes fases: óxidos de ferro (magnetita/hematita), actinolita, feldspato (albita/feldspato potássico), mica (biotita/muscovita) e clorita. Os padrões difratométricos dos grupos indicam que:

- As amostras dos clusters 1 e 2 (cluster A para critério de 4 grupos) possuem em comum elevada proporção de actinolita e menor conteúdo de quartzo e feldspato, sendo que as do grupo 1 possuem pico de magnetita/hematita, ausente no grupo 2 .

- As amostras dos grupos 3, 4 (cluster B para critério de 4 grupos) e 5 (cluster C para critério de 4 grupos) são mais ricas em quartzo. O cluster 5 (ou C) se diferencia por apresentar menor proporção de feldspato em relação às demais. Os clusters 3 e 4 (ou B) distinguem-se em relação à proporção de quartzo e actinolita.

- As amostras dos clusters 6 e 7 (cluster D para critério de 4 grupos) contém actinolita, quartzo e feldspato, sendo o grupo 6 distinto do grupo 7 em relação às proporções de mica e clorita. 
Variações nas proporções minerais entre amostras de mesmo grupo (diferenças nas intensidades dos picos) são compatíveis com a gênese do depósito, de evolução hidrotermal.

Existem algumas dificuldades para estabelecer relações diretas entre o agrupamento e a geologia da Mina do Sossego, parte delas deve-se a indiferenciação das proporções de albita/feldspato potássico, magnetita/hematita e biotita/muscovita, outra parte deve-se a própria complexidade mineralógica e estruturação do depósito (superposição dos estágios de alteração hidrotermal) e dificuldades de definição de litotipos diretamente a partir de testemunhos de sondagens..

As informações de localização e principais fases minerais constituintes dos grupos (padrão difratométrico dos clusters) são coerentes com as interpretações sobre a distribuição regional dos estágios de alteração hidrotermal apontadas por Monteiro et.al. (2008). Concluiu-se que:

- As amostras dos clusters 1 e 2 (cluster A), provenientes do corpo Sequeirinho, são características de regiões onde a alteração sódica-cálcica foi mais intensa e houve a formação de corpos de actinolititos e magnetititos.

- Amostras dos clusters 6 e 7 (cluster D), também do corpo Sequeirinho, são características dos estágios de alteração sódica-cálcica e sódica. Há maior influência de alteração clorítica no cluster 7 e potássica ou hidrolítica no cluster 6.

- Os clusters 3 e 5 (parte do cluster B e cluster C) englobam amostras do corpo Sossego. O cluster 5 é representado por amostras com maior influência de alteração hidrolítica, enquanto o cluster 3, de alteração clorítica.

- Provavelmente as amostras do cluster 4 representam litotipos formados em ambiente transicional, sob influência de diversas alterações hidrotermais e por isso reúne amostras de ambos corpos. 
Pode-se dizer que o agrupamento refletiu os diferentes ambientes geológicos de formação, agrupando as amostras de acordo com a(s) alteração(ões) hidrotermal(is) predominante(s).

Para o conjunto de dados, os três primeiros componentes principais descrevem cerca de $85 \%$ das informações. A análise do posicionamento das amostras em função destas variáveis indica que o agrupamento foi satisfatório, visto que os grupos ocupam regiões distintas do gráfico 3D.

A técnica permitiu a identificação dos principais tipos de minério presentes na Mina do Sossego de forma rápida e objetiva. A classificação das amostras sem a necessidade da identificação das fases otimizou o tempo da análise dos dados e minimizou a subjetividade da interpretação do difratograma.

Desta forma, acredita-se que o método possui potencial para aplicação em diversas fases do empreendimento mineiro: na fase de exploração para o reconhecimento dos litotipos presentes e determinação da variabilidade mineralógica do depósito e definição de amostras para ensaios de processamento mineral / metalúrgicos e no planejamento de lavra para auxílio em blendagens e em estudos específicos para seleção de amostras representativas do universo amostral.

Os estudos de caracterização tecnológica foram conduzidos com base no resultado do agrupamento relativo a quatro tipos de minério, de forma que as amostras dos grupos 1 e 2 foram compostas no cluster A, as do grupo 3 e 4 no cluster B e as dos grupos 6 e 7 no cluster D. O cluster 5 é o próprio cluster C.

Os resultados de caracterização tecnológica visaram a determinação da composição mineralógica e a forma de ocorrência da calcopirita e sua liberação nos gupos definidos.

Vários são os minerais de ganga, os quais: quartzo, plagioclásio (albita

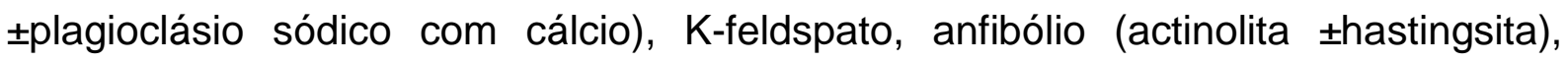
magnetita, apatita, epídoto, clorita, escapolita, micas (biotita/flogopita e muscovita) e calcita. Os minerais acessórios são: piroxênio, titanita, rutilo, zircão, alanita, monazita, ilmenita, thorita e uraninita.

A calcopirita é praticamente o único mineral de interesse econômico, visto que responde por 96 a $100 \%$ do cobre presente. A pirita é o segundo sulfeto mais 
abundante; os demais sulfetos incluem calcocita $\left(\mathrm{Cu}_{2} \mathrm{~S}\right)$, siegenita $\left((\mathrm{Ni}, \mathrm{Co})_{3} \mathrm{~S}_{4}\right)$ e milerita (NiS) e ocorrem como minerais traços.

A calcopirita ocorre tanto na forma de microcristais inclusos nos minerais de ganga quanto como cristais maiores. As amostras apresentam curvas de liberação bastante distintas; de modo geral as amostras do corpo "Sequeirinho", representadas pelos clusters $A$ e $D$, são as que possuem menores liberação. $O$ comportamento nas frações mais grossas podem indicar as possíveis perdas de calcopirita em partículas mistas mais grossas, principalmente nos clusters $A$ e $D$, durante o processo de flotação.

Com relação à recuperação do $\mathrm{Cu}$ versus teor de $\mathrm{Cu}$ para o material acumulado acima de $0,10 \mathrm{~mm}$ e as condições de cominuição empregadas, considerando teores observados para o concentrado rougher, entre 13 e 17\% de Cu, estas recuperações, teoricamente, seriam da ordem de 97 a 100\%; para concentrados com teor de 30\% de Cu ter-se-iam recuperações teóricas de 99\% do total de cobre do cluster C; $97 \%$ do cluster B e 91 e $87 \%$ dos clusters A e D, respectivamente.

\subsection{Sugestões de trabalhos complementares}

Para verificar a aplicabilidade da ferramenta de classificação por agrupamento de difratogramas de raios $X$ em suporte ao planejamento de lavra, sugere-se realizar estudos mais aprofundados, envolvendo maior número de amostras (ampliação do universo amostral) considerando ainda os resultados em função das respostas dos materiais frente aos processos de beneficiamento, como moagem, flotação rougher e cleaner, num conceito mais amplo de abordagem geometalúrgica, além de acompanhadas por estudos de caracterização por MLA. 


\section{REFERÊNCIAS BIBLIOGRÁFICAS}

ANTONIASSI J.L. et al. Análise grupal por difratometria de raios $X$ em apoio à exploração e geometalurgia. In: CONGRESSO BRASILEIRO DE GEOLOGIA, 44, 2008, Curitiba, PR. [Anais]. Curitiba: SBG, 2008.

AUGUSTO R. A. et al. Zonas de alteração hidrotermal e paragênese do minério de cobre do Alvo Bacaba, Província Mineral de Carajás (PA). Revista Brasileira de Geociências, SBG, São Paulo, v. 38, n. 2, p. 263-277, Jun. 2008.

BARTON, M. D.; JOHNSON, D. A. Footprints of Fe-oxide(-Cu-Au) systems. SEG 2004: Predictive Mineral Discovery Under Cover. Centre for Global Metallogeny, Spec. Pub. 33, The University of Western Australia, 112-116. 2004

BARTON, M. D.; JOHNSON, D. A., 1996, Evaporitic-source model for igneousrelated Fe oxide-(REE-Cu-Au-U) mineralization: Geology (Boulder), v. 24, p. 259262.

BERGERMAN, M. G.Modelagem e simulação do circuito de moagem do Sossego. 2009. Dissertação (Mestrado). Departamento de Engenharia de Minas e de petróleo, Escola Politécnica da Universidade de São Paulo, São Paulo, 2009.

BIONDI, J. C. Sistema Hidrotermal Magmático. In: Processos metalogenéticos e os depósitos minerais brasileiros. São Paulo: Oficina de Textos, 2003. Cap. 3, $528 \mathrm{pp}$.

BISH, D. L.; POST, J. E. (Eds). 1989. Modern powder diffraction. Mineralogical Society of America. Reviews in mineralogy, v. 20, 369 pp.

BULATOVIC, S. M. Flotation of Copper Sulfide Ores. In: Handbook of Flotation Reagents: Chemistry, Theory and Practice. Elsevier Science \& Technology Books, v. 1, 2007. Capítulo 12, p. 235-293. 
COX, D. P.; SINGER, D. A, Descriptive and grade-tonnage models and database for iron oxide Cu-Au deposits: U.S. Geological Survey Open-File Report 2007-1155. 2007.

DOCEGEO. Revisão litoestratigráfica da Província Mineral de Carajás litoestratigrafia e principais depósitos minerais. In: CONGRESSO BRASILEIRO DE GEOLOGIA, 35, 1988, Belém. Anais. Belém: SBG, 1988. p. 11-54.

FANDRICH, R.; GU, Y.; BURROWS, D.; MOELLER, K. Modern SEM-Based mineral liberation analysis. Int. J. Miner. Process, v. 84, n. 1-4, p. 310-320, 2007.

GALARZA, T. M. A.; MACAMBIRA, M. J. B.; MOURA, C. A. V. Geocronologia Pb-Pb e Sm-Nd das rochas máficas do depósito Igarapé Bahia, Província Mineral de Carajás (PA). In: SIMPÓSIO DE GEOLOGIA DA AMAZÔNIA, 8, Manaus, AM. Atas. 2003. SBG [CD-ROM].

GRAINGER, C. J. et al. Metallogenesis of the Carajás Mineral Province, Southern Amazon Craton, Brazil: Varying styles of Archean through Paleoproterozoic to Neoproterozoic base-and precious-metal mineralization. Ore Geology Reviews, v. 33, p. 451-489, 2008.

GUILBERT, J. M.; PARK Jr, C.F. The geology of ore deposits. Waveland Press. 2007. 985 pp.

HENLEY, K. J. Ore-dressing mineralogy. A review of techniques, applications and recent developments. In: INTERNATIONAL CONGRESS ON APPLIED MINERALOGY, 1, ICAM'81. Johannesburg, África do Sul. 1981, Proceedings in Special Publication of Geological Society of South Africa, 7, 1983. p.175-200.

JONES, M. P. Applied mineralogy: a quantitative approach. London: Graham \& Trotman, 1987. 259 p. 
$\mathrm{KAHN}, \mathrm{H}$. et al. Mineralogia quantitativa através de análise de imagens automatizada conjugada a MEV/EDS: Estudos de caso aplicados a minérios de fosfato e ouro. In: CONGRESSO BRASILEIRO DE GEOLOGIA, 44. 2008, Curitiba, PR. [Anais]. Curitiba: SBG, 2008. p. 669.

KAHN, H.; MANO, E. S.; TASSINARI, M. M. M. L. Image analysis coupled with a SEM-EDS applied to the characterization of a partially weathered $\mathrm{Zn}-\mathrm{Pb}$ ore. Journal of Minerals \& Materials Characterization \& Engineering, EUA, v. 1, n. 1, p. 1-9, 2002.

LASTRA, R. Seven practical application cases of liberation analysis. . International Journal of Mineral Processing 84 (2007) 337-347.

MACCHIAROLA K. et al. Modern X-ray diffraction techniques for exploration and analysis of ore bodies. In: DECENNIAL INTERNATIONAL CONFERENCE ON MINERAL EXPLORATION, 5, 2007, Toronto, Canada.

MACHADO,N. et al. U-Pb geochronology of Archeanmagmatismand basement reactivation in the Carajás area, Amazon Shield, Brazil. Precambrian Research, 49, 1-26. 1991.

MARSCHIK, R.; LEVEILLE, R. A. 2001. Iron oxide Cu-Au deposits in South America: Candelária, Chile, and Sossego, Brazil. Geological Society of America Abstract with Programs 33.

MINGOTI. S. A. Análise de Dados Através de Métodos de Estatística Multivariada Uma Aborgagem Aplicada. Belo Horizonte: Editora. UFMG 2005.300 pp.

MOITA NETO, J. M.; MOITA G. C. 1998. Uma Introdução à Análise Exploratória de Dados Multivariados. Química Nova, São Paulo, SP: v. 21, n. 4, p. 467-469. 
MONTEIRO, L. V. S. et al. Mineral chemistry of ore and hydrothermal alteration at the Sossego iron oxide-copper-gold deposit, Carajás Mineral Province, Brazil. Ore Geology Reviews, v. 34, p. 317-336, 2008a.

MONTEIRO, L. V. S. et al. Spatial and temporal zoning of hydrothermal alteration and mineralization in the Sossego iron oxide-copper-gold deposit, Carajás Mineral Province, Brazil: paragenesis and stable isotope constraints. Mineralium Deposita, v. 43, p. 129-159, 2008b.

NEUMANN, R.; SCHNEIDER, C. L.; NETO, A. A. Caracterização tecnológica de minérios. In: Tratamento de Minérios. 4ª edição-CETEM. 2004. p. 55-109.

NEVES, M. P. Estudos isotópicos (Pb-Pb, Sm-Nd, C e O) do depósito Cu-Au do Sossego, Província Mineral de Carajás. 2006. 104 p. Dissertação (Mestrado) Centro de Geociências, Universidade Federal do Pará, Pará. 2006.

NOGUEIRA, A. C. R. Análise faciológica e aspectos estruturais da Formação Águas Claras, região central da Serra dos Carajás. 1995. Tese (Doutorado) Universidade Federal do Pará, Pará, 1995.

NORUŠIS, M. J. 2010. Cluster Analysis. In: Norušis, M.J. (Ed.), SPSS 17.0 Statistical Procedures Companion. p. 361-391: Prentice Hall.

PETRUK, W. (Ed.) 1989. Short course on image analysis applied to mineral and earth sciences. Mineralogical association of Canadá, Otawa, 156 pp.

PETRUK, W. 2000. Applied mineralogy in the mining industry. Ottawa: Elsevier, 1st ed., 268 pp.

PIDGEON, R.T., MACAMBIRA, M.J.B., LAFON, J.M., 2000. Th-U-Pb isotopic systems and internal structures of complex zircons from an enderbite from the Pium 
Complex, Carajás Province, Brazil: evidence for the ages of granulite facies metamorphism and the protolith of the enderbite. Chemical Geology, 166, 159-171

PINHEIRO R. V. L.; HOLDSWORTH R. E. Evolução tectonoestratigraáfica dos sistemas transcorrentes Carajás e Cinzento, Cinturão Itacaiúnas, na borde leste do Cratón Amazônico, Pará. Revista Brasileira de Geociências, SBG, São Paulo, v. 30, n. 4, p. 597-606, 2000.

REIS, R. L. G. Com Sossego, o Brasil entra na rota do cobre. Revista Brasil Mineral. v. 230 , p. 38-45, 2004.

RIBEIRO, J.A. S. 2011. Cobre. In: Sumário Mineral Brasileiro 2011. DNPM Departamento Nacional de Produção Mineral. Brasil, 2011. v31, p.33-34.

RODRIGUES, A. F. S.; HEIDER, M. Cobre. In: Economia mineral do Brasil. DNPM Departamento Nacional de Produção Mineral. Brasil, 2009. 764p. cap. 4.3,p. 216235.

RODRIGUES, E.S.; LAFON, J.M.; SCHELLER, T. Geocronologia Pb-Pb da Província Mineral de Carajás: primeiros resultados. In: CONGRESSO BRASILEIRO DE GEOLOGIA, 1992, vol. 37, Boletim de Resumos Expandidos. SBG, vol. 2, pp. 183-184.

SANT'AGOSTINO, L. M.; KAHN, H. Metodologia para a caracterização tecnológica de matérias primas minerais. São Paulo: EPUSP, 1997. 29 P. (Boletim Técnico da Escola Politécnica da USP. Departamento de Engenharia de Minas, BT/PMI/069)

SKIRROW, R. Iron oxide Cu-Au deposits: An Australian perspective on their unifying characteristics. In: McPhie, J. and McGoldrick, P. (editors), 2004. Dynamic Earth: Past, Present and Future. Abstracts of the 17th Australian Geological Convention, Hobart, Tasmania. February 8-13, Geological Society of Australia, Abstracts n. 73, p. 121. 2004 
SUTHERLAND, D. N.; GOTTLIEB, P. Application of automated quantitative mineralogy in mineral processing. Minerals Engineering, Clayton: Pergamon Press, v. 4, n. 7-11, p. 753-762, 1991.

TAN, P. N.; STEINBACH, M.; KUMAR, V. 2006. Cluster Analysis: Basic Conceps and Algorithms. In: Introduction to data mining. Pearson Addison-Wesley. Cap.8, p.125-146.

WILLIAMS, P. J. et al. Iron oxide copper-gold deposits: geology, space-time distribution, and possible modes of origin. In Hedenquist, J.W., Thompdon, J.F.H., Goldfarb, R.J., and Richards, J.P., eds., Economic Geology 100th anniversary volume, 1902-2005, p. 371-405, 2005 
ANEXOS

Anexo 1 - Relação das amostras estudadas

Anexo 2 - Difratogramas de raios-x das amostras mais representativas de cada grupo

Anexo 3 - Composição química das fases minerais - banco de dados MLA

Anexo 4 - Composições químicas dosadas (FRX) e calculadas (MLA) 


\begin{tabular}{|c|c|c|c|c|c|c|c|}
\hline ID & $\begin{array}{c}\text { Massa } \\
\text { recebida kg }\end{array}$ & $\begin{array}{c}\text { Cluster } \\
\text { (4 grupos) }\end{array}$ & $\begin{array}{c}\text { Cluster } \\
\text { (7 grupos) }\end{array}$ & $\begin{array}{c}\text { Code } \\
\text { Amostra }\end{array}$ & Litologia & $\begin{array}{c}\text { Teor } \\
\text { Cu (\%) }\end{array}$ & $\begin{array}{l}\text { Classificação } \\
\text { moabilidade }\end{array}$ \\
\hline SOSD $022290-300$ & 3,64 & $\mathrm{~A}$ & 1 & 2008SEQ_AT & ACT & 0,90 & MDA \\
\hline SOSD $033263-273$ & 3,68 & $A$ & 1 & 2008SEQ_SAT & BSE & 2,83 & ALT \\
\hline SOSD 033 289-299 & 3,90 & $A$ & 1 & 2008SEQ_SAT & MAG & 3,37 & ALT \\
\hline SOSD $033300-310$ & 3,70 & $A$ & 1 & 2008SEQ_SAT & MAG & 3,37 & MDA \\
\hline SOSD $050292-302$ & 3,68 & $A$ & 1 & 2008SEQ_SAT & BSE & 4,22 & MDA \\
\hline SOSD 097 287-297 & 3,65 & $A$ & 1 & 2008SEQ_AT & MAG & 0,72 & MED \\
\hline SOSD $098235-245$ & 3,74 & $A$ & 1 & 2008SEQ_AT & $\mathrm{ACT}$ & 0,99 & $\mathrm{ALT}$ \\
\hline SOSD 117 256-266 & 3,94 & $A^{* * *}$ & $1 * * *$ & 2008SEQ_AT & MAG & 0,82 & ALT \\
\hline SOSD 117 267-277 & 3,86 & A & 1 & 2008SEQ_SAT & ACT & 1,64 & ALT \\
\hline SOSD 177 279-289 & 3,78 & $A$ & 1 & 2008SEQ_AT & ACT & 0,99 & ALT \\
\hline SOSD $259372-282$ & 4,34 & $A$ & 1 & & & & MDA \\
\hline SOSD 316 289-299 & 3,84 & $A$ & 1 & 2008SEQ_AT & MAG & 0,57 & ALT \\
\hline SOSD 316 299-309 & 3,74 & $A$ & 1 & 2008SEQ_AT & MAG & 0,57 & MDA \\
\hline SOSD 316 309-319 & 4,16 & $A$ & 1 & 2008SEQ_BT & MAG & 0,17 & $\mathrm{ALT}$ \\
\hline SOSD $316320-330$ & 3,10 & $A$ & 1 & 2008SEQ_AT & ACT & 1,03 & ALT \\
\hline SOSD 379 261-271 & 4,28 & $A$ & 1 & 2008SEQ_SAT & BSE & 3,60 & MDA \\
\hline SOSD $220287-297$ & 3,80 & $A$ & 2 & 2008SEQ_AT & GBA & 0,95 & $\mathrm{ALT}$ \\
\hline SOSD 232 265-275 & 4,26 & $A$ & $2 * * *$ & 2008SEQ_AT & GBA & 0,93 & ALT \\
\hline SOSD $259262-272$ & 3,76 & $A$ & 2 & 2008SEQ_SAT & ACT & 5,06 & MED \\
\hline SOSD 001 137-147 & 3,84 & B & 3 & 2008SOS_AT & BHT & 0,51 & $\mathrm{ALT}$ \\
\hline SOSD 001 147-157 & 3,78 & B & 3 & 2008SOS_AT & BHT & 0,51 & ALT \\
\hline SOSD 001 157-167 & 4,08 & $B$ & 3 & 2008SOS_AT & BHT & 0,51 & ALT \\
\hline SOSD 019 130-140 & 3,92 & $\mathrm{~B}$ & 3 & 2008SOS_AT & GRF & 1,50 & ALT \\
\hline SOSD 020 094-102 & 3,00 & $\mathrm{~B}$ & 3 & 2008SOS_AT & GRF & 0,99 & ALT \\
\hline SOSD $020108-118$ & 3,94 & $\mathrm{~B}$ & 3 & 2008SOS_AT & GRF & 0,99 & $\mathrm{ALT}$ \\
\hline SOSD $020127-137$ & 3,98 & $\mathrm{~B}$ & 3 & 2008SOS_AT & GRF & 0,99 & ALT \\
\hline SOSD $020137-145$ & 2,80 & B & $3 * * *$ & 2008SOS_AT & GRF & 0,99 & ALT \\
\hline SOSD 047 280-290 & 3,18 & B & 3 & 2008SEQ_AT & GRA & 0,60 & ALT \\
\hline SOSD 053 121-131 & 4,06 & B & 3 & 2008SOS_AT & BHT & 0,64 & $\mathrm{ALT}$ \\
\hline SOSD 053 144-154 & 3,22 & $\mathrm{~B}$ & 3 & 2008SOS_AT & $\mathrm{BHT}$ & 0,64 & MDA \\
\hline SOSD 053 154-162 & 2,36 & B & 3 & 2008SOS_AT & BHT & 0,64 & $\mathrm{ALT}$ \\
\hline SOSD 053 166-176 & 2,82 & B & 3 & 2008SOS_AT & BHT & 0,64 & ALT \\
\hline SOSD 054 117-126 & 3,54 & $\mathrm{~B}$ & 3 & 2008SOS_AT & GRF & 1,31 & $\mathrm{ALT}$ \\
\hline SOSD $080286-296$ & 4,12 & B & 3 & 2008SEQ_AT & MVA & 1,05 & $\mathrm{ALT}$ \\
\hline SOSD 282 129-138 & 3,42 & $B$ & 3 & 2008SOS_AT & GRF & 1,78 & ALT \\
\hline SOSD 292 088-095 & 2,76 & B & 3 & 2008SOS_AT & $\mathrm{BHT}$ & 0,56 & ALT \\
\hline SOSD 315 100-110 & 3,92 & B & 3 & 2008SOS_AT & GRF & 0,93 & ALT \\
\hline SOSD 315 110-120 & 4,50 & $\mathrm{~B}$ & 3 & 2008SOS_AT & GRF & 0,93 & ALT \\
\hline SOSD 315 120-130 & 3,84 & B & 3 & 2008SOS_AT & GRF & 0,93 & ALT \\
\hline SOSD 315 152-162 & 4,23 & B & 3 & 2008SOS_AT & GRF & 0,93 & ALT \\
\hline SOSD 419 048-058 & 3,86 & B & 3 & & & & ALT \\
\hline SOSD $420063-073$ & 4,04 & $\mathrm{~B}$ & 3 & & & & ALT \\
\hline SOSD 019 165-175 & 4,08 & B & 4 & 2008SOS_AT & GRF & 0,36 & ALT \\
\hline SOSD 049 306-316 & 2,82 & $\mathrm{~B}$ & 4 & 2008SEQ_AT & GRA & 1,17 & $\mathrm{ALT}$ \\
\hline SOSD 051 291-301 & 3,54 & B & 4 & 2008SEQ_AT & GRA & 1,53 & MDA \\
\hline SOSD $130251-261$ & 3,72 & $B$ & 4 & 2008SEQ_AT & GBA & 0,76 & $\mathrm{ALT}$ \\
\hline SOSD $236185-193$ & 2,64 & $B$ & 4 & 2008SOS_AT & BHT & 0,97 & ALT \\
\hline SOSD $296130-140$ & 3,86 & B & 4 & 2008SOS_AT & GRF & 0,87 & ALT \\
\hline SOSD 299 096-105 & 3,60 & B & 4 & 2008SOS_BT & BHT & 0,56 & ALT \\
\hline SOSD 299 107-115 & 2,82 & B & 4 & 2008SOS_AT & GRF & 0,70 & ALT \\
\hline SOSD 302 119-127 & 2,98 & $\mathrm{~B} * * *$ & $4 * * *$ & 2008SOS_AT & GRF & 0,44 & ALT \\
\hline SOSD 302 154-164 & 3,80 & B & 4 & 2008SOS_AT & GRF & 0,61 & ALT \\
\hline SOSD 308 117-127 & 4,32 & $\mathrm{~B}$ & 4 & 2008SOS_AT & BHT & 0,39 & ALT \\
\hline SOSD 308 127-137 & 4,06 & $\mathrm{~B}$ & 4 & 2008SOS_AT & $\mathrm{BHT}$ & 0,39 & $\mathrm{ALT}$ \\
\hline SOSD $310215-225$ & 3,96 & B & 4 & 2008SEQ_AT & ACT & 1,16 & ALT \\
\hline SOSD $311111-119$ & 2,98 & $B$ & 4 & 2008SOS_AT & GRF & 0,90 & ALT \\
\hline SOSD 317 242-252 & 4,58 & $\mathrm{~B}$ & 4 & 2008SEQ_SAT & $\mathrm{ACT}$ & 2,69 & $\mathrm{ALT}$ \\
\hline SOSD 318 110-120 & 3,80 & $\mathrm{~B}$ & 4 & 2008SOS_AT & BHT & 0,38 & ALT \\
\hline SOSD $379215-225$ & 3,46 & B & 4 & & & & ALT \\
\hline SOSD 379250260 & 3,82 & B & 4 & 2008SEQ_AT & ACT & 0,90 & ALT \\
\hline
\end{tabular}




\begin{tabular}{|c|c|c|c|c|c|c|c|}
\hline ID & $\begin{array}{c}\text { Massa } \\
\text { recebida kg }\end{array}$ & $\begin{array}{c}\text { Cluster } \\
\text { (4 grupos) }\end{array}$ & $\begin{array}{c}\text { Cluster } \\
\text { (7 grupos) }\end{array}$ & $\begin{array}{l}\text { Código } \\
\text { Amostra }\end{array}$ & Litologia & $\begin{array}{c}\text { Teor } \\
\mathrm{Cu}(\%)\end{array}$ & $\begin{array}{l}\text { Classificação } \\
\text { moabilidade }\end{array}$ \\
\hline SOSD 013 087-093 & 3,94 & $\mathrm{C}$ & 5 & & & & \\
\hline SOSD 019 140-150 & 3,97 & $\mathrm{C}$ & 5 & 2008SOS_SAT & $\mathrm{BHT}$ & 3,60 & MDA \\
\hline SOSD 021 109-119 & 3,22 & C & 5 & & & & MTA \\
\hline SOSD 236 164-174 & 3,60 & $\mathrm{C}$ & 5 & 2008SOS_AT & $\mathrm{BHT}$ & 0,97 & ALT \\
\hline SOSD 296 164-171 & 2,84 & $\mathrm{C}$ & 5 & 2008SOS_AT & GRF & 0,87 & ALT \\
\hline SOSD 302 164-174 & 4,12 & $\mathrm{C}$ & 5 & 2008SOS_AT & GRF & 0,61 & ALT \\
\hline SOSD 302 174-182 & 2,80 & $\mathrm{C}$ & 5 & 2008SOS_AT & GRF & 0,61 & $\mathrm{ALT}$ \\
\hline SOSD 302 190-200 & 3,92 & $\mathrm{C}$ & 5 & 2008SOS_AT & GRF & 0,61 & ALT \\
\hline SOSD 314 122-132 & 4,14 & $\mathrm{C}$ & 5 & 2008SOS_AT & GRF & 0,82 & ALT \\
\hline SOSD 314 135-145 & 4,14 & $\mathrm{C} * * *$ & $5 * * *$ & 2008SOS_AT & GRF & 0,82 & ALT \\
\hline SOSD 315 142-152 & 3,96 & $\mathrm{C}$ & 5 & 2008SOS_AT & GRF & 0,93 & $\mathrm{ALT}$ \\
\hline SOSD 319 155-162 & 2,54 & $\mathrm{C}$ & 5 & 2008SOS_SAT & $\mathrm{BHT}$ & 2,72 & ALT \\
\hline SOSD 319 176-186 & 4,32 & $\mathrm{C}$ & 5 & 2008SOS_AT & $\mathrm{BHT}$ & 2,44 & MDA \\
\hline SOSD $016245-255$ & 3,58 & $\mathrm{D}$ & 6 & & & & MDA \\
\hline SOSD 046 214-224 & 3,22 & $\mathrm{D}$ & 6 & & & & $\mathrm{ALT}$ \\
\hline SOSD 049 316-326 & 3,00 & $\mathrm{D}$ & 6 & 2008SEQ_AT & GRA & 1,17 & ALT \\
\hline SOSD 102 275-285 & 3,80 & $\mathrm{D}$ & 6 & 2008SEQ_BT & $\mathrm{ACT}$ & 0,28 & ALT \\
\hline SOSD 119 197-207 & 3,30 & $\mathrm{D}$ & 6 & & & & ALT \\
\hline SOSD $130290-300$ & 3,86 & $\mathrm{D}$ & 6 & 2008SEQ_AT & MVA & 0,83 & ALT \\
\hline SOSD 239 190-200 & 3,44 & $\mathrm{D}$ & 6 & & & & ALT \\
\hline SOSD $241292-300$ & 3,02 & $\mathrm{D}$ & 6 & 2008SEQ_AT & MVA & 0,54 & ALT \\
\hline SOSD 247 116-126 & 3,94 & $\mathrm{D}$ & 6 & & & & ALT \\
\hline SOSD 247 126-136 & 3,92 & $\mathrm{D}$ & 6 & & & & \\
\hline SOSD 406 167-177 & 3,88 & $\mathrm{D}$ & 6 & & & & ALT \\
\hline SOSD 408 248-258 & 4,38 & D & 6 & 2008SEQ_AT & MVA & 0,95 & ALT \\
\hline SOSD 408 262-272 & 4,10 & $\mathrm{D}$ & 6 & 2008SEQ_AT & MVA & 0,95 & ALT \\
\hline SOSD 408 273-283 & 4,06 & D & $6 * * *$ & 2008SEQ_AT & MVA & 0,95 & ALT \\
\hline SOSD 408 283-293 & 3,92 & $\mathrm{D}$ & 6 & 2008SEQ_AT & MVA & 0,95 & ALT \\
\hline SOSD 017 201-211 & 3,70 & $\mathrm{D}$ & 7 & 2008SEQ_BT & ACT & 0,36 & ALT \\
\hline SOSD 031 186-196 & 3,74 & $\mathrm{D}$ & 7 & 2008SEQ_BT & $\mathrm{ACT}$ & 0,30 & ALT \\
\hline SOSD $051260-270$ & 3,82 & $\mathrm{D}$ & 7 & 2008SEQ_AT & GRA & 1,53 & ALT \\
\hline SOSD $051271-281$ & 3,62 & $\mathrm{D}$ & 7 & 2008SEQ_AT & GRA & 1,53 & ALT \\
\hline SOSD 098 214-224 & 4,14 & $\mathrm{D}$ & 7 & 2008SEQ_AT & $\mathrm{ACT}$ & 0,99 & ALT \\
\hline SOSD $098225-235$ & 3,86 & $\mathrm{D}$ & 7 & 2008SEQ_AT & ACT & 0,99 & ALT \\
\hline SOSD 102 256-266 & 3,76 & $\mathrm{D}$ & 7 & 2008SEQ_AT & $\mathrm{ACT}$ & 0,62 & MTA \\
\hline SOSD 102 310-320 & 3,76 & $\mathrm{D}$ & 7 & 2008SEQ_AT & GBA & 0,77 & ALT \\
\hline SOSD $130241-251$ & 4,08 & $\mathrm{D}$ & 7 & 2008SEQ_AT & GBA & 0,76 & ALT \\
\hline SOSD 130 266-275 & 3,42 & $\mathrm{D}$ & 7 & 2008SEQ_SAT & $\mathrm{ACT}$ & 2,62 & ALT \\
\hline SOSD 177 268-278 & 3,54 & $\mathrm{D}$ & 7 & 2008SEQ_SAT & $\mathrm{ACT}$ & 1,64 & ALT \\
\hline SOSD 215 204-213 & 3,84 & $\mathrm{D} * * *$ & 7 & & & & ALT \\
\hline SOSD 232 265-275 & 4,26 & D & 7 & 2008SEQ_AT & $\mathrm{ACT}$ & 1,17 & \\
\hline SOSD 232 277-287 & 3,84 & $\mathrm{D}$ & 7 & 2008SEQ_AT & ACT & 1,17 & ALT \\
\hline SOSD 309 224-234 & 3,88 & $\mathrm{D}$ & 7 & 2008SEQ_SAT & $\mathrm{ACT}$ & 1,70 & ALT \\
\hline SOSD 311 101-110 & 3,46 & $\mathrm{D}$ & 7 & 2008SOS_AT & GRF & 0,90 & ALT \\
\hline SOSD 311 126-136 & 4,02 & $\mathrm{D}$ & 7 & 2008SOS_BT & GRF & 0,23 & ALT \\
\hline SOSD 316 212-222 & 2,78 & $\mathrm{D}$ & 7 & & & & MTA \\
\hline SOSD 316 336-346 & 4,00 & $\mathrm{D}$ & 7 & 2008SEQ_AT & ACT & 1,03 & $\mathrm{ALT}$ \\
\hline SOSD 316 351-361 & 3,84 & $\mathrm{D}$ & $7 * * *$ & 2008SEQ_AT & $\mathrm{ACT}$ & 1,03 & ALT \\
\hline SOSD 355 103-113 & 3,86 & $\mathrm{D}$ & 7 & 2008SEQ_AT & GBA & 1,48 & ALT \\
\hline SOSD 403 220-230 & 3,74 & $\mathrm{D}$ & 7 & 2008SEQ_AT & BSE & 1,03 & ALT \\
\hline
\end{tabular}

\section{Legenda:}

Código da amostra: SEQ Sequeirinho, SOS Sossego, ESTER estéril, AT alto teor, SAT super alto teor, BT baixo teor;

Litologia: ACT actinolitito, MAG magnetitito, GRA granito, GBA gabro, GRF granófiro, MVA meta vulcânica ácida, BHT brecha heterolítica, BSE brecha sulfetada sequeirinho, BSO brecha sulfetada sossego, BIX biotita xisto

Classificação de moabilidade:, MTA - Muito alta, ALT - alta, MDA -média alta- , MED - média moabilidade 


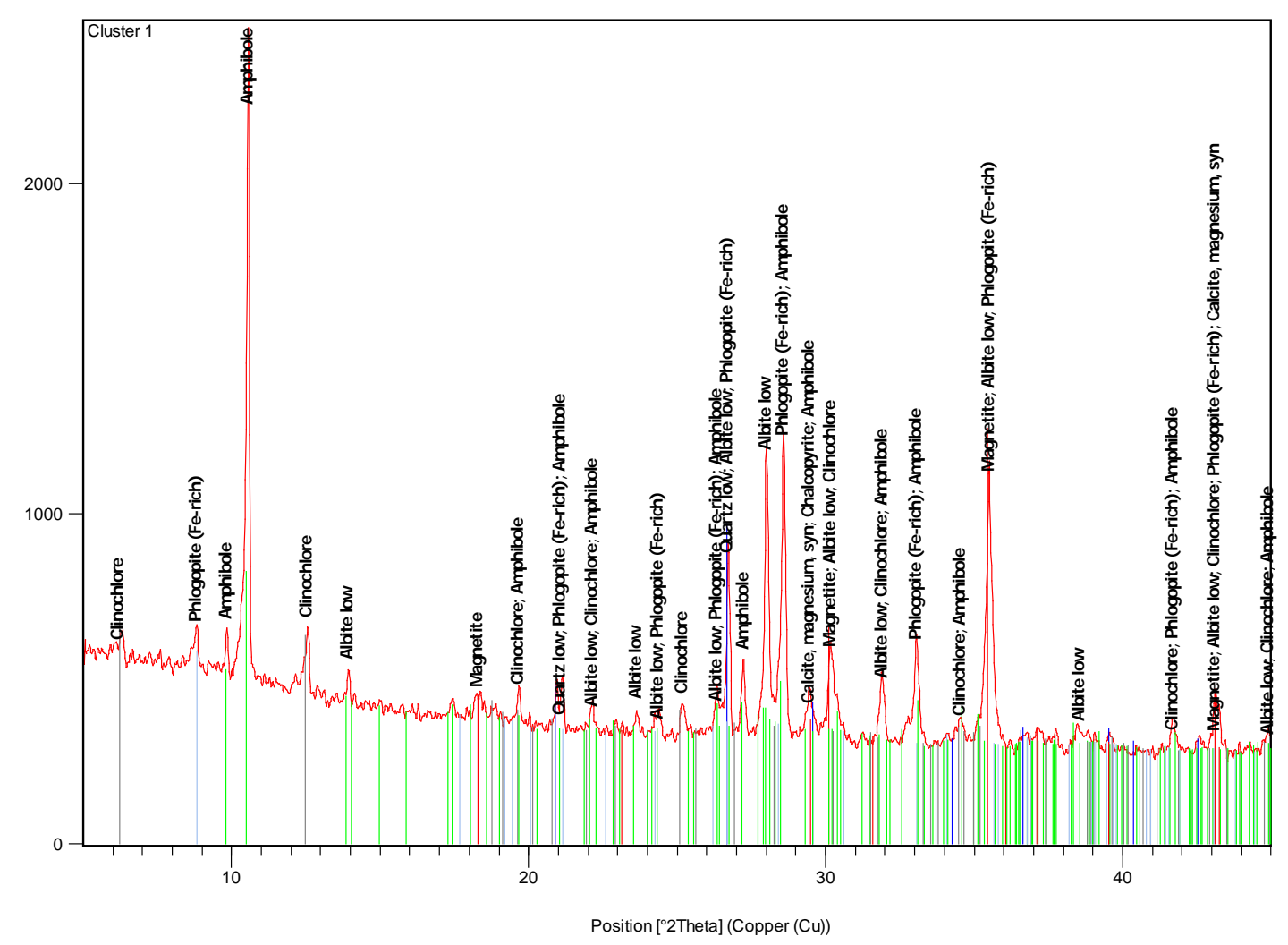

Difratograma da amostra SOSD 017 256-266 m - clusters A e 1

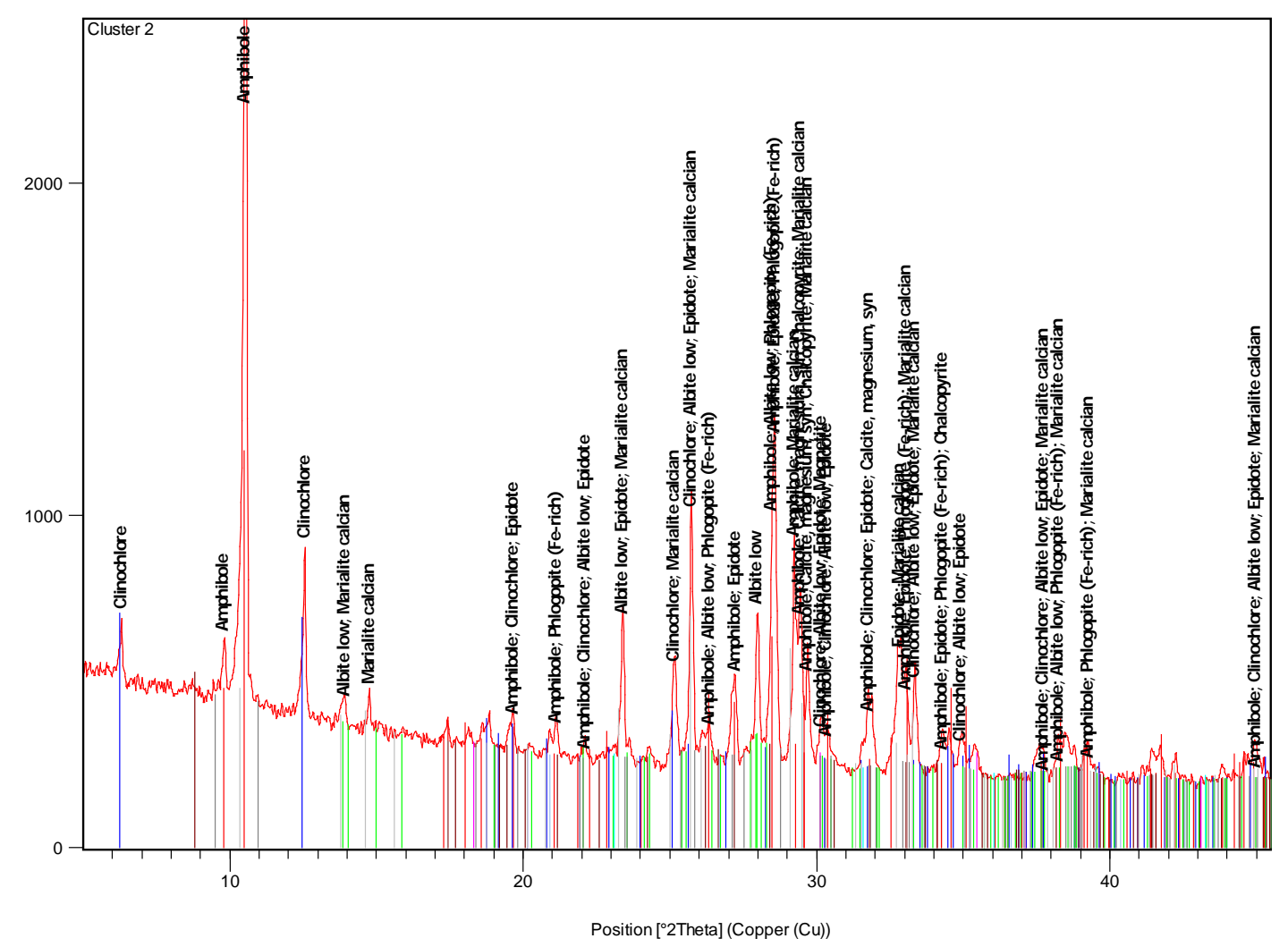

Difratograma da amostra SOSD 232265 - 275 m - cluster 2 
ANEXO 2 - DIFRATOGRAMAS DE RAIOS X DAS AMOSTRAS MAIS

REPRESENTATIVAS DE CADA GRUPO

ounts

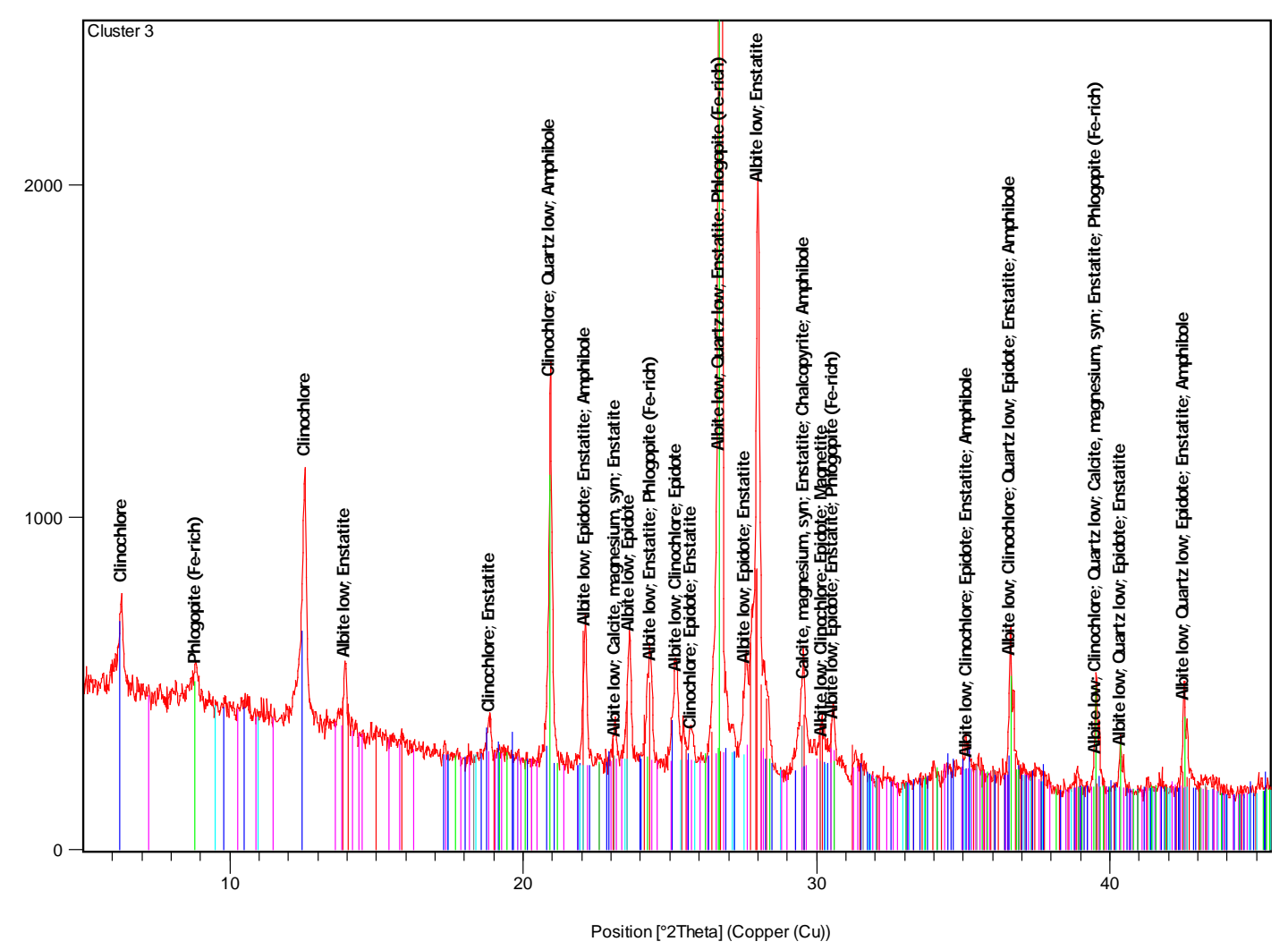

Difratograma da amostra SOSD 020 137-145 m - cluster 3

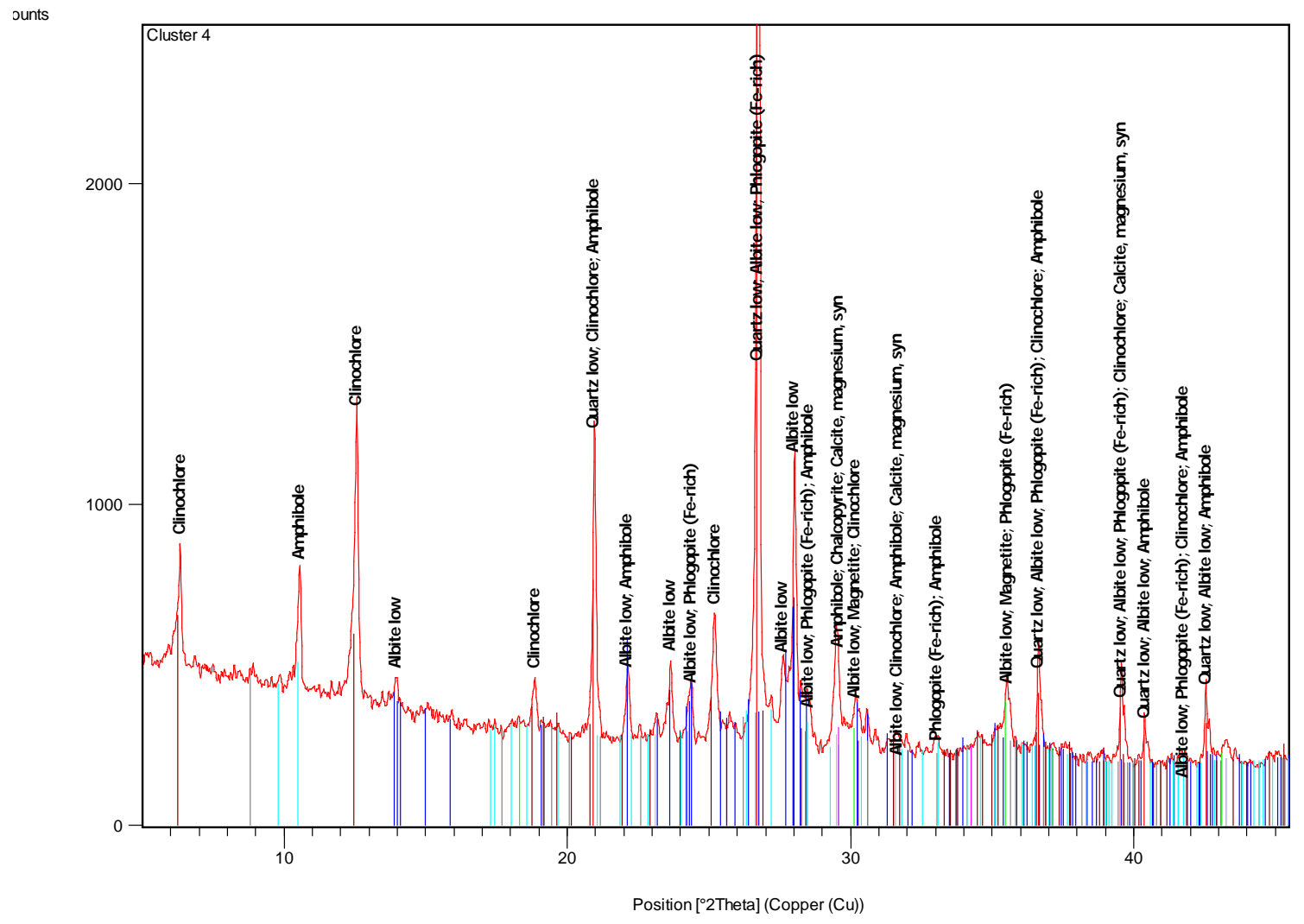

Difratograma da amostra SOSD 302 119-127 m - clusters B e 4 
ANEXO 2 - DIFRATOGRAMAS DE RAIOS X DAS AMOSTRAS MAIS

REPRESENTATIVAS DE CADA GRUPO

ounts

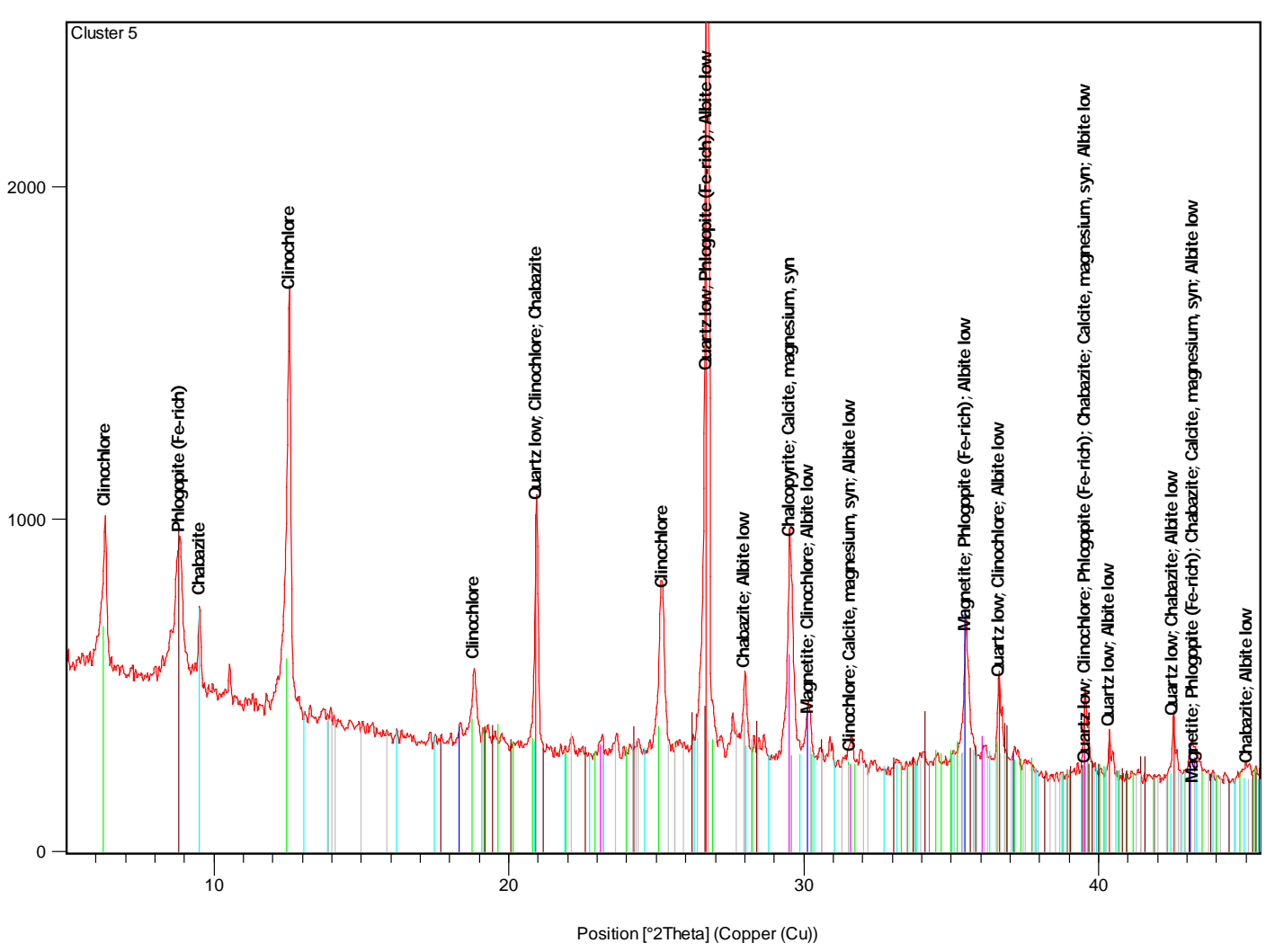

Difratograma da amostra SOSD 314 135-145 m - clusters 5 e C

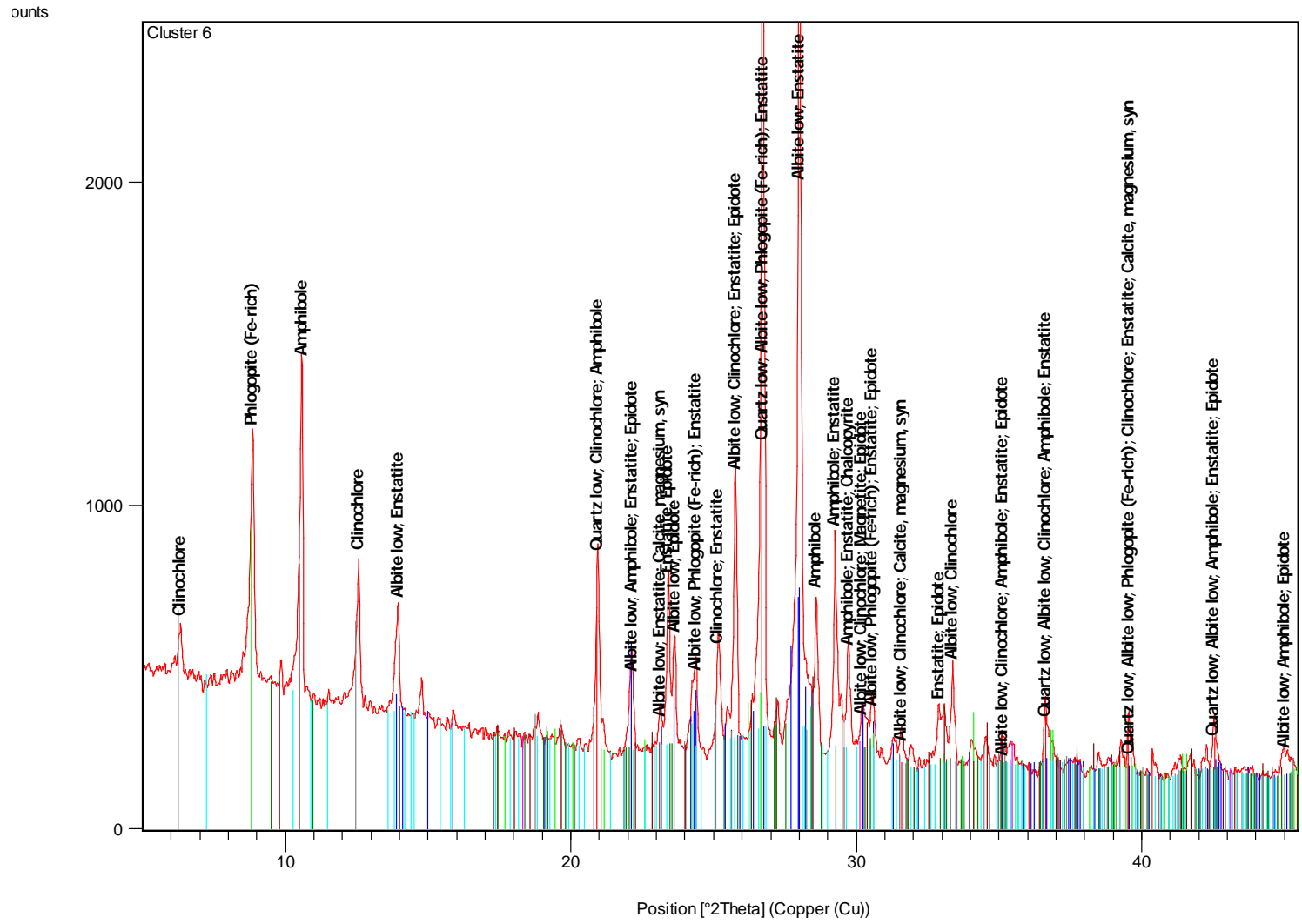

Difratograma da amostra SOSD 408 273-283 m - cluster 6 
ANEXO 2 - DIFRATOGRAMAS DE RAIOS X DAS AMOSTRAS MAIS

REPRESENTATIVAS DE CADA GRUPO

ounts

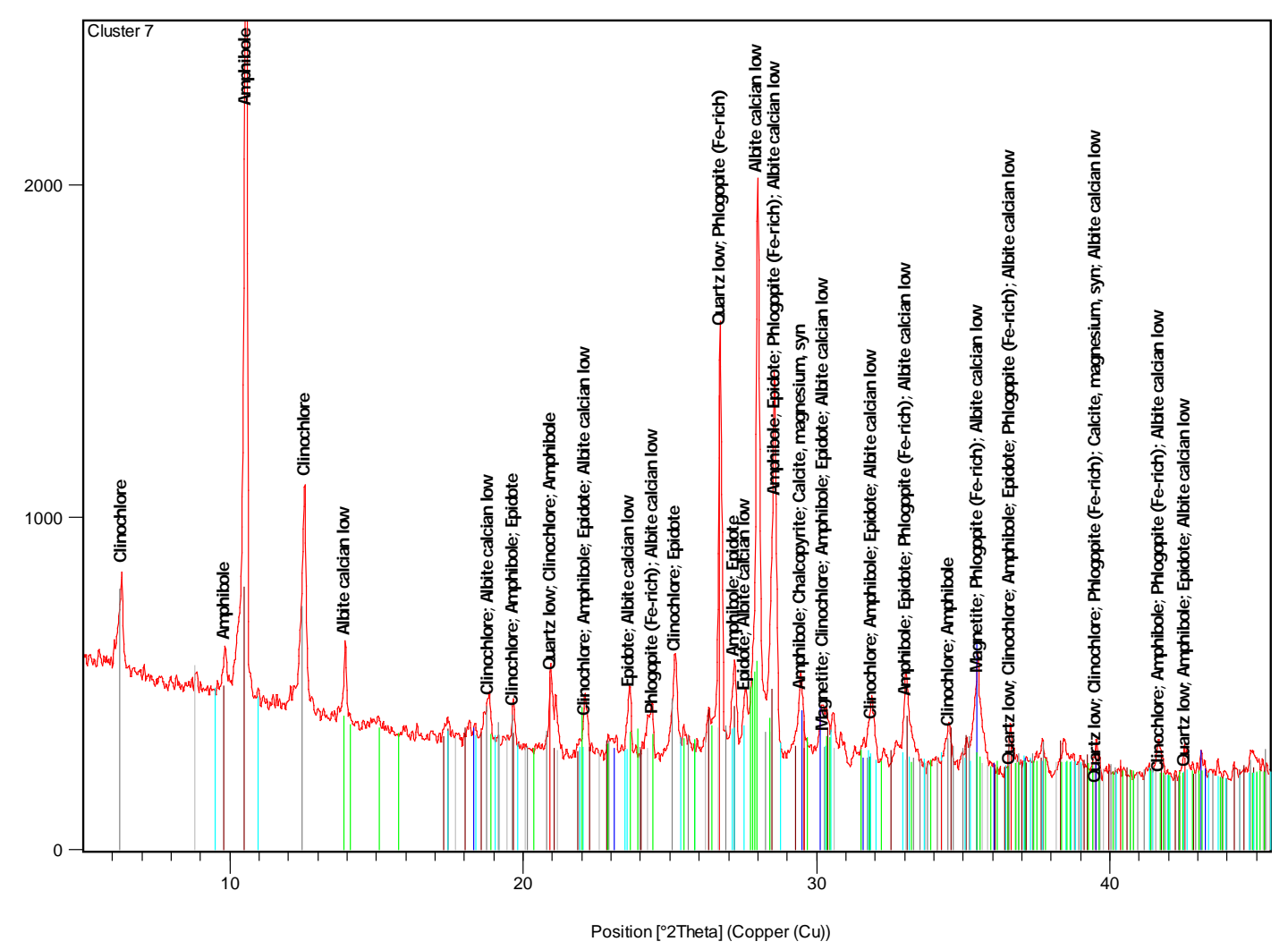

Difratograma da amostra SOSD316 351-361 m - cluster 7

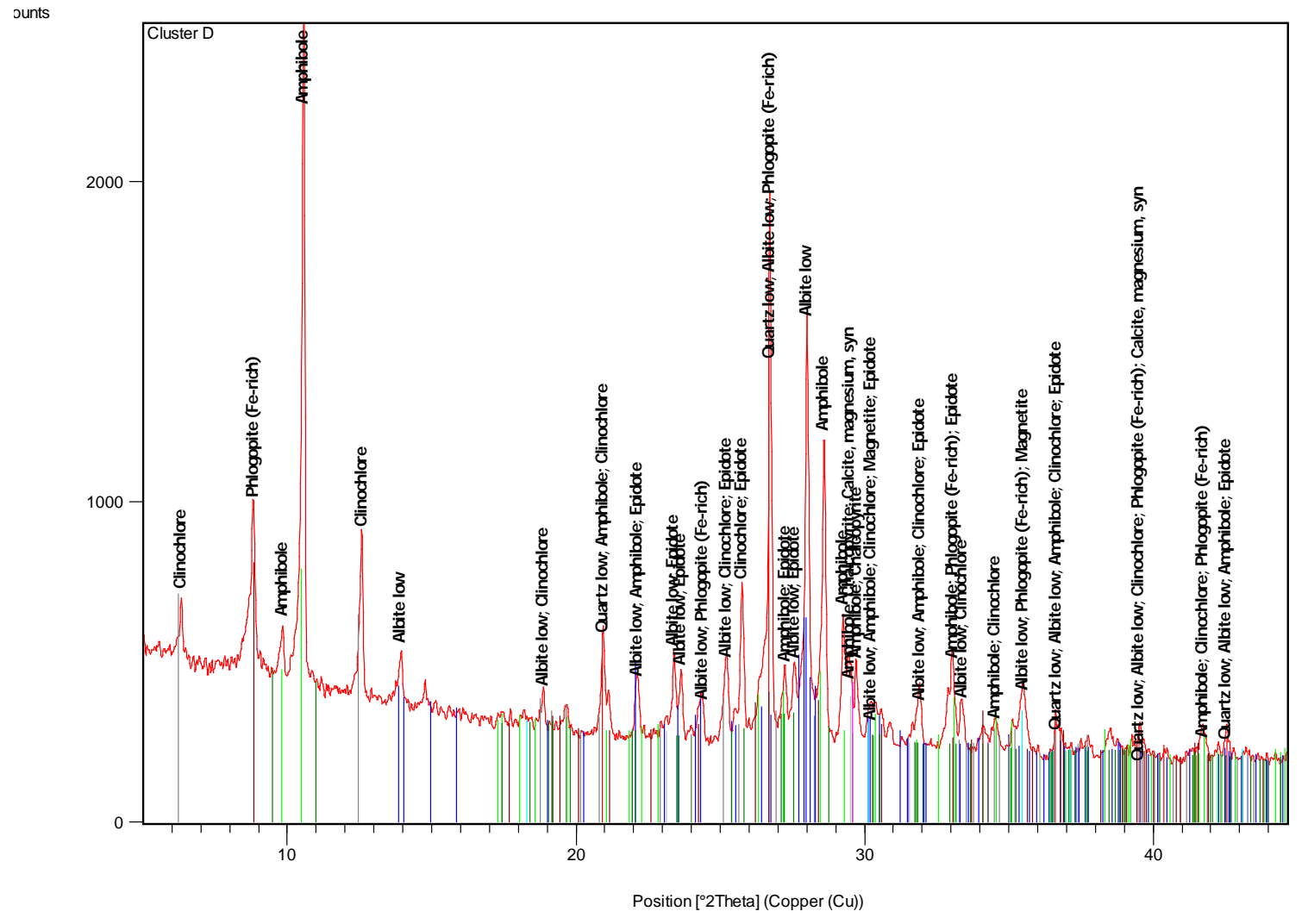

Difratograma da amostra SOSD 215 204-213 m - cluster D 
ANEXO 3 - COMPOSIÇÃO QUÍMICA DAS FASES MINERAIS -

BANCO DE DADOS MLA

\begin{tabular}{|l|c|c|c|c|c|c|}
\hline \multicolumn{7}{|c|}{ Sulfetos } \\
\hline Mineral & Dens. & $\mathrm{S}$ & $\mathrm{Cu}$ & $\mathrm{Fe}$ & $\mathrm{Ni}$ & $\mathrm{Co}$ \\
\hline calcopirita & 4,2 & 34,8 & 34,4 & 30,8 & & \\
\hline calcocita & 5,7 & 20,2 & 79,9 & & & \\
\hline pirita & 5,1 & 53,5 & & 46,6 & & \\
\hline milerita & 5,5 & 35,3 & & & 64,7 & \\
\hline siegenita & 4,8 & 42,1 & & & 43,4 & 14,5 \\
\hline
\end{tabular}

\begin{tabular}{|c|c|c|c|c|c|c|c|c|c|c|c|c|c|c|c|c|c|}
\hline \multicolumn{18}{|c|}{ Principais minerais } \\
\hline Mineral & $\frac{\dot{c}}{\bar{D}}$ & $\frac{O}{n}$ & 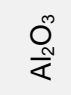 & O্ণ & $\begin{array}{l}\text { O } \\
\frac{\pi}{Z}\end{array}$ & $\begin{array}{l}\text { ON } \\
\text { Y }\end{array}$ & 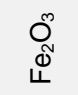 & $\stackrel{\circ}{\Sigma}$ & $\stackrel{\text { O }}{\stackrel{\text { L }}{\Sigma}}$ & $\stackrel{O^{N}}{\models}$ & 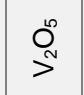 & ర్లు & O̊ & $\stackrel{\text { O }}{\text { I }}$ & $\bar{U}$ & $\sqcup$ & $\begin{array}{l}\text { ○ } \\
\stackrel{4}{~}\end{array}$ \\
\hline quartzo & 2,7 & 100 & & & & & & & & & & & & & & & \\
\hline Kfeldsp & 2,6 & 64,1 & 19,3 & & & 16,6 & & & & & & & & & & & \\
\hline albita & 2,6 & 68,8 & 20,3 & & 10,9 & & & & & & & & & & & & \\
\hline plagioc $\mathrm{NaCa}$ & 2,8 & 44,4 & 35,8 & 19,2 & 0,56 & & & & & & & & & & & & \\
\hline escapolita & 2,6 & 57,2 & 23,1 & 6,76 & 9,81 & 0,57 & & & & & & & & & 2,54 & & \\
\hline epidoto & 3,4 & 41,0 & 19,6 & 22,4 & & & 15,1 & & & & & & & 1,93 & & & \\
\hline actinolita & 3,0 & 57,0 & 2,74 & 10,4 & 0,44 & & 9,00 & 17,2 & & & & & & 2,85 & 0,32 & & \\
\hline hastingsita & 3,4 & 38,5 & 12,9 & 10,5 & 2,08 & 1,50 & 26,0 & 6,34 & & & & & & & 2,16 & & \\
\hline muscovita & 2,8 & 45,0 & 38,2 & & & 11,8 & & & & & & & & 4,06 & & 0,95 & \\
\hline bt-flog & 3,0 & 35,0 & 14,6 & & & 7,49 & 27,9 & 10,4 & & 1,13 & & & & 2,92 & 0,69 & & \\
\hline Fe-clinocloro & 2,7 & 26,5 & 17,1 & & & & 32,0 & 12,4 & & & & & & 12,1 & & & \\
\hline magnetita & 5,0 & 0,10 & & & & & 99,2 & & & 0,40 & 0,30 & & & & & & \\
\hline Cr-magnetita & 5,2 & & & & & & 88,0 & & 12,0 & & & & & & & & \\
\hline ilmenita & 4,8 & & & & & & 47,9 & & & 49,7 & 2,44 & & & & & & \\
\hline calcita & 2,7 & & & 56,0 & & & & & & & & & 44,0 & & & & \\
\hline anquerita & 2,7 & & & 27,2 & & & & 5,86 & 3,43 & & & & 42,7 & & & & 20,9 \\
\hline apatita & 3,2 & & & 54,5 & & & & & & & & 42,1 & & & 0,66 & 2,76 & \\
\hline
\end{tabular}

\begin{tabular}{|c|c|c|c|c|c|c|c|c|c|c|c|c|c|c|c|c|c|}
\hline \multicolumn{18}{|c|}{ Minerais traços } \\
\hline Mineral & $\begin{array}{l}\dot{D} \\
\stackrel{D}{\Phi} \\
0\end{array}$ & $\stackrel{\text { ON }}{n}$ & 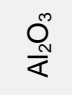 & O্ & $\begin{array}{l}O_{\mathbb{N}}^{\infty} \\
\stackrel{\sim}{\Psi}\end{array}$ & ర్లి & $\stackrel{N}{\underline{N}}$ & $\sqcup$ & 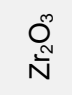 & $\mathbb{J}_{\mathcal{N}}^{\infty}$ & 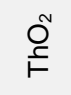 & $\begin{array}{l}\text { ON } \\
\text { 오 }\end{array}$ & 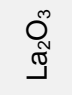 & $\frac{O_{0}^{\infty}}{\frac{\pi}{Z}}$ & $\stackrel{N}{\supset}$ & 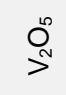 & ₹ \\
\hline enstatita & 3,3 & 64,1 & & & & & 8,90 & 27,0 & & & & & & & & & \\
\hline piroxênio & 3,3 & 41,0 & 32,1 & 1,65 & 1,65 & & 11,5 & 11,4 & & 0,78 & & & & & & & \\
\hline zircão & 4,7 & 31,7 & & & & & & & 58,4 & 2,30 & & 5,53 & 2,10 & & & & \\
\hline titanita & 3,5 & 30,4 & 5,16 & 26,9 & 2,02 & & 30,3 & 0,96 & & 2,15 & & & 2,10 & & & & \\
\hline rutilo & 4,3 & & & & & & & & & & & & & & & 100 & \\
\hline monazita & 5,1 & & & & & 29,5 & & & & 34,1 & 5,50 & & 16,9 & 14,0 & & & \\
\hline uraninita & 9,5 & & & & & & & & & & & & & & 100 & & \\
\hline thorita & 5,3 & 18,5 & & & & & & & & & 81,5 & & & & & & \\
\hline alanita & 3,9 & 29,3 & 18,7 & 5,47 & 9,74 & & & & & 31,3 & & & 5,51 & & & & \\
\hline andradita & 3,9 & & & 33,1 & 31,4 & & & & & & & & & & 35,5 & & \\
\hline ouro & 17 & & & & & & & & & & & & & & & & 100 \\
\hline
\end{tabular}




\section{Cluster A}

\begin{tabular}{|c|c|c|c|c|c|c|c|c|c|c|c|c|}
\hline \multirow{2}{*}{$\begin{array}{c}\text { Fração } \\
(\mathrm{mm})\end{array}$} & \multicolumn{12}{|c|}{ AQ -Teores (\%) } \\
\hline & $\mathrm{Cu}$ & $\mathbf{s}$ & $\mathrm{SiO}_{2}$ & $\mathrm{Fe}_{2} \mathrm{O}_{3}$ & $\mathrm{Al}_{2} \mathrm{O}_{3}$ & $\mathrm{CaO}$ & MgO & $\mathrm{Na}_{2} \mathrm{O}$ & $\mathrm{K} 2 \mathrm{O}$ & $\mathrm{TiO}_{2}$ & $\mathrm{P}_{2} \mathrm{O}_{5}$ & PF \\
\hline$+0,21$ & 1,18 & 1,44 & 44,2 & 23,2 & 6,59 & 8,17 & 6,02 & 2,07 & 0,51 & 0,43 & 3,23 & 1,66 \\
\hline$-0,21+0,150$ & 1,48 & 1,82 & 40,4 & 26,3 & 6,07 & 8,43 & 5,75 & 1,83 & 0,44 & 0,43 & 4,00 & 1,58 \\
\hline$-0,150+0,074$ & 1,76 & 2,19 & 38,4 & 27,7 & 5,55 & 8,63 & 5,75 & 1,72 & 0,37 & 0,37 & 4,57 & 1,52 \\
\hline$-0,074+0,037$ & 2,24 & 2,63 & 36,6 & 28,4 & 5,06 & 8,80 & 5,85 & 1,40 & 0,39 & 0,39 & 4,49 & 2,04 \\
\hline$-0,037+0,020$ & 2,63 & 3,08 & 36,3 & 27,2 & 5,37 & 8,34 & 6,13 & 1,33 & 0,44 & 0,35 & 4,27 & 2,66 \\
\hline$-0,020$ & 2,61 & 2,06 & 37,7 & 26,6 & 5,54 & 8,92 & 6,36 & 1,30 & 0,40 & 0,36 & 4,89 & 1,88 \\
\hline Fração & \multicolumn{12}{|c|}{ MLA -Teores (\%) } \\
\hline$(\mathrm{mm})$ & $\mathrm{Cu}$ & $\mathbf{s}$ & $\mathrm{SiO}_{2}$ & $\mathrm{Fe}_{2} \mathrm{O}_{3}$ & $\mathrm{Al}_{2} \mathrm{O}_{3}$ & $\mathrm{CaO}$ & MgO & $\mathrm{Na}_{2} \mathrm{O}$ & $\mathrm{K} 2 \mathrm{O}$ & $\mathrm{TiO}_{2}$ & $\mathrm{P}_{2} \mathrm{O}_{5}$ & PF \\
\hline$+0,21$ & 1,25 & 1,51 & 41,1 & 26,7 & 7,53 & 8,61 & 6,04 & 1,96 & 0,53 & 0,49 & 2,49 & 1,61 \\
\hline$-0,21+0,150$ & 1,50 & 1,75 & 36,8 & 31,5 & 6,70 & 8,92 & 5,43 & 1,66 & 0,47 & 0,49 & 3,04 & 1,53 \\
\hline$-0,150+0,074$ & 1,69 & 1,95 & 34,2 & 34,3 & 6,07 & 9,10 & 5,21 & 1,44 & 0,43 & 0,47 & 3,42 & 1,57 \\
\hline$-0,074+0,037$ & 2,05 & 2,36 & 34,2 & 33,5 & 5,77 & 9,10 & 5,84 & 1,31 & 0,43 & 0,42 & 3,39 & 1,75 \\
\hline$-0,037+0,020$ & 2,98 & 3,23 & 31,2 & 35,3 & 5,61 & 8,90 & 5,89 & 1,11 & 0,45 & 0,45 & 3,39 & 1,95 \\
\hline$-0,020$ & 3,19 & 3,48 & 34,0 & 30,3 & 5,73 & 9,55 & 6,74 & 1,18 & 0,46 & 0,42 & 3,35 & 2,06 \\
\hline
\end{tabular}

Cluster B

\begin{tabular}{|c|c|c|c|c|c|c|c|c|c|c|c|c|}
\hline \multirow{2}{*}{$\begin{array}{c}\text { Fração } \\
(\mathrm{mm})\end{array}$} & \multicolumn{12}{|c|}{ AQ -Teores (\%) } \\
\hline & $\mathrm{Cu}$ & $\mathbf{s}$ & $\mathrm{SiO}_{2}$ & $\mathrm{Fe}_{2} \mathrm{O}_{3}$ & $\mathrm{Al}_{2} \mathrm{O}_{3}$ & $\mathrm{CaO}$ & MgO & $\mathrm{Na}_{2} \mathrm{O}$ & $\mathrm{K} 2 \mathrm{O}$ & $\mathrm{TiO}_{2}$ & $\mathrm{P}_{2} \mathrm{O}_{5}$ & PF \\
\hline$+0,21$ & 0,37 & 0,40 & 67,5 & 7,40 & 9,64 & 2,96 & 2,20 & 3,32 & 1,74 & 0,45 & 0,64 & 3,00 \\
\hline$-0,21+0,150$ & 0,55 & 0,64 & 65,5 & 8,19 & 9,30 & 3,57 & 2,32 & 3,14 & 1,69 & 0,43 & 0,88 & 3,42 \\
\hline$-0,150+0,074$ & 0,75 & 0,85 & 64,9 & 8,95 & 9,23 & 4,30 & 2,46 & 3,06 & 1,65 & 0,40 & 1,18 & 1,71 \\
\hline$-0,074+0,037$ & 0,86 & 0,99 & 61,0 & 9,97 & 8,64 & 4,88 & 2,70 & 2,73 & 1,46 & 0,43 & 1,21 & 4,54 \\
\hline$-0,037+0,020$ & 1,05 & 1,14 & 58,2 & 11,42 & 8,45 & 5,40 & 2,91 & 2,47 & 1,40 & 0,42 & 1,25 & 5,33 \\
\hline$-0,020$ & 0,93 & 0,66 & 60,0 & 12,18 & 8,22 & 6,13 & 2,81 & 2,45 & 1,35 & 0,45 & 1,46 & 2,94 \\
\hline Fração & \multicolumn{12}{|c|}{ MLA -Teores (\%) } \\
\hline$(\mathrm{mm})$ & $\mathrm{Cu}$ & $\mathbf{s}$ & $\mathrm{SiO}_{2}$ & $\mathrm{Fe}_{2} \mathrm{O}_{3}$ & $\mathrm{Al}_{2} \mathrm{O}_{3}$ & $\mathrm{CaO}$ & MgO & $\mathrm{Na}_{2} \mathrm{O}$ & K2O & $\mathrm{TiO}_{2}$ & $\mathrm{P}_{2} \mathrm{O}_{5}$ & PF \\
\hline$+0,21$ & 0,31 & 0,33 & 67,6 & 7,10 & 10,8 & 3,09 & 1,93 & 3,17 & 2,09 & 0,43 & 0,52 & 2,37 \\
\hline$-0,21+0,150$ & 0,62 & 0,68 & 66,0 & 7,73 & 10,7 & 3,35 & 2,15 & 3,04 & 2,09 & 0,33 & 0,52 & 2,69 \\
\hline$-0,150+0,074$ & 0,75 & 0,76 & 63,5 & 9,05 & 10,4 & 4,18 & 2,23 & 2,87 & 1,97 & 0,42 & 0,79 & 3,08 \\
\hline$-0,074+0,037$ & 0,92 & 0,94 & 62,0 & 9,85 & 9,79 & 4,75 & 2,38 & 2,64 & 1,79 & 0,40 & 0,88 & 3,58 \\
\hline$-0,037+0,020$ & 1,28 & 1,26 & 55,9 & 13,4 & 9,48 & 5,84 & 2,76 & 2,37 & 1,62 & 0,49 & 0,84 & 4,69 \\
\hline$-0,020$ & 1,12 & 1,13 & 56,0 & 12,0 & 9,71 & 6,45 & 3,11 & 2,49 & 1,58 & 0,48 & 1,07 & 4,88 \\
\hline
\end{tabular}


Cluster C

\begin{tabular}{|c|c|c|c|c|c|c|c|c|c|c|c|c|}
\hline \multirow{2}{*}{$\begin{array}{c}\text { Fração } \\
\text { (mm) }\end{array}$} & \multicolumn{12}{|c|}{ AQ -Teores (\%) } \\
\hline & $\mathrm{Cu}$ & $\mathbf{S}$ & $\mathrm{SiO}_{2}$ & $\mathrm{Fe}_{2} \mathrm{O}_{3}$ & $\mathrm{Al}_{2} \mathrm{O}_{3}$ & $\mathrm{CaO}$ & MgO & $\mathrm{Na}_{2} \mathrm{O}$ & K2O & $\mathrm{TiO}_{2}$ & $\mathrm{P}_{2} \mathrm{O}_{5}$ & PF \\
\hline$+0,21$ & 0,88 & 0,93 & 54,6 & 15,6 & 6,81 & 5,76 & 4,49 & 0,98 & 1,46 & 0,40 & 1,12 & 6,38 \\
\hline$-0,21+0,150$ & 1,20 & 1,31 & 52,1 & 16,7 & 6,48 & 6,26 & 4,48 & 0,94 & 1,32 & 0,38 & 1,35 & 6,72 \\
\hline$-0,150+0,074$ & 1,37 & 1,48 & 50,1 & 17,7 & 6,25 & 6,90 & 4,47 & 0,84 & 1,29 & 0,40 & 1,58 & 6,80 \\
\hline$-0,074+0,037$ & 1,42 & 1,54 & 47,1 & 19,9 & 6,26 & 6,93 & 4,79 & 0,72 & 1,20 & 0,38 & 1,62 & 7,22 \\
\hline$-0,037+0,020$ & 1,27 & 1,34 & 45,3 & 21,0 & 6,53 & 7,05 & 5,33 & 0,63 & 1,27 & 0,40 & 1,50 & 7,45 \\
\hline$-0,020$ & 1,15 & 0,79 & 47,6 & 22,0 & 5,97 & 8,31 & 4,82 & 0,72 & 1,21 & 0,46 & 1,65 & 4,73 \\
\hline Fração & \multicolumn{12}{|c|}{ MLA -Teores (\%) } \\
\hline$(\mathrm{mm})$ & $\mathrm{Cu}$ & S & $\mathrm{SiO}_{2}$ & $\mathrm{Fe}_{2} \mathrm{O}_{3}$ & $\mathrm{Al}_{2} \mathrm{O}_{3}$ & $\mathrm{CaO}$ & $\mathrm{MgO}$ & $\mathrm{Na}_{2} \mathrm{O}$ & K2O & $\mathrm{TiO}_{2}$ & $\mathrm{P}_{2} \mathrm{O}_{5}$ & PF \\
\hline$+0,21$ & 0,92 & 0,96 & 53,9 & 17,8 & 7,30 & 5,93 & 3,83 & 0,86 & 1,70 & 0,37 & 0,82 & 5,37 \\
\hline$-0,21+0,150$ & 1,17 & 1,19 & 51,4 & 18,4 & 7,11 & 7,06 & 3,68 & 0,85 & 1,56 & 0,42 & 1,02 & 6,06 \\
\hline$-0,150+0,074$ & 1,49 & 1,52 & 47,1 & 22,6 & 6,82 & 7,05 & 3,70 & 0,73 & 1,43 & 0,36 & 1,25 & 6,04 \\
\hline$-0,074+0,037$ & 1,75 & 1,77 & 45,4 & 22,6 & 6,79 & 7,62 & 3,87 & 0,67 & 1,44 & 0,34 & 1,5 & 6,38 \\
\hline$-0,037+0,020$ & 1,25 & 1,27 & 39,9 & 28,7 & 6,74 & 7,58 & 4,09 & 0,57 & 1,36 & 0,5 & 1,25 & 6,70 \\
\hline$-0,020$ & 1,29 & 1,31 & 41,8 & 24,7 & 6,80 & 8,51 & 4,25 & 0,63 & 1,50 & 0,55 & 1,11 & 7,34 \\
\hline
\end{tabular}

Cluster D

\begin{tabular}{|c|c|c|c|c|c|c|c|c|c|c|c|c|}
\hline \multirow{2}{*}{$\begin{array}{c}\text { Fração } \\
(\mathrm{mm})\end{array}$} & \multicolumn{12}{|c|}{ AQ -Teores (\%) } \\
\hline & $\mathrm{Cu}$ & $\mathbf{S}$ & $\mathrm{SiO}_{2}$ & $\mathrm{Fe}_{2} \mathrm{O}_{3}$ & $\mathrm{Al}_{2} \mathrm{O}_{3}$ & $\mathrm{CaO}$ & MgO & $\mathrm{Na}_{2} \mathrm{O}$ & K2O & $\mathrm{TiO}_{2}$ & $\mathrm{P}_{2} \mathrm{O}_{5}$ & PF \\
\hline$+0,21$ & 0,48 & 0,56 & 59,9 & 9,54 & 10,7 & 5,32 & 3,98 & 4,12 & 1,12 & 0,53 & 0,90 & 1,96 \\
\hline$-0,21+0,150$ & 0,61 & 0,72 & 58,0 & 10,6 & 10,4 & 5,59 & 3,98 & 4,02 & 1,07 & 0,53 & 1,16 & 2,30 \\
\hline$-0,150+0,074$ & 0,84 & 0,99 & 56,0 & 11,8 & 9,98 & 6,11 & 4,08 & 3,81 & 1,00 & 0,52 & 1,67 & 2,18 \\
\hline$-0,074+0,037$ & 1,23 & 1,36 & 53,2 & 13,5 & 9,44 & 6,43 & 4,28 & 3,50 & 0,92 & 0,47 & 1,93 & 2,61 \\
\hline$-0,037+0,020$ & 1,39 & 1,59 & 52,0 & 13,8 & 9,21 & 6,52 & 4,77 & 3,31 & 0,91 & 0,47 & 1,90 & 2,86 \\
\hline$-0,020$ & 1,40 & 1,02 & 52,1 & 15,1 & 9,05 & 6,89 & 4,77 & 3,24 & 0,92 & 0,49 & 2,14 & 1,87 \\
\hline Fração & \multicolumn{12}{|c|}{ MLA-Teores (\%) } \\
\hline$(\mathrm{mm})$ & $\mathrm{Cu}$ & $\mathbf{S}$ & $\mathrm{SiO}_{2}$ & $\mathrm{Fe}_{2} \mathrm{O}_{3}$ & $\mathrm{Al}_{2} \mathrm{O}_{3}$ & $\mathrm{CaO}$ & $\mathrm{MgO}$ & $\mathrm{Na}_{2} \mathrm{O}$ & K2O & $\mathrm{TiO}_{2}$ & $\mathrm{P}_{2} \mathrm{O}_{5}$ & PF \\
\hline$+0,21$ & 0,45 & 0,50 & 58,4 & 9,17 & 13,1 & 5,66 & 4,04 & 4,37 & 1,22 & 0,50 & 0,75 & 1,43 \\
\hline$-0,21+0,150$ & 0,57 & 0,67 & 56,2 & 11,1 & 12,6 & 5,96 & 4,03 & 4,13 & 1,22 & 0,51 & 0,96 & 1,51 \\
\hline$-0,150+0,074$ & 0,78 & 1,02 & 54,3 & 12,7 & 12,0 & 6,34 & 4,22 & 3,82 & 1,15 & 0,54 & 1,22 & 1,64 \\
\hline$-0,074+0,037$ & 1,19 & 1,32 & 52,9 & 13,4 & 11,6 & 6,53 & 4,50 & 3,64 & 1,12 & 0,52 & 1,34 & 1,76 \\
\hline$-0,037+0,020$ & 1,55 & 1,55 & 48,9 & 16,6 & 10,5 & 7,15 & 5,18 & 3,06 & 1,04 & 0,49 & 1,61 & 2,11 \\
\hline$-0,020$ & 1,69 & 1,81 & 48,6 & 16,7 & 9,99 & 7,22 & 5,7 & 2,86 & 0,98 & 0,55 & 1,56 & 2,28 \\
\hline
\end{tabular}


ANEXO 4 - COMPOSIÇÕES QUÍMICAS DOSADAS (FRX) E CALCULADAS (MLA)
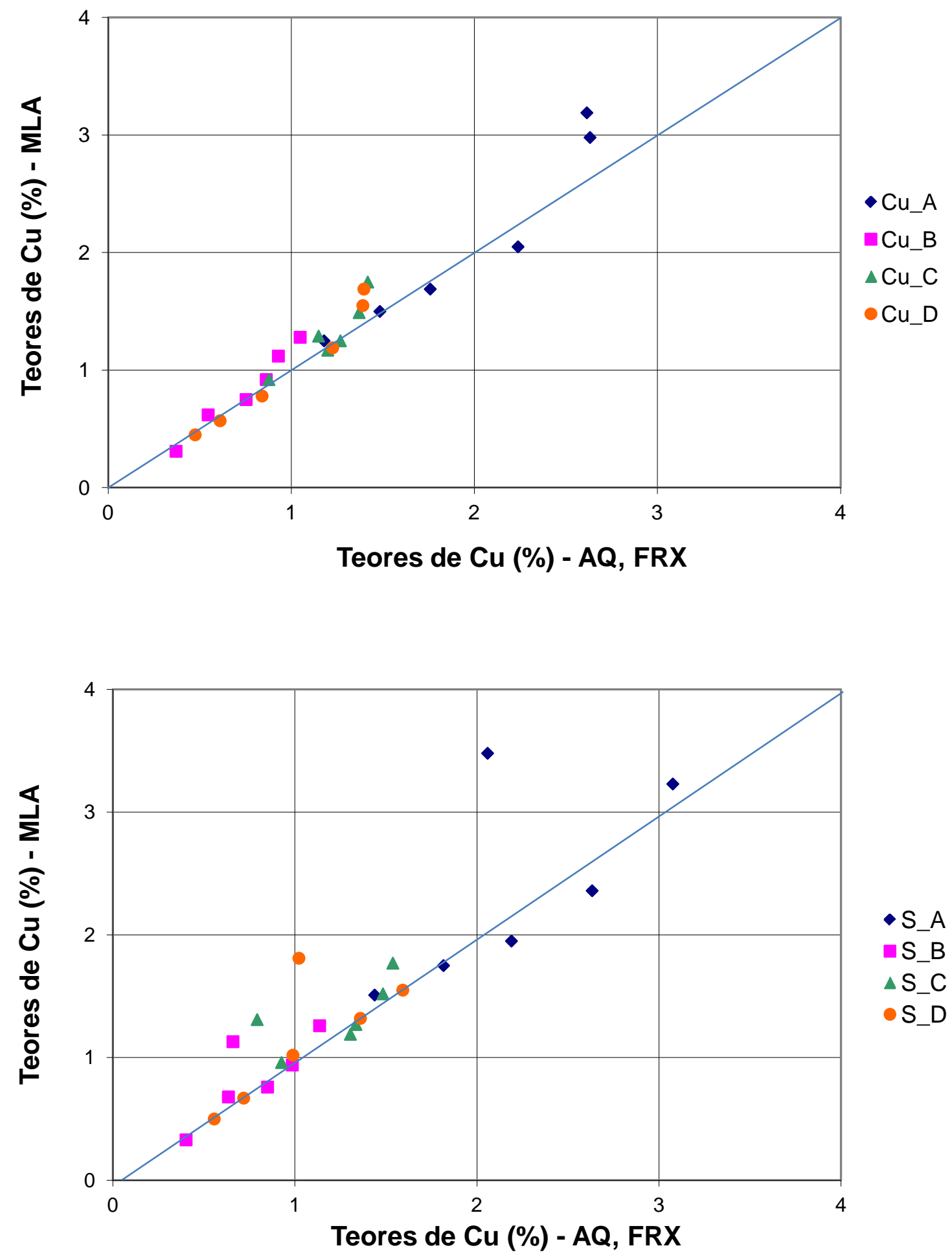